Florida International University

FIU Digital Commons

FIU Electronic Theses and Dissertations

University Graduate School

$6-25-2014$

\title{
Application of Biomarkers and Compound Specific Stable Isotopes for the Assessment of Hydrology as a Driver of Organic Matter Dynamics in the Everglades Ecosystem
}

Ding He

Florida International University, dhe001@fiu.edu

DOI: $10.25148 /$ etd.FI14071137

Follow this and additional works at: https:// digitalcommons.fiu.edu/etd

Part of the Analytical Chemistry Commons, Biogeochemistry Commons, Environmental Chemistry Commons, and the Organic Chemistry Commons

\section{Recommended Citation}

He, Ding, "Application of Biomarkers and Compound Specific Stable Isotopes for the Assessment of Hydrology as a Driver of Organic Matter Dynamics in the Everglades Ecosystem" (2014). FIU Electronic Theses and Dissertations. 1569.

https://digitalcommons.fiu.edu/etd/1569 


\title{
FLORIDA INTERNATIONAL UNIVERSITY
}

Miami, Florida

\begin{abstract}
APPLICATION OF BIOMARKERS AND COMPOUND SPECIFIC STABLE ISOTOPES FOR THE ASSESSMENT OF HYDROLOGY AS A DRIVER OF ORGANIC MATTER DYNAMICS IN THE EVERGLADES ECOSYSTEM
\end{abstract}

A dissertation submitted in partial fulfillment of

the requirements for the degree of

DOCTOR OF PHILOSOPHY

in

CHEMISTRY

by

Ding $\mathrm{He}$

2014 
To: Interim Dean Michael R. Heithaus

College of Arts and Sciences

This dissertation, written by Ding He, and entitled Application of Biomarkers and Compound Specific Stable Isotopes for the Assessment of Hydrology as a Driver of Organic Matter Dynamics in the Everglades Ecosystem, having been approved in respect to style and intellectual content, is referred to you for judgment.

We have read this dissertation and recommend that it be approved.

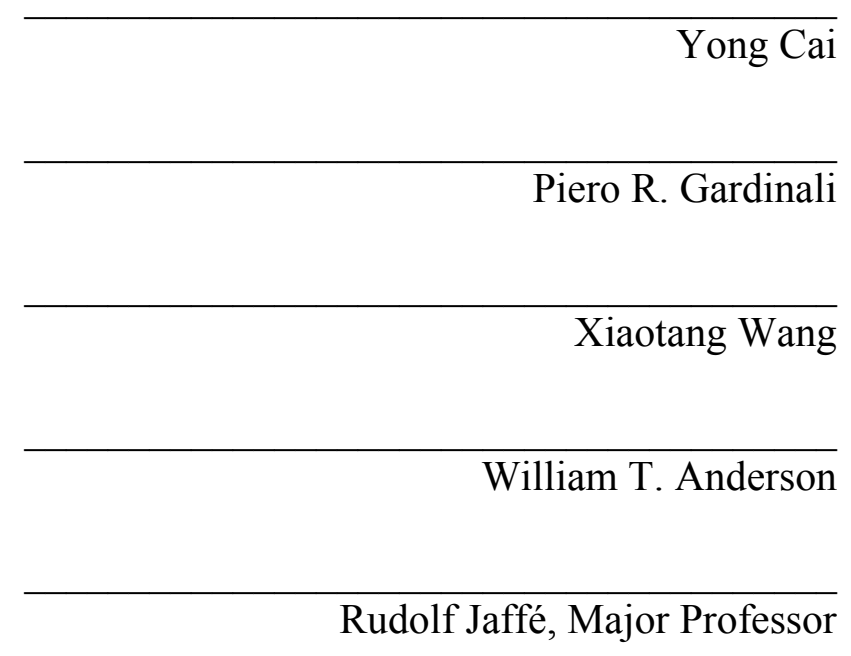

Date of Defense: June 25, 2014

The dissertation of Ding He is approved.

Interim Dean Michael R. Heithaus College of Arts and Sciences

Dean Lakshmi N. Reddi University Graduate School

Florida International University, 2014 
(C) Copyright 2014 by Ding He

All rights reserved. 


\section{DEDICATION}

I dedicate this dissertation to my parents Zheng He and Zhongzhi Ye. Without

their patience, love, and support this work would not have been finished. This dissertation is also dedicated to the memory of my grandparents Shengde He and Zonggui Wang. 


\section{ACKNOWLEDGMENTS}

I would like to thank my research advisor, Dr. Rudolf Jaffé, for his excellent support, help and assistance throughout this thesis work. Special thanks go to Dr. Bernd R.T. Simoneit and Dr. Laura Belicka, without whose assistance, enthusiastic help and advice this dissertation would have not been accomplished. I also want to express my appreciation to John Harris, Drs Colin J. Saunders, Julian Sachs, Dirk Sachse, Sue Newman, Carlos Coronado, Pisani Oliva, Yan Ding, Jian Wang, and Meilian Chen for their technical assistance and advice.

I wish to express my deepest appreciation to the members of my committee members: Drs William T. Anderson, Yong Cai, Piero Gardinali, and Xiaotang Wang, for their helpful comments and patience. I am also grateful to Chao Ya, Dr. Yunping Xu, Dr. Kaelin Cawley, Dr. Cristina Romera-Castillo, Sasha Wagner, Blanca Jarra, Peter Regier, and Wenxi Huang for their advice. Thanks to Hansen Chris, Tate-Boldt Erik, Dr. Joseph M. Smoak, Dr. Youhei Yamashita, Dr. Min Gao, Joshua Cloutier, Joshua L. Breithaupt for field support and sampling assistants. Thanks to Southeast Environmental Research the Stable Isotope Facility for providing analytical support and to South Florida Wetlands Ecosystems Lab, especially Rafael Travieso, Adam Hines and Olga Sanchez for providing sampling logistics.

I wish to thank Dr. Yong Cai and Dr. Yanbin Li for their encouragements through the years and all the past and present members of our lab for their help and cooperation. Last but not least, I thank the National Science Foundation through the FCE-LTER program (DBI-0620409), the South Florida Water Management District, and the Southeast Environmental Research Center through a Cristina Menendez Fellowship for 
financial support. I also thank the Department of Chemistry and Biochemistry for supporting my studies through Teaching Assistantships for several semesters. 


\begin{abstract}
OF THE DISSERTATION
APPLICATION OF BIOMARKERS AND COMPOUND SPECIFIC STABLE

ISOTOPES FOR THE ASSESSMENT OF HYDROLOGY AS A DRIVER OF

ORGANIC MATTER DYNAMICS IN THE EVERGLADES ECOSYSTEM
\end{abstract}

by

Ding He

Florida International University, 2014

Miami, Florida

Professor Rudolf Jaffé, Major Professor

The Everglades is a sub-tropical coastal wetland characterized among others by its hydrological features and deposits of peat. Formation and preservation of organic matter in soils and sediments in this wetland ecosystem is critical for its sustainability and hydrological processes are important divers in the origin, transport and fate of organic matter. With this in mind, organic matter dynamics in the greater Florida Everglades was studied though various organic geochemistry techniques, especially biomarkers, bulk and compound specific $\delta^{13} \mathrm{C}$ and $\delta \mathrm{D}$ isotope analysis. The main objectives were focused on how different hydrological regimes in this ecosystem control organic matter dynamics, such as the mobilization of particulate organic matter (POM) in freshwater marshes and estuaries, and how organic geochemistry techniques can be applied to reconstruct Everglades paleo-hydrology. For this purpose organic matter in typical vegetation, floc, surface soils, soil cores, and estuarine suspended particulates were characterized in samples selected along hydrological gradients in the Water Conservation Area 3, Shark River Slough and Taylor Slough. 
This research focused on three general themes: (1) Assessment of the environmental dynamics and source-specific particulate organic carbon export in a mangrove-dominated estuary. (2) Assessment of the origin, transport and fate of organic matter in freshwater marsh. (3) Assessment of historical changes in hydrological conditions in the Everglades (paleo-hydrology) though biomarkes and compound specific isotope analyses. This study reports the first estimate of particulate organic carbon loss from mangrove ecosystems in the Everglades, provides evidence for particulate organic matter transport with regards to the formation of ridge and slough landscapes in the Everglades, and demonstrates the applicability of the combined biomarker and compound-specific stable isotope approach as a means to generate paleohydrological data in wetlands. The data suggests that: (1) Carbon loss from mangrove estuaries is roughly split 50/50 between dissolved and particulate carbon; (2) hydrological remobilization of particulate organic matter from slough to ridge environments may play an important role in the maintenance of the Everglades freshwater landscape; and (3) Historical changes in hydrology have resulted in significant vegetation shifts from historical slough type vegetation to present ridge type vegetation. 


\section{TABLE OF CONTENTS}

CHAPTER

PAGE

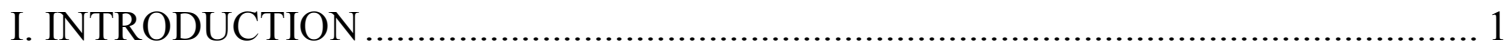

1.1 Everglades National Park and CERP ...................................................... 2

1.2 Linking hydrology to organic matter dynamics using biomarkers and

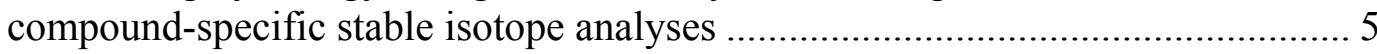

1.3 Research Approach ................................................................................ 7

1.3.1 Study Sites ...................................................................... 7

1.3.2 Molecular and Compound Stable Isotopic Proxies........................ 9

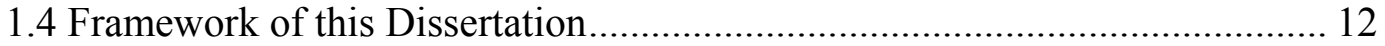

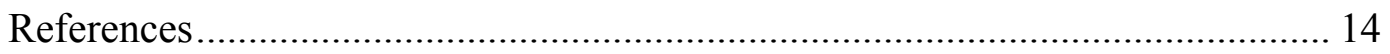

II. ASSESSING BIOMASS CONTRIBUTIONS TO PARTICULATE ORGANIC MATTER IN A SUBTROPICAL ESTUARY: A BIOMARKER APPROACH............ 18

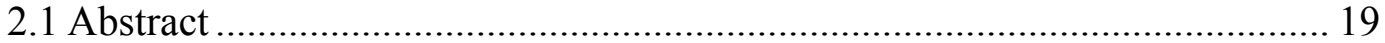

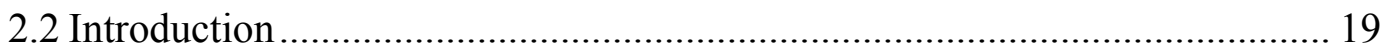

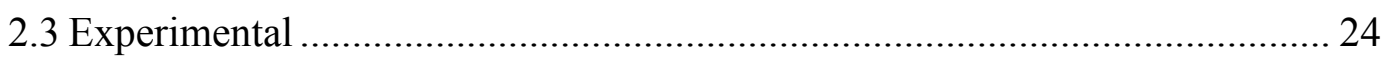

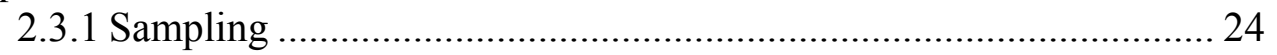

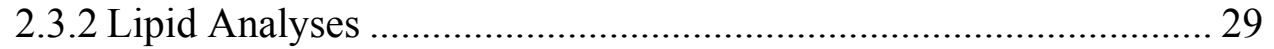

2.3.3 Principal Component Analysis...................................................... 29

2.4.1 Validation of conceptual three end-member mixing model............ 30

2.4.2 Principal component analysis (PCA) ......................................... 37

2.4.3 Carbon budget assessment .................................................... 42

2.4.4 Mangrove-derived POC loss estimate........................................... 45

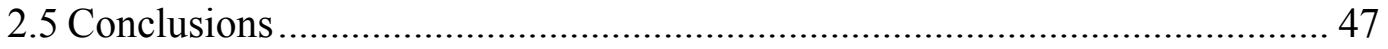

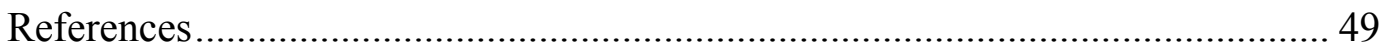

III. OCCURRENCE AND DISTRIBUTION OF A SERIES OF

MONOMETHYLALKANES IN THE FRESHWATER WETLAND ECOSYSTEM

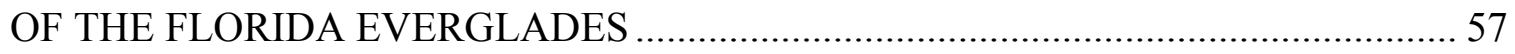

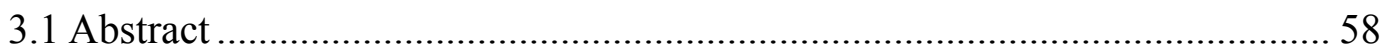

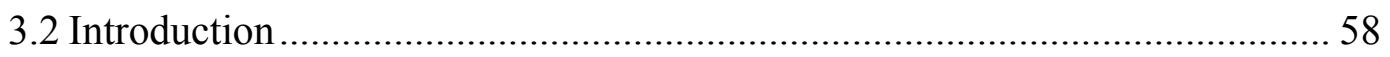

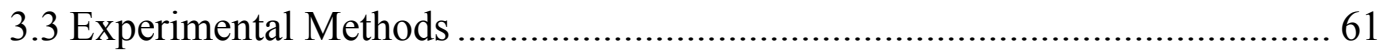

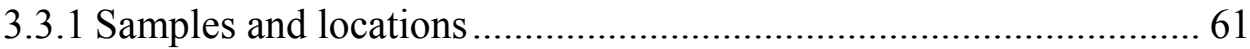

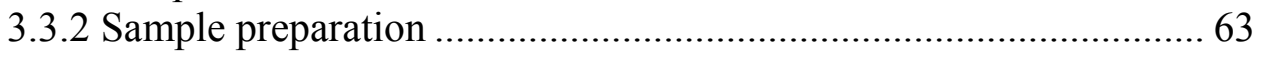

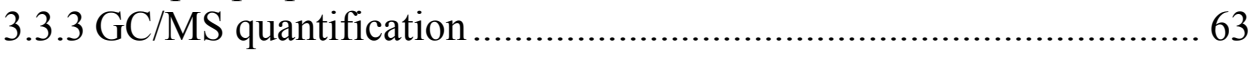

3.3.4 Compound specific carbon isotope analyses ................................ 64

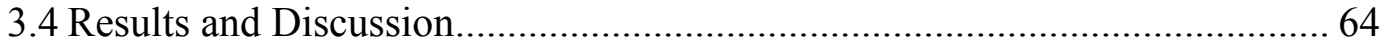

3.4.1 Identification of MMA structures ............................................... 64

3.4.2 Distribution and occurrence of MMAs in the Everglades .............. 72

3.4.3 Potential sources of MMAs in the Everglades freshwater wetlands 74

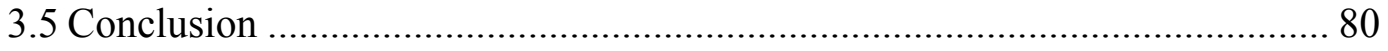

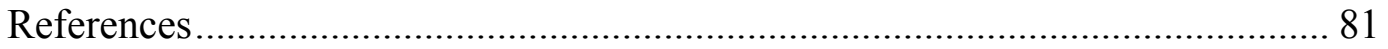




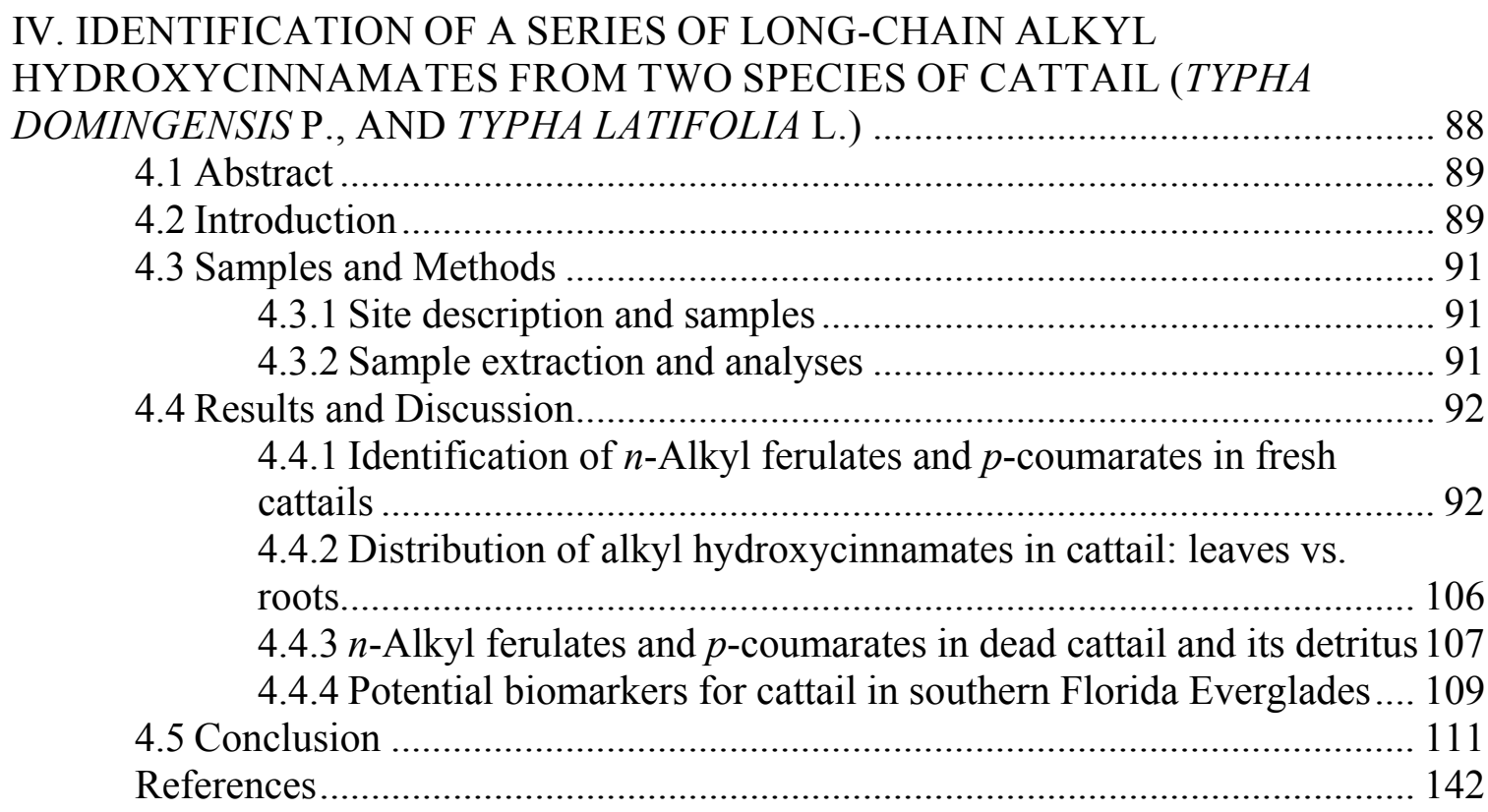

V. SHEET FLOW EFFECTS AND CANAL BACKFILLING ON SEDIMENT SOURCE AND TRANSPORT IN THE DECOMP PHYSICAL MODEL:

ANALYSIS OF MOLECULAR ORGANIC BIOMARKERS ….............................. 117

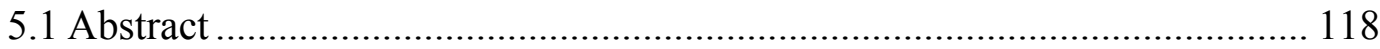

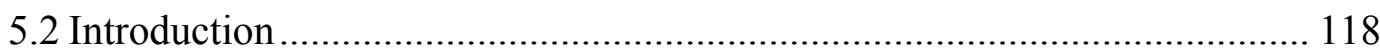

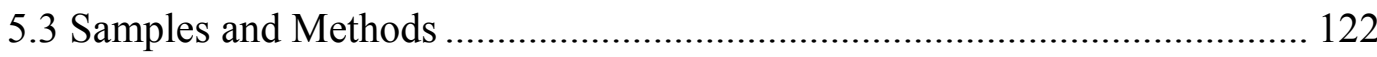

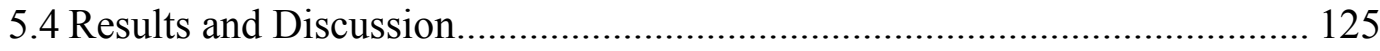

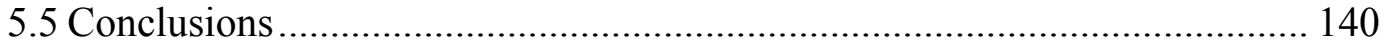

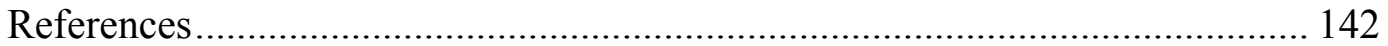

VI. DISTRIBUTION OF $N$-ALKANES AND THE $\delta$ D AND $\delta^{13} \mathrm{C}$ PATERNS IN

TYPICAL PLANTS ACROSS A SUBTROPICAL TREE ISLAND TO WETLAND GRADIENT AND ESTUARY SYSTEM: IMPLICATION FOR PALEO-

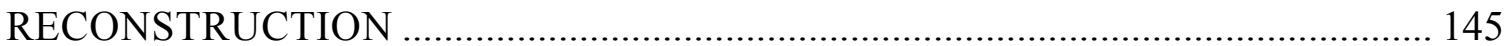

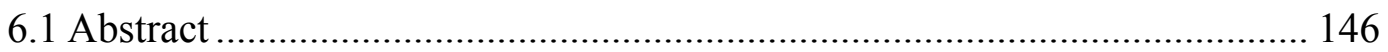

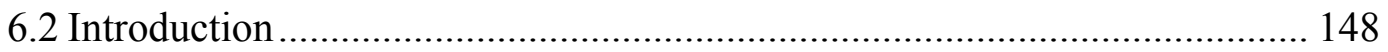

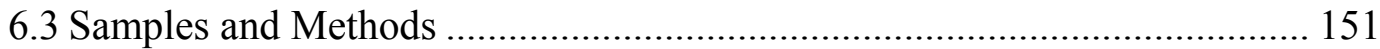

6.3.1 Site Description and samples ................................................. 151

6.3.2 Determination of $n$-alkanes by GC/MS ................................. 155

6.3.3 n-Alkane molecular parameters ............................................. 155

6.3.4 Compound specific carbon and hydrogen isotope analysis .......... 156

6.3.5 Mean annual precipitation $\delta \mathrm{D}$ values....................................... 157

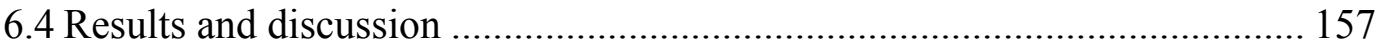

6.4.1 $n$-Alkane abundance and distribution patterns in aboveground vegetation (leaves and stems) ..................................................... 157

6.4.2 Roots (below ground) $n$-alkanes abundance and distribution pattern 
6.4.3 Compound-specific stable carbon and hydrogen isotopic compositions (leaf part)

6.4.4 Compound-specific stable carbon and hydrogen isotopic

compositions (root part)................................................................. 172

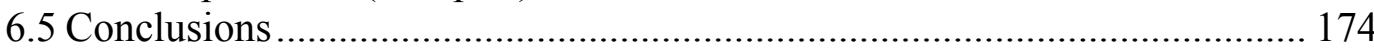

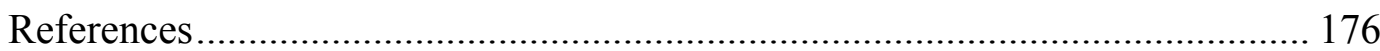

VII. COMPOUND SPECIFIC $\delta$ D AND $\delta{ }^{13} \mathrm{C}$ ANALYSES AS A TOOL FOR THE ASSESSMENT OF HYDROLOGICAL CHANGE IN A SUBTROPICAL

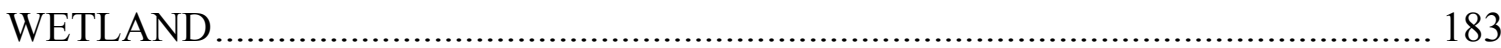

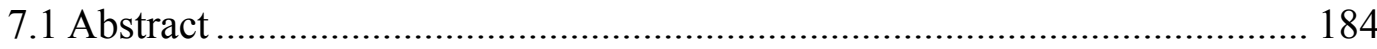

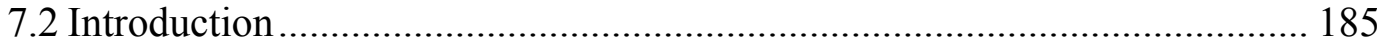

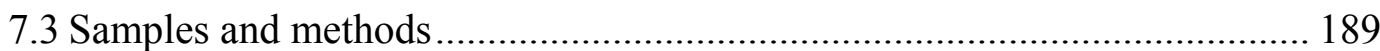

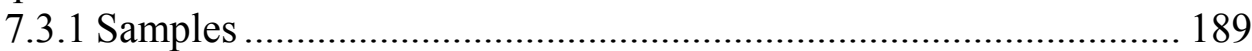

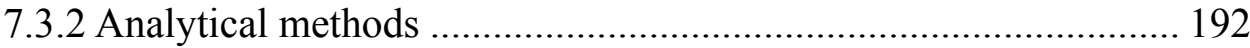

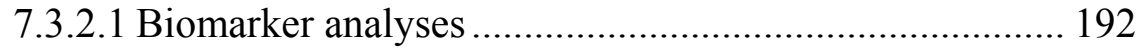

7.3.2.2 Soil core dating ......................................................... 193

7.3.2.3 Compound specific isotope $(\mathrm{C}$ and $\mathrm{H})$ analyses ............ 194

7.3.2.4 Mean annual precipitation and surface water $\delta \mathrm{D}$ values 196

7.3.2.5 Calculation of the net "apparent" isotopic fractionations 196

7.4 Results and Discussion.

7.4.1 Paq and $\mathrm{C}_{20} \mathrm{HBI}$ in dominant wetland plants, surface soil and soil cores

7.4.2 Isotopic $(\mathrm{C}$ and $\mathrm{H})$ compositions of $n$-alkanes in typical

Everglades wetland plants.

7.4.3 Isotopic ( $\mathrm{C}$ and $\mathrm{H}$ ) compositions of $n$-alkanes/ $\mathrm{C}_{20} \mathrm{HBI}$ across wetland surface soil transect ............................................................ 208

7.4.4 Isotopic ( $\mathrm{C}$ and $\mathrm{H}$ ) compositions of $n$-alkanes and $\mathrm{C}_{20} \mathrm{HBI}$ in wetland soil cores

7.4.5 Net "apparent" isotopic fractionation and its application in sub-

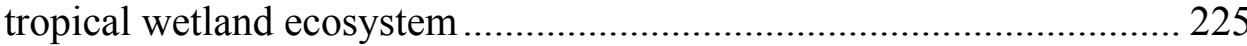

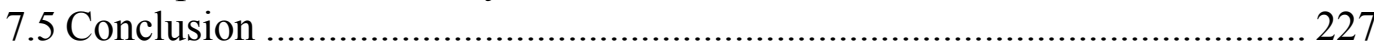

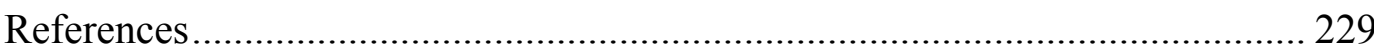

VIII. GENERAL CONCLUSION AND REMARKS ................................................ 237

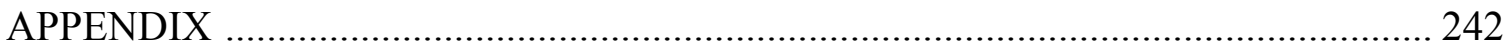

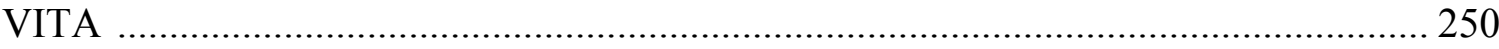




\section{LIST OF TABLES}

TABLE

PAGE

2.1 Different types of samples used for biomarker analysis across the Everglades .28

3.1 List of MMAs detected in periphyton, floc, surface soil and sediments across the Everglades freshwater wetlands....

3.2 Average contents of MMAs at different sites across the Everglades wetland ecosystem $(\mu \mathrm{g} / \mathrm{gdw})$.

4.1 Alkyl hydroxycinnamates occurrence in plant kingdom

4.2 Alkyl-ferulate distributions in leaves, roots and detritus from Typha domingensis

P., and Typha latifolia L.

4.3 Alkyl-p-coumarate distributions in leaves, roots and detritus from Typha domingensis $\mathrm{P}$. , and Typha latifolia $\mathrm{L}$

5.1 Sample classification and location information

6.1 Sampling information of plants from the Florida Coastal Everglades.

$6.2 n$-Alkane concentrations and distributions across studied plant leaves of the

Florida Coastal Everglades.....

$6.3 n$-Alkane concentrations and distributions across studied plant roots of the Everglades freshwater wetland.

$6.4 \delta \mathrm{D}$ and $\delta^{13} \mathrm{C}$ values of $n$-alkanes between plants leaf and root of the Florida Coastal Everglades.

7.1 Paq values of the dominant plant species in the Everglades freshwater wetlands. ..198

7.2 Summary of plants biomarker and hydrology in adjacent ridge and slough communities in the two study sites SRS2 and TSPh2..... .200

7.3 SRS2 and TSPh2 plants $n$-alkane $\delta^{13} \mathrm{C}$ and $\delta \mathrm{D}$ values distribution .205

$7.4 n$-Alkane and $\mathrm{C}_{20} \mathrm{HBI} \delta^{13} \mathrm{C}$ and $\delta \mathrm{D}$ values across SRS2 surface soil transects .209

7.5 n-Alkane and $\mathrm{C}_{20} \mathrm{HBI} \delta^{13} \mathrm{C}$ and $\delta \mathrm{D}$ values down SRS2 ridge core .216

7.6 -Alkane and $\mathrm{C}_{20} \mathrm{HBI} \delta^{13} \mathrm{C}$ and $\delta \mathrm{D}$ values down SRS2 slough core .218 


\section{LIST OF FIGURES}

FIGURE

PAGE

1.1 Partial map of the greater Everglades indicating study sites of interest. ....................8

1.2 Shark River Slough (SRS-1-6) and offshore site (PLB) ....................................

2.1 Sampling sites along Shark River Slough (SRS-1-6). Sub-environments: freshwater marsh (peat; SRS-1-3), mangrove estuary (peat; SRS-4-6) and offshore sites (PLB-1 and PLB-2).

2.2 Relative distribution of molecular markers in soil/sediment used to construct the three end-member mixing model.

2.3 Concentration $(\mu \mathrm{g} / \mathrm{g}$ POM) of the three molecular markers used to trace the input of freshwater marsh $\left(\mathrm{C}_{20} \mathrm{HBI}\right)$, marine $\left(\mathrm{C}_{25} \mathrm{HBI}\right)$ and the mangrove (taraxerol) $\mathrm{OM}$ to the Shark River Estuary

2.4 Three end-member model applied for the salinity transect study

2.5 Three end-member model applied for tidal studies A and B...

2.6 PCA of $\ln$ transformed relative concentrations of $\mathrm{C}_{20} \mathrm{HBI}, \mathrm{C}_{25} \mathrm{HBI}$, and taraxerol in POM for all Shark River samples

2.7 Plot of PC1 scores for all POM biomarker data

3.1 Map of the study areas and sampling locations in the Florida Everglades wetlands...62

3.2 (a) GC-MS data for a periphyton sample at SRS2 (aliphatic fraction, partial, total ion current, TIC trace). (b) GC-MS data for a floc sample at WCA3-A (aliphatic fraction, partial TIC trace).

3.3 Examples of mass spectra of some MMAs identified in this study.....

3.4 The distribution of (a) MMAs versus position of methyl branching, (b) MMAs versus total carbon number in this study and (c) Relative percentages of different methyl branching MMAs for periphyton and floc samples

3.5 Compound specific carbon isotope compositions of $n$-alkanes, MMAs and $\mathrm{C}_{20} \mathrm{HBI}$

of floc samples.....

4.1 Chemical structures of the ferulic and $p$-coumaric acids and esters. 
4.2 Mass-chromatogram (partial, total ion total ion current, TIC trace) of alcohol fractions from fresh cattail species..

4.3 Mass-chromatogram of alcohol fractions (ion 236/219 extracted) from fresh cattail species to show alkyl ferulates and alkyl $p$-coumarates .98

4.4 Mass spectra of (a) $n$-hexadecyl E-ferulate, (b) $n$-hexadecyl Z-ferulate, (c) standard: $n$-docosyl E-ferulate, (d) $n$-docosyl E-ferulate (e) $n$-hexadecyl E- $p$ coumarate, (f) $n$-hexadecyl Z- $p$-coumarate, and (g) E-Docosyl ferulate. All compounds are TMS ether derivatives..

4.5 Interpretation of the mass spectrometric fragmentation pattern for: (a) $n$-hexadecyl

E-ferulate-TMS, and (b) $n$-hexadecyl E- $p$-coumarate-TMS.

4.6 Mass-chromatogram (partial, total ion total ion current, TIC trace) of alcohol fractions from dead cattail and its detritus. 108

4.7 Mass-chromatogram of alcohol fractions (ion 236/219 extracted) from dead cattail and its detritus to show alkyl ferulates and alkyl $p$-coumarates

5.1 Map of DPM study site indicating sampling sites for the biomarker study.....

5.2 Distribution of $\mathrm{P} a q$ values determined for selected vegetation samples. Some samples include both above- and belowground tissues

5.3 Biomarker distributions along ridge-to-slough transects for two different sampling events at sites Z5-1 and Z6-1..

5.4 Ridge and slough floc biomarker distribution time series for site RS1

5.5 Ridge and slough floc biomarker distribution time series for site RS2

5.6 Ridge and slough floc biomarker distribution time series for site $\mathrm{C} 1$

5.7 Biomarker distribution time series for slough floc at sites DB1-3 and CC2S

5.8 Biomarker distribution time series for sediment trap samples at CB1-3 and CC1-2.134

5.9 Comparison between average biomarker distributions for all slough, ridge and sediment trap samples.

5.10 Cluster analyses for biomarker distributions for all slough, ridge and sediment trap samples 
5.11 PCA analysis for biomarker distributions for all slough, ridge and sediment trap samples.

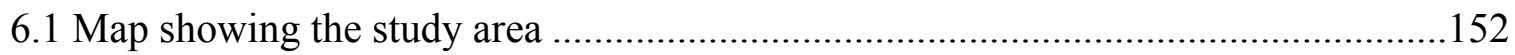

6.2n-Alkane distributions and their $\delta \mathrm{D}$ and $\delta^{13} \mathrm{C}$ values across studied plant leaves ....161

6.3 n-Alkane distribution and the average $\delta \mathrm{D}$ and $\delta^{13} \mathrm{C}$ values between leaf and root

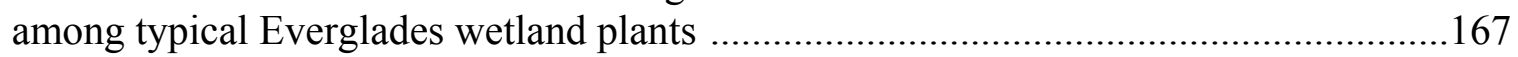

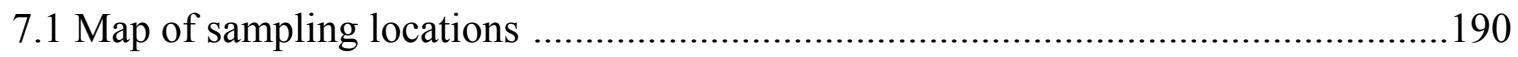

7.2 SRS2 and TSPh2 plants $n$-alkane $\delta^{13} \mathrm{C}$ and $\delta \mathrm{D}$ mean values distribution ................204

7.3 a) SRS2 surface soil $n$-alkane and $\mathrm{C}_{20} \mathrm{HBI} \delta^{13} \mathrm{C}$ values; b) SRS2 surface soil $n$-alkane and $\mathrm{C}_{20} \mathrm{HBI} \delta \mathrm{D}$ values

7.4 a) Ridge core $n$-alkane and $\mathrm{C}_{20} \mathrm{HBI} \delta^{13} \mathrm{C}$ value depth profile; b) Ridge core $n$-alkane and $\mathrm{C}_{20} \mathrm{HBI} \delta \mathrm{D}$ value depth profile; c) Slough core $n$-alkane and $\mathrm{C}_{20} \mathrm{HBI} \delta^{13} \mathrm{C}$ value depth profile; d) Slough core $n$-alkane and $\mathrm{C}_{20} \mathrm{HBI} \delta \mathrm{D}$ value depth profile .220 


\author{
ABBREVIATIONS \\ ACL: Average Chain Length \\ CERP: Comprehensive Everglades Restoration Plan \\ DOM: Dissolved Organic Matter \\ DPM: Decomp Physical Model \\ ENP: Everglades National Park \\ FCE: Florida Coastal Everglades \\ HBI: Highly Branched Isoprenoid \\ LTER: Long Term Ecological Research \\ MMA: Monomethylalkane \\ OM: Organic Matter \\ PCA: Principle Component Analysis \\ PLB: Ponce de Leon Bay \\ POC: Particulate Organic Carbon \\ POM: Particulate Organic Matter \\ SRS: Shark River Slough \\ TMS: Trimethylsilyl \\ TSM: Total Suspended Matter \\ TSPh: Taylor Slough/Panhandle area \\ WCA: Water Conservation Area
}




\section{CHAPTER I}

INTRODUCTION 


\subsection{Everglades National Park and CERP}

Everglades National Park (ENP), with a variety of environmental, hydrologic and soil-type gradients, is located within the largest subtropical wetland ecosystem in North America. It is characterized by shallow sheet flow) through freshwater marsh ridge and slough environments leading gradually to the fringe mangrove estuaries to the south and south-west. Freshwaters drain through two main routes, namely Shark River Slough (SRS) and Taylor Slough (TS). The estuarine zone of the Shark River, which is associated with mangrove rivers and intricate tidal creeks, is an important transfer zone not only of water but also of carbon from the freshwater wetlands end-ember to the coastal zone and ultimately the Gulf of Mexico (Fig. 1.1).

Tree islands, imbedded in the ridge and slough landscape of the Everglades make up the mosaic of this wetland ecosystem (Larsen et al., 2011). In addition to shallowwater sheetflow, the Everglades is characterized by its oligotrophic conditions, periodic fires, clearly seasonal wet and dry periods, historical climatic disturbances (hurricanes), and extreme sensitivity to anthropogenic stress (Steward and Ornes, 1983; Davis et al., 1994). The Everglades wetland ecosystem is commonly referred to as a "River of grass" (Douglas, 1947) because of the predominant vegetation coverage (over 65\%) of sawgrass (Cladium jamaicense). In addition, not only sawgrass, but woody vegetation, submerged or other emergent plants are widely distributed in this habitat where community structure and character is strongly influences by hydrological conditions such as hydroperiod (depth and inundation period). Various other factors can affect the vegetation distribution including fire frequency, soil type, nutrient levels, and others. Among all these factors, 
water depth and hydroperiod are dominant drivers that affect the landscape as well as control vegetation type and distribution in the Everglades wetland (Ross et al., 2003).

In the event of continuous flooding conditions or higher water depth, sawgrass is replaced by other slough vegetation communities, such as Eleocharis cellulosa (spikerush, emergent species), Utricularia sp. (bladderwort, submerged species) and Nymphaea sp. (water lily, floating aquatic species). In contrast, during prolonged dry conditions, ridgetype vegetation such as sawgrass could be replaced by woody, upland vegetation, generally represents a minor vegetation component within the ridge and slough environment. Clearly, however, changes to shorter hydproperiods can induce vegetation shifts from slough to ridge type vegetation. In addition to hydroperiod and water depth, nutrient levels are also responsible for biomass distribution. Elevated phosphorus levels can lead to Typha domingensis and Typha latifolia (cattails) to invade and eventually replace sawgrass.

Within the diverse distribution of dominant higher plants, periphyton mats are widely distributed throughout this ecosystem (Gaiser et al., 2011; Hagerthey et al., 2011), blanketing shallow surface sediment and submerged plants, forming ubiquitous and important biomass component of the Florida Everglades ecosystem. Considered to be the primary ecosystem engineer, periphyton plays a critical role in forming the base of the food web (Belicka et al., 2012), stabilizing soil, sustaining the landscape mosaic, and generating oxygen gas in the water column (Gaiser et al., 2011). With negligible presence of free floating phytoplankton in the Everglades, most of the suspended particulate organic matter (POM) is present in the form of floc, or flocculent material, which consists of a non-consolidated layer of microorganisms (generally bacteria), organic (e.g., detritus) 
and inorganic particles (e.g., carbonate), and represents an important biogeochemical component controlling carbon and nutrient transport, food web dynamics, and other biogeochemical processes in this ecosystem (Neto et al., 2006).

Since the early $20^{\text {th }}$ century the Everglades freshwater wetlands have been drained significantly because of structural modifications for flood control, urban and agricultural development. The Everglades wetlands were severely reduced in size and over $5,000 \mathrm{~km}^{2}$ $(50 \%)$ of the original landscape has been converted to agricultural and urban use during the last half century. Throughout this period, drainage of the wetlands resulted in increased fire frequency, shifts in the composition and distribution of vegetation cover, changes of the landscape (loss of ridge and slough features), as well as alteration in water quality, soil characteristics, and abundance of wildlife (Davis et al., 1994). Moreover, nutrients and runoff from the agricultural and urban areas cause further degradation of the Everglades wetland.

To respond to these changes which have compromised the quality of this ecosystem (water level and quality), the Comprehensive Everglades Restoration Plan (CERP) was initiated within the Water Resources Development Act of 2000 (http://www.evergladesplan.org). This plan aims at reestablishing water quantity, quality and timing to conditions similar to those existing prior to anthropogenic alteration (Richardson et al., 2010). 


\subsection{Linking hydrology to organic matter dynamics using biomarkers and compound-specific stable isotope analyses}

Hydrology changes have severely affected the ecology and biogeochemistry of the Everglades. To better establish restoration targets for CERP, among others, more information is needed to assess past, present and future changes in organic matter dynamics in relation to variations in the hydrological regime. For example, determining the original condition of the Everglades wetlands and estuaries is important for establishing restoration targets, as well as to better assess the topographic and vegetation changes resulting from anthropogenic influences. Moreover, it is important to understand how the planned changes in freshwater delivery to the Everglades would affect the organic matter dynamics to lay the framework for post restoration management plan.

In sub-tropical wetlands and estuaries, it is important to determine how OM dynamics (source strengths, mobility, carbon budgets and fluxes) are affected by hydrological changes (e.g., tidal change, seasonal change, climatological change such as sea-level rise and natural disturbances such as hurricanes). In order further understand the effects of hydrological changes on OM dynamics in the Everglades, it is important to obtain historical information on precipitation, water level changes (hydroperiod) and vegetation successions associated with water availability variations. Source-specific biomarkers have already successfully been identified in the Everglades (Jaffé et al., 2001; Mead et al., 2005; Jaffé et al. 2006; Saunders et al., 2006) and their paleo-environmental applications have demonstrated a vegetation shift with reduction of hydroperiod over the past decades (Saunders et al., 2006). However, because of the complexity of OM sources in this system, multi-proxy approaches are needed in order to provide additional, 
comprehensive information on the coupling of OM dynamics with hydrological change in ENP. Specifically for pealeo-hydrology studies, a combination of source-specific biomarkers analysis, combined with compound specific $\delta \mathrm{D}$ isotope analysis would be required. This compound specific isotope analysis approach can be used to assess hydrological changes in ENP and to reconstruct past hydroperiod conditions and provide insights into the local hydrology changes caused by human pressures on the Everglades. However, this approach is novel to this ecosystem and needs to be validated along vegetation gradients and hydrological gradients prior to a possible paleo-hydrology application. For estuarine systems, source-specific biomarkers should be applied to separately assess carbon export from the freshwater and mangrove sub-systems. Compound-specific stable isotope proxies also need to be developed for future paleoenvironmental applications in the coastal zone.

Thus, molecular biomarkers and compound specific $\delta^{13} \mathrm{C}$ and $\delta \mathrm{D}$ isotopic analysis were applied to assess OM dynamics and reconstruct paleo-climatic and paleoenvironmental conditions in this ecosystem. The main goals of this work are:

1. Characterization of biomarkers distributions and compound-specific isotopic signatures in Everglades freshwater marshes and estuaries in order to:

a. Validate molecular proxies as to their OM source specificity for freshwater marsh environments.

b. Apply validated molecular proxies in the assessment of POM sources and mobility in ridge and slough environments. 
c. Apply existing molecular, biomarker-based proxies to assess sourcespecific carbon loss from the Everglades mangrove ecosystem through POM export.

d. Determine new biomarker and compound-specific stable isotope based proxies to assess $\mathrm{OM}$ dynamics and potential paleo-environmental changes in mangrove environments.

2. Reconstruct the vegetation history and paleo-hydrological variations in the Everglades freshwater wetlands through the application of the combined and validated biomarker and compound-specific stable isotope approach.

\subsection{Research Approach}

\subsubsection{Study Sites}

\subsubsection{Freshwater wetlands}

The Everglades freshwater wetlands are oligotrophic and extremely sensitive to anthropogenic stress. There are two major drainage basins in the Everglades, namely Shark River Slough (SRS) and the Taylor Slough/Panhandle area (TSPh). The differences in the nutrient patterns and hydrological status between SRS and TSPh result in different soil types and different vegetation community structures. Briefly, freshwater TSPh areas are characterized by marl type soils while peats are typical for the freshwater SRS. The dominant wetland vegetation is Cladium, Eleocharis, Utricularia, Nymphaea and periphyton. While Cladium is usually more abundant at the ridges (shallow water), Eleocharis, Utricularia and Nymphaea are more common in the sloughs (Saunders et al., 
2006). In this whole dissertation, various sites (WCA-3A/B, SRS1-3, TSPh2-3) with varying nutrient and hydroperiod characteristics were selected (Fig. 1.1).

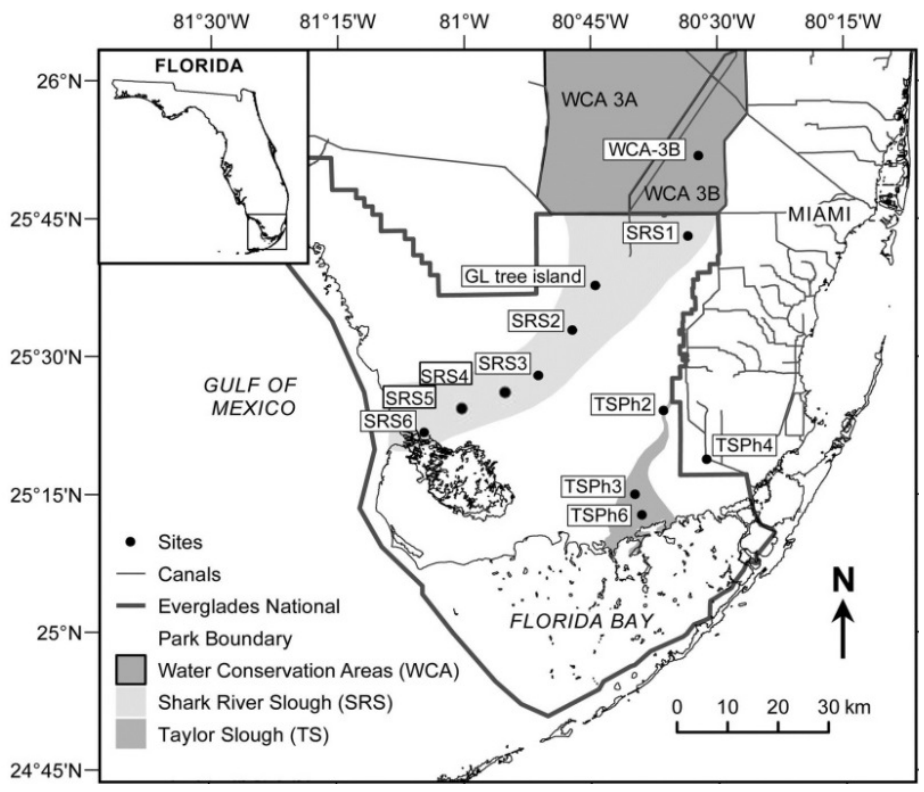

Figure 1.1 Partial map of the greater Everglades indicating study sites of interest.

\subsubsection{Shark River Estuary}

The study was performed mainly in the estuarine zone of the Shark River in the southwestern section of the Everglades National Park (ENP). The combined Shark River Slough and associated mangrove rivers make up the main water drainage system for much of ENP, where water drains from the freshwater marshes through fringe mangrove swamps into the Gulf of Mexico (Fig. 1.2). The vegetation of ENP's freshwater marshes is characterized by abundant calcareous periphyton, Cladium jamaicense (sawgrass) and Eleocharis (spikerush) in the freshwater zone (SRS1-SRS3; Richards, 2001) while fringe mangrove forests, mainly of Rhizophora mangle (Red mangrove; Twilley, 1985; Davis et al., 2003), dominate the estuarine zone (SRS4-SRS6). The coastal zone is characterized mainly by sandy bottom sediments (Ponce de Leon Bay) with patchy seagrass beds 
towards the Florida Shelf with Thalassia testudinum as the main species (Fourqurean, 1993). Annual rainfall is typically between 122 and $152 \mathrm{~cm}$, with most (80\%) occurring during the wet season (Southeast Regional Climate Center, http://www.sercc.com). The field stations chosen have been established by the Florida Coastal Everglades Long Term Ecological Research program (http://fcelter.fiu.edu/) (Fig. 1.2), and represent a hydrological and salinity gradient covering the freshwater to marine end-members of the system.
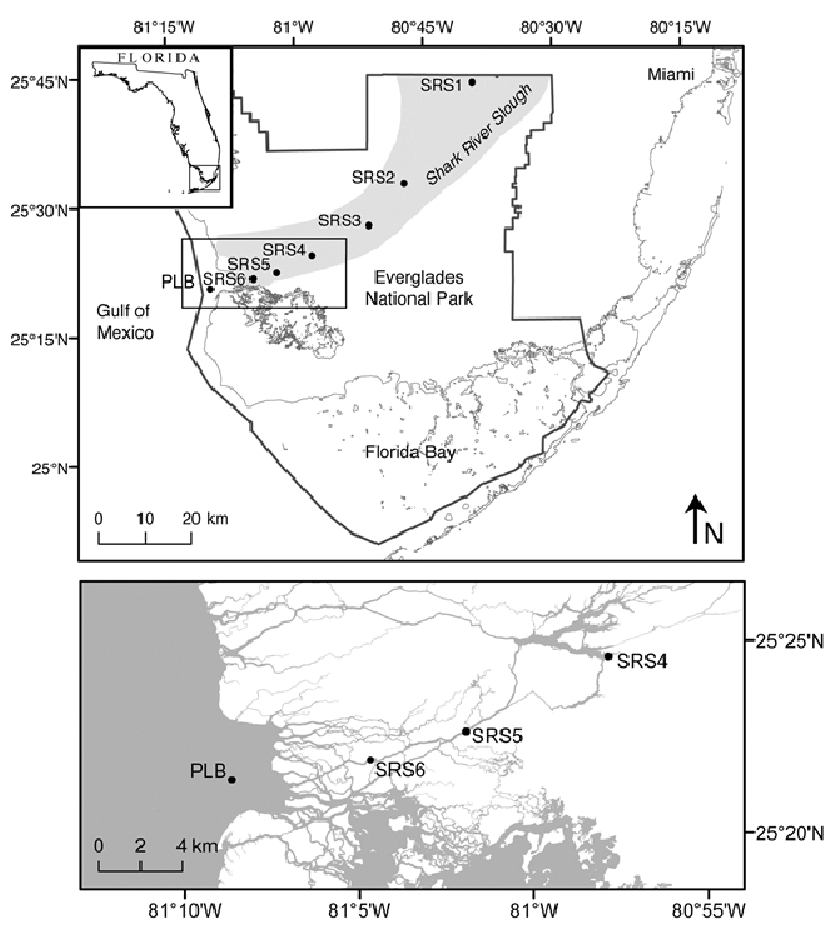

Figure 1.2 Shark River Slough (SRS-1-6) and offshore site (PLB).

\subsubsection{Molecular and Compound Stable Isotopic Proxies}

\subsubsection{Lipid Biomarkers for OM Sources, Transport and Paleo-environmental Studies}

$n$-Alkanes are one of the most abundant lipid molecules biosynthesized by various

plants because of their resistance towards secondary structural modification or 
degradation during deposition. They have been shown to be indicators for various sources, like relatively short chain $n$-alkanes $\left(\mathrm{C}_{15}, \mathrm{C}_{17}\right.$ and $\left.\mathrm{C}_{19}\right)$ are mainly attributed to algae and/or bacteria (Gelpi et al., 1970). Mid-chain ones $\left(C_{21}\right.$ to $\left.C_{25}\right)$ could be generated from aquatic submerged or floating plants, moss etc. (Ficken et al., 2000). While terrestrial woody plants are mainly characterized by the longer chain $n$-alkanes $\left(\mathrm{C}_{27}\right.$ to $\mathrm{C}_{35}$; Rieley et al., 1991; Collister et al., 1994). On the basis of the distribution patterns, sources of OM may be differentiated and lots of other related parameters were generated on the basis of the $n$-alkanes distribution, such as Paq (\% of aquatic plants; Ficken et al., 2000), average chain length (ACL), and other numerical parameters (Marzi et al., 1993; Jansen et al., 2006). These $n$-alkanes based/derived parameters, combined with other proxies, in geological samples can be utilized to reconstruct paleo-environmental conditions.

Lipids, solvent-extractable organic compounds, are derived from cuticular waxes, cell wall component, and other sources and may be specific markers for certain groups of organisms (Eglinton and Hamilton, 1967). Because of their resistance towards secondary structural modification or degradation during deposition, lipids were used as biomarkers to trace organic matter source and record certain environmental information even only consist a few percent of total organic carbon (Ficken et al., 2000; Bechtel et al., 2003). Examples of biomarkers are $n$-alkanes, highly branched isoprenoids (HBIs), diterpenoid, triterpenoid, and others (Ficken et al., 2000; Jaffé et al., 2001; Mead et al., 2003; Gao et al., 2007). A combination of these biomarkers was used to assess OM sources and dynamics in this subtropical wetland and estuary system. 


\subsubsection{Compound Specific $\delta^{13} C$ and $\delta D$ Isotopes for Paleo-climatic Reconstructions}

Lipids, especially $n$-alkanes, with hydrogens covalently bounded to carbons, are stable to preserve long term isotopic information in the sediment (Schimmelmann et al., 1999) for paleo-climatic reconstruction (Sachse et al., 2004). $n$-Alkanes in sediments are well known to record the plant $\delta^{13} \mathrm{C}$ and $\delta \mathrm{D}$ values (Chikaraishi and Naraoka, 2003; Sachse et al., 2004), and numerous studies on the $\delta^{13} \mathrm{C}$ and $\delta \mathrm{D}$ of $n$-alkanes in plants have been carried out (Chikaraishi et al., 2004; Sachse et al., 2006; Sessions et al., 2006; Smith and Freeman, 2006; Pedentchouk et al., 2008). On the basis of the plant calibration studies, several paleo-studies were performed to reconstruct the climate in the past, and this has been successfully used in a lot of environmental areas such as forest, high mountains, lake sediments (Huang et al., 2002; Sachse et al., 2012 and references therein), and others. Generally, $\delta^{13} \mathrm{C}$ of $n$-alkanes has been widely used to assess the vegetation type change $\left(\mathrm{C}_{3} / \mathrm{C}_{4}\right)$, which can infer the climatic conditions (e.g., Yamada and Ishiwatari, 1999; Huang et al., 2001), while $\delta \mathrm{D}$ of $n$-alkanes was used as a proxy for precipitation, relative humidity, temperature and salinity of the past in various environments (Xie et al., 2000; Liu and Huang, 2005; Sachse and Sachs, 2008). Thus, the combination of compound specific $\delta^{13} \mathrm{C}$ and $\delta \mathrm{D}$ analysis for specific compounds (especially $n$-alkanes), integrated with lipid biomarkers, has been used as a powerful technique for a variety of studies to provide qualitative or quantitative paleo-ecological information for various environmental factors, such as organic matter source, temperature, relative humidity, and precipitation (Huang et al., 2001; Liu et al., 2006; Pagani et al., 2006; Liu and Yang, 2008). 
In the Everglades fresh water wetland system, in order to provide additional information for paleo-reconstruction, compound specific $\delta \mathrm{D}$ and $\delta^{13} \mathrm{C}$ isotopes analyses were performed for various plants ( 25 species, representing 19 families), ridge-slough soil transects within wetland to assess and validate these molecular proxies. They were then applied to assess changes in hydroperiod to two soil cores (one ridge core and one slough core).

\subsection{Framework of this Dissertation}

In addition to this introductory chapter, this dissertation contains additional six chapters, which were organized in the following way:

Chapter II: Assessing biomass contributions to particulate organic matter in a subtropical estuary: a biomarker approach. In this chapter, a biomarker based three-endmember model was used to assess POM source strengths along the Shark River Estuary. POM flux from mangroves to the Gulf of Mexico was estimated on the basis of this model.

Chapter III: Occurrence and distribution of a series of monomethylalkanes in the freshwater ecosystem of the Florida Everglades. This chapter focuses on the identification of a series of monomethylalkanes (MMAs) with carbon numbers from $\mathrm{C}_{10}$ to $\mathrm{C}_{23}$ and $\mathrm{C}_{29}$ across freshwater wetlands of the Everglades, and an attempt to determine their potential biogenic source. Potential applications of this molecular proxy are indicated.

Chapter IV: Identification of a series of long-chain alkyl hydroxycinnamates from two species of cattail (Typha domingensis P., and Typha latifolia L.). This chapter 
focuses on the identification of several long-chain $n$-alkyl coumarates and ferulates as potential biomarkers for cattails (Typha domingensis and Typha latifolia; both roots and leaves) in the freshwater marshes of the Florida Everglades.

Chapter V: Sheet flow effects and canal backfilling on sediment source and transport in the Decomp Physical Model: analysis of molecular organic biomarkers. In this chapter, a biomarker conceptual model was validated and applied to determine POM sources and mobility across the freshwater marsh ridge-and-slough landscape.

Chapter VI: Distribution of $n$-alkanes and the $\delta \mathrm{D}$ and $\delta^{13} \mathrm{C}$ patterns in typical living plants across a subtropical tree island to wetland gradient and estuary system: implication for paleo-reconstruction. This chapter describes the investigation of the distributions of $n$-alkanes and their $\delta \mathrm{D}$ and $\delta^{13} \mathrm{C}$ patterns in typical living plants across a subtropical tree island/wetland/estuary system to assess their application as molecular proxies for paleo-environmental studies in the Everglades ecosystem.

Chapter VII: Compound specific $\delta \mathrm{D}$ and $\delta^{13} \mathrm{C}$ analyses as a tool for the assessment of hydrological change in a subtropical wetland. This chapter describes an approach to assess vegetation shifts and hydrological change though biomarker and compound specific $\delta \mathrm{D}$ and $\delta^{13} \mathrm{C}$ based molecular proxies applications in the Everglades freshwater wetland.

Chapter VIII: General conclusion and remarks. 


\section{REFERENCES}

Belicka, L. L., Sokol, E. R., Hoch, J. M., Jaffé, R., Trexler, J. C. (2012). A molecular and stable isotopic approach to investigate algal and detrital energy pathways in a freshwater marsh. Wetlands, 32(3), 531-542.

Chikaraishi, Y., Naraoka, H. (2003). Compound-specific $\delta \mathrm{D}-\delta^{13} \mathrm{C}$ analyses of n-alkanes extracted from terrestrial and aquatic plants. Phytochemistry, 63(3), 361-371.

Chikaraishi, Y., Naraoka, H., Poulson, S. R. (2004). Hydrogen and carbon isotopic fractionations of lipid biosynthesis among terrestrial (C3, C4 and CAM) and aquatic plants. Phytochemistry, 65(10), 1369-1381.

Collister, J. W., Rieley, G., Stern, B., Eglinton, G., Fry, B. (1994). Compound-specific $\delta^{13} \mathrm{C}$ analyses of leaf lipids from plants with differing carbon dioxide metabolisms. Organic Geochemistry, 21(6), 619-627.

Daoust, R.J., Childers, D.L., (2004) Ecological effects of low-level phosphorus additions on two plant communities in a neotropical freshwater wetland ecosystem. Oecologia, 141(4), 672-686.

Davis III, S.E., Childers, D.L., Day Jr., J.W., Rudnick, D.T., Sklar, F.H. (2003). Factors affecting the concentration and flux of materials in two southern Everglades mangroves wetlands. Marine Ecology Progress Series, 253, 85-96.

Davis, S.M., Gunderson, L.H., Park, W.A., Richardson, J.R., Mattson, J.E., (1994) Landscape dimension, composition, and function in a changing Everglades ecosystem. In: S.M. Davis, J.C. Ogden (Eds.), Everglades: the Ecosystem and Its Restoration (Ed. by S.M. Davis, J.C. Ogden), pp. 419-444. St. Lucie Press, Delray Beach, Florida.

Douglas, M.S., (1947) The Everglades river of grass (revised edition, 1988). Pineapple, Sarasota, Florida.

Eglinton, G., Hamilton, R.J. (1967). Leaf epicuticular waxes. Science, 156(3780), 13221335.

Ewe, S., Gaiser, E., Childers, D., Iwaniec, D., Rivera-Monroy, V., Twilley, R., (2006) Spatial and temporal patterns of aboveground net primary productivity (ANPP) along two freshwater-estuarine transects in the Florida Coastal Everglades. Hydrobiologia, 569(1), 459-474.

Ficken, K.J., Li, B., Swain, D.L., Eglinton, G. (2000). An $n$-alkane proxy for the sedimentary input of submerged/floating freshwater aquatic macrophytes. Organic Geochemistry, 31(7), 745-749. 
Fourqurean, J.W., Jones, R.D., Zieman, J.C., (1993) Process influencing water column nutrient characteristics and phosphorus limitation of phytoplankton biomass in Florida Bay, FL, USA: inferences from spatial distributions. Estuarine, Coastal and Shelf Science $36,295-314$.

Gaiser, E.E., McCormick, P.V., Hagerthey, S.E., Gottlieb, A.D. (2011) Landscape patterns of periphyton in the Florida Everglades. Critical Reviews in Environmental Science and Technology, 41(S1), 92-120.

Gao, M., Simoneit, B.R., Gantar, M., Jaffé, R. (2007). Occurrence and distribution of novel botryococcene hydrocarbons in freshwater wetlands of the Florida Everglades. Chemosphere, 70(2), 224-236.

Gelpi, E., Schneider, H., Mann, J., Oro, J. (1970). Hydrocarbons of geochemical significance in microscopic algae. Phytochemistry, 9(3), 603-612.

Hagerthey, S. E., Bellinger, B. J., Wheeler, K., Gantar, M., Gaiser, E. (2011) Everglades periphyton: a biogeochemical perspective. Critical Reviews in Environmental Science and Technology, 41(S1), 309-343.

Hinrichs, K. U., Schneider, R. R., Müller, P. J., Rullkötter, J. (1999). A biomarker perspective on paleoproductivity variations in two Late Quaternary sediment sections from the Southeast Atlantic Ocean. Organic Geochemistry, 30(5), 341-366.

Huang, Y. A., Street-Perrott, F. A., Metcalfe, S.E., Brenner, M., Moreland, M., Freeman, K. H. (2001). Climate change as the dominant control on glacial-interglacial variations in C3 and C4 plant abundance. Science, 293(5535), 1647-1651.

Huang, Y., Shuman, B., Wang, Y., Webb, T. (2002). Hydrogen isotope ratios of palmitic acid in lacustrine sediments record late Quaternary climate variations. Geology, 30(12), 1103-1106.

Jaffé, R., Mead, R., Hernandez, M. E., Peralba, M. C., DiGuida, O. A. (2001). Origin and transport of sedimentary organic matter in two subtropical estuaries: a comparative, biomarker-based study. Organic Geochemistry, 32(4), 507-526.

Jaffé, R., Rushdi, A.I., Medeiros, P.M., Simoneit, B.R. (2006). Natural product biomarkers as indicators of sources and transport of sedimentary organic matter in a subtropical river. Chemosphere, 64(11), 1870-1884.

Jansen, B., Nierop, K.G., Hageman, J.A., Cleef, A.M., Verstraten, J.M. (2006). The straight-chain lipid biomarker composition of plant species responsible for the dominant biomass production along two altitudinal transects in the Ecuadorian Andes. Organic Geochemistry, 37(11), 1514-1536. 
Larsen, L., Aumen, N., Bernhardt, C., Engel, V., Givnish, T., Hagerthey, S., Harvey, J., Leonard, L., McCormick, P., McVoy, C., Noe, G., Nungesser, M., Rutchey, K., Sklar, F., Troxler, T., Volin, J., Willard, D. (2011). Recent and Historic Drivers of Landscape Change in the Everglades Ridge, Slough, and Tree Island Mosaic. Critical Reviews in Environmental Science and Technology, 41, 344-381.

Liu, W., Huang, Y. (2005). Compound specific D/H ratios and molecular distributions of higher plant leaf waxes as novel paleoenvironmental indicators in the Chinese Loess Plateau. Organic Geochemistry, 36(6), 851-860.

Liu, W., Yang, H. (2008). Multiple controls for the variability of hydrogen isotopic compositions in higher plant $n$-alkanes from modern ecosystems. Global Change Biology, 14(9), 2166-2177.

Liu, W., Yang, H., Li, L. (2006). Hydrogen isotopic compositions of $n$-alkanes from terrestrial plants correlate with their ecological life forms. Oecologia, 150(2), 330-338.

Marzi, R., Torkelson, B.E., Olson, R.K. (1993). A revised carbon preference index. Organic Geochemistry, 20(8), 1303-1306.

Mead, R., Xu, Y., Chong, J., Jaffé, R. (2005). Sediment and soil organic matter source assessment as revealed by the molecular distribution and carbon isotopic composition of $n$-alkanes. Organic Geochemistry, 36(3), 363-370.

Neto, R., Mead, R.N., Louda, W., and Jaffé, R. (2006). Organic biogeochemistry of detrital flocculent material (floc) in a subtropical, coastal wetland. Biogeochemistry 77:283-304.

Pedentchouk, N., Sumner, W., Tipple, B., Pagani, M. (2008). $\delta^{13} \mathrm{C}$ and $\delta \mathrm{D}$ compositions of n-alkanes from modern angiosperms and conifers: An experimental set up in central Washington State, USA. Organic Geochemistry, 39(8), 1066-1071.

Richards, J.H., (2001). Bladder function in Utricularia purpurea (Lentilbulaiacae): is carnivory important? American Journal of Botany 88, 170-176.

Richardson, C. J. (2010). The Everglades: North America's subtropical wetland. Wetlands Ecology and Management, 18(5), 517-542.

Rieley, G., Collier, R.J., Jones, D.M., Eglinton, G., Eakin, P.A., Fallick, A.E. (1991). Sources of sedimentary lipids deduced from stable carbon-isotope analyses of individual compounds. Nature, 352, 425-427.

Ross, M.S., Reed, D.L., Sah, J.P., Ruiz, P.L., Lewin, M.T., (2003). Vegetation: environment relationships and water management in Shark Slough, Everglades National Park. Wetlands Ecology and Management, 11(5), 291-303. 
Sachse, D., Billault, I., Bowen, G.J., Chikaraishi, Y., Dawson, T.E., Feakins, S.J., ... and Kahmen, A. (2012). Molecular paleo-hydrology: interpreting the hydrogen isotopic composition of lipid biomarkers from photosynthetic organisms. Annual Review of Earth Planetary Science, 40, 221-249.

Sachse, D., Radke, J., Gleixner, G. (2004). Hydrogen isotope ratios of recent lacustrine sedimentary n-alkanes record modern climate variability. Geochimica et Cosmochimica Acta, 68(23), 4877-4889.

Sachse, D., Radke, J., Gleixner, G. (2006). $\delta$ D values of individual n-alkanes from terrestrial plants along a climatic gradient-Implications for the sedimentary biomarker record. Organic Geochemistry, 37(4), 469-483.

Sachse, D., Sachs, J.P. (2008). Inverse relationship between D/H fractionation in cyanobacterial lipids and salinity in Christmas Island saline ponds. Geochimica et Cosmochimica Acta, 72(3), 793-806.

Saunders, C. J., Gao, M., Lynch, J. A., Jaffé, R., Childers, D. L. (2006). Using soil profiles of seeds and molecular markers as proxies for sawgrass and wet prairie slough vegetation in Shark Slough, Everglades National Park. Hydrobiologia, 569(1), 475-492.

Schimmelmann, A., Lewan, M.D., Wintsch, R.P. (1999). D/H isotope ratios of kerogen, bitumen, oil, and water in hydrous pyrolysis of source rocks containing kerogen types I, II, IIS, and III. Geochimica et Cosmochimica Acta, 63(22), 3751-3766

Sessions, A.L. (2006). Seasonal changes in D/H fractionation accompanying lipid biosynthesis in Spartina alterniflora. Geochimica et Cosmochimica Acta, 70(9), 21532162.

Smith, F.A., Freeman, K.H. (2006). Influence of physiology and climate on $\delta \mathrm{D}$ of leaf wax n-alkanes from C3 and C4 grasses. Geochimica et Cosmochimica Acta, 70(5), 11721187.

Twilley, R.R., (1985). The exchange of organic carbon in basin mangrove forests in a southwest Florida estuary. Estuarine, Coastal and Shelf Science 20, 543-557.

Xie, S., Nott, C.J., Avsejs, L.A., Volders, F., Maddy, D., Chambers, F.M., ... Evershed, R.P. (2000). Palaeoclimate records in compound-specific $\delta$ D values of a lipid biomarker in ombrotrophic peat. Organic Geochemistry, 31(10), 1053-1057.

Yamada, K., Ishiwatari, R. (1999). Carbon isotopic compositions of long-chain $n$-alkanes in the Japan Sea sediments: implications for paleoenvironmental changes over the past 85 kyr. Organic Geochemistry, 30(5), 367-377. 
CHAPTER II

ASSESSING BIOMASS CONTRIBUTIONS TO PARTICULATE ORGANIC MATTER IN A SUBTROPICAL ESTUARY: A BIOMARKER APPROACH 


\subsection{Abstract}

Assessing the sources and quantifying the contributions of particulate organic matter (POM) in estuaries is a challenge. Here I apply source-specific biomarkers to assess POM sources in an estuary receiving suspended material from freshwater wetlands, fringe mangroves and coastal environments. A three end-member mixing model, including terrestrial, estuarine and marine end-member contributions was developed and successfully validated to assess general organic matter dynamics and hydrologic processes that control POM distributions within the Shark River Estuary in South Florida. Low tide and wet season conditions coincided with an enhanced signal of the freshwater end-member biomarker abundance, while high tide and dry season conditions resulted in enhanced POM input of marine origin. Incoming tide was observed to be an important factor in the re-suspension and tidal pumping of mangrove-derived POM, which seems to be the dominant source of particulate organic carbon (POC) in the estuary. The three end-member conceptual model was tested to obtain a rough estimate of POC source strength, with the ultimate goal of constraining carbon budgets in this subtropical estuary. Mangrove-derived POC flux of ca. $5.3 \times 10^{5}$ to $1.0 \times 10^{6} \mathrm{~kg} / \mathrm{yr}$ POC from the Shark River to the Gulf of Mexico were estimated, but end-member values used in the assessment need to be better constrained to reduce the degree of variability.

\subsection{Introduction}

Estuaries are located at the interface where the land meets the sea and are important conduits of organic matter (OM) to the ocean. Most of the estuarine research dealing with coastal carbon cycling has focused on large river-dominated systems 
(Gordon and Goñi, 2003) because of the fact that they provide the most significant load of allochthonous material to coastal environments (Hedges and Keil, 1995). However, understanding fluvial transport and the sources of particulate organic carbon (POC) in smaller, river-dominated estuaries are critical in order to better constrain global carbon budgets (Kristensen et al., 2008; Adame et al., 2011).

Various approaches have been applied to assess POM sources and contributions in estuaries, including stable carbon isotopes $\left({ }^{14} \mathrm{C}\right.$ and $\left.{ }^{13} \mathrm{C}\right), \mathrm{C}: \mathrm{N}_{\mathrm{a}}$ and molecular markers (e.g., Thornton et al., 1994; Canuel, 2001; Raymond and Bauer, 2001; Jaffé et al., 2001; Gordon and Goñi, 2003). Most of the earlier studies were on the basis of two endmember mixing models where $\delta^{13} \mathrm{C}$ values were used to estimate the relative abundance of terrestrial vs. marine OC sources (e.g., Canuel et al., 1995), or mangrove vs. marine phytoplankton sources (Tue et al., 2012). Other reports separated the terrestrial endmember into two different OM sources, as vascular plant and soil derived (Gordon and Goñi, 2003) and, by including marine OM, introduced a three end-member model approach. Most of previous $\delta^{13} \mathrm{C}$ based end-member models assume that POC decay processes along the estuary do not affect the POC isotope or biomarker composition between end-member source inputs and outputs, and generally assume that the autochthonous OM contribution to estuarine POM is negligible. However, in sub-tropical estuaries, such as the fringe mangrove systems in South Florida, delivery of OM from the upper watershed, combined with mangrove-produced OM in the local estuary, and the marine OM delivered through tidal exchange (Jaffé et al., 2001, 2006; Mead et al., 2005), complicate such assessments because it is difficult to differentiate OM contributions from these sources using the carbon isotope composition because of their similar $\delta^{13} \mathrm{C}$ values 
(Cloern et al., 2002).

From a practical perspective, OM dynamics in aquatic environments, especially in estuaries, are complex and challenging to understand because of the varied OM input sources (Hedges and Keil, 1999; Canuel, 2001). In addition, an integrated view of the overall OM processing in this kind of ecosystem remains elusive (Bouillon et al., 2008b) because the fate of $\mathrm{OM}$ is controlled largely by its reactivity and residence time within the system. Physical processes that control the residence time of particles and hence OM within estuaries vary from semi-diurnal (tidal), seasonal (water discharge), climatological to multi-year to decadal scales (e.g., ENSO, Pacific Decadal Oscillation) and interactions between these forcings can have a critical effect on the retention, flocculation, burial and respiration of carbon. As such, there is a need to develop novel approaches to assess OM sources and dynamics in estuarine systems through multi-end-member conceptual models, including terrestrial, estuarine and marine components. These models need sourcespecific biomarkers or molecular proxies, which should be refractory or retain their source information even after some structural alteration.

Biomarker based OM source tracing has been commonly used in marine (e.g., Prahl et al., 1994; Wakeham et al., 2002), coastal (Jaffé et al., 2001; Mead et al., 2005) and estuarine (Bianchi et al., 1993; Canuel et al., 1997, 1999; Goñi and Thomas, 2000) systems. One class of compounds that has received considerable attention in the Everglades ecosystem because of its potential application as stable biomass-specific markers, is the $\mathrm{C}_{20}$ and $\mathrm{C}_{25}$ highly branched isoprenoids (HBIs; Jaffé et al., 2001; Xu et al., 2006a, 2007). These have been reported in coastal (Farrington et al., 1977; Requejo and Quinn, 1983) and marine (Wraige et al., 1997; Prahl et al., 2000) ecosystems. The 
presence of the $\mathrm{C}_{20} \mathrm{HBI}$ (reported here as the sum of $\mathrm{C}_{20: 0}$ and $\mathrm{C}_{20: 1}$ ) has been attributed to cyanobacteria and its main source in the Everglades ecosystem is thought to be freshwater periphyton (Jaffé et al., 2001; Pisani et al., 2013). A second useful group of HBIs is the $\mathrm{C}_{25}$ homologues (reported here as the sum of $\mathrm{C}_{25: 1: 1}$ and $\mathrm{C}_{25: 2: 2}$ ) which have been found in sediments from the Florida Coastal Everglades (Jaffé et al., 2001; Xu et al., 2006b, 2007) and have been assigned a marine diatom source. The $\mathrm{C}_{20}$ and $\mathrm{C}_{25}$ HBIs provide two largely unambiguous markers for freshwater and marine end-members, respectively, with the triterpenoid taraxerol serving as a unique marker for estuarine input in the South Florida Everglades ecosystem. Taraxerol has been reported as a biomarker for mangrove vegetation, specifically Rhizophora mangle (Killops and Frewin, 1994; Koch et al., 2003, 2005, 2011; Versteegh et al., 2004), and is widely observed in sediments from South Florida estuaries (Jaffé et al., 2006; Xu et al., 2006a, 2007) which feature abundant fringe mangrove forests (Welch et al., 1999; Davis et al., 2003; RiveraMonroy et al., 2007).

A three end-member model is proposed for addressing POM sources in the estuarine zone of the Florida coastal Everglades. In this conceptual model, the freshwater marsh POC input is represented by the periphyton derived $\mathrm{C}_{20} \mathrm{HBI}$, the marine endmember by the marine diatom derived $\mathrm{C}_{25} \mathrm{HBIs}$ and the estuary by the mangrove derived taraxerol. In addition to the need to validate this conceptual model, end-member characterization is needed to allow correlation of the selected biomarker concentrations with actual organic matter $(\mathrm{OM})$ concentrations of the freshwater marsh, mangrove estuary and marine end-member sources. This approximation is essential in order to assess POC fluxes from the different sub-environments, but its accuracy is strongly 
dependent on the reliability and representative nature of the end-member values. As such, the $\mathrm{C}_{20} \mathrm{HBI}$ was quantified in floc and soil samples from the freshwater marshes to assess bulk OM contributions from this end-member (i.e. including OM from other types of plants in addition to periphyton). Similarly, the $\mathrm{C}_{25} \mathrm{HBI}$ was used to quantify bulk marine end-member sources including seagrass. Although the relative molecular distributions of $n$-alkan-2-ones and/or of $n$-alkanes have been applied as a relative indicator of seagrassderived and macrophyte-derived OM in sediments and soils (Hernandez et al., 2001; Mead et al., 2005; Saunders et al., 2006), no specific biomarkers have been identified for representing a quantitative proxy for such vegetation. Clearly some important caveats must be addressed when attempting this approach. First, these biomass-specific biomarkers are used only to qualitatively represent the POC contributions from the freshwater marsh, coastal marine and estuarine zones in this system. The autochthonous planktonic estuarine contribution, which has been reported to be relatively low, is not considered (Boyer et al., 1997). Second, since differential degradation rates have not been accounted for, the assumption is that all three compounds present similar diagenetic behavior and are relatively stable on timescales important for POM transport and exchange in the system under consideration. In support of this assumption, recent work by Koch et al. (2005) and Versteegh et al. (2004) shows that taraxerol is quite resistant to microbial degradation, and the highly branched nature of the HBIs, which have been reported in immature crude oils (Sinninghe Damste et al., 1989), suggests that these compounds are resistant to degradation. In addition, both the $\mathrm{C}_{20}$ and $\mathrm{C}_{25} \mathrm{HBIs}$ have been detected in sediment cores from the Everglades region (Xu et al., 2007), indicating that they are relatively stable on the order of at least decades. 
The main objectives of the work were to (i) validate the effectiveness of the three end-member conceptual mixing model under different environmental conditions, (ii) assess the origin and fate of POM in the Shark River estuary and (iii) obtain a semi quantitative estimate of the source contributions from freshwater, fringe mangroves and marine organic matter to the POC annual flux from the Shark River to the Gulf of Mexico. On the basis of the above justifications, I apply $\mathrm{C}_{20} \mathrm{HBI}, \mathrm{C}_{25} \mathrm{HBI}$ and taraxerol as specific biomarkers for assessing Shark River estuary freshwater, marine and estuarine end-member contributions to the POM pool, respectively. This is the first study where these molecular markers have been used together to trace specific biomass in estuaries. The ultimate goal is to apply the conceptual model to better constrain the carbon budget in ecosystems with fringing mangroves in South Florida and other tropical coastlines, in particular for the assessment of carbon losses from the fringing mangrove system through mangrove-specific POC export.

\subsection{Experimental}

\subsubsection{Sampling}

\subsubsection{Study area}

The study was performed mainly in the estuarine zone of the Shark River in the southwestern section of the Everglades National Park (ENP). The combined Shark River slough and associated mangrove rivers, including the Shark River proper, make up the main water drainage system for much of ENP and South Florida, where water drains from the freshwater marshes through fringe mangrove swamps into the Gulf of Mexico (Fig. 2.1). The vegetation of ENP's freshwater marshes is characterized by abundant 
calcareous periphyton, Cladium jamaicense (sawgrass) and Eleocharis cellulosa (spikerush) in the freshwater zone (Richards, 2001; SRS1-SRS3) while fringe mangrove forests, mainly of Rhizophora mangle (Red mangrove; Davis et al., 2003; Twilley, 1985), dominate the estuarine zone (SRS4-SRS6). The coastal zone is characterized mainly by sandy bottom sediments (Ponce de Leon Bay; PLB1, PLB2) with patchy seagrass beds towards the Florida Shelf with Thalassia testudinum as the main species (Fourqurean, 1993). Annual rainfall is typically between 122 and $152 \mathrm{~cm}$, with most (80\%) occurring during the wet season (Southeast Regional Climate Center, http://www.sercc.com). Well constrained wet and dry seasons define the climate in this region, where the wet season is from May to October and the dry season from November to April. The tides in the Shark River Estuary are semi-diurnal, with a mean amplitude of 0.5-1.0 $\mathrm{m}$ and flood discharge being of shorter duration but relatively stronger than the ebb discharge (Levesque, 2004; Romigh et al., 2006). Annual discharge from the Shark River to the Gulf of Mexico is ca. $2.44 \times 10^{11} \pm 0.702 \times 10^{11} 1$ (Woods, 2010). The field stations chosen have been established by the Florida Coastal Everglades Long Term Ecological Research program (http://fcelter.fiu.edu/) (Fig. 2.1), and represent a hydrological and salinity gradient covering the freshwater to marine end-members of the system. Since POC in the oligotrophic waters of the Everglades freshwater marshes is extremely low (Neto et. al., 2006) this study was performed in the Shark River estuary and does not include samples from the freshwater wetlands. Thus site SRS4 is the least saline and most fresh in the set and considered representative of the freshwater end-member. During the peak wet season, salinity at SRS4 is completely fresh while during the peak dry season it can be as high as 10-12. Although this station is characterized by the presence of fringe mangroves, the 
riparian zone consisting of mixed woody vegetation (including red mangroves) is quite narrow and adjacent to open sawgrass prairies directly up-water from the mangrove fringe.
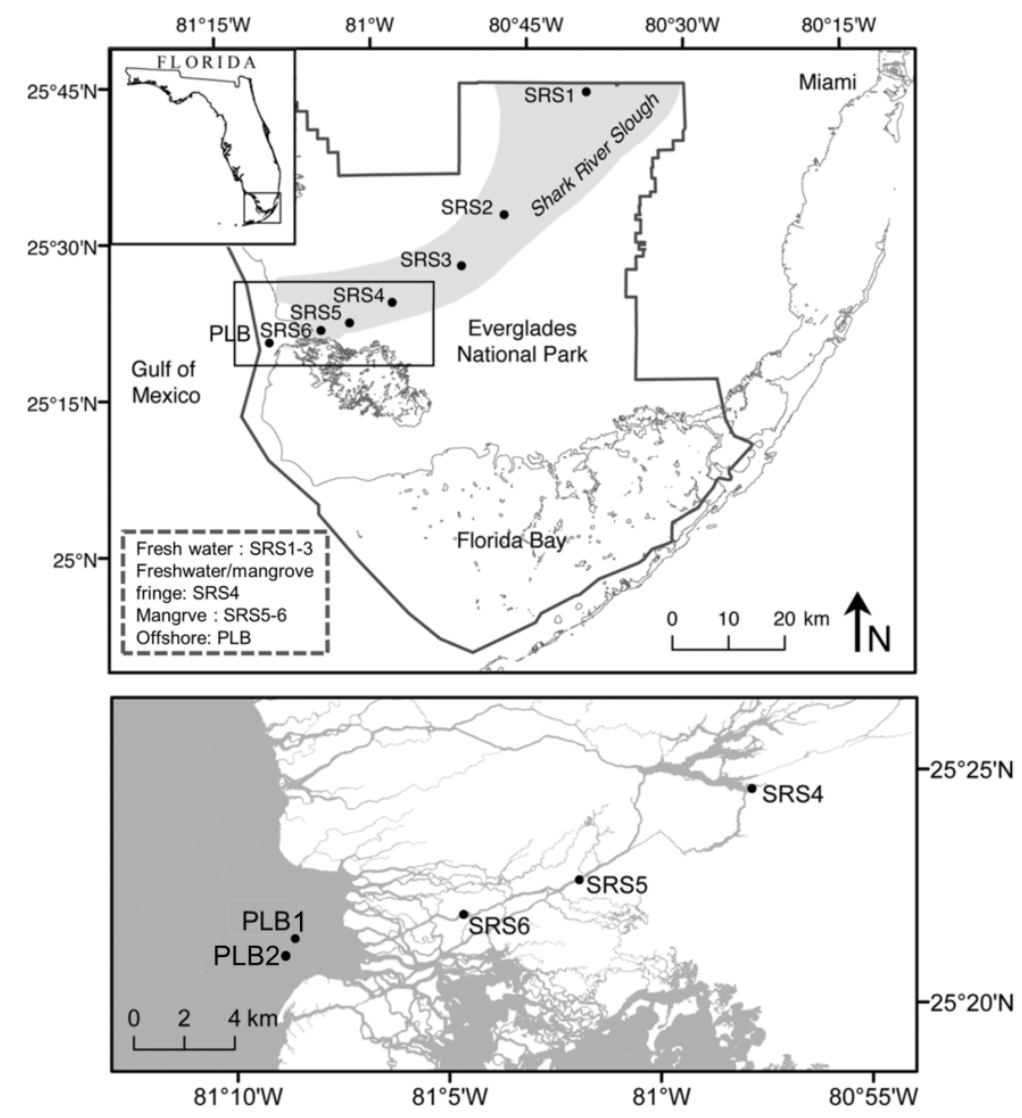

Figure 2.1 Sampling sites along Shark River Slough (SRS-1-6). Sub-environments: freshwater marsh (peat; SRS-1-3), mangrove estuary (peat; SRS-4-6) and offshore sites (PLB-1 and PLB-2).

\subsubsection{Sample collection:}

Samples for conceptual model validation

Specific sampling sites are shown in Fig. 2.1. To validate the proposed conceptual model, several approaches were applied, each of which determined the type of samples to be collected. Sample types are described in Table 2.1 and below. For the soil/sediment 
transect (Type-1), seven surface soil/sediments (top 5-10 cm) were collected along Shark River slough LTER sites (SRS1-6) and two coastal sites in PLB (PLB1 and PLB2) with a Lexan corer (soils) or an Ekman dredge (sediments) in 2002. For POM sampling (20012002), different locations and salinity ranges within the estuary were covered, both during high and low tide, and during both wet and dry seasons (Type-2). Simultaneously, when large volume POM samples for biomarker analysis were collected (ca. 25 1), additional triplicate POM samples were collected in 11 polycarbonate bottles and later filtered through pre-combusted $47 \mathrm{~mm}$ GF/F filters $(0.7 \mu \mathrm{m}$ nominal pore size $)$ for determination of total suspended matter (TSM) and POM. A set of five POM samples was collected along the salinity gradient between Tarpon Bay, in the upper estuary (freshwater end-member), and PLB, in the lower estuary (marine end-member) during November 2010 (Type-3). An additional set of samples (Type 4) were collected randomly over several consecutive days in the Shark River during November 2011 (T11) and 2012 (T12) (6 and 7 samples respectively) between SRS4 and SRS6. Finally, POM was sampled every h for $6 \mathrm{~h}$, throughout two tidal cycles in 2011at station SRS5 (Type-5). In summary, a total of 62 surface water samples (for POM) were collected over a period of several yr using clean 251 polycarbonate bottles (Nalgene). All samples were filtered through pre-combusted $142 \mathrm{~mm} \mathrm{GF} / \mathrm{F}$ filters $(0.7 \mu \mathrm{m}$ nominal pore size) for collection of the suspended particles. Samples were kept cool and in the dark until filtration. Filters were kept frozen at $-20^{\circ} \mathrm{C}$ until analyzed. 
Table 2.1 Different types of samples used for biomarker analysis across the Everglades. Note: a, for each separate sample (type 2 - 5) used for biomarker analysis, triplicate samples were sampled at the same time and used for TSM and POM measurements.

\begin{tabular}{lcccc}
\hline Time & $\begin{array}{c}\text { Season } \\
\text { type }\end{array}$ & Locations & $\begin{array}{c}\text { Study } \\
\text { type }\end{array}$ & $\begin{array}{c}\text { Sample } \\
\text { number }\end{array}$ \\
\hline Nov. 2002 & Wet & SRS1-PLB & Type 1 & 7 \\
Mar. 2001 & Dry & SRS4- PLB & Type 2 & 8 \\
Oct. 2001 & Wet & SRS4- PLB & Type 2 & 8 \\
Mar. 2002 & Dry & SRS4- PLB & Type 2 & 8 \\
Oct. 2002 & Wet & SRS4- PLB & Type 2 & 8 \\
Nov. 2010 & Wet & SRS4-PLB & Type 3 & 5 \\
Nov. 2011 & Wet & SRS4-SRS6 & Type 4 & 6 \\
Dec. 2012 & Wet & SRS4-SRS6 & Type 4 & 7 \\
Mar. 2011 & Dry & SRS5 & Type 5 & 12 \\
\hline
\end{tabular}

Samples for end-member characterization:

For the freshwater periphyton end-member, OM-normalized concentrations of the $\mathrm{C}_{20} \mathrm{HBI}$ were determined from flocculent material (floc), surface soil and periphyton samples in the Everglades freshwater marshes (sites SRS1 and SRS2; Gao et al., 2007; Pisani et al., 2013). For the fringe mangrove swamps, surface floc or unconsolidated sediments were used to determine the OM-based concentration of taraxerol (see Pisani et al., 2013 for collection method). Lastly, the marine end-member OM-based $\mathrm{C}_{25} \mathrm{HBI}$ concentration was determined from a series of POM samples from Ponce de Leon Bay.

Freshwater end-member samples consisted of mixed periphyton (7 quarterly samples in early wet, late wet, and dry seasons across 2007 to 2009 from SRS2), floc (8 quarterly samples in early wet, late wet and dry seasons across 2007 to 2009 from SRS2) and surface sediment samples (6 from SRS1 and 6 from SRS2; Gao et al., 2007; Pisani et 
al., 2013). Early wet, late wet and dry seasons were defined as May-July, AugustNovember and December-April, respectively. Eight surface sediments and surface floc samples were used as estuary end-member samples (SRS4-6). Five suspended particulate samples (covering both wet and dry seasons) from offshore sites (close to the edge of PLB) were used as marine end-member samples. All samples (filtered suspended particles, surface soil/sediments, periphyton and floc samples) were freeze dried to constant wt. Sediments and floc samples were sieved ( 35 mesh, $500 \mu \mathrm{m})$ to remove coarse particles like large detritus, shells and other debris, ground using a mortar and pestle, and stored in pre-combusted glass vials in a freezer until analysis.

\subsubsection{Lipid Analyses}

Freeze dried filters (for POM), surface soils/sediments, periphyton and floc samples were placed into the muffle furnace at $500{ }^{\circ} \mathrm{C}$ for $4 \mathrm{~h}$ to obtain the ash free wt. The $\% \mathrm{POM}$ or $\% \mathrm{OM}$ as appropriate was calculated by mass difference $(\mathrm{RSD}=7 \% ; \mathrm{n}=$ $6)$.

For all the freeze-dried samples, biomarkers were analyzed as described by Jaffé et al. (2001) and the concentration of each biomarker was normalized to POM content as appropriate. Briefly, solid samples were subjected to Soxhlet extraction for $24 \mathrm{~h}$ with $\mathrm{CH}_{2} \mathrm{Cl}_{2}$ (Optima, Fisher, USA). Activated $\mathrm{Cu}$ was added to the round bottom flask during extraction to eliminate elemental S. Total extracts were concentrated by rotary evaporation and saponified with $0.5 \mathrm{~N} \mathrm{KOH}$ to separate into neutral and acid fractions. Each neutral fraction was fractionated using adsorption chromatography over silica gel. The alcohol and sterol fractions were derivatized with N,O- 
bis(trimethylsilyl)trifluoroacetamide (BSTFA; Aldrich) and $5 \mu 1$ pyridine (Fisher) prior to analysis using gas chromatography-mass spectrometry (GC-MS). A known amount of squalane was added as internal standard to the aliphatic hydrocarbon and alcohol fractions. GC-MS was performed with a Hewlett-Packard 6890 gas chromatograph linked to a HP 5973 MS system, and fitted with a Rtx-1 or a Rtx-5MS column $(30 \mathrm{~m} \times 0.25 \mathrm{~mm}$ i.d., $0.25 \mu \mathrm{m}$ df) from RESTEK, USA. The Rtx-1 column was used for the hydrocarbon fractions and the Rtx-5MS column for the alcohol and ketone fractions (Jaffé et al., 2001). Assignment of $\mathrm{C}_{20} \mathrm{HBI}, \mathrm{C}_{25} \mathrm{HBI}$ and taraxerol (alcohol and ketone fractions combined) was performed by comparison of chromatographic retention time and literature mass spectra. The error in the reproducibility of biomarker data was below $15 \%$ for replicates.

\subsubsection{Principal component analysis}

Principal component analysis was performed on IBM SPSS Statistics 20. Each biomarker concentration data was normalized then ln-transformed before PCA.

\subsection{Results and discussion}

\subsubsection{Validation of conceptual three end-member mixing model}

\subsubsection{Soils/Sediments}

To test the proposed hypothesis for the three end-member conceptual model, surface sediment samples collected along a transect from Shark River slough (freshwater marsh end-member; SRS1) to Ponce de Leon Bay (marine end-member; PLB1,2) were analyzed for the above biomarkers. Because of the large concentration difference between taraxerol and the HBIs (2-3 orders of magnitude) for mangrove area sediments, 
relative instead of absolute abundances were used to show the trend across the transect. Relative abundance $(\mu \mathrm{g} / \mathrm{g}$ dry mass of one biomarker divided by the total concentration of three biomarkers at each particular site) of the freshwater marker $\left(\mathrm{C}_{20} \mathrm{HBI}\right)$, mangrove marker (taraxerol) and marine marker $\left(\mathrm{C}_{25} \mathrm{HBI}\right)$ were calculated (Fig. 2.2). The abundance of the $\mathrm{C}_{20} \mathrm{HBI}$ was highest at the freshwater end-member (stations SRS1 and SRS2) and showed a decreasing trend along the transect, with low values at the lower estuary (SRS5 and SRS6). The $\mathrm{C}_{25} \mathrm{HBI}$ was detected only at the offshore stations and lower estuary and was not detected inland of the mid-estuarine station (SRS5). Taraxerol was detected only at the estuarine stations and was not present at the offshore stations and freshwater marsh sites. On the basis of these distributions, the conceptual three endmember mixing model was validated for the soil/sediment phase, as a reflection of the main OM inputs characterizing each of the three zones under consideration.

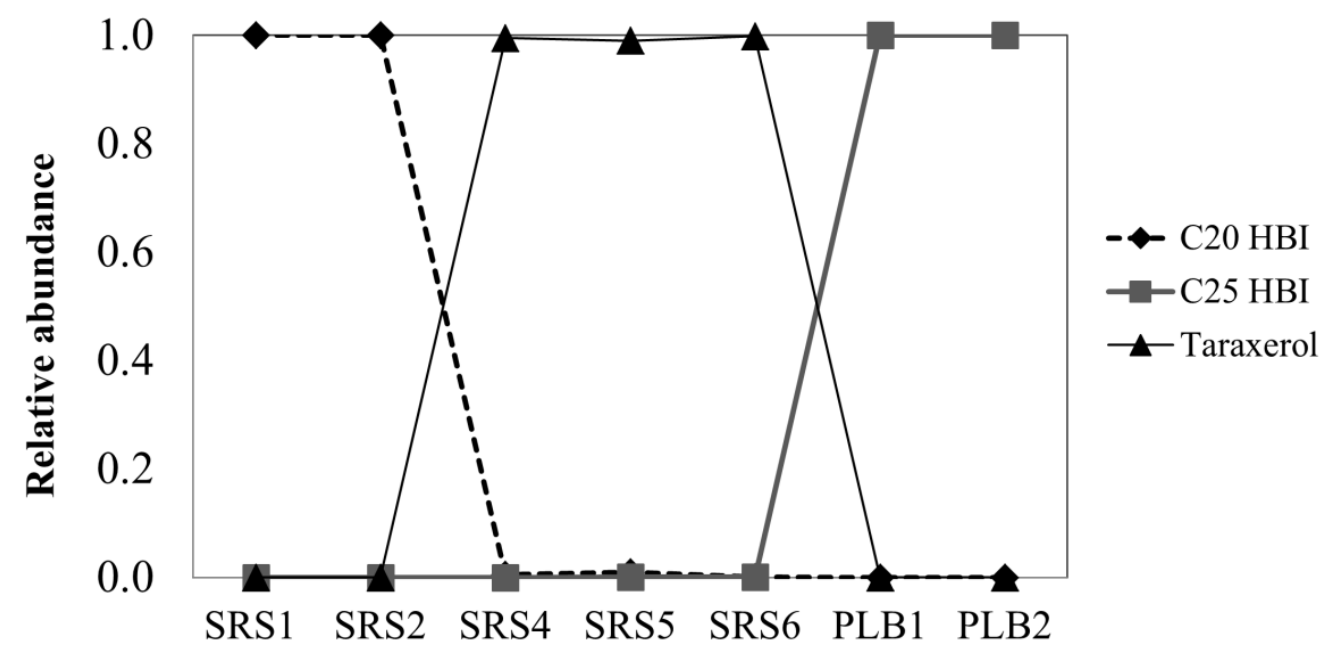

Figure 2.2 Relative distribution of molecular markers in soil/sediment used to construct the three end-member mixing model. The freshwater, estuary and marine markers are $\mathrm{C}_{20}$ $\mathrm{HBI}$, taraxerol and $\mathrm{C}_{25} \mathrm{HBI}$, respectively. 


\subsubsection{Suspended POM - spatial and temporal variation}

To test the validity of the conceptual model for the POM, a similar approach to the soils/sediments was applied to filtered suspended material. Biomarker data for POM samples spatially distributed between the freshwater and marine end-members were considered for the wet and dry seasons (Fig. 2.3). Biomarker data collected under similar tidal conditions (high vs. low) and during wet and dry seasons for both 2001 and 2002 were combined to get average concentration values. All biomarker data were normalized to POM ( $\mu$ g biomarker/g POM). The concentration distributions of the three biomarkers showed a similar trend to that for the soils/sediments shown above. POM dynamics during wet and dry seasons also followed the expected trends for the proposed three endmember mixing model, with the highest concentration of the marine biomarker $\left(\mathrm{C}_{25} \mathrm{HBI}\right)$ at offshore sites and highest concentrations of the freshwater biomarker $\left(\mathrm{C}_{20} \mathrm{HBI}\right)$ at lower salinity. Estuarine sources, represented by taraxerol, typically peaked at the midestuarine sites (e.g., SRS-5), but shifted up- or down-estuary in response to temporal variations in discharge and tidal range. In addition, higher contributions were observed for mangrove and marine-derived biomarkers during the dry season and during high tides, while the freshwater marker was more abundant during the wet season and low tides when the freshwater discharge was higher. The latter observation is fully in agreement with the local hydrological conditions. $\mathrm{C}_{20} \mathrm{HBI}$ showed the highest abundances during periods of high freshwater flow and conditions when freshwater export to the estuary is enhanced during the wet season and on a shorter time scale during outgoing-to-low tide. Similarly, the $\mathrm{C}_{25} \mathrm{HBIs}$ were most abundant during incoming-to-high tide and during the dry season when the freshwater head was lower and tidal amplitude higher. Taraxerol 
abundance was consistently high in the mid-sections of the estuary and likely exported from the mangrove swamps through tidal pumping. This trend was particularly apparent for the salinity transect study (Fig. 2.4), where the three biomarkers showed a clear coincidence with expectations from the conceptual model. Considering the presence of the fringe mangroves as a significant mid-estuary $\mathrm{OM}$ source, it is not surprising to observe a mid-salinity maximum for the taraxerol abundance. In contrast, the marine marker $\left(\mathrm{C}_{25} \mathrm{HBI}\right)$ showed a relatively conservative end-member mixing trend, increasing with increasing salinity. In agreement with the proposed conceptual model, the freshwater marker $\left(\mathrm{C}_{20} \mathrm{HBI}\right)$ did gradually decrease with increasing salinity, but showed a less significant linear correlation compared to the $\mathrm{C}_{25} \mathrm{HBI}$. It is possible that variations in contributions of the freshwater marker along the upper to middle estuary (between SRS4 and just below SRS5) where freshwater marshes exist above the narrow mangrove fringe, may contribute to this pattern. In addition, the contribution of mangrove-derived $\mathrm{OM}$ in the mid-estuary may cause an apparent reduction in the $\mathrm{C}_{20} \mathrm{HBI}$ distribution because of dilution. However, both the seasonal site-specific study, as well as the salinity gradient POM data contribute to the validation of the proposed conceptual three endmember mixing model. 

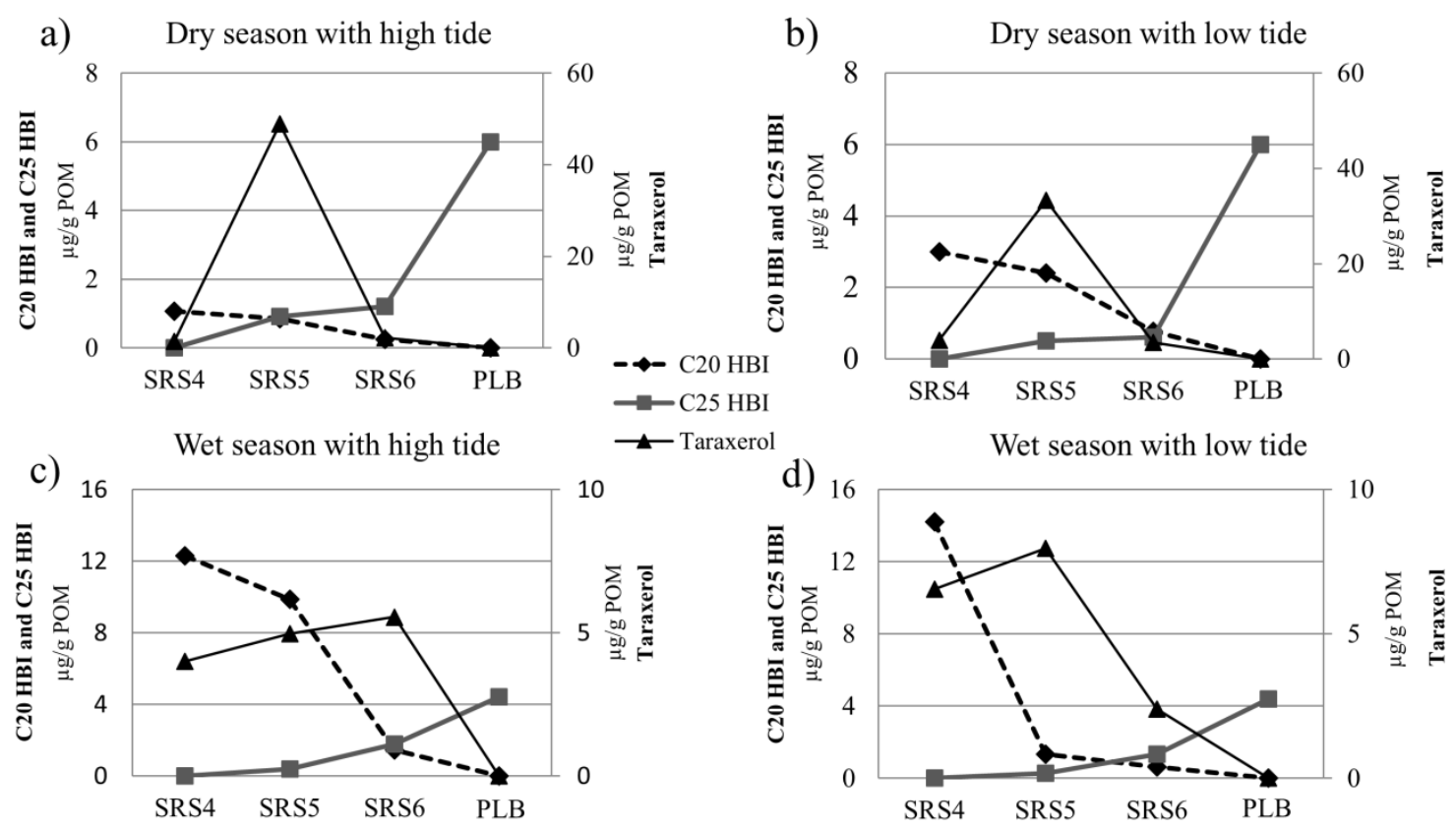

Figure 2.3 Concentration ( $\mu \mathrm{g} / \mathrm{g} \mathrm{POM})$ of the three molecular markers used to trace the input of freshwater marsh $\left(\mathrm{C}_{20} \mathrm{HBI}\right)$, marine $\left(\mathrm{C}_{25} \mathrm{HBI}\right)$ and the mangrove (taraxerol) $\mathrm{OM}$ to the Shark River Estuary. Note: taraxerol is plotted on the secondary axis of ordinates (right side).

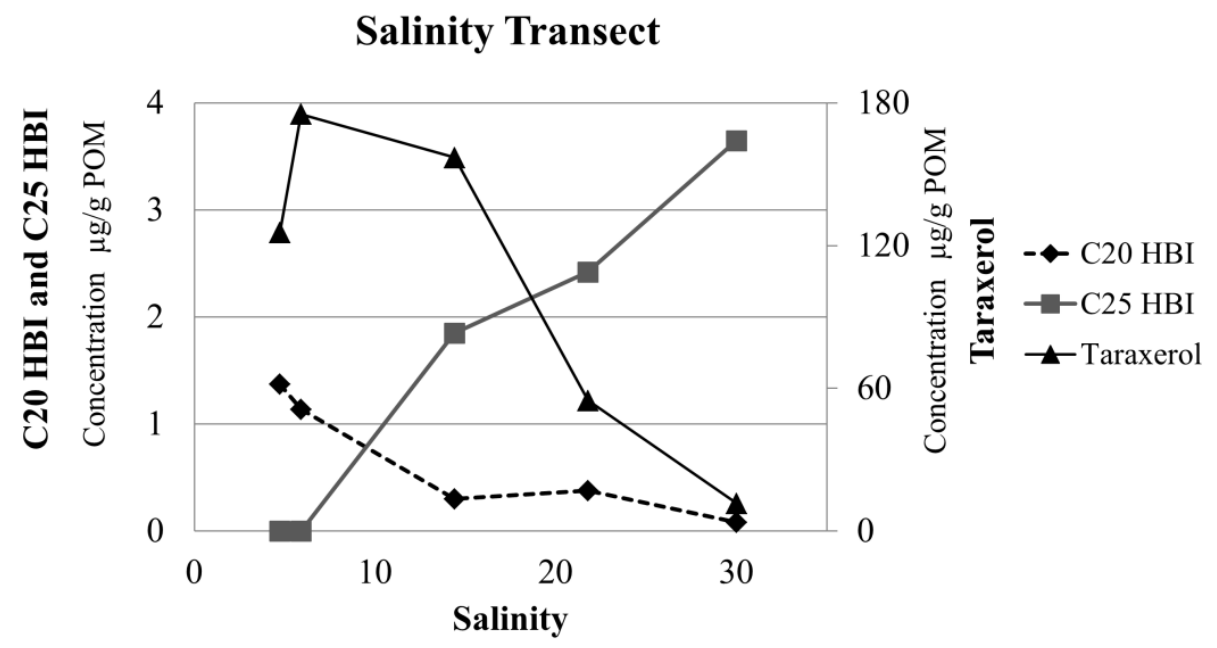

Figure 2.4 Three end-member model applied for the salinity transect study. Note: taraxerol is plotted on the secondary axis of ordinates (right side). 


\subsubsection{POM- tidal study}

Two tidal cycles (on two consecutive days) were monitored to test the sensitivity of the conceptual model to small changes in salinity. In order to better visualize each biomarker as well as salinity in the same graph, the taraxerol concentration was divided by a factor of 100 and salinity was the secondary axis (Fig. 2.5a, b). Salinity at the fixed sampling station in the mid-estuary over the $6 \mathrm{~h}$ tidal cycle sampling ranged from 24.09 to 29.98. As expected from the conceptual model, and observable even with small changes in salinity, concentrations of $\mathrm{C}_{20} \mathrm{HBI}$ (representing freshwater periphyton), were highest at the lowest salinity (low tide), while $\mathrm{C}_{25} \mathrm{HBI}$ concentration, indicative of marine OM, peaked at the highest salinity (high tide). For taraxerol (tidal study A, Fig. 2.5a), the abundance was highest during the end of the outgoing tide and the start of the incoming tide. This suggests that the early stages of the incoming tide may be critical in the resuspension of POM and tidal pumping (out-welling) of mangrove-derived OM in soils at this station (SRS5; Fig. 2.5a). This observation is in agreement with other work (Tue et al., 2012), where ebb tide was found to coincide with the maximum contribution of mangrove detritus to tidal creeks. Not only for POC, but also elevated DOC out welling during ebb tide has been reported for fringe mangrove systems (Bouillon et al., 2007). However, this pattern was not clear in tidal study B (Fig. 2.5b), where the taraxerol concentration trend was less consistent throughout the whole tidal cycle, although it still increased during incoming tide. This may be caused by significantly stronger wind conditions (Chi-square test, $\mathrm{p}<0.001)$ when the sampling was performed during tide $\mathrm{B}$ $(3.30 \mathrm{~m} / \mathrm{s}$, Fig. $2.5 \mathrm{c}, \mathrm{d})$ compared with tide A $(2.37 \mathrm{~m} / \mathrm{s}$, Fig. $2.5 \mathrm{c}, \mathrm{d})$. This hypothesis is also supported by the patterns for some of the bulk parameter measurements (turbidity 
and POM), where the average turbidity and POM for tide B was significantly higher (Chi-square test, $\mathrm{p}<0.05$ ) compared with that for tide A (turbidity: 5.48 and 4.75 respectively; POM: $5.94 \mathrm{mg} / 1$ and $5.16 \mathrm{mg} / \mathrm{l}$, respectively). The correlation between salinity and turbidity was also higher in tide $A\left(R^{2}=0.83\right)$ vs. tide $B\left(R^{2}=0.50\right)$, suggesting that more turbulent, wind-induced conditions resuspended mangrove detritus during tide B. Although biomarker data for tide A validated the conceptual model, data for tide B, as supported by other studies (Geyer et al., 2004; Goñi et al., 2005, 2009), suggest that the external physical forces such as local wind and possibly other factors such as tidal amplitude, may affect mixing, re-suspension, and remobilization along this estuarine system. However, in general terms the proposed conceptual model was also validated for tidal cycles, even though the range in salinity change was quite small $(<6$ units), suggesting that the methodology is sensitive to relatively minor changes such as salinity, wind conditions, and others. 


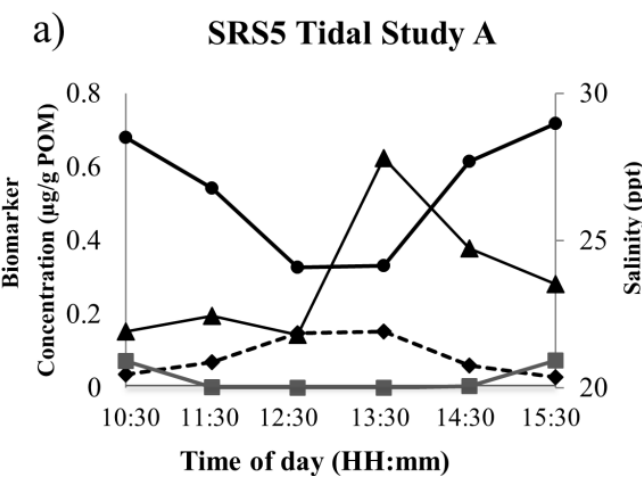

c) Tidal study whole day wind speed

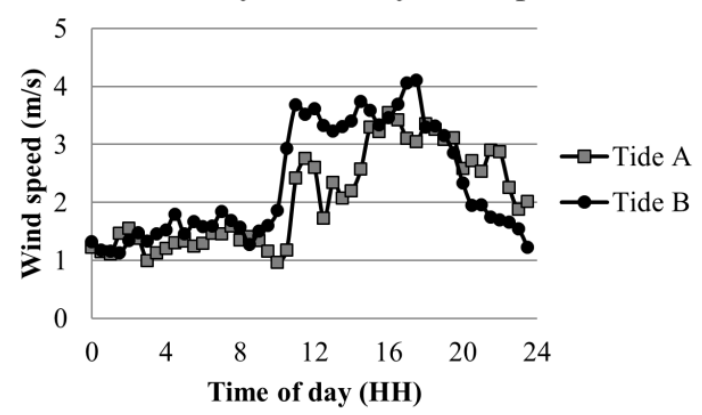

b)

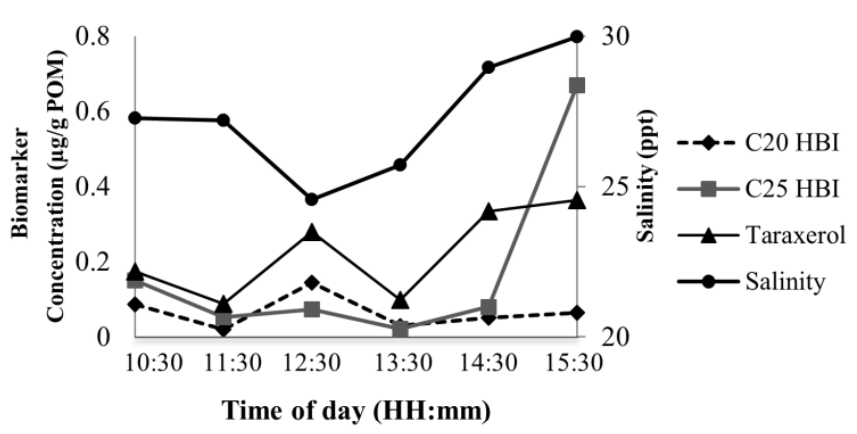

d) Tidal study sampling time wind speed

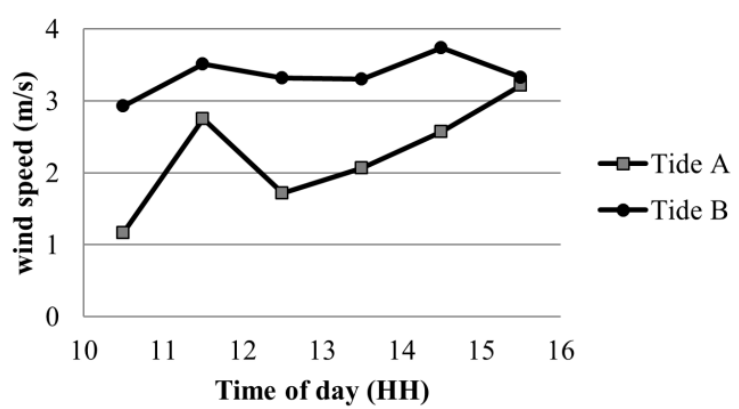

Figure 2.5 Three end-member model applied for tidal studies A (Fig. 2.5a) and B (Fig. 2.5 b; taraxerol concentration was divided by a factor of 100). Salinity scale shown on the secondary y axis (right side). Fig. 2.5c: Wind information for each tidal sampling day.

Fig. 2.5d: Wind information for each tidal sampling period ( $5 \mathrm{~h}$ period).

\subsubsection{Principal components analysis (PCA)}

PCA, a multivariate statistical technique, has been used in various biomarkerbased studies to extract key information such as OM composition and sources from complex organic geochemical data in estuarine and costal environments (e.g., Yunker et al., 1995; Canuel, 2001; Hernandez et al., 2001; Mead et al., 2005; Xu et al., 2007; Waterson and Canuel, 2008). It was applied here to elucidate the primary drivers responsible for OM source variation in the Shark River estuary. In order to stabilize the skew because of the variability in different biomarker values across different years, biomarker values were normalized to the total biomarker concentration before PCA 
(concentration of each biomarker variable was divided by the concentration of three biomarkers used). Since this normalization can introduce a negative bias among the corrections used to determine the principal components (Bonn, 1998), a natural log (ln) transformation of the compositional data was used, as commonly applied for this purpose (e.g., Yunker and Macdonald, 2003; Yunker et al., 2005; Buccianti et al., 2006; Van den Berg et al., 2006; Grunsky, 2010). The combined ln-transformed biomarker data for all POM samples, and the loadings of $\mathrm{C}_{20} \mathrm{HBI}, \mathrm{C}_{25} \mathrm{HBI}$ and taraxerol, are shown in Fig. 2.6a, $\mathrm{b}$ as a PCA score plot.

The first and second principal component (PC1 and PC2) accounted for 62.0\% and $29.2 \%$ of the data variability. The variability among samples seems to be controlled mainly by season and tide and is directly linked to OM sources. Samples along the estuarine salinity gradient (SRS4-SRS6 and transect samples) were clearly separated on the basis of the three source-specific biomarkers. Samples from SRS4 and the oligohaline zone clustered mainly in the area controlled by the $\mathrm{C}_{20} \mathrm{HBI}$ freshwater marker. Most of the mid-estuary samples from SRS5 and the transect study clustered in the estuarine area controlled by taraxerol. In contrast, most of the samples from SRS6 and the lower estuarine transect clustered in the area controlled by the $\mathrm{C}_{25} \mathrm{HBI}$ marine end-member marker. The green arrow shows the sample sequence for the salinity transect study which clearly transitions from the $\mathrm{C}_{20} \mathrm{HBI}$ dominated area, through the estuarine taraxerol dominated zone, towards the $\mathrm{C}_{25} \mathrm{HBI}$ dominated marine end-member zone along the salinity gradient. The samples from the tidal studies A and B, shown in red and green dots and connected by arrows as time-based sequences, cover a much smaller variation in the PC1 and PC2 range, which is not surprising considering that the salinity change was 
$<6$ units, but follow a similar trend as the salinity transect samples. In particular for tide A, the shift towards the freshwater end-member during outgoing tide, followed by a reversal to a shift towards the marine end-member, clearly indicates the sensitivity of the three end-member conceptual model approach.

When all POM samples were compared on the basis of their PC1 scores (Fig. 2.7), most samples (the offshore samples, SRS6 and some of SRS5 samples) associated with high tides or higher salinity clustered preferentially at more negative PC1 scores, while samples taken under outgoing or low tide, or samples taken close to the freshwater endmember were shifted to more positive PC1 values. Similarly most samples obtained during the dry season (dots in Fig. 2.6) were shifted to more negative PC1 values compared with those for the wet season samples (triangles in Fig. 2.6). This shows a clear trend that the dry season conditions and incoming/high tides (both characterized by higher salinity) behave similarly, while the same is true for the wet season samples and those collected during outgoing/low tide (both characterized by lower salinity). Considering these observations, the salinity, and consequently the OM source, may be the most dominant factor represented by $\mathrm{PC} 1$, which explained $62 \%$ of the variability in the dataset. Absolute PC1 values are indicative of the marine (more negative PC1) and freshwater (more positive PC1) OM contributions respectively. While PC2 only explains a significantly lower part of the variability in the data compared to PC1, it seems to separate mangrove and non-mangrove derived OM. However, attempting to explain this would be purely speculative. Thus I focus on $\mathrm{PC} 1$ as this parameter explains $62 \%$ of the variability in the data. Consequently, the combined dataset represented in the PCA plot, further validates the three end-member conceptual model. 


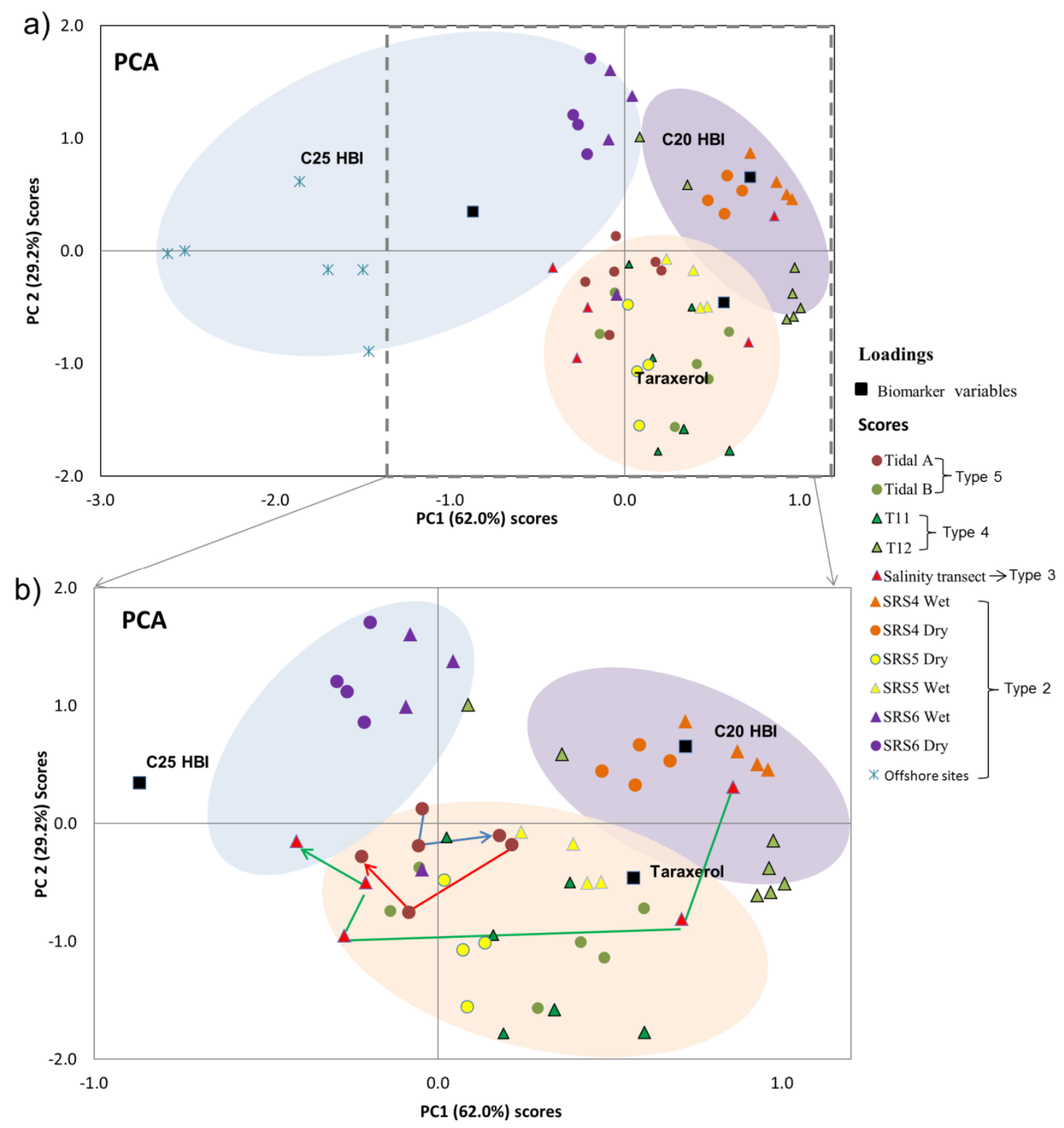

Figure 2.6 PCA analyses of $\mathrm{lg}$ transformed concentrations of $\mathrm{C}_{20} \mathrm{HBI}, \mathrm{C}_{25} \mathrm{HBI}$, and taraxerol in POM for all Shark River samples. Samples collected during the dry season are plotted as circles $(\bullet)$ and wet season as triangles $(\Delta)$. Salinity transect, green arrow; tidal cycle, blue (outgoing tide) and red arrows (incoming tide). 


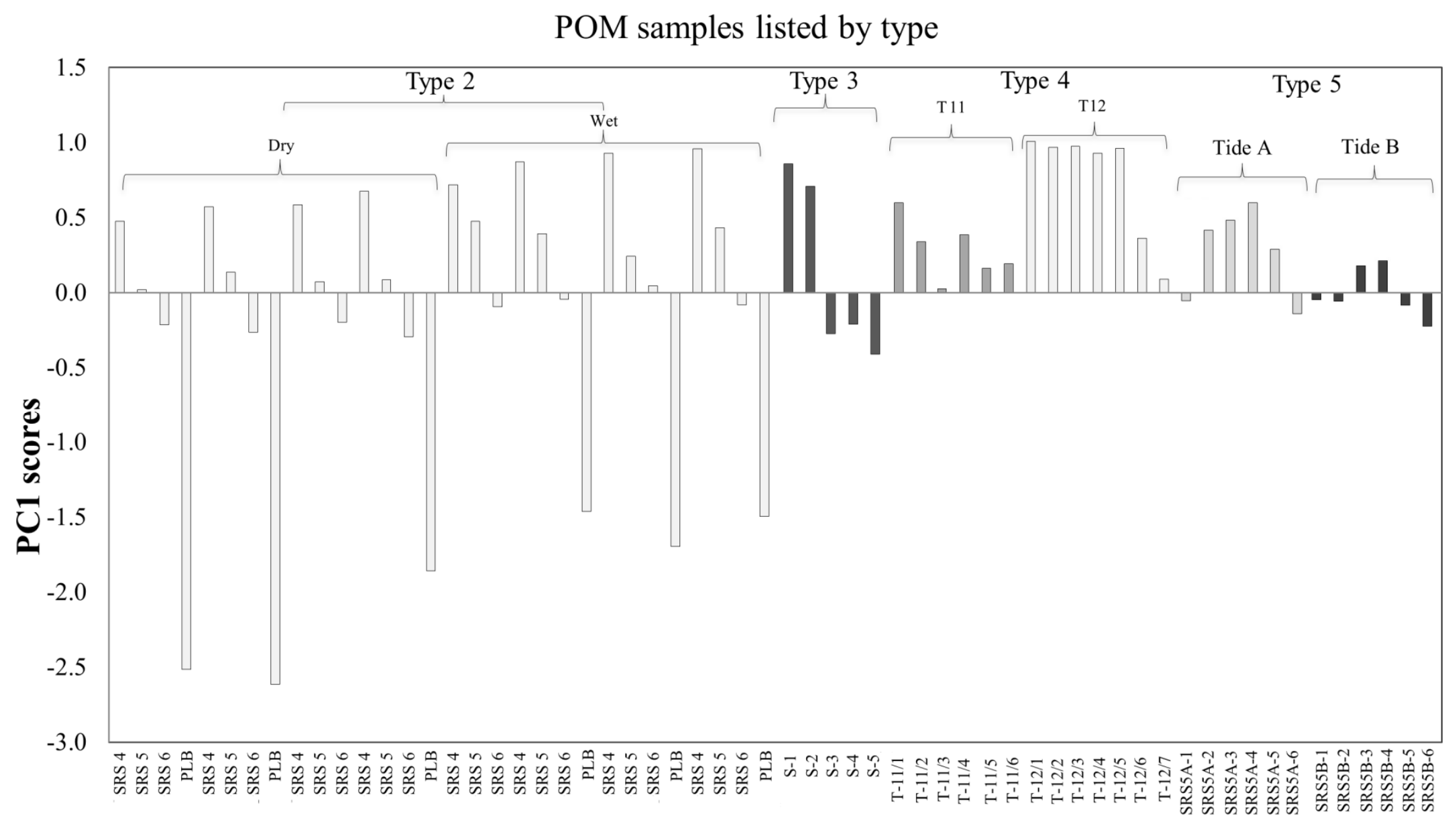

Figure 2.7 Plot of PC1 scores for all POM biomarker data. Different color bars represent different studies. 


\subsubsection{Carbon budget assessment}

Various studies have been performed to address carbon (C) budgets in Everglades coastal wetlands and have recently been summarized (Troxler et al., 2013). An important source of $\mathrm{C}$ in the estuarine regions of the Everglades is the mangrove forests, and aboveand belowground primary production and soil $\mathrm{C}$ accumulation for mangroves have been estimated (Castañeda-Moya et al., 2011; Smoak et al., 2013). However, C flux estimates (summarized by Barr et al., 2010) have been made without considering lateral export of dissolved OC (DOC), dissolved inorganic C (DIC) and POC (Troxler et al., 2013) and such considerations are critical in better constraining $\mathrm{C}$ cycling in the Everglades. Here, the ultimate goal of this study is the application of the validated three end-member conceptual mixing model in order to assess $\mathrm{C}$ fluxes from specific sources and constrain $\mathrm{C}$ budgets for the fringe mangrove ecosystem through the determination of $\mathrm{C}$ losses in the form of POC. Generally the major POC source in the Everglades freshwater marshes consists of flocculent material (floc; Neto et al., 2006; Pisani et al., 2013), which has been shown to be mobilized and can contribute to the formation of the ridge-and-slough landscape in the region (Larsen et al., 2009a,b). While Cawley et al. (2013) applied optical properties to assess fringe mangrove inputs to the DOC pool in the estuary and estimated a C flux of $0.075 \times 10^{9}$ to $0.27 \times 10^{9} \mathrm{mg} \mathrm{C} / \mathrm{d}$ of mangrove-derived DOC (ca. $20 \%$ of the total DOC) from the Shark River estuary to the Florida costal ocean, no such estimates have been reported for POC export. Here, a biomarker approach was used in an attempt to roughly assess source-specific POC fluxes in the estuary. Average biomarker concentrations from the mid-estuarine section (SRS5) were determined on the basis of the above sample set. The values were compared with OM-normalized end-member 
biomarker values (see below) and used to determine an OM-based contribution for each end-member (on the basis of the mid-estuarine biomarker abundances). The $\%$ estimate of OM contribution from each freshwater marsh, fringe mangrove swamp and the marine end-member were then related to the annual water discharge and associated POM content. In this assessment it is assumed that the biomarkers used are stable throughout their estuarine transport period, that autochthonous primary productivity by estuarine plankton is not a significant contribution to the overall POC pool in the Shark River (see also above). In fact, no correlation was observed between POM and Chl-a concentrations for all my type 2 samples $\left(\mathrm{R}^{2}=0.02 ; \mathrm{n}=32\right)$, which suggests that the autochthonous planktonic contribution to POM is not significant. Thus, for this first estimate of sourcespecific POM export, the uncertainty range of each term in the budget calculation was defined by the $95 \%$ confidence interval of the mean $(\mathrm{X}): \mathrm{X}-\mathrm{t} \times \frac{s}{\sqrt{n}} \leq \mathrm{X} \leq \mathrm{X}+\mathrm{t} \times \frac{s}{\sqrt{n}}(\mathrm{~s}$ is the standard deviation of $\mathrm{n}$ measurements from which $\mathrm{X}$ was determined and $\mathrm{t}$ the student parameter with n-1 degrees of freedom at a confidence level of 95\%). The confidence interval of variables was calculated by considering the 'worst-case' combination, where both extreme values such as highest and lowest within the determined range were used in the calculation.

In order to first estimate the relative contribution of each end-member, the concentration of each biomarker was measured for each case. To be specific, periphyton, floc and surface soils from SRS1-2 (freshwater area) were used as freshwater endmember, and the freshwater end-member representative biomarker $\mathrm{C}_{20} \mathrm{HBI}$ was assumed to contribute equally to the POC pool from periphyton, floc and surface soils origin. As 
such, the freshwater end-member concentration of $\mathrm{C}_{20} \mathrm{HBI}$ was estimated at $67.2 \pm 28.3$ $\mu \mathrm{g} / \mathrm{g}$ POM $(\mathrm{n}=30)$. For the estuarine end-member characterization, unconsolidated surface sediments and floc from SRS5 and 6 were used, and taraxerol concentration averaged $213 \pm 64.9 \mu \mathrm{g} / \mathrm{g}$ POM $(\mathrm{n}=8)$. Lastly, suspended particulates from offshore collected during different years (wet and dry seasons) were used as marine end-member (PLB), to provide a $\mathrm{C}_{25} \mathrm{HBI}$ average concentration of $3.51 \pm 2.83 \mu \mathrm{g} / \mathrm{g}$ POM $(\mathrm{n}=6)$.

To obtain an estimate of the source contributions from the above-defined endmembers to the Shark River estuary, a mid-estuary area was chosen as representative of the estuarine mixing zone (SRS5). Each biomarker concentration was determined, on the basis of 12 samples (from the SRS5 area) average, as $\mathrm{C}_{20} \mathrm{HBI}(0.36 \pm 0.12 \mu \mathrm{g} / \mathrm{g}$ POM), $\mathrm{C}_{25} \mathrm{HBI}(0.10 \pm 0.05 \mu \mathrm{g} / \mathrm{g} \mathrm{POM})$ and taraxerol $(27 \pm 9.7 \mu \mathrm{g} / \mathrm{g}$ POM $)$. Without considering potential differential diagenetic degradation rate among the biomarkers, these mid-estuary POC biomarker values were normalized to end-member values and \% contributions of each were estimated though the following approach:

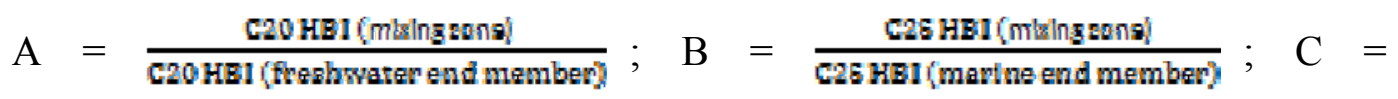

Tapexerol (mixing soñ)

Tenexerol (extuary end member);

Fresh member POM contribution $(\%)=\frac{A}{A+B+C}$

Marine member POM contribution $(\%)=\frac{B}{A+B+C}$

Estuary member POM contribution $(\%)=\frac{\mathrm{C}}{\mathrm{A}+\mathrm{B}+\mathrm{C}}$

Relative contributions (\%) for each member in the SRS5 mixing zone were therefore estimated as: freshwater-derived POM, 1 to $8 \%$; mangrove-derived POM, 70 to 
$90 \%$; marine-derived POM, 6 to $20 \%$. These ranges are reasonable since POM values for the freshwater Everglades are reported to be very low (Childers et al., 2006) and most of the POM in the freshwater marshes is in the form of flocculent material present in the form of an unconsolidated layer at the bottom of the water column (Droppo et al., 1997; Neto et al., 2006; Pisani et al., 2011, 2013) or in the form of periphyton mats (Neto et al., 2006; Larsen et al., 2009b; Pisani et al., 2011, 2013). Although bioturbation of floc by mosquito fish (Gambusia holbrooki), grass shrimp (Palaemonetes paludosus) and crayfish (Procambarus spp.) has been reported and remobilization by storms is possible (Larsen et al., 2009a, b), the floc contribution to the estuarine POM pool is expected to be low (Larsen et al., 2009a, b). In contrast, coastal primary productivity of plankton in the Gulf of Mexico is seasonally variable (Lohrenz et al., 1994, 1999) and thus can contribute at different levels over time. Consequently, it is indeed not surprising that the contribution of mangrove detritus was found to be highest for the Shark River and $>70 \%$ in all cases. Mangrove ecosystems are well known to export OM both as POC and DOC to the coastal ocean (Lee et al., 1995; Cawley et al., 2013; Dittmar and Lara, 2001a, b; Dittmar et al., 2006; Jaffé et al., 2004; Romigh et al., 2006; Twilley, 1985, and others).

\subsubsection{Mangrove-derived POC loss estimate}

On the basis of the annual water discharge (D) of Shark River to the Gulf of Mexico $\left(\mathrm{D}=2.44 \times 10^{11} \pm 0.702 \times 10^{11} 1\right.$; Woods, 2010), and an average POM concentration $([\mathrm{POM}]=5.20 \pm 0.614 \mathrm{mg} / \mathrm{l}(\mathrm{n}=22)$ in the middle estuary area, and considering the estimated contribution [POM (\%)] from the mangrove end-member discussed above, the POM loss from the mangrove estuary to the Gulf of Mexico can be 
estimated as $\mathrm{D} \times[\mathrm{POM}] \times(70$ to $90 \%)=9.2 \times 10^{5}$ to $1.8 \times 10^{6} \mathrm{~kg} \mathrm{POM} / \mathrm{yr}$, or an estimated mangrove-derived POM flux of $0.21 \times 10^{9}$ to $0.45 \times 10^{9} \mathrm{mg} \mathrm{OM} / \mathrm{d}$ for the Shark River. When POM is transformed to POC applying the widely accepted $58 \%$ OC in soil OM (Howard, 1965), this flux value can be reported as ranging from $0.12 \times 10^{9}$ to $0.26 \times 10^{9} \mathrm{mg} / \mathrm{d}$. Considering the low number of end-member values used for estuarine and marine contribution estimates, the low number of available samples for determining the annual average POM concentration, and the fact that several environmental factors on global, regional and local scales (i.e. seasonality, tidal stage, geomorphological setting, nutrient concentration, physical forcing such as wind, and any combination of those) can affect POC export, the flux values reported here represent only a first preliminary estimate of C loss from the Shark River mangroves in the form of POC. While there are needs to better constrain these $\mathrm{C}$ loss values, this study provides an estimated order of magnitude for the process. Interestingly, this roughly estimated POC loss from the mangrove system is of the same order of magnitude as the DOC loss for the Shark River (Cawley et al., 2013), which was estimated at $0.27 \times 10^{9} \mathrm{mg} \mathrm{C} / \mathrm{d}\left(0.23 \times 10^{5} \mathrm{~mol} \mathrm{C/d}\right)$ and $0.075 \times 10^{9} \mathrm{mg} \mathrm{C} / \mathrm{d}\left(0.063 \times 10^{5} \mathrm{~mol} \mathrm{C/d}\right)$ for the wet and dry season respectively. Contrary to the POC flux estimates reported here, Cawley et al. (2013) suggested, however, that the majority (ca. 80\%) of DOC exported from the Shark River Estuary was derived from the freshwater end-member and only about $20 \%$ was mangrove-derived. In contrast, for POC, the majority of $\mathrm{C}$ exported seems derived from the fringe mangroves.

Since POC flux values (export) reported here are specific for the Shark River and are not watershed-based, it is at this point difficult to directly integrate the data with other 
C flux studies for the region (Twilley, 1985; Romigh et al., 2006). However, when comparing with estimated DOC export rates for the Shark River estuary (Cawley et al., 2013), the mangrove-derived POC export rates were quite similar. Other authors have estimated DOC and POC export from Everglades mangrove forests as 4.7 and $5.3 \mathrm{~mol} \mathrm{C/}$ $\mathrm{m}^{2} /$ yr respectively (Romigh et al., 2006; Twilley, 1985). Export of DOC and POC on very similar levels have also been reported for global average values, where DOC export and POC export were estimated as $11.4 \pm 14.3$ and $12.5 \pm 11.2 \mathrm{~mol} \mathrm{C} / \mathrm{m}^{2} / \mathrm{yr}$ (Duarte et al., 2005; Bouillon et al., 2008a; Barr et al., 2010). For instance, for mangrove estuaries in Brazil (Dittmar, 2006; Dittmar and Lara, 2001a,b) where DOC export ranged from 4 to $12 \mathrm{~mol} \mathrm{C} / \mathrm{m}^{2} / \mathrm{yr}$, the POC export rate in the same region was estimated at $3 \mathrm{~mol} \mathrm{C} / \mathrm{m}^{2} /$ yr. POC export measured in an Australian riverine mangrove forest was $35 \mathrm{~mol} \mathrm{C} / \mathrm{m}^{2} / \mathrm{yr}$ (Boto and Bunt, 1981). While the estimated mangrove-derived POC flux from the Shark River seems to fit this general pattern, this work represents the development and validation of a three end-member conceptual model for the Shark River, Florida, and additional work is needed to further constrain carbon fluxes which represent rough estimates in this initial assessment.

\subsection{Conclusions}

A biomarker-based, three end-member mixing model was validated and then tested to assess POM dynamics along the subtropical Shark River Estuary, Florida. The results demonstrate that mangroves are the dominant source of POM in the estuary. The model effectively reflects seasonal and tidal effects on POM dynamics and was sensitive to how other external physical forcing like winds could affect resuspension of POM. The 
transition from outgoing to incoming tide seems critical for substantial mangrove POM release associated with tidal pumping and out-welling. Preliminary estimates of POM flux showed a high degree of variability driven by high ranges in end-member calibrations, but reflect the importance of mangroves as a source of POM to the coastal ocean. Subsequent studies should further constrain the variability of end-member biomarker concentrations in order to better calibrate the model and consequently constrain POC flux values. Although the POC flux estimates presented are preliminary, they provide the first attempt to address source-specific POC budgets and have the potential to be applied to other aquatic systems. Interestingly, and in agreement with other reports, the estimated mangrove-derived DOC flux values for the same region were of the same order of magnitude as the POC.

As sea level continues to rise, the mangroves of the Shark River are expected to transgress further inland. However, the ongoing Everglades restoration project aims to introduce more freshwater to the southern estuarine area through engineering enhanced water delivery. The balance between sea level rise and increased freshwater flow will ultimately drive the fate of the mangrove system. The proposed three end-member conceptual model could potentially be used to evaluate the changes in the OM dynamics of the system over time and ultimately aid in modeling the success or lack thereof of the Everglades restoration. 


\section{REFERENCES}

Adame, M.F., Lovelock, C.E., 2011. Carbon and nutrient exchange of mangrove forests with the coastal ocean. Hydrobiologia 663, 23-50.

Andrews, J. E., Greenway, A.M., Dennis, P.F., 1998. Combined carbon isotope and C/N ratios of source and fate of organic matter in a poorly flushed tropical estuary: Hunts Bay, Kingston Harbour, Jamaica. Estaurine, Coastal and Shelf Science 46, 743-756.

Barr, J.G., Engel, V., Fuentes, J.D., Zieman, J.C., O'Halloran, T.L., Smith, T.J., \& Anderson, G.H., 2010. Controls on mangrove forest-atmosphere carbon dioxide exchanges in western Everglades National Park. Journal of Geophysical Research: Biogeosciences (2005-2012), 115 (G2).

Bianchi, T.S., Findlay, S., Dawson, R., 1993. Organic matter sources in the water column and sediments of the Hudson River Estuary: the use of plant pigments as tracers. Estuarine, Coastal and Shelf Science 36, 359-376.

Bonn, B. A.,1998. Polychlorinated dibenzo-p-dioxin and dibenzofuran concentration profiles in sediment and fish tissue of the Willamette Basin, Oregon. Environmental science and technology 32, 729-735.

Boto, K.G., Bunt, J.S., 1981. Tidal export of particulate organic matter from a northern Australian mangrove system. Estuarine, Coastal and Shelf Science 13, 247-255.

Bouillon, S., Borges, A.V., Castañeda-Moya, E., Diele, K., Dittmar, T., Duke, N.C., Kristensen, E., Lee, S.Y., Marchand, C., Middelburg, J.J., Rivera-Monroy, V.H., Smith III, T.J., Twilley, R.R., 2008a. Mangrove production and carbon sinks: a revision of global budget estimates. Global Biogeochemical Cycles 22, GB2013.

Bouillon, S., Connolly, R.M., Lee, S.Y., 2008b. Organic matter exchange and cycling in mangrove ecosystems: Recent insights from stable isotope studies. Journal of Sea Research 59, 44-58.

Bouillon, S., Middelburg, J.J., Dehairs, F., Borges, A.V., Abril, G., Flindt, M.R., Ulomi, S., Kristensen, E., 2007. Importance of intertidal sediment processes and porewater exchange on the water column biogeochemistry in a pristine mangrove creek (Ras Dege, Tanzania). Biogeosciences Discussions 4, 317-348.

Boyer, J.N., Fourqurean, J.W., Jones, R.D., 1997. Spatial characterization of water quality in Florida Bay and Whitewater Bay by multivariate analyses: Zones of similar influence. Estuaries 20, 743-758. 
Buccianti, A., Mateu-Figueras, G., Glahn, V. P. (Eds.)., 2006. Compositional data analysis in the geosciences: from theory to practice (No. 264). Geological Society.

Canuel, E.A., 2001. Relations between river flow, primary production and fatty acid composition of particulate organic matter in San Francisco and Chesapeake Bays: a multivariate approach. Organic Geochemistry 32, 563-583.

Canuel, E.A., Cloern, J.E., Ringelberg, D.B., Guckert, J.B., Rau, G.H., 1995. Molecular and isotopic tracers used to examine sources of organic matter and its incorporation into the food webs of San Francisco Bay. Limnology and Oceanography 40, 67-81.

Canuel, E.A., Zimmerman, A.R., 1999. Composition of particulate organic matter in the southern Chesapeake Bay: sources and reactivity. Estuaries 22, 980-994.

Canuel, E.A., Freeman, K.H., Wakeham, S.G., 1997. Isotopic compositions of lipid biomarker compounds in estuarine plants and surface sediments. Limnology and Oceanography 42, 1570-1583.

Castañeda-Moya, E., Twilley, R.R., Rivera-Monroy, V.H., Marx, B.D., Coronado-Molina, C., Ewe, S.M., 2011. Patterns of root dynamics in mangrove forests along environmental gradients in the Florida coastal everglades, USA. Ecosystems 14, 1178-1195.

Cawley, K., Yamashita, Y., Maie, N., Jaffé, R., 2013. Using optical properties to quantify fringe mangrove inputs to the dissolved organic matter (DOM) pool in a subtropical estuary. Estuaries and Coasts doi:10.1007/s12237-013-9681-5.

Childers, D.L., Boyer, J.N., Davis, S.E., Madden, C.J., Rudnick, D.T., Sklar, F.H., 2006. Relating precipitation and water management to nutrient concentrations in the oligotrophic "upside-down" estuaries of the Florida Everglades. Limnology and Oceanography 51, 602-616.

Cloern, J. E., Canuel, E. A., Harris, D, 2002. Stable carbon and nitrogen isotope composition of aquatic and terrestrial plants of the San Francisco Bay estuarine system. Limnology and Oceanography 47, 713-729.

Davis III, S.E., Childers, D.L., Day Jr., J.W., Rudnick, D.T., Sklar, F.H., 2003. Factors affecting the concentration and flux of materials in two southern Everglades mangroves wetlands. Marine Ecology Progress Series 253, 85-96.

Dittmar, T., Lara, R.J., 2001a. Driving forces behind nutrient and organic matter dynamics in a mangrove tidal creek in North Brazil. Estuarine, Coastal and Shelf Science $52,249-259$. 
Dittmar, T., Hertkorn, N., Kattner, G. and Lara, R.J., 2006. Mangroves, a major source of dissolved organic carbon to the oceans. Global Biogeochemical Cycles 20 doi.org/10.1029/2005GB002570.

Dittmar, T., Lara, R.J., Kattner, G., 2001b. River or Mangrove? Tracing major organic matter sources in tropical Brazilian waters. Marine Chemistry 73, 253-271.

Droppo, I.G., Leppard, G.G., Flannigan, D.T., Liss, S.N., 1997. The freshwater floc: a functional relationship of water and organic and inorganic floc constituents affecting suspended sediment properties. Water, Air, and Soil Pollution 99, 43-54.

Duarte, C.M., Middelburg, J.J., Caraco, N., 2005. Major role of marine vegetation on the oceanic carbon cycle. Biogeosciences 2, 1-8.

Farrington, J.W., Frew, N.M., Gschwend, P.M. and Tripp, B.W., 1977. Hydrocarbons in cores of Northwestern Atlantic Coastal and continental margin sediments. Estuarine Coastal Shelf Science 5, 793-808.

Fourqurean, J.W., Jones, R.D.,Zieman, J.C., 1993. Process influencing water column nutrient characteristics and phosphorus limitation of phytoplankton biomass in Florida Bay, FL, USA: inferences from spatial distributions. Estuarine, Coastal and Shelf Science 36, 295-314.

Gao, M., 2007. Chemical characterization of soil organic matter in an oligotrophic, subtropical, freshwater wetland system: Sources, diagenesis and preservation. ProQuest ETD Collection for FIU. Paper AAI3279223.

Geyer, W.R., Hill, P.S., Kineke, G.C., 2004. The transport, transformation and dispersal of sediment by buoyant coastal flows. Continental Shelf Research 24, 927-949.

Goñi, M.A., and Thomas, K.A., 2000. Sources and Transformations of Organic matter in surface soils and sediments from a tidal estuary (North Inlet, South Carolina, USA). Estauries 23, 548-564.

Goñi, M.A., Cathey, M.W., Kim, Y.H., Voulgaris, G., 2005. Fluxes and sources of suspended organic matter in an estuarine turbidity maximum region during low discharge conditions. Estuarine, Coastal and Shelf Science 63, 683-700.

Goñi, M.A., Voulgaris, G., Kim, Y.H., 2009. Composition and fluxes of particulate organic matter in a temperate estuary (Winyah Bay, South Carolina, USA) under contrasting physical forcings. Estuarine, Coastal and Shelf Science 85, 273-291.

Gordon, E.S., Goñi, M.A., 2003. Sources and distribution of terrigenous organic matter delivered by the Atchafalaya River to sediments in the northern Gulf of Mexico. Geochimica et Cosmochimica Acta 67, 2359-2375. 
Grunsky, E.C., 2010. The interpretation of geochemical survey data. Geochemistry: Exploration, Environment, Analysis 10, 27-74.

Hedges, J.I., and Keil, R.G., 1995. Sedimentary organic matter preservation: an assessment and speculative synthesis. Marine Chemistry 49, 81-115.

Hedges, J. I., and Keil, R. G., 1999. Organic geochemical perspectives on estuarine processes: sorption reactions and consequences. Marine Chemistry 65, 55-65.

Hernandez, M.E., Mead, R., Peralba, M.C., Jaffé, R., 2001. Origin and transport of $n$ alkane-2-ones in a subtropical estuary: potential biomarkers for seagrass-derived organic matter. Organic Geochemistry 32, 21-32.

Howard, P.J.A., 1965. The carbon-organic matter factor in various soil types. Oikos 15, 229-236.

Jaffé, R., Boyer, J.N., Lu, X., Maie, N., Yang, C., Scully, N.M. and Mock, S., 2004. Source characterization of dissolved organic matter in a subtropical mangrove-dominated estuary by fluorescence analysis. Marine Chemistry 84, 195-210.

Jaffé, R., Mead, R., Hernandez, M.E., Peralba, M.C., DiGuida, O.A., 2001. Origin and transport of sedimentary organic matter in two subtropical estuaries: a comparative, biomarker-based study. Organic Geochemistry 32, 507-526.

Jaffé, R., Rushdi, A.I., Medeiros, P.M., Simoneit, B. R., 2006. Natural product biomarkers as indicators of sources and transport of sedimentary organic matter in a subtropical river. Chemosphere 64, 1870-1884.

Killops, S.D., Frewin, N.L., 1994. Triterpenoid diagenesis and cuticular preservation. Organic Geochemistry 21, 1193-1209.

Koch, B.P., Rullkötter, J., Lara, R.J., 2003. Evaluation of triterpenols and sterols as organic matter biomarkers in a mangrove ecosystem in northern Brazil. Wetlands Ecology and Management 11, 257-263.

Koch, B.P., Harder, J., Lara, R.J., Kattner, G., 2005. The effect of selective microbial degradation on the composition of mangrove derived pentacyclic triterpenols in surface sediments. Organic Geochemistry 36, 273-285.

Koch, B.P., Souza Filho, W.M., Behling H., Cohen, M.C., Kattnera, G., Rullkötterf, J., Barbara, S.B., Rubén, J.L., 2011. Triterpenols in mangrove sediments as a proxy for organic matter derived from the red mangrove (Rhizophora mangle). Organic Geochemistry 42, 62-73. 
Kristensen, E., Bouillon, S., Dittmar, T., Marchand, C., 2008. Organic carbon dynamics in mangrove ecosystems: A review. Aquatic Botany 89, 201-219.

Larsen, L.G., Harvey, J.W., Crimaldi, J.P., 2009. Morphologic and transport properties of natural organic floc. Water Resources Research 45, W01410.

Larsen, L.G., Harvey, J.W., Noe, G.B., Crimaldi, J.P., 2009b. Predicting organic floc transport dynamics in shallow aquatic ecosystems: insights from the field, the laboratory, and numerical modeling. Water Resources Research 45, W01411.

Lee, S.Y., 1995. Mangrove outwelling: a review. Hydrobiologia 295, 203-212.

Levesque, V.A., 2004. Water flow and nutrient flux from five estuarine rivers along the southwest coast of Everglades National Park, Florida, 1997-2001, USGS Scientific Investigations Report 2004-5142.

Lohrenz, S.E., Fahnenstiel, G.L., Redalje, D.G., 1994. Spatial and temporal variations in photosynthesis parameters in relation to environmental conditions in coastal waters of the northern Gulf of Mexico. Estuaries 17, 779-795.

Lohrenz, S.E., Wiesenburg, D.A., Arnone, R.A., Chen, X., 1999. What controls primary production in the Gulf of Mexico? In Sherman, K., H. Kumpf \& K. Steidinger (eds), The Gulf of Mexico Large Marine Ecosystem, Assessment, Sustainability, and Management. Blackwell Science, Malden, Massachusetts:151-170.

Mead, R., Xu, Y., Chong, J., Jaffé, R., 2005. Sediment and soil organic matter source assessment as revealed by the molecular distribution and carbon isotopic composition of $n$-alkanes. Organic Geochemistry 36, 363-370.

Neto, R. Mead, R.N., Louda, J.W., Jaffé, R., 2006. Organic biogeochemistry of detrital flocculent material (floc) in a subtropical, coastal wetland. Biogeochemistry 77, 283-304.

Pisani, O., Louda, J.W., Jaffé, R., 2013. Biomarker assessment of spatial and temporal changes in the composition of flocculent material (floc) in the subtropical wetland of the Florida Coastal Everglades. Environmental Chemistry10, 424-436.

Pisani, O., Yamashita, Y., Jaffe, R., 2011. Photo-dissolution of flocculent, detrital material in aquatic environments: contributions to the dissolved organic matter pool. Water Research 45, 3836-3844.

Prahl, F.G., Ertel, J.R., Goni, M.A., Sparrow, M.A., Eversmeyer, B., 1994. Terrestrial organic carbon contributions to sediments on the Washington margin. Geochimica et Cosmochimica Acta 58, 3035-3048. 
Prahl, F.G., Dymond, J., Sparrow, M.A., 2000. Annual biomarker record for export production in the central Arabian Sea. Deep Sea Research Part II: Topical Studies in Oceanography 47, 1581-1604.

Raymond, P.A., and Bauer, J.E., 2001. Use of ${ }^{14} \mathrm{C}$ and ${ }^{13} \mathrm{C}$ natural abundances for evaluating riverine, estuarine and coastal DOC and POC sources and cycling: a review and synthesis. Organic Geochemistry 32, 469-485.

Requejo, A.G., Quinn, J.G., 1983. Geochemistry of $\mathrm{C}_{25}$ and $\mathrm{C}_{30}$ biogenic alkenes in sediments of the Narragasett Bay estuary. Geochimica et Cosmochimica Acta 47, 10751090

Richards, J.H., 2001. Bladder function in Utricularia purpurea (Lentilbulaiacae): is carnivory important? American Journal of Botany 88, 170-176.

Rivera-Monroy, V.H., de Mutsert, K., Twilley, R.R., Castaneda-Moya, E., Romigh, M.M. and Davis, S.E., 2007. Patterns of nutrient exchange in a riverine mangrove forest in the Shark River estuary, Florida, USA. Hydrobiologica 17, 169-178.

Romigh, M.M., Davis, S.E., Rivera-Monroy, V.H., Twilley, R.R., 2006. Flux of organic carbon in a riverine mangrove wetland in the Florida Coastal Everglades. Hydrobiologia 569, 505-516Sinninghe Damste, J.S., van Koert, E.R., Kock-van Dalen, A.C., de Leeuw, J.W., Schenck, P.A., 1989. Characterisation of highly branched isoprenoid thiophenes occurring in sediments and immature crude oils, Organic Geochemistry 14, 555-567.

Saunders C., Gao M., Lynch J., Jaffé R. Childers D. 2006. Using soil profiles of seeds and molecular markers as proxies for sawgrass and wet parairie slough vegetation in Shark Slough, Everglades National Park. Hydrobiologia 569, 475-492.

Smoak, J.M., Breithaupt, J.L., Smith III, T.J., Sanders, C.J., 2013. Sediment accretion and organic carbon burial relative to sea-level rise and storm events in two mangrove forests in Everglades National Park. Catena 104, 58-66.

Thornton, S.F., McManus, J.,1994. Application of organic carbon and nitrogen stable isotope and $\mathrm{C} / \mathrm{N}$ ratios as source indicators of organic matter provenance in estuarine systems: evidence from the Tay Estuary, Scotland. Estuarine, Coastal and Shelf Science $38,219-233$.

Troxler, T.G., Gaiser, E., Barr, J., Fuentes, J.D., Jaffe, R., Childers, D.L., Collado-Vides, L., Rivera-Monroy, V.H., Castaneda-Moya, E., Anderson, W., Chambers, R., Chen, M., Coronado-Molina, C., Davis, S.E., Engel, V., Fitz, C., Fourqurean, J., Frankovich, T., Kominoski, J.; Madden, C.; Malone, S.L.; Oberbauer, S.F.; Olivas, P.; Richards, J.; Saunders, C., Schedlbauer, J., Scinto, L.J., Sklar, F., Smith, T., Smoak, J.M., Starr, G., Twilley, R.R., Whelan, K. 2013. Integrated carbon budget models for the Everglades 
terrestrial-coastal-oceanic gradient: Current status and needs for inter-site comparisons. Oceanography 26, 98-107.

Tue, N.T., Quy, T.D., Hamaoka, H., Nhuan, M.T., Omori, K., 2012. Sources and exchange of particulate organic matter in an estuarine mangrove ecosystem of Xuan Thuy National Park, Vietnam. Estuaries and Coasts 35, 1060-1068.

Twilley, R.R., 1985. The exchange of organic carbon in basin mangrove forests in a southwest Florida estuary. Estuarine, Coastal and Shelf Science 20, 543-557.

Van den Berg, R.A., Hoefsloot H.C., Westerhuis J.A., Smilde, A.K., van der Werf, M.J., 2006. Centering, scaling, and transformations: improving the biological information content of metabolomics data. BMC Genomics doi:10.1186/1471-2164-7-142.

Versteegh, G.J.M., Sshefub, E., Dupont, L., Marret, F., Sinninghe Damste, J.S., Jansen, J.H.F., 2004. Taraxerol and Rhizophora pollen as proxies for tracking past mangrove environments. Geochemica Cosmochimica Acta 68, 411-422.

Wakeham S.G., Peterson, M.L., Hedges, J.I., Lee, C., 2002. Lipid biomarker fluxes in the Arabian Sea, with a comparison to the equatorial Pacific Ocean. Deep-Sea Research, Part II: Topical Studies in Oceanography 49, 2265-2301.

Waterson, E. J. and Canuel, E. A., 2008. Sources of sedimentary organic matter in the Mississippi River and adjacent Gulf of Mexico as revealed by lipid biomarker and $\delta^{13} \mathrm{C}_{\mathrm{TOC}}$ analyses. Organic Geochemistry 39, 422-439.

Welch, R., Madden M., Doren, R., 1999. Mapping the Everglades. Photogrammetric Engineering andRemote Sensing 65, 163-170.

Woods, J., 2010. Surface Water Discharge and Salinity Monitoring of Coastal Estuaries in Everglades National Park, USA, in support of the Comprehensive Everglades Restoration Plan. In: Proceedings of the 3rd International Perspective on Current and Future State of Water Resources and the Environment, Chennai, India.

Wraige, E.J., Belt, S.T., Lewis, C.A., Cooke, D.A., Robert, J.M., Massé, G. and Rowland, S.J., 1997. Variations in structures and distributions of $\mathrm{C}_{25}$ highly branched isoprenoid (HBI) alkenes in cultures of the diatom, Haslea ostrearia (Simonsen). Organic Geochemistry 27, 497-505.

Xu, Y., Holmes, C., and Jaffé, R., 2007. A lipid biomarker record of environmental change in Florida Bay over the past 150 years. Estuarine, Coastal and Shelf Science 73, 201-210. 
Xu, Y., Jaffé, R., Wachnicka, A., Gaiser, E.E., 2006a. Occurrence of $\mathrm{C}_{25}$ highly branched isoprenoids (HBIs) in Florida Bay: Paleoenvironmental indicators of diatom-derived organic matter inputs. Organic Geochemistry 37, 847-859.

Xu, Y., Mead, R.N., Jaffé, R., 2006b. A molecular marker-based assessment of sedimentary organic matter sources and distributions in Florida Bay. Hydrobiologia 569, 179-192.

Yunker, M.B. and Macdonald, R.W., 2003. Alkane and PAH depositional history, sources and fluxes in sediments from the Fraser River Basin and Strait of Georgia, Canada. Organic Geochemistry 34, 1429-1454.

Yunker, M.B., Belicka, L. L., Harvey, H. R., and Macdonald, R. W., 2005. Tracing the inputs and fate of marine and terrigenous organic matter in Arctic Ocean sediments: A multivariate analysis of lipid biomarkers. Deep Sea Research Part II: Topical Studies in Oceanography 52, 3478-3508.

Yunker, M.B., Macdonald, R.W., Veltkamp, D.J., Cretney, W.J., 1995. Terrestrial and marine biomarkers in a seasonally ice-covered Arctic estuary-integration of multivariate and biomarker approaches. Marine Chemistry 49, 1-50. 
CHAPTER III

OCCURRENCE AND DISTRIBUTION OF MONOMETHYLALKANES IN THE FRESHWATER WETLAND ECOSYSTEM OF THE FLORIDA EVERGLADES 


\subsection{Abstract}

A series of mono-methylalkanes (MMAs) with carbon numbers from $\mathrm{C}_{10}$ to $\mathrm{C}_{23}$ and $\mathrm{C}_{29}$ were detected in freshwater wetlands of the Everglades. A decrease in concentration and molecular complexity was observed in the order from periphyton and floc, to surface soil and deeper soil horizons. These compounds were present in varying amounts up to $27 \mu \mathrm{g} / \mathrm{gdw}$ in periphyton, $74 \mu \mathrm{g} / \mathrm{gdw}$ in floc, $1.8 \mu \mathrm{g} / \mathrm{gdw}$ in surface soil, $<0.03 \mu \mathrm{g} / \mathrm{gdw}$ in deeper soils $(12-15 \mathrm{~cm})$. A total of 46 MMAs, including one iso and six anteiso-alkanes, were identified. Compound specific carbon isotopes values were determined for some dominant MMAs, and suggest that they originate from microbial sources, including cyanobacteria. Potential decarboxylation from fatty acids could also potentially contribute to the MMAs detected. Early diagenetic degradation was suggested to affect the accumulation of MMAs in soils and further studies are needed to address their applications as biomarkers.

\subsection{Introduction}

Mono-methylalkanes (MMAs) with mid-chain branching have an extensive geochemical history and were identified in numerous sample types, such as ambient aerosol (Turpin et al., 2000; Ho et al., 2008), exhaled breath (Phillips, 1997), insect cuticular lipids (Nelson et al., 1981; Bernier et al., 1998), microbial mats (Shiea et al., 1990; Logan et al., 1999; Arouri et al., 2000), sedimentary organic matter (Summons et al., 1988), orebody (Logan et al., 2001), oil sand (Lu et al., 2003) and crude oils (Höld et al., 1999). Their origin has been debated for years and two major hypotheses have been proposed as either biological or geosynthetic origins. The geosynthetic hypothesis 
includes (1) diagenetic transformation of functionalized lipid precursors such as common bacteria derived iso- and anteiso-fatty acids (Summons, 1987; Kaneda, 1991), and some bacterial mid-chain branched fatty acids (Summons, 1987; Summons et al., 1988); (2) products of acid clay mineral catalyzed reactions of alkenes (Kissin, 1987); or (3) longterm equilibration products from a limited range of isomers (e.g., Klomp, 1986). However, microbial culture studies suggest that MMAs can have a direct biogenic input from cyanobacteria (e.g., Han et al., 1968; Han and Calvin 1969; Shiea et al., 1990), cyanobacterium Nostoc sp. (Dembitsky et al., 1999), or marine Chloroflexus-like organisms (Parentheau et al., 2010; Jahnke et al., 2014). Moreover, other studies showed the direct biogenic input of MMAs from other non-microbial sources such as vascular plant leaf waxes (Brieskorn and Beck, 1970; Grice et al., 2008; Huang et al., 2011), earthworms (Nooner et al., 1973) and insect waxes (Nelson et al., 1981; Bernier et al., 1998).

Freshwater wetlands have been considered among the most productive ecosystems in the world (Leith, 1975). The Florida Everglades ecosystem, with a variety of environmental, hydrologic and soil-type gradients, is the largest subtropical wetland in North America. The vegetation shifts along the Everglades landscape from tree islands with terrestrial trees and ferns, to sloughs (deeper water) with submerged (water lily) and emergent (spikerush) aquatic plants, to ridges (shallow water) with sawgrass dominated communities (Davis et al., 1994). Within this diverse distribution of dominant higher plant species, periphyton, an abundant calcareous mixture of cyanobacteria, diatoms and green algae (Gaiser et al., 2011; Hagerthey et al., 2011), is widely distributed throughout this ecosystem. Periphyton, often forming thick mats and blanketing shallow surface 
sediment and submerged plants, is a ubiquitous and important biomass component of the Florida Everglades ecosystem. Considered to be the primary ecosystem engineer, periphyton plays a critical role in stabilizing soil, sustaining the landscape mosaic, controlling local food webs, and generating oxygen gas in the water column (Gaiser et al., 2011). While periphyton is present primarily as benthic or floating mats, the presence of free floating phytoplankton in the Everglades is negligible. As such, most of the suspended particulate organic matter (POM) is present in the form of floc, or flocculent material, which consists of a non-consolidated layer of microorganisms (generally bacteria), organic (e.g., detritus) and inorganic particles (e.g., carbonate), and represents an important biogeochemical component controlling carbon and nutrient transport, food web dynamics, and the other biogeochemical processes in this ecosystem (Neto et al., 2006). Disaggregated periphyton remains have been suggested as an important component of the floc in this environment.

Although MMAs are widespread in several species (e.g., algae, bacteria, insects, plant wax), and in various ecosystems, they have not been reported present in the Everglades wetlands. Considering the potential microbial origin of MMAs, I hypothesize that the abundant floating or benthic periphyton mats of the Florida Everglades could be a potential source for these compounds, which subsequent transfer to floc, surface soils and deeper sediments. As presented below, the distribution of MMAs found in this study was more complex compared to previous studies, where only a few homologues were detected in natural environments. In addition, the molecular complexity and concentration of the MMAs in the Everglades was found to decrease from periphyton and floc, to surface soils and lastly deeper sediments. Here I report on the presence of MMAs 
in this aquatic system, discuss their mass spectra, stable isotopic compositions and propose potential sources.

\subsection{Experimental Methods}

\subsubsection{Samples and locations}

The sampling sites used in this study were distributed along a several locations featuring nutrient and hydroperiod gradients in Everglades National Park (ENP, Fig. 3.1). WCA3 is located in the Water Conservation Area 3, located to the North of Everglades National Park (ENP), with the highest nutrient ( $\mathrm{P}$ and $\mathrm{N}$ ) levels and longest hydroperiod among all sites. Sites SRS1-3 are located in the Shark River Slough within ENP, featuring intermediate nutrient levels and hydroperiod. Sites TSPh2-3 are located at Taylor Slough, ENP, with lowest nutrient levels and hydroperiod, while TSPh4 is located adjacent to the C111 canal draining the Homestead Agricultural Area to the East of ENP. SRS1-3 and TSPh2-3 all represent freshwater marsh environments, characterized by diverse aquatic vegetation and microbial communities, such as abundant calcareous periphyton, Cladium jamaicense (sawgrass), Eleocharis (spikerush), Utricularia sp. (bladderworts) and Nuphar lutea (water lily) (Richardson, 2010). TSPh6 and SRS6 are located in mangrove-dominated estuarine areas. SRS6 is characterized by a mixture of white (Laguncularia racemosa), black (Avicennia germinans) and red mangroves (Rhizophora mangle) while TSPh6 is characterized primarily by the presence of dwarf red $(<2 \mathrm{~m})$ mangrove forests as well as abundant saltwort (Batis maritima). While SRS6 is subject to tidal mixing, $\mathrm{TSPh} 6$ is seasonally affected by seawater intrusions (dry season), is more phosphours limited and featuring extended inundation periods. 
Floating and submerged periphyton was collected by hand, and placed into Ziploc bags after removing large plant fragments. Floc, surface soil and sediments were collected following the procedures as described previously (e.g., Neto et al., 2006; Pisani et al., 2013). Dominant Everglades plants such as Cladium, Eleocharis, Nymphaeaceae, Utricularia, Chara (macroalga), Typha domingensis P., and Typha latifolia L. were also randomly sampled, each sample consisting of at least 5 individual samples from different locations within ENP or the WCA-3. Plant samples (both leaves and roots when applicable) were wrapped in aluminum foil immediately after collection. Upon retrieval, all samples were kept cool on ice during return to the laboratory, where they were transferred into pre-combusted glass jars with Teflon lined caps and stored in a freezer ($20^{\circ} \mathrm{C}$ ) until analysis.

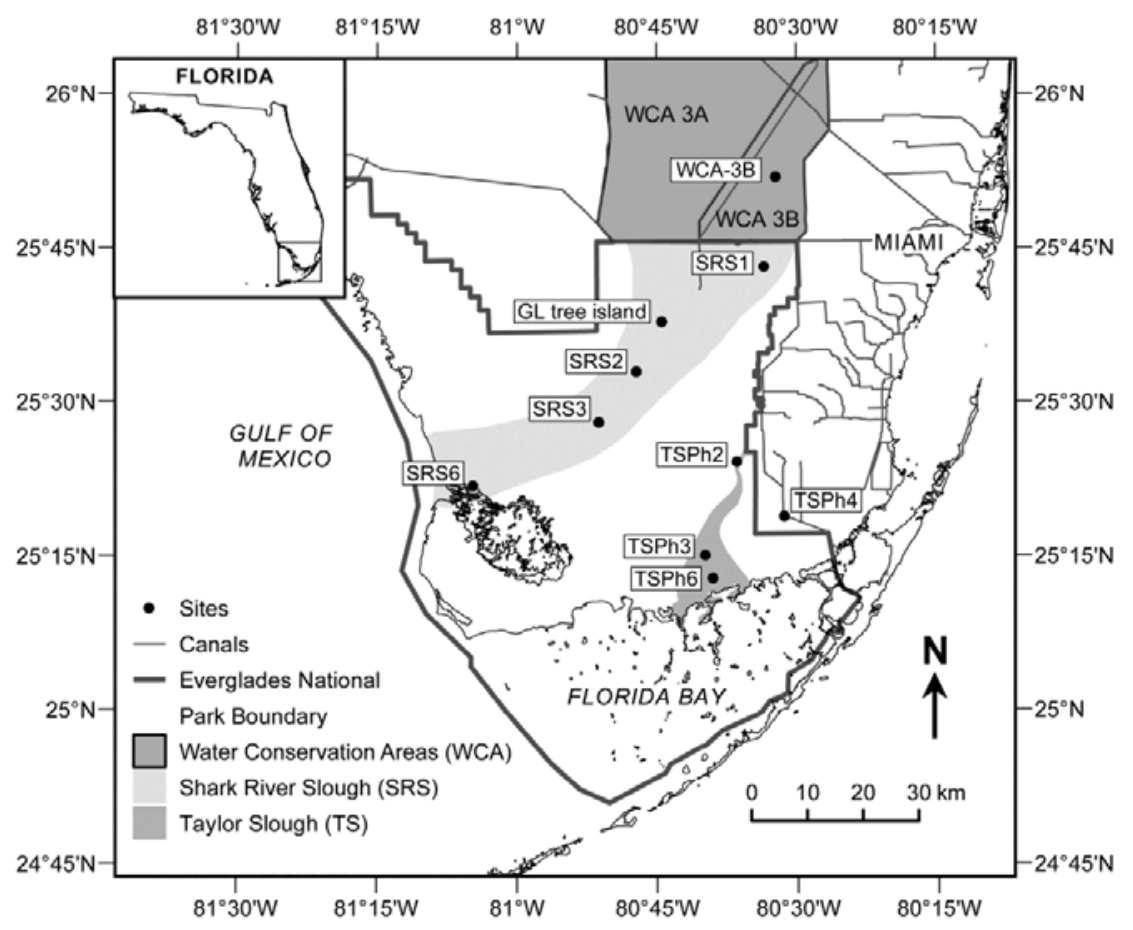

Figure 3.1 Map of the study areas and sampling locations in the Florida Everglades wetlands. 


\subsubsection{Sample preparation}

All samples were freeze-dried at $-50^{\circ} \mathrm{C}$, then shredded if necessary (leaf and root materials), and sieved through a 32 mesh $(500 \mu \mathrm{m})$ sieve to remove coarse material. Aliphatic hydrocarbons were isolated and analyzed as described previously (Jaffé et al., 2001) with some modifications. Briefly, freeze dried biomass (1 to $2 \mathrm{~g}$ ) was subjected to sonication extraction three times ( 0.5 hours each) with pure methylene chloride (Optima, Fisher, USA) as solvent. Activated copper was added during the extraction to eliminate elemental sulfur. Total extracts were concentrated and further fractionated by adsorption chromatography over silica gel. Saturated hydrocarbons were obtained using $n$-hexane as eluent. Ziploc bags used for sampling were washed with $n$-hexane. They were treated as control blanks and were randomly analyzed to assess potential sample crosscontamination.

\subsubsection{GC/MS quantification}

The GC/MS analyses were performed on a Hewlett-Packard 6890 GC linked to a HP 5973 MS system, and fitted with a Rtx-1 (30 meters long, $0.25 \mathrm{~mm} \mathrm{ID,} 0.25 \mu \mathrm{m} \mathrm{df}$ ) column from Restek, USA. All MMAs in this study were quantified relative to squalane (internal standard), assuming a similar response factor. Kovats retention indexes (RI) (Kovats, 1958) were calculated (listed in Table 3.1) following the formula: RI $=100 n+$ $100 \times\left(\mathrm{R}_{x}-\mathrm{R}_{n}\right) /\left(\mathrm{R}_{n+1}-\mathrm{R}_{n}\right)$, where $\mathrm{x}$ is the compound of interest, $\mathrm{n}$ and $\mathrm{n}+1$ are the carbon number for the nearest $n$-alkane and $(n+1)$-alkane eluting before and after $\mathrm{x}$, respectively, on the $\mathrm{GC}$, and $\mathrm{R}$ denotes the $\mathrm{GC}$ retention time. The identification of the MMAs was 
performed on the basis of the interpretation of the mass spectra and comparison with published mass spectra, and retention indexes if available (e.g., Krkošová et al., 2008).

\subsubsection{Compound specific carbon isotope analyses}

The $\delta^{13} \mathrm{C}$ values of individual $n$-alkanes and MMAs were measured using a gas chromatograph-isotope ratio mass spectrometer (GC-IRMS) system, which consists of a HP 6890 GC equipped with a Rtx-1 fused silica capillary column (30 m long, $0.25 \mathrm{~mm}$ ID, $0.25 \mu \mathrm{m} \mathrm{df}$ ), a combustion interface (Finnigan GC combustion IV), and a Finnigan MAT delta Plus mass spectrometer. Between every four samples, three standard mixtures containing $\mathrm{C}_{17} n$-alkane and squalane (different concentrations as $30 \mathrm{ng} / \mu \mathrm{L}, 100 \mathrm{ng} / \mu \mathrm{L}$ and $500 \mathrm{ng} / \mu \mathrm{L}$, with known $\delta^{13} \mathrm{C}$ values for each pure compound) were measured to check instrument performance throughout the analysis period and also used for correction purpose. A known amount of squalane was also co-injected with samples as an internal standard for stable carbon isotopic measurements. $\delta^{13} \mathrm{C}$ values are given in the per mil (\%) notation relative to the Peedee Belemnite (PDB) standard. The reproducibility of this GCIRMS system was $<0.5 \%$.

\subsection{Results and Discussion}

\subsubsection{Identification of MMA structures}

A series of MMAs with 10 to 23 carbon atoms eluted among the $\mathrm{C}_{10}$ to $\mathrm{C}_{23} n$ alkanes (Fig. 3.2). One additional $\mathrm{C}_{29}$ MMA (3-methyl octacosane) eluted between the $\mathrm{C}_{28}$ and $\mathrm{C}_{29} n$-alkanes. Generally, the mid-chain methyl-substituted alkane isomers eluted earlier than isomers substituted near the chain terminus (e.g., iso or anteiso), in 
agreement with previous reports (e.g., Klomp, 1986; Fowler and Douglas, 1987; Lu et al., 2003). A total of 46 MMAs were tentatively identified (Table 3.1). Examples of identified MMAs mass spectra for homologues with different carbon numbers and positions of the methyl branching are illustrated in Figure 3.3. The MMA mass spectra feature the molecular characteristic even mass fragment ion peaks formed by the cleavage of the carbon-carbon bonds adjacent to tertiary carbon atoms with a H transfer (Summons, 1987; Fowler and Douglas, 1987). The molecular ion $\left(\mathrm{M}^{+}\right)$of $m / z 142$ has the composition of $\mathrm{C}_{10} \mathrm{H}_{22}$, typical for an alkane, but the even ions of $m / z 56$ and 112 are $\left[\mathrm{C}_{4} \mathrm{H}_{8}\right]^{+}$and $\left[\mathrm{C}_{8} \mathrm{H}_{16}\right]^{+}$, respectively, indicating methyl branching of $\mathrm{C}-3$ for 3methylnonane (anteiso- decane, Fig. 3.3a). The $\mathrm{M}^{+}$of $\mathrm{m} / z 156$ represents $\mathrm{C}_{11} \mathrm{H}_{24}$, with even fragment ions at $m / z 70$ and 112 for $\mathrm{C}_{5} \mathrm{H}_{10}$ and $\mathrm{C}_{8} \mathrm{H}_{16}$ respectively, indicating methyl branching at C-4 for 4-methyldecane (Fig. 3.3b). The other MMAs shown by Figure $3.3 \mathrm{c}-1$ are on the basis of the same interpretation approach described previously. The key ions to elucidate the MMAs in hydrocarbon mixtures are in conjunction with $m / z 57$ or 71 as follows: $\mathrm{m} / \mathrm{z} 56$ for 3-methyl, $\mathrm{m} / \mathrm{z} 70$ for 4-methyl, $\mathrm{m} / \mathrm{z} 84$ for 5-methyl, etc. However, the extensive GC co-elution of isomers increases as the methyl substituent is located toward the mid-chain. A general EOP (even over odd predominance) was found for these MMAs. This could be explained in several ways: (1) even C-number fatty acids (Han and Calvin, 1969) generate alkanes with odd C-number upon decarboxylation, (2) iso- and anteiso-fatty acids (with odd C-numbers) generate alkanes with even C-numbers upon decarboxylation, (3) monounsaturated fatty acids with even C-number are transformed into alkanes with even C-number upon methylation and decarboxylation (Han et al. 1969), 
or (4) reduction of even fatty acids via decarbonylation generates odd alkanes in cyanobacteria (Schirmer et al., 2010).

Various MMAs have been reported in the literature covering the carbon chain range from $\mathrm{C}_{4}$ to $\mathrm{C}_{33}$ (e.g., Audino et al., 2001; Lu et al., 2003; Krkošová et al., 2008). However, a great majority of them were detected in crude oil or diesel fuel (Krkošová et al., 2008), and only in a few in non-petroleum sources (recent organic matter; e.g., Köster et al., 1999; Huang et al., 2011; Jahnke et al., 2014). Kenig et al. (1995) also reported numerous MMAs in modern and Holocene microbial mats with carbon number ranging from $\mathrm{C}_{17}$ to $\mathrm{C}_{34}$. However, only seven MMAs were detected with carbon numbers less than 23. In addition, the carbon range and isomer distribution (for MMAs with carbon number less than 23) from Kenig et al. (1995) were different from this present study. This study is, to my best knowledge, the first to report numerous types of MMAs in presentday aquatic environments. 


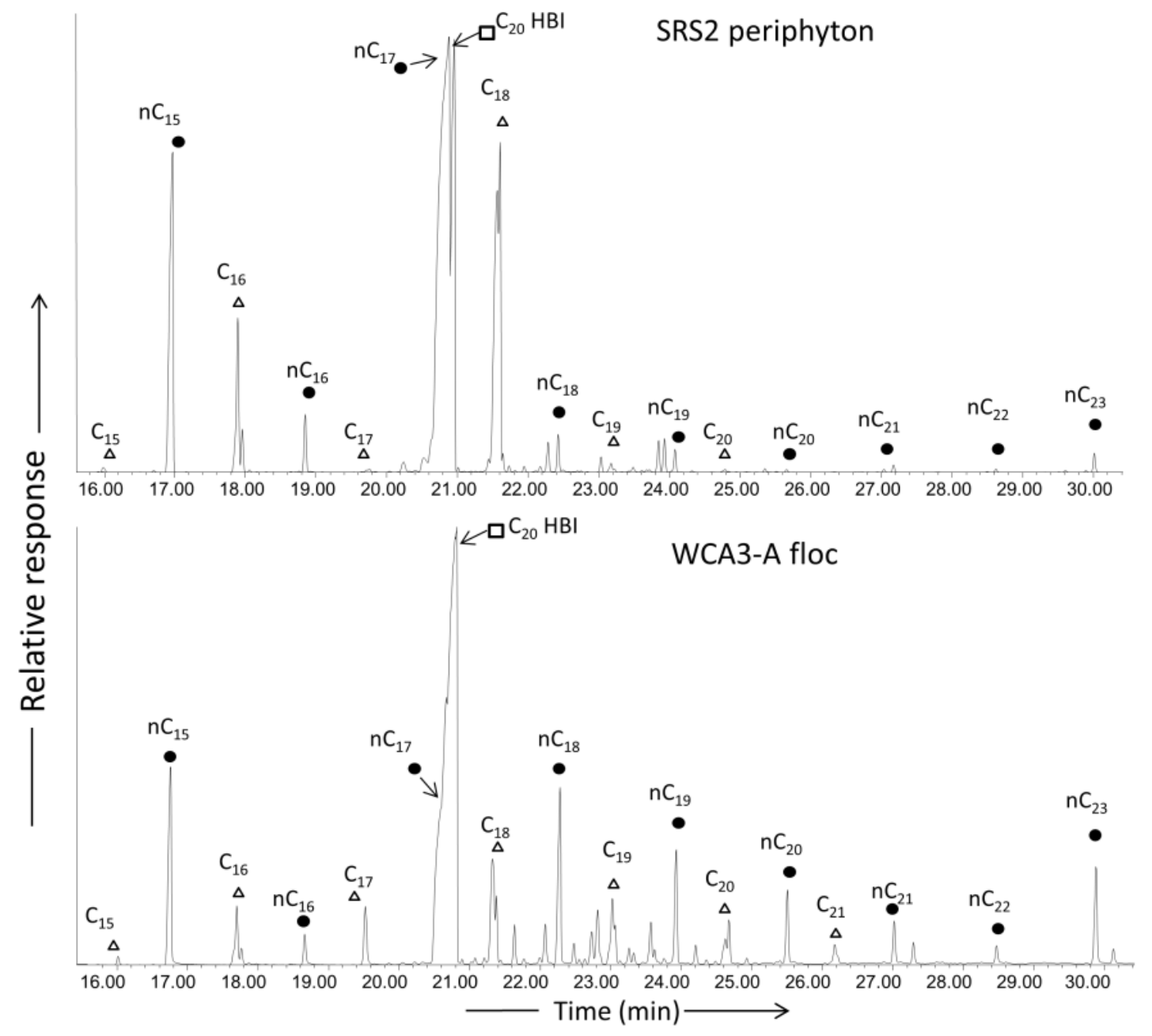

Figure 3.2 (a) GC-MS data for a periphyton sample at SRS2 (aliphatic fraction, partial, total ion current, TIC trace). (b) GC-MS data for a floc sample at WCA3-A (aliphatic fraction, partial TIC trace). MMAs are indicated by triangles and $n$-alkanes by black dots (GC-MS conditions were described in the methods section). Note: This sample shows a very high content of $\mathrm{C}_{20}$ HBIs and the highest diversity of MMAs. 


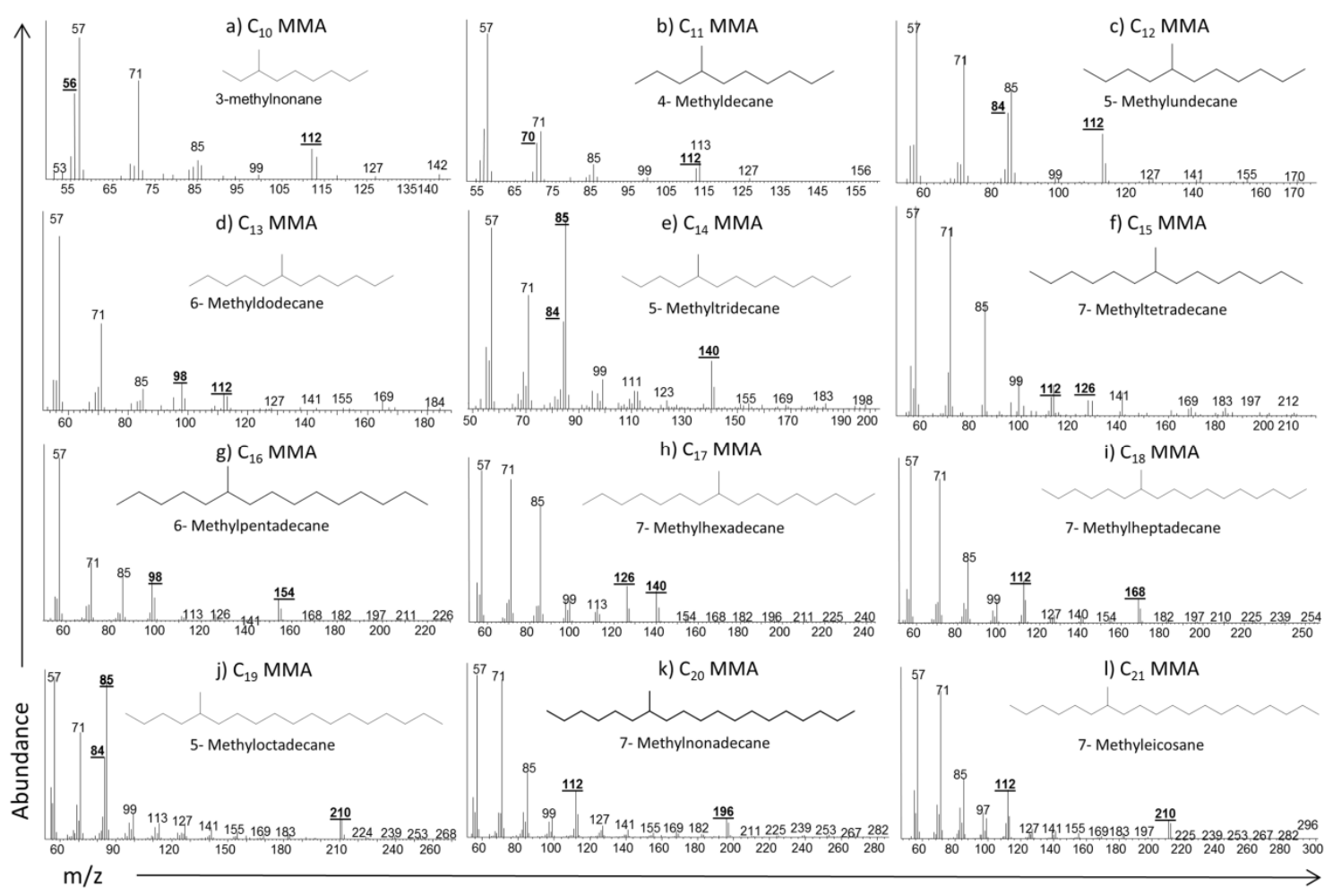

Figure 3.3 Examples of mass spectra of some MMAs identified in this study. All identifications are in fact tentative (see text in section 3.4.1). Note: characteristic ions are underlined and bold. 
Table 3.1 List of MMAs detected in periphyton, floc, surface soil and sediments across the Everglades freshwater wetlands.

Note: a, deviation is \pm 3 . Compounds are listed according to the retention time; ' + ' $=$ detected; blank $=$ not detected; N.A. $=$ not analyzed. Compounds listed according to retention time.

References: (1) Ali et al., 1988; (2) Armold et al., 1969; (3) Bird and Lynch, 1974; (4) Brassell and Krumbein, 1994; (5) Dembitsky et al., 2001; (6) Dobson et al., 1988; (7) Fehler and Light, 1970; (8) Friedman and Krumbein, 1985; (9) Gelpi et al., 1970; (10) Giruts and Gordadze, 2013; (11) Han et al., 1968; (12) Han and Calvin, 1969; (13) Herzner et al., 2011; (14) Huang et al., 2011 ; (15) Kenig et al., 1995; (16) Kohl et al., 2003; (17) Köster et al., 1999; (18) Krkošová et al., 2008; (19) Löfqvist, 1980; (20) Lu et al., 2014; (21) Morgan et al., 2003; (22) Nadaf et al., 2013; (23) Oró and Gelpi, 1968; (24) Nooner et al., 1973; (25) Olufunke, 2013; (26) Peschke and Metzler, 1987; (27) Regnier et al., 1973; (28) Robinson and Eglinton, 1990; (29) Rosy et al., 2012; (30) Rzama et al., 1995; (31) Patricia et al., 2013; (32) Shiea et al., 1990; (33) Siddiquee et al., 2012; (34) Thijsse and Zwilling-De Vries, 1959.

\begin{tabular}{|c|c|c|c|c|c|c|c|c|c|c|}
\hline $\begin{array}{l}\text { MMAs } \\
\text { detected }\end{array}$ & Compound name & MW & $\begin{array}{l}\text { Characteritic } \\
\text { ions }\end{array}$ & $\begin{array}{l}\text { Retention } \\
\text { Index } \\
(\mathrm{DB}-1)^{\mathrm{a}}\end{array}$ & Periphyton & Floc & $\begin{array}{l}\text { Surface } \\
\text { soil }\end{array}$ & $\begin{array}{l}\text { Sediment } \\
\text { core }\end{array}$ & Possible source or detected in other organisms & References \\
\hline C10 MMA & 3-methylnonane & 142 & 56,112 & N.A. & & + & & & Cyanobacterium Microcoleus vaginatus & 5 \\
\hline C11 MMA & 4-methyldecane & 156 & 70,112 & 1062 & & + & & & Cyanobacterium Microcoleus Vaginatus & 5 \\
\hline \multirow[t]{3}{*}{ C12 MMA } & 5-methylundecane & 170 & 84,112 & 1156 & & + & & & $\begin{array}{c}\text { Camponotus aegyptiacus, Cataglyphis savignyi } \\
\text { (insects) }\end{array}$ & 1 \\
\hline & 2-methylundecane & 170 & 127,155 & 1171 & & + & & & $\begin{array}{c}\text { Camponotus aegyptiacus, Cataglyphis savignyi, } \\
\text { Camponotus sericeiventris, Camponotus } \\
\text { castaneus (insects) }\end{array}$ & 1,16 \\
\hline & 3-methylundecane & 170 & 56,140 & 1174 & & + & & & $\begin{array}{l}\text { Aspergillus niger (fungus); Streptomyces } \\
\text { griseof lavus (bacteria) }\end{array}$ & 33 \\
\hline C13 MMA & 6-methyldodecane & 184 & 98,112 & 1275 & & + & & & $\begin{array}{l}\text { Pogonomyrmex rugosus; Pogonomyrmex barbatus } \\
\text { (insect) }\end{array}$ & 27 \\
\hline \multirow[t]{2}{*}{ C14 MMA } & 5-methyltridecane & 198 & 84,140 & 1354 & & + & & & $\begin{array}{l}\text { Pogonomyrmex rugosus; Pogonomyrmex barbatus } \\
\text { (insects) }\end{array}$ & 27 \\
\hline & 3-methyltridecane & 198 & 56,168 & 1371 & & + & & & Formica polyctena (insect) & 19 \\
\hline \multirow[t]{3}{*}{ C15 MMA } & 7-methyltetradecane & 212 & 112,126 & 1448 & & + & & & Ponerinae (insect) & 21 \\
\hline & 6-methyltetradecane & 212 & 98,140 & 1449 & + & + & & & $\begin{array}{l}\text { Pogonomyrmex rugosus; Pogonomyrmex barbatus } \\
\text { (insect) }\end{array}$ & 27 \\
\hline & 5-methyltetradecane & 212 & 84,154 & 1452 & + & + & & & Cissus species & 29 \\
\hline C16 MMA & 8-methylpentadecane & 226 & 126 & 1546 & & + & & & Gavish Sabkha microbial mats & 8 \\
\hline
\end{tabular}




\begin{tabular}{|c|c|c|c|c|c|c|c|c|c|c|}
\hline & 7-methylpentadecane & 226 & 112,140 & 1548 & + & + & & & Lumbricus terrestris (earthworm) & 24 \\
\hline & 6-methylpentadecane & 226 & 98,154 & 1550 & + & + & + & & $\begin{array}{c}\text { Meteorites Carbonaceous chondrites, Camponotus } \\
\text { sericeiventris }\end{array}$ & 16,23 \\
\hline & 5-methylpentadecane & 226 & 84,168 & 1554 & + & + & + & & Cyanobacterium Microcoleus vaginatus & 5 \\
\hline & 4-methylpentadecane & 226 & 70,182 & 1559 & + & + & & & Pseudomonas 475; green microalgae & $11,30,34$ \\
\hline & 2-methylpentadecane & 226 & 183,221 & 1565 & + & + & & & Cyanobacterium Microcoleus vaginatus & 5 \\
\hline \multirow[t]{3}{*}{ C17 MMA } & 8-methylhexadecane & 240 & 126,140 & 1645 & + & + & + & & Cyanobacterium Microcoleus vaginatus & 5 \\
\hline & 7-methylhexadecane & 240 & 112,154 & 1647 & + & + & & & $\begin{array}{c}\text { Chroococcus turgidus; Lumbricus terrestris } \\
\text { (earthworm) }\end{array}$ & 9,24 \\
\hline & 6-methylhexadecane & 240 & 98,168 & 1649 & + & + & & & Chroococcus turgidus & 9 \\
\hline \multirow[t]{6}{*}{ C18 MMA } & 8-methylheptadecane & 254 & 126,154 & 1745 & & + & + & & Cyanobacteria; Mastigocladus laminosus; & $3,4,7,12,13$ \\
\hline & 7-methylheptadecane & 254 & 112,168 & 1748 & + & + & + & + & Cyanobacteria & $\begin{array}{l}3,4,6,7,12 \\
13,17,32\end{array}$ \\
\hline & 6-methylheptadecane & 254 & 98,182 & 1750 & + & + & + & + & Cyanobacteria; Mastigocladus laminosus & $5,17,28,32$ \\
\hline & 5-methylheptadecane & 254 & 84,196 & 1753 & + & + & & & Cyanobacteria; Mastigocladus laminosus & $5,17,28,32$ \\
\hline & 4-methylheptadecane & 254 & 70,210 & 1759 & + & + & & & Cyanobacteria; Vernonanthura patens & 17,31 \\
\hline & 2-methylheptadecane & 254 & 211,239 & 1764 & + & + & + & & Cyanobacteria; Ziziphora persica & 17,22 \\
\hline \multirow[t]{4}{*}{ C19 MMA } & 8-methyloctadecane & 268 & 126,168 & 1844 & + & + & & & Rice husks & 20 \\
\hline & 7-methyloctadecane & 268 & 112,182 & 1846 & + & + & + & + & Crude Oil & 10 \\
\hline & 6-methyloctadecane & 268 & 98,196 & 1847 & + & + & + & + & Crude Oil & 10 \\
\hline & 5-methyloctadecane & 268 & 84,210 & 1852 & & + & & & Lumbricus terrestris (earthworm) & 24 \\
\hline \multirow[t]{4}{*}{ C20 MMA } & 9-methylnonadecane & 282 & 140,168 & 1940 & & + & & & Gavish Sabkha microbial mats; & 8 \\
\hline & 8-methylnonadecane & 282 & 126,182 & 1942 & + & + & + & & Abu Dhabi Cyanobacterial mats & 15 \\
\hline & 7-methylnonadecane & 282 & 112,196 & 1945 & + & + & + & & Abu Dhabi Cyanobacterial mats & 15 \\
\hline & 6-methylnonadecane & 282 & 98,210 & 1948 & + & + & & & Abu Dhabi Cyanobacterial mats & 15 \\
\hline \multirow[t]{4}{*}{ C21 MMA } & 10-methylicosane & 296 & 154,168 & 2039 & + & + & & & Antiaris africana; Antiaris grandis (insect) & 23,25 \\
\hline & 9-methylicosane & 296 & 140,182 & 2041 & & + & & & & \\
\hline & 8-methylicosane & 296 & 126,196 & 2042 & & + & & & Ampulex compressa (insect) & 13 \\
\hline & 7-methylicosane & 296 & 112,210 & 2044 & & + & & & Ampulex compressa (insect) & 13 \\
\hline
\end{tabular}




\begin{tabular}{|c|c|c|c|c|c|c|c|c|}
\hline \multirow{4}{*}{ C22 MMA } & 6-methylicosane & 296 & 98,224 & 2047 & & + & Ampulex compressa (insect) & 13 \\
\hline & 9-methylheneicosane & 310 & 140,196 & 2141 & & + & $\begin{array}{l}\text { Pteronarcys carlifonia } ; \text { Ampulex compressa } \\
\text { (insects) }\end{array}$ & 2,13 \\
\hline & 8-methylheneicosane & 310 & 126,210 & 2143 & & + & Diesel fuel & 18 \\
\hline & 7-methylheneicosane & 310 & 112,224 & 2145 & & + & Aleochara curtula; Ampulex compressa (insects) & 13 \\
\hline \multirow{3}{*}{ C23 MMA } & 6-methylheneicosane & 310 & 98,238 & 2147 & + & + & Diesel fuel & 18 \\
\hline & 7-methyldocosane & 324 & 112,238 & 2243 & + & + & Ampulex compressa (insect) & 13 \\
\hline & 6-methyldocosane & 324 & 98,252 & 2247 & & + & Rove beetle (insect) & 26 \\
\hline C29 MMA & 3-methyloctacosane & 422 & 56,392 & 2858 & & + & Lamiaceae and tobacco plants & 14 \\
\hline
\end{tabular}




\subsubsection{Distribution and occurrence of MMAs in the Everglades}

While only $\mathrm{C}_{15}$ to $\mathrm{C}_{20}$ MMAs were detected in the Everglades periphyton, all the identified MMAs $\left(\mathrm{C}_{10}\right.$ to $\mathrm{C}_{23}$ and $\left.\mathrm{C}_{29}\right)$ were present in Everglades floc, $\mathrm{C}_{16}$ to $\mathrm{C}_{20}$ MMAs in the surface soil, and only $\mathrm{C}_{18}$ and $\mathrm{C}_{19}$ MMAs were present in the deeper soils/sediment at $c a .12 \mathrm{~cm}$ below the surface. MMA average concentrations $(\mu \mathrm{g} / \mathrm{gdw})$ for all identified homologues in periphyton, floc and soils for all sites are shown in Table 3.2. Generally, there is a decreasing order from periphyton, and floc, to surface soil then to the deeper sediments. Moreover, higher molecular complexity in the MMA isomer distribution in periphyton and floc samples was observed compared to the surface soil or sediments. Several possibilities could cause the complexity and concentration differences: (1) the complex microbial composition of periphyton and floc (more than 1700 species identified; Gaiser et al., 2011; Hagerthey et al., 2011) compared to soils, (2) the potentially limited incorporation of floc to soils or the diagenetic reworking of periphyton and floc MMAs prior to incorporation into soils, or (3) early diagenetic reworking of these compounds, suggesting microbial degradation by heterotrophs such as bacteria and fungi (Leahy and Colwell, 1990). 
Table 3.2 Average contents of MMAs at different sites across the Everglades wetland ecosystem $(\mu \mathrm{g} / \mathrm{gdw})$.

\begin{tabular}{lccccccc}
\hline Locations & Periphyton & $\mathrm{n}(\mathrm{SD})$ & Floc & $\mathrm{n}(\mathrm{SD})$ & $\begin{array}{c}\text { Surface } \\
\text { soil }\end{array}$ & $\mathrm{n}(\mathrm{SD})$ & $\begin{array}{c}\text { Sediment } \\
(\mathrm{depth})\end{array}$ \\
\hline WCA-3A & 18.39 & $4(3.24)$ & 39.95 & $10(21.31)$ & N.A. & N.A. & N.A. \\
WCA-3B & 9.33 & $3(2.75)$ & 20.17 & $5(18.34)$ & 0.12 & $12(0.05)$ & $0.02(12-15 \mathrm{~cm})$ \\
SRS1 & 8.53 & 1 & 10.33 & 1 & 1.13 & $12(0.31)$ & $0.00(3-6 \mathrm{~cm})$ \\
GL & N.A. & N.A. & N.A. & N.A. & 1.72 & $3(0.35)$ & N.A. \\
SRS2 & 13.80 & $5(5.43)$ & 10.69 & $5(4.26)$ & 1.82 & $12(0.57)$ & $0.03(6-9 \mathrm{~cm})$ \\
SRS3 & 26.81 & $2(7.35)$ & 4.24 & $2(2.14)$ & 1.52 & $12(0.21)$ & $0.00(3-6 \mathrm{~cm})$ \\
TSPh2 & 20.33 & $5(6.29)$ & 5.64 & $5(2.12)$ & 1.21 & $12(0.32)$ & $0.02(10-12 \mathrm{~cm})$ \\
TSPh3 & 8.19 & 1 & 3.62 & 1 & N.A. & N.A. & N.A. \\
TSPh4 & 9.51 & 1 & N.A. & N.A. & N.A. & N.A. & N.A. \\
SRS6 & N.A. & N.A. & 0.00 & $4(0.00)$ & N.A. & N.A. & N.A. \\
TSPh6 & N.A. & N.A. & 0.83 & $4(0.23)$ & N.A. & N.A. & N.A. \\
\hline
\end{tabular}

See Fig. 3.1 for locations and abbreviations of sample names. Note: All numbers are normalized by $\mu \mathrm{g} / \mathrm{gdw}$ (sample); N.A. = not analyzed; $\mathrm{n}=$ number of samples measured; $\mathrm{SD}=$ standard deviation.

The highest concentrations of MMAs were observed in periphyton and floc from the Everglades freshwater marshes, such as SRS1-3, WCA3A, WCA3B and TSPh2-3, while only minor amounts of MMAs were found in mangrove floc at TSPh6 (less than 10\% compared with most of the fresh water wetland samples) and no MMAs were detected at SRS6. This suggests these MMAs should be derived predominantly from freshwater organisms in this ecosystem. Transport of floc from the freshwater marshes to the estuaries has been reported but subjected to significant dilution (Pisani et al., 2013). In addition, a large variation in MMA concentrations and compositions was found within different freshwater sites. Within the SRS transect, higher MMA concentrations were observed in SRS2 and 3 compared with SRS1, in agreement with the higher primary 
productivity of periphyton in the central slough (SRS2, 3) compared with SRS1 (Gaiser et al., 2011). This could be caused by the nutrient level difference between the freshwater sites. Moreover, it is known that species compositions of algae and bacteria differ spatially and seasonally, with highest rates of periphyton production reported during the wet season. Thus, variations in microbial community structure on spatial and temporal scales may also contribute the compositional complexity and concentration difference of the MMAs among the studied sites. The freshwater marsh samples from Taylor Slough feature shorter hydroperiods and consequently reduced organic matter preservation in surface soils. As such, they are expected to have lower levels of MMAs.

\subsubsection{Potential sources of MMAs in the Everglades freshwater wetlands}

The dominant wetland plants (Cladium, Eleocharis, Nymphaeaceae, Utricularia, Typha domingensis $\mathrm{P}$., and Typha latifolia $\mathrm{L}$.) were also sampled across the Everglades and both leaves and roots were analyzed. No MMAs were detected in any of these plant species. This suggests that the MMAs detected are not derived from the most common higher plants in this ecosystem. Only the $\mathrm{C}_{29}$ MMA (3-methyl octacosane) in this particular study was observed in a few Utricularia/periphyton mixture samples and in some the floc samples. It was however, neither detected in the reference periphyton sample (not specified as a mixture between periphyton and Utricularia), nor in all Utricularia samples surveyed. Thus, I am assuming that Utricularia-associated organic matter, may be the source of this particular 3-methyl octacosane. To my best knowledge, 3-methyl octacosane has only been reported in some Lamiaceae and tobacco plants 
(Grice et al., 2008; Huang et al., 2011). Because of its inconsistent detection across my entire sample set (13 out of 124), it is not discussed further in this manuscript.

Previous studies showed that specific sources for MMAs can be suggested from the position of the methyl branching pattern. In this study, the methyl substituents are located at both even- and odd- numbered carbon atoms (Fig. 3.4c). Moreover, the dominant MMAs are with carbon chain ranged from $C_{15}$ to $C_{22}$. All these infer that the major part of the MMAs reported here are not insect-derived, where the dominant carbon chain length is higher than $\mathrm{C}_{23}$, and the methyl substituents are preferentially located at odd-numbered carbon atoms (e.g., Nelson et al., 1981; Kenig et al., 1995). The most dominant methyl branching sites are located at C-7 and C-6 (Fig. 3.4c). These results suggest that most of the MMAs in the Everglades are likely derived from a microbial source (mainly cyanobacteria; e.g., Shiea et al., 1990; Kenig et al., 1995). 

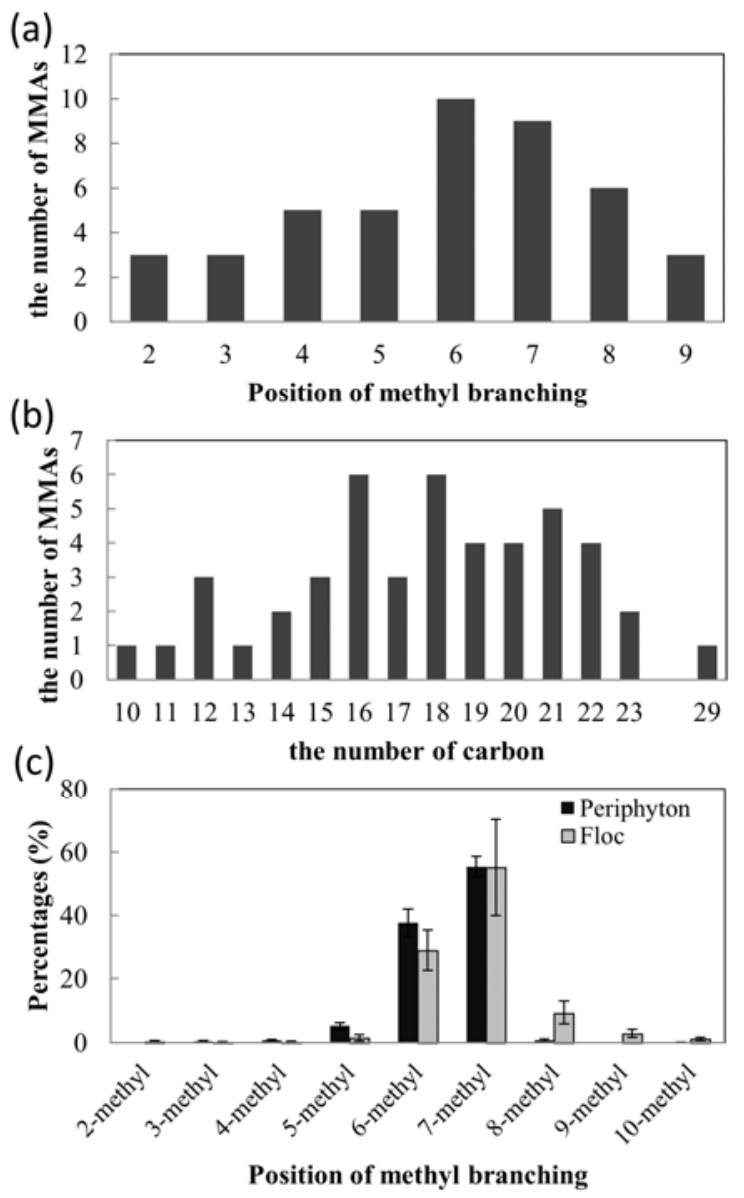

Figure 3.4 The distribution of (a) MMAs versus position of methyl branching, (b) MMAs versus total carbon number in this study and (c) Relative percentages of different methyl branching MMAs for periphyton and floc samples. Note: For better comparison, the periphyton and floc samples shown in Fig. 3.4c were chosen from the sample sites (WCA3A, WCA3B, SRS1-3, TSPh2-4). Relative percentages in Fig. 3.4c are calculated by: $\frac{\text { Total concentration }\left(\frac{\mu g}{g d w}\right) \text { of the same carbon number } M M A s}{\text { Total concentration }\left(\frac{\mu g}{g d w}\right) \text { of all MMAs detected }} \times 100 \%$. Note: The selected samples show the least co-elution of $\mathrm{C}_{17} n$-alkane and $\mathrm{C}_{20: 1} \mathrm{HBI}$.

Compound specific ${ }^{13} \mathrm{C}$ isotope analysis was also performed on MMAs and other components of the aliphatic fractions of floc samples. Because of the lower sensitivity of GC-IRMS relative to GC-MS, only a few of the most abundant compounds were analyzed and reported. Because of the difficulty to completely chromatographically resolve each isomer of MMAs with same carbon number, the $\delta^{13} \mathrm{C}$ values were reported 
as averages for the MMAs with the same carbon number (mixtures of different isomers with different methyl branching). $\delta^{13} \mathrm{C}$ values of MMAs reported here ranged from $-32.6 \%$ o to $-42.0 \%$, which are more depleted compared to most previously reported values. For example, the isotopic signatures for four series of MMAs reported from Botrococcus braunii-rich torbanite samples by Audino et al. (2001) ranged in $\delta^{13} \mathrm{C}$ values from -20 to $8 \%$, the $\delta^{13} \mathrm{C}$ of longer chain MMAs $\left(\mathrm{C}_{25}-\mathrm{C}_{31}\right)$ from 11 Botryococcus braunii-rich torbanites from Scotland, South Africa and Australia ranged from -16 to -6\%o (Grice et al., 2001), significantly more enriched compared to MMAs in the Evergades. Two groups of MMAs (short and long-chain) in an oil sand sample from the Tarim Basin, NW China (Lu et al., 2003) suggested different sources on the basis of their different range of $\delta^{13} \mathrm{C}$ values and the most abundant methyl substituents in these two groups of MMAs. These authors report that the $\delta^{13} \mathrm{C}$ of short chain MMAs $\left(\mathrm{C}_{14}-\mathrm{C}_{22}\right)$ ranged from -33.4 to $-31.9 \%$ o and the methyl substituents in these MMAs were located mainly at C-4, C-5, C-6 and C-7, suggesting a cyanobacterial origin (Summons et al., 1988). However, the $\delta^{13} \mathrm{C}$ of the long chain MMAs $\left(\mathrm{C}_{25}-\mathrm{C}_{36}\right)$ ranged from -31.4 to $-30.1 \%$, and is likely associated with microorganisms of phytoplankton or heterotrophic bacteria, rather than cyanobacteria, because the long-chain MMAs are mostly 9-methyl and 10-methyl isomers (Kenig et al., 1995). The average $\delta^{13} \mathrm{C}$ of mid-chain MMAs $\left(\mathrm{C}_{18}-\mathrm{C}_{24}\right)$ were reported as $-36.8 \pm 0.4 \%$ in Huqf crude oil from Oman (Höld et al., 1999). In combination with the $\delta^{13} \mathrm{C}$ values, offline pyrolysis and chemical degradation results, they suggested these MMAs could be derived from biological precursor molecules such as sulfur- (and possibly sulfur- and ether-) bound lipids with methyl branching at C-12 or C-13 position (Höld et al., 1999). 
In this study, the stable carbon isotopic compositions of $n$-alkanes, $\mathrm{C}_{20}$ highly branched isoprenoid (HBI) and MMAs (only $\mathrm{C}_{16}-\mathrm{C}_{21}$ are reported) are shown in Figure 3.5. In order to minimize the effect of co-elution on the $\mathrm{C}_{17} n$-alkane carbon isotope data, only two selected floc samples (with low concentrations of the co-eluting $\mathrm{C}_{20} \mathrm{HBIs}$ ) were analyzed (Fig. 3.5 a, b). However, I also realize that a small degree of co-elution may also affect the $\delta^{13} \mathrm{C}_{\text {of }} \mathrm{C}_{17} n$-alkane for Fig. 3.5a. No co-elutions for other $n$-alkanes were observed.

The $\delta^{13} \mathrm{C}$ values of the $\mathrm{C}_{20} \mathrm{HBI}$ ranged from $-36.1 \%$ to $-41.8 \%$ in the freshwater Everglades floc, which were 6-10\% lower relative to terrestrially-derived long-chain $n$ alkanes in this region ( -30\%; Mead et al., 2005). This large $\delta^{13} \mathrm{C}$ offset may suggest that $\mathrm{C}_{20} \mathrm{HBI}$-producing organisms (likely cyanobacteria; Jaffé et al., 2001) at least partially utilize recycled ( ${ }^{13} \mathrm{C}$ depleted) $\mathrm{CO}_{2}$ produced from respired $\mathrm{OM}$ as their carbon sources rather than atmospheric $\left({ }^{13} \mathrm{C}\right.$ enriched) $\mathrm{CO}_{2}$. The $\delta^{13} \mathrm{C}$ values of the MMAs showed a large range from $-32.6 \%$ to $-42.0 \%$. Here, the discrepancies among methyl branching (Fig. 3.4 and Table 3.1) and stable carbon isotopic compositions (Fig. 3.5 a, b) between the shorter-chain $\left(\leq \mathrm{C}_{19}\right)$ and longer-chain MMAs $\left(\geq \mathrm{C}_{20}\right)$ suggest that they may have different sources. The $\delta{ }^{13} \mathrm{C}$ values of the shorter chain MMAs $\left(\leq \mathrm{C}_{19}\right)$ are more depleted in all floc and periphyton samples (-36.1 to $-42.0 \%$; examples are shown in Fig. 3.5a, b) compared with $n$-alkanes (-36.0 to $-25.1 \%$ ) but similar to those of the $\mathrm{C}_{20} \mathrm{HBI}(-36.1 \%$ o to $-41.8 \%$ ). On the other hand, the $\delta{ }^{13} \mathrm{C}$ values of longer chain MMAs $\left(\geq \mathrm{C}_{20}\right)$ featured slightly more enriched values $(-32.6$ to $-36.7 \%$ ), which are similar to those of the $n$ alkanes in the same sample. While this is in agreement with previous suggestions that these MMAs could be generated through a series of alkylation and decarboxylation 
reactions from submerged macrophyte derived unsaturated fatty acids (Han and Calvin, 1969), the potential sources of these MMAs $\left(\geq C_{20}\right)$ remains unclear. However, a significant correlation (concentration based) between $\mathrm{C}_{20} \mathrm{HBI}$ and MMAs (all combined) was found across the whole sample set $\left(n=124 ; R^{2}=0.70, P<0.01\right)$, which infers that cyanobacteria may be the source for the majority of the MMAs (particularly the shortchain homologues) detected. However, the contribution from other source organisms (with similar carbon isotope ratios) to the whole MMA pool cannot be ruled out.

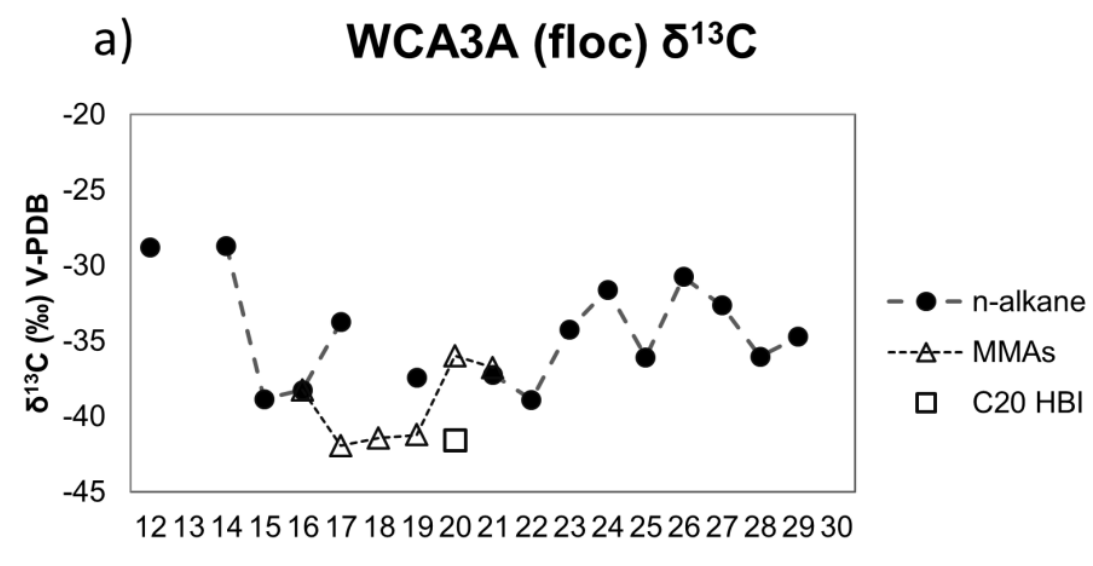

Carbon number

b) WCA3B (floc) $\delta^{13} \mathrm{C}$

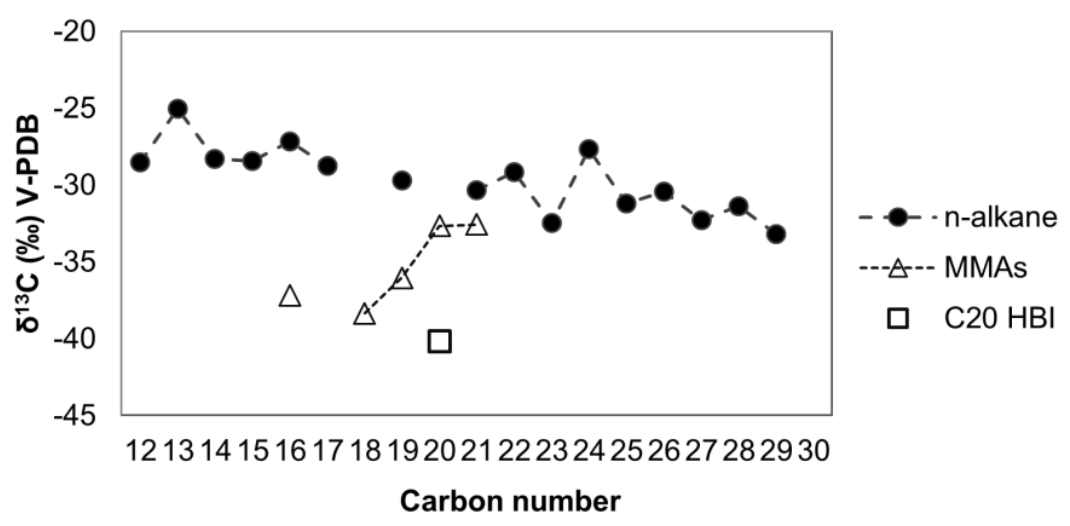

Figure 3.5 Compound specific carbon isotope compositions of $n$-alkanes, MMAs and $\mathrm{C}_{20}$ HBI of floc samples: (a) WCA3A floc, (b) WCA3B floc. Black dots, triangles and rectangles stand for $n$-alkanes, MMAs and $\mathrm{C}_{20} \mathrm{HBI}$, respectively. 


\subsection{Conclusions}

A series of short-to-mid chain MMAs were detected in periphyton, floc and soils of the Everglades wetlands and may possibly be derived from cyanobacteria and other microorganism associated with periphyton or floc. The origin of the much less abundant longer chain MMAs was less certain but could also be periphyton derived or generated through diagenetic reworking of lipids from emergent or aquatic plants after detrital incorporation into floc. These hypotheses are supported by the similar $\delta^{13} \mathrm{C}$ values of low-to-mid chain MMAs with $\mathrm{C}_{20} \mathrm{HBI}$ and the longer chain MMAs with the long chain $n$-alkanes. The MMA concentrations and molecular distributions were shown to decrease from periphyton and floc to surface soil, then to the deeper sediment, suggesting that these compounds are subject to degradation. However, because of the complexity of the organic matter sources and diagenetic transformations in floc, detailed source identifications of MMAs in the Everglades requires further assessment. 


\section{REFERENCE}

Ali, M. F., Billen, J. P., Jackson, B. D., Morgan, E. D. (1988). Secretion of the dufour glands of two African desert ants, Camponotus aegyptiacus and Cataglyphis savignyi (Hymenoptera: Formicidae). Biochemical Systematics and Ecology, 16(7), 647-654.

Armold, M. T., Blomquist, G. J., Jackson, L. L. (1969). Cuticular lipids of insects-III. The surface lipids of the aquatic and terrestrial life forms of the big stonefly, Pteronarcys californica Newport. Comparative Biochemistry and Physiology, 31(5), 685-692.

Arouri, K., Conaghan, P. J., Walter, M. R., Bischoff, G. C. O., Grey, K. (2000). Reconnaissance sedimentology and hydrocarbon biomarkers of Ediacarian microbial mats and acritarchs, lower Ungoolya Group, Officer Basin. Precambrian Research, 100(1), 235-280.

Audino, M., Grice, K., Alexander, R., Boreham, C. J., Kagi, R. I. (2001). Unusual distribution of monomethylalkanes in Botryococcus braunii-rich samples: origin and significance. Geochimica et Cosmochimica Acta, 65(12), 1995-2006.

Bernier, U. R., Carlson, D. A., Geden, C. J. (1998). Gas chromatography/mass spectrometry analysis of the cuticular hydrocarbons from parasitic wasps of the genus Muscidifurax. Journal of the American Society for Mass Spectrometry, 9(4), 320-332.

Bird, C. W., Lynch, J. M. (1974). Formation of hydrocarbons by micro-organisms. Chemical Society Reviews, 3(3), 309-328.

Brassell, S.C., (1994). Isopentenoids and geochemistry, in: W.D. Nes (Ed.), Isopentenoids and Other Natural Products: Evolution and Function, American Chemical Society Symposium Series, vol. 562 (1994), pp. 2-30.

Brieskorn, C. H., Beck, K. R. (1970). Die Kohlenwasserstoffe des Blattwachses von Rosmarinus officinalis. Phytochemistry, 9(7), 1633-1640.

Davis, S.M., Gunderson, L.H., Park, W.A., Richardson, J.R., Mattson, J.E., (1994) Landscape dimension, composition, and function in a changing Everglades ecosystem. In: S.M. Davis, J.C. Ogden (Eds.), Everglades: the Ecosystem and Its RestorationSt. Lucie Press, Delray Beach, Florida, pp. 419-444.

Dembitsky, V. M., Dor, I., Shkrob, I., Aki, M. (2001). Branched $n$-alkanes and other apolar compounds produced by the Cyanobacterium Microcoleus vaginatus from the Negev Desert. Russian Journal of Bioorganic Chemistry, 27(2), 110-119.

Dembitsky, V. M., Shkrob, I., Dor, I. (1999). Separation and identification of hydrocarbons and other volatile compounds from cultured blue-green alga Nostoc sp. by 
gas chromatography-mass spectrometry using serially coupled capillary columns with consecutive nonpolar and semipolar stationary phases. Journal of Chromatography A, 862(2), 221-229.

Dobson, G., Ward, D. M., Robinson, N., Eglinton, G. (1988). Biogeochemistry of hot spring environments: extractable lipids of a cyanobacterial mat. Chemical Geology, 68(1), 155-179.

Fehler, S. W., Light, R. J. (1970). Biosynthesis of hydrocarbons in Anabaena variabilis. Incorporation of [methyl-14C] and [methyl-2H2] methionine into 7-and 8-methylheptadecanes. Biochemistry, 9(2), 418-422.

Fowler, M. G., Douglas, A. G. (1987). Saturated hydrocarbon biomarkers in oils of Late Precambrian age from Eastern Siberia. Organic Geochemistry, 11(3), 201-213.

Friedman, G. M., Krumbein, W. E. (1985). Hypersaline Ecosystems. Berlin: SpringerVerlag.

Gaiser, E. E., McCormick, P. V., Hagerthey, S. E., Gottlieb, A. D. (2011). Landscape patterns of periphyton in the Florida Everglades. Critical Reviews in Environmental Science and Technology, 41(S1), 92-120.

Gao, M., Simoneit, B. R. T., Gantar, M., Jaffé, R. (2007). Occurrence and distribution of novel botryococcene hydrocarbons in freshwater wetlands of the Florida Everglades. Chemosphere, 70(2), 224-236.

Gelpi, E., Schneider, H., Mann, J., Oro, J. (1970). Hydrocarbons of geochemical significance in microscopic algae. Phytochemistry, 9(3), 603-612.

Giruts, M. V., Gordadze, G. N. (2013). Differentiation of crude oils and condensates by distribution of saturated hydrocarbons: 1. Oil types determinable by gas-liquid chromatography. Petroleum Chemistry, 53(4), 209-219.

Grice, K., Audino, M., Boreham, C. J., Alexander, R., Kagi, R. I. (2001). Distributions and stable carbon isotopic compositions of biomarkers in torbanites from different palaeogeographical locations. Organic Geochemistry, 32(10), 1195-1210.

Grice, K., Lu, H., Zhou, Y., Stuart-Williams, H., Farquhar, G. D. (2008). Biosynthetic and environmental effects on the stable carbon isotopic compositions of anteiso-(3methyl) and iso-(2-methyl) alkanes in tobacco leaves. Phytochemistry, 69(16), 2807-2814.

Gunderson, L.H. (1994) Vegetation of the Everglades: determinants of community composition. Everglades: The ecosystem and its restoration. St. Lucie Press, Delray Beach, FL, 323-340. 
Hagerthey, S. E., Bellinger, B. J., Wheeler, K., Gantar, M., Gaiser, E. (2011). Everglades periphyton: a biogeochemical perspective. Critical Reviews in Environmental Science and Technology, 41(S1), 309-343.

Han, J., Calvin, M. (1969). Hydrocarbon distribution of algae and bacteria, and microbiological activity in sediments. Proceedings of the National Academy of Sciences, 64(2), 436-443.

Han, J., McCarthy, E. D., Calvin, M., Benn, M. H. (1968). Hydrocarbon constituents of the blue-green algae Nostoc muscorum, Anacystis nidulans, Phormidium luridium and Chlorogloea fritschii. Journal of the Chemical Society C, 2785-2791.

Herzner, G., Ruther, J., Goller, S., Schulz, S., Goettler, W., Strohm, E. (2011). Structure, chemical composition and putative function of the postpharyngeal gland of the emerald cockroach wasp, Ampulex compressa (Hymenoptera, Ampulicidae). Zoology, 114(1), 3645.

Ho, S. S. H., Yu, J. Z., Chow, J. C., Zielinska, B., Watson, J. G., Sit, E. H. L., \& Schauer, J. J. (2008). Evaluation of an in-injection port thermal desorption-gas chromatography/mass spectrometry method for analysis of non-polar organic compounds in ambient aerosol samples. Journal of Chromatography A, 1200(2), 217-227.

Höld, I. M., Schouten, S., Jellema, J., Sinninghe Damsté, J. S. (1999). Origin of free and bound mid-chain methyl alkanes in oils, bitumens and kerogens of the marine, Infracambrian Huqf Formation (Oman). Organic Geochemistry, 30(11), 1411-1428.

Huang, X., Meyers, P. A., Wu, W., Jia, C., Xie, S. (2011). Significance of long chain iso and anteiso monomethyl alkanes in the Lamiaceae (mint family). Organic Geochemistry, 42(2), 156-165.

Jaffé, R., Mead, R., Hernandez, M. E., Peralba, M. C., DiGuida, O. A. (2001). Origin and transport of sedimentary organic matter in two subtropical estuaries: a comparative, biomarker-based study. Organic Geochemistry, 32(4), 507-526.

Jahnke, L. L., Turk-Kubo, K. A., N Parenteau, M., Green, S. J., Kubo, M. D. Y., Vogel, M., Summons, R.E., Des Marais, D. J. (2014). Molecular and lipid biomarker analysis of a gypsum-hosted endoevaporitic microbial community. Geobiology, 12(1), 62-82.

Kaneda, T. O. S. H. I. (1991). Iso-and anteiso-fatty acids in bacteria: biosynthesis, function, and taxonomic significance. Microbiological Reviews, 55(2), 288-302.

Kenig, F., Sinninghe Damsté, J. S., Kock-van Dalen, A. C., Rijpstra, W. I. C., Huc, A. Y., de Leeuw, J. W. (1995). Occurrence and origin of mono-, di-, and trimethylalkanes in modern and Holocene cyanobacterial mats from Abu Dhabi, United Arab Emirates. Geochimica et Cosmochimica Acta, 59(14), 2999-3015. 
Kissin, Y. V. (1987). Catagenesis and composition of petroleum: Origin of n-alkanes and isoalkanes in petroleum crudes. Geochimica et Cosmochimica Acta, 51(9), 2445-2457.

Klomp, U.C. (1986). The chemical structure of a pronounced series of iso-alkanes in South Oman crudes. Organic Geochemistry, 10(4), 807-814.

Kohl, E., Hölldobler, B., Bestmann, H. J. (2003). Trail pheromones and Dufour gland contents in three Camponotus species $(C$. castaneus, $C$. balzani, C. sericeiventris: Formicidae, Hymenoptera). Chemoecology, 13(3), 113-122.

Köster, J., Volkman, J. K., Rullkötter, J., Scholz-Böttcher, B. M., Rethmeier, J., Fischer, U. (1999). Mono-, di-and trimethyl-branched alkanes in cultures of the filamentous cyanobacterium Calothrix scopulorum. Organic Geochemistry, 30(11), 1367-1379.

Kovats, E. (1958). Gas chromatographic characterization of organic compounds. I. Retention indexes of aliphatic halides, alcohols, aldehydes, and ketones. Helvetica Chimica Acta, 41, 1915-1932.

Krkošová, Ž., Kubinec, R., Soják, L., Amann, A. (2008). Temperature-programmed gas chromatography linear retention indices of all $\mathrm{C}_{4}-\mathrm{C}_{30}$ monomethylalkanes on methylsilicone OV-1 stationary phase: Contribution towards a better understanding of volatile organic compounds in exhaled breath. Journal of Chromatography A, 1179(1), 59-68.

Leahy, J. G., Colwell, R.R. (1990). Microbial degradation of hydrocarbons in the environment. Microbiological Reviews, 54(3), 305-315.

Leith, H., (1975). Primary productivity of the major vegetation units of the world: In H. Leith \& R. H. Whittaker (eds), Primary Productivity of the Biosphere. Springer Verlag, New York: 203-216.

Löfqvist, J., Bergström, G. (1980). Volatile communication substances in Dufour's gland of virgin females and old queens of the ant Formica polyctena. Journal of Chemical Ecology, 6(2), 309-320.

Logan, G.A., Calver, C.R., Gorjan, P., Summons, R. E., Hayes, J.M., Walter, M. R. (1999). Terminal Proterozoic mid-shelf benthic microbial mats in the Centralian Superbasin and their environmental significance. Geochimica et Cosmochimica Acta, 63(9), 1345-1358.

Logan, G.A., Hinman, M.C., Walter, M.R., Summons, R.E. (2001). Biogeochemistry of the $1640 \mathrm{Ma}$ McArthur River (HYC) lead-zinc ore and host sediments, Northern Territory, Australia. Geochimica et Cosmochimica Acta, 65(14), 2317-2336. 
Lu, H., Peng, P. A., Sun, Y. (2003). Molecular and stable carbon isotopic composition of monomethylalkanes from one oil sand sample: source implications. Organic Ggeochemistry, 34(6), 745-754.

Lu, Y., Wei, X. Y., Wen, Z., Chen, H. B., Lu, Y. C., Zong, Z. M., ... Zhao, Y. P. (2014). Photocatalytic depolymerization of rice husk over $\mathrm{TiO}_{2}$ with $\mathrm{H}_{2} \mathrm{O}_{2}$. Fuel Processing Technology, Volume 117, January 2014, Pages 8-16, ISSN 0378-3820, http://dx.doi.org/10.1016/j.fuproc.2013.04.001.

Mead, R., Xu, Y., Chong, J., Jaffé, R. (2005). Sediment and soil organic matter source assessment as revealed by the molecular distribution and carbon isotopic composition of $n$-alkanes. Organic Geochemistry, 36(3), 363-370.

Morgan, E.D., Jungnickel, H., Keegans, S. J., Do Nascimento, R.R., Billen, J., Gobin, B., Ito, F. (2003). Comparative survey of abdominal gland secretions of the ant subfamily Ponerinae. Journal of Chemical Ecology, 29(1), 95-114.

Nadaf, M., Halimi, M., Nasrabadi, M. (2013). Identification of compounds in nonpolar extract Ziziphora persica growing in Iran by GC-MS. Middle-East Journal of Scientific Research, 13(2), 187-190.

Nelson, D.R., Dillwith, J. W., Blomquist, G.J. (1981). Cuticular hydrocarbons of the house fly, Musca domestica. Insect Biochemistry, 11(2), 187-197.

Neto, R., Mead, R.N., Louda ,W., and Jaffé, R. (2006). Organic biogeochemistry of detrital flocculent material (floc) in a subtropical, coastal wetland. Biogeochemistry 77:283-304.

Nooner, D. W., Oro, J., Cerbulis, J. (1973). Paraffinic hydrocarbon composition of earthworms (Lumbricus terrestris). Lipids, 8(9), 489-492.

Olufunke, M. D., Zaki, F. U. (2013). Chemical Constituents of the Leaf, Stem-bark and Root Essential oils of Antiaris africana. Journal of Applied Pharmaceutical Science, Vol, 3(06), 168-171.

Oró, J., Gelpi, E. (1969). Gas-Chromatographic Mass-Spectrometric Studies on the Isoprenoids and Other Isomeric Alkanes in Meteorites. Springer Netherlands, pp. 518523.

Parenteau M.N., Jahnke L.L., Green S.J., Boomer S.M., Pierson B.K. (2010). Marine Chloroflexus-like organisms synthesize mid-chain branched monomethylalkanes. In: Astrobiology Science Conference. Lunar and Planetary Institute, Houston Texas, pp. No. 5336. 
Patricia Manzano, S., Migdalia, M., Juan Abreu, P., Mario, S., Víctor, H., \& Esther, P. (2013). Gas chromatography-mass spectrometry study from the leaves fractions obtained of Vernonanthura patens (Kunth) H. Rob. International Journal of Organic Chemistry, 3, 105.

Peschke, K., Metzler, M. (1987). Cuticular hydrocarbons and female sex pheromones of the rove beetle, Aleochara curtula (Goeze)(Coleoptera: Staphylinidae). Insect Biochemistry, 17(1), 167-178.

Phillips, M. (1997). Method for the collection and assay of volatile organic compounds in breath. Analytical Biochemistry, 247(2), 272-278.

Pisani, O., Louda, W., Jaffé, R. (2013). Biomarker assessment of spatial and temporal changes in the composition of flocculent material (floc) in the subtropical wetland of the Florida Coastal Everglades. Environmental Chemistry, 10(5) 424-436.

Regnier, F.E., Nieh, M., Hölldobler, B. (1973). The volatile Dufour's gland components of the harvester ants Pogonomyrmex rugosus and $P$. barbatus. Journal of Insect Physiology, 19(5), 981-992.

Richardson, C.J. (2010). The Everglades: North America's subtropical wetland. Wetlands Ecology and Management, 18(5), 517-542.

Robinson, N., Eglinton, G. (1990). Lipid chemistry of Icelandic hot spring microbial mats. Organic Geochemistry, 15(3), 291-298.

Rosy, B.A., Rosakutty, P.J. (2012). GC-MS analysis of methanol wild plant and callus extracts from three Cissus species, Family Vitaceae. Journal of Chemical and Pharmaceutical Research, 2012, 4 (7): 3420-3426.

Rzama, A., Benharref, A., Arreguy, B., Dufourc, E.J. (1995). Volatile compounds of green microalgae grown on reused waste water. Phytochemistry, 38(6), 1375-1379.

Schirmer, A., Rude, M.A., Li, X., Popova, E., Del Cardayre, S.B. (2010). Microbial biosynthesis of alkanes. Science, 329(5991), 559-562.

Shiea, J., Brassell, S.C., Ward, D. M. (1990). Mid-chain branched mono-and dimethyl alkanes in hot spring cyanobacterial mats: A direct biogenic source for branched alkanes in ancient sediments? Organic Geochemistry, 15(3), 223-231.

Siddiquee, S., Azad, S.A., Abu Bakar, F., Naher, L., Vijay Kumar, S. (2012). Separation and identification of hydrocarbons and other volatile compounds from cultures of Aspergillus niger by GC-MS using two different capillary columns and solvents. Journal of Saudi Chemical Society. http://dx.doi.org/10.1016/j.jscs.2012.02.007. 
Summons, R. E. (1987). Branched alkanes from ancient and modern sediments: isomer discrimination by $\mathrm{GC} / \mathrm{MS}$ with multiple reaction monitoring. Organic Geochemistry, 11(4), 281-289.

Summons, R.E., Powell, T.G., Boreham, C.J. (1988). Petroleum geology and geochemistry of the Middle Proterozoic McArthur Basin, Northern Australia: III. Composition of extractable hydrocarbons. Geochimica et Cosmochimica Acta, 52(7), 1747-1763.

Thijsse, G.J., Zwilling-De Vries, J.T. (1959). The oxidation of straight and branched alkanes by Pseudomonas strains. Antonie van Leeuwenhoek, 25(1), 332-336.

Turpin, B.J., Saxena, P., Andrews, E. (2000). Measuring and simulating particulate organics in the atmosphere: problems and prospects. Atmospheric Environment, 34(18), 2983-3013. 


\section{CHAPTER IV}

IDENTIFICATION OF A SERIES OF LONG-CHAIN ALKYL

HYDROXYCINNAMATES FROM TWO SPECIES OF CATTAIL (TYPHA

DOMINGENSIS P., AND TYPHA LATIFOLIA L.) 


\subsection{Abstract}

Several long-chain $n$-alkyl coumarates and ferulates were identified in cattails (Typha domingensis and Typha latifolia) from the Florida Everglades. Characterization of these compounds was achieved based on the interpretation of mass spectra obtained by GCMS as their trimethylsilyl ether derivatives, comparison with published mass spectra and available standards. Both $n$-alkyl $p$-coumarates and $n$-alkyl ferulates were identified in roots and leaves of both Typha species, featuring unique distribution patterns and differences between leaf and root biomass. For both Typha species, roots have higher concentrations and a much greater diversity of $n$-alkyl $p$-coumarates and ferulates but with different side chain carbon numbers ranging from $\mathrm{C}_{14}$ to $\mathrm{C}_{28}$. Typha domingensis leaves only contained $n$-alkyl ferulates with traces of $n$-alkyl $p$-coumarates, while both types of compounds were present in Typha latifolia leaf material. These biomarkers were not found in the other dominant wetland vegetation, which suggests their potential for application as molecular markers of cattails in the Everglades ecosystem. The long-chain $n$-alkyl $p$-coumarates and ferulates were present in coarse cattail detritus, but featuring a different composition, indicative of early diagenetic trans-esterification.

\subsection{Introduction}

Cattails, invasive aquatic plants, make up the genus Typha of the family Typhaceae, and are common wetland plants (Gallardo-Williams et al., 2002). Because of their size, growth habits, adaptability to surrounding environmental conditions, and release of compounds that can prevent the growth of other plants, they can expand into areas that were previously occupied by other species (Gallardo et al., 1998). There are ten 
species in the Typha genus. Two Typha species, namely Typha latifolia L. and the southern cattail Typha domingensis P. are found in the Florida Everglades (Lakela and Long, 1976). These monotypic Typha species readily cover a significant portion (over 11,000 ha) of the Everglades ecosystem, and have also become one of the most dominant emergent aquatic plants in Florida public waters (Schardt, 1997). Cattails can quickly inhabit disturbed areas (particularly those enriched in phosphorus) and ultimately reduce biodiversity and productivity of wetland systems.

While little is known about the natural products chemistry of cattails, several previous studies have focused on characterizing their biologically active substances, especially the production of phytotoxic compounds, in order to better understand the highly invasive (allelopathic) properties of this plant species. In this respect, a variety of compounds have been isolated and characterized, including eleven phenolic compounds identified in female flowers of T. latifolia (Ozawa and Imagawa, 1988), a new flavonol glucoside, three steroids and three fatty acids in extracts of T. latifolia (Ishida et al., 1988; Aliotta et al., 1990), several free and acyl glucosylated stigmasterols in T. latifolia (Della Greca et al., 1990a), two carotenoid-like compounds in extracts of T. latifolia (Della Greca et al., 1990b), 2-chlorophenol and salicyl aldehyde in T. domingensis (Gallardo et al., 1998), and others. Some of these compounds were indeed proven to have allelopathic properties.

However, cattail-specific biomarkers, to be applied as geochemical tracers in organic geochemistry, have to our best knowledge not been reported. Thus, this study describes the molecular characteristics and abundances of a few components of lipid extracts of cattail biomass (leaf and root materials), which were detected in reasonably 
high abundance, but were absent in other typical Everglades wetland biomass. These include 34 different $n$-alkyl-p-coumarates and $n$-alkyl ferulates that were observed in extracts from leaves and roots of the two most dominant cattail species in the Florida Everglades, T. latifolia and T. domingensis.

\subsection{Samples and Methods}

\subsubsection{Site description and samples}

Fresh cattail samples (Typha domingensis P., and Typha latifolia L.) were collected in the water conservation area (WCA-3A/B; Bruland et al., 2007), near a tree island between 2011 and 2013. Senescent cattail (T. domingensis) leaves including those above and below the water surface, and coarse detrital materials underneath cattail stands, were collected at a cattail enriched area. Dominant Everglades wetland plants and algae such as Cladium, Eleocharis, Nymphaeaceae, Utricularia, Chara, and periphyton were also sampled randomly from the same general area mentioned above. Plants (both leaves and roots) and periphyton were wrapped in aluminum foil immediately after collection and stored on ice. After transport to the laboratory, they were rinsed repeatedly with deionized water, freeze dried, crushed to a fine powder and kept frozen $\left(-20{ }^{\circ} \mathrm{C}\right)$ until analysis.

\subsubsection{Sample extraction and analyses}

The lipids were extracted following a modification of the method reported by Folch et al. (1957). Briefly, freeze dried biomass ( 1 to $2 \mathrm{~g}$ ) was subjected to three consecutive ultrasonic extractions $(30 \mathrm{~min}$ each) with pure dichloromethane (DCM; 
Optima, Fisher, USA) as solvent. Activated copper was added during the extraction to eliminate elemental sulfur (for detritus and floc). Total extracts were concentrated by rotary evaporation. Each extract was further fractionated by silica gel adsorption chromatography (Jaffé et al., 2001) with a solvent polarity gradient, to obtain saturated hydrocarbons (hexane eluent), aromatic hydrocarbons (hexane: toluene 15:5; v:v), wax esters (hexane: toluene 10:10; v:v), methyl esters (hexane: ethyl acetate 19:1; v:v), ketones/aldehydes (hexane: ethyl acetate 18:2; v:v), long chain alcohols (hexane: ethyl acetate 17:3; v:v), short-chain alcohols/sterols (hexane: ethyl acetate 16:4; v:v), and polar compounds (methanol). The alcohol and sterol fractions were derivatized with N, Obis(trimethylsilyl)trifluoroacetamide (BSTFA). Unfractionated total lipid extracts were also derivatized with BSTFA. A known amount of squalane was added as internal standard to the total lipid extract and to the alcohol/sterol fractions for quantification. GC-MS analyses were performed on a Hewlett-Packard 6890 GC coupled to a HP 5973 MSD system, and fitted with a Rtx-5 capillary column (30 m long, $0.25 \mathrm{~mm}, 0.25 \mu \mathrm{m}$ film thickness; Restek, USA). Compound identifications were based on comparisons with published mass spectra, a commercially available standard ( $n$-docosyl E-ferulate was

purchased from the U.S. Pharmacopeial Convention, Reference Standards), and interpretation of mass spectra.

\subsection{Results and Discussion}

\subsubsection{Identification of n-Alkyl ferulates and p-coumarates in fresh cattails}

Phenylpropanoid esters (e.g., alkyl ferulates, I, and coumarates, III; structures with Roman numerals are shown in Fig. 4.1) are components of suberins and cutins, and 
occur as wax esters in epicuticular waxes of numerous plants (e.g., Griffiths et al., 1999; Whitaker et al., 2001; Jetter et al., 2002; del Río et al., 2004; Lee et al., 2004; Cefarelli et al., 2005). They can occur as phenylpropanoid acid esters (e.g., coumaric acid, ferulic acid, etc.) or phenylpropanoid alcohol esters (e.g., coumaryl alcohol, ferulyl alcohol) coupled to the respective fatty alcohol or fatty acid. Alkyl hydroxycinnamate esters, one type of phenylpropanoid acid ester, are believed to form though esterification between a fatty alcohol and the phenylpropanoid acid (Dixon et al., 2002; Millar and Kunst, 1997). Alkyl hydroxycinnamate esters are typically ferulic, coumaric, or caffeic acids, esterified to fatty alcohols.<smiles>[R]OC(=O)/C=C/c1ccc(O)c(OC)c1</smiles>

I. E-Ferulic acid, $\mathrm{R}=\mathrm{H}$ Alkyl E-ferulates, $\mathrm{R}=\left(\mathrm{CH}_{2}\right)_{\mathrm{n}} \mathrm{CH}_{3}, \mathrm{n}=16-28$<smiles>[R]OC(=O)/C=C/c1ccc(O)cc1</smiles>

III. E-p-coumaric acid, $\mathrm{R}=\mathrm{H}$ Alkyl E-p-coumarates, $\mathrm{R}$ as in I<smiles>[R]OC(=O)/C=C\c1ccc(O)c(OC)c1</smiles>

II. Z-Ferulic acid, $\mathrm{R}=\mathrm{H}$ Alkyl Z-ferulates, $R$ as in I<smiles>[R]OC(=O)/C=C\c1ccc(O)cc1</smiles>

IV. Z-p-coumaric acid, R=H Alkyl Z-p-coumarates, $\mathrm{R}$ as in I

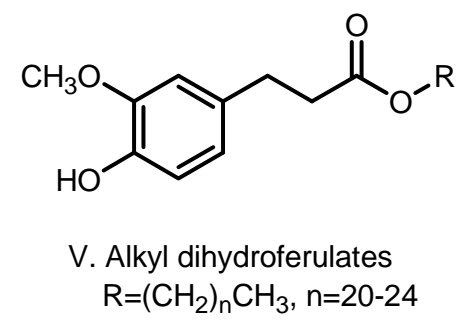

Figure 4.1 Chemical structures of the ferulic and $p$-coumaric acids and esters. 
A series of alkyl ferulates (I) and alkyl dihydroferulates (V) with the alcohol moieties of $\mathrm{C}_{20}, \mathrm{C}_{22}$ and $\mathrm{C}_{24}$ for both types of structures were found in soils of Corvallis, OR (Medeiros et al., unpublished results), and similar types of $n$-alkyl ferulate compounds with different carbon number homologues have been reported in a few other plant species (Table 4.1) such as: (1) Vine and root latex of sweet potato (Snook et al., 1994) featuring alkyl coumarates and ferulates with the alcohol moieties of $C_{15}, C_{17}$ and $\mathrm{C}_{19}$; (2) Leaf fibers of abaca contain $n$-alkyl ferulates with $n$-fatty alcohol moieties of $\mathrm{C}_{20}$ $\mathrm{C}_{28}$, and $n$-alkyl $p$-coumarates with $n$-fatty alcohol moieties of $\mathrm{C}_{22}$ and $\mathrm{C}_{24}$ (del Río et al., 2004); (3) Roots of Ipomoea batatas (Kawanishi et al., 1990) with alkyl ferulates and $\mathrm{C}_{15}$, $\mathrm{C}_{16}, \mathrm{C}_{17}$ alcohol moieties; (4) Potato pulp and periderm with alkyl ferulates and $\mathrm{C}_{16}-\mathrm{C}_{31}$ alcohol moieties (Yunoki et al., 2004; Schreiber et al., 2005; Serra et al., 2010); (5) Agave sisalana with alkyl ferulates and $\mathrm{C}_{20}-\mathrm{C}_{30}$ alcohol moieties (Gutiérrez et al., 2008); and others. A specific ferulate, i.e. hexacosyl E-ferulate, was reported in oats and assumed to function as an antioxidant (Daniels and Martin, 1967). Due to their potential physiological functions such as antimicrobial or antioxidant activities in food, cosmetic and pharmaceutical formulations (Baranowski and Nagel, 1984; Ou and Kwok, 2004; Tapia et al. 2004), it is of interest to further explore the distribution of alkyl hydroxycinnamates (alkacins) in plants. 
Table 4.1 Alkyl hydroxycinnamates occurrence in plant kingdom.

\begin{tabular}{|c|c|c|c|c|c|}
\hline Organism & Tissue & $\begin{array}{l}\text { Sample } \\
\text { locations }\end{array}$ & Compound class & $\begin{array}{c}\text { Alcohol } \\
\text { chain } \\
\text { length }\end{array}$ & References \\
\hline Acacia sp. & $\begin{array}{l}\text { Periderm } \\
\text { (bark) }\end{array}$ & $\begin{array}{l}\text { Aveiro, } \\
\text { Portugal }\end{array}$ & $\begin{array}{c}\text { Alkyl caffeates } \\
\text { Alkyl ferulates } \\
\text { Alkyl coumarates }\end{array}$ & $\mathrm{C}_{16}-\mathrm{C}_{28}$ & Freire et al., 2007 \\
\hline Agave sisalana & Leaf fiber & $\begin{array}{l}\text { Tortosa, } \\
\text { Spain }\end{array}$ & $\begin{array}{l}\text { Alkyl ferulates } \\
\text { Alkyl caffeates }\end{array}$ & $\mathrm{C}_{20}-\mathrm{C}_{30}$ & $\begin{array}{c}\text { Gutiérrez et al., } \\
2008\end{array}$ \\
\hline $\begin{array}{l}\text { Arabidopsis } \\
\text { thaliana }\end{array}$ & $\begin{array}{c}\text { Root } \\
\text { Surface } \\
\text { (periderm) }\end{array}$ & N.A. & $\begin{array}{c}\text { Alkyl ferulates } \\
\text { Alkyl coumarates }\end{array}$ & $\mathrm{C}_{18}-\mathrm{C}_{22}$ & $\begin{array}{c}\text { Li et al., 2007; } \\
\text { Molina et al., } 2009\end{array}$ \\
\hline $\begin{array}{c}\text { Crepis } \\
\text { taraxacifolia }\end{array}$ & Root wax & N.A. & Alkyl coumarates & $\mathrm{C}_{20}$ & Kisiel et al., 1995 \\
\hline Hedera helix & Leaf wax & N.A. & Alkyl coumarates & $\mathrm{C}_{18}-\mathrm{C}_{32}$ & Santos et al., 2007 \\
\hline $\begin{array}{l}\text { Ipomoea } \\
\text { batatas }\end{array}$ & $\begin{array}{l}\text { Vine and } \\
\text { root latex }\end{array}$ & Japan; USA & $\begin{array}{c}\text { Alkyl ferulates } \\
\text { Alkyl coumarates }\end{array}$ & $\begin{array}{c}\mathrm{C}_{15}-\mathrm{C}_{17} \\
\mathrm{C}_{19}\end{array}$ & $\begin{array}{c}\text { Kawanishi et al., } \\
\text { 1990; Snook et al., } \\
1994\end{array}$ \\
\hline $\begin{array}{l}\text { Larix } \\
\text { kaempferi }\end{array}$ & Stem bark & Japan & $\begin{array}{c}\text { Alkyl ferulates } \\
\text { Alkyl coumarates }\end{array}$ & $\mathrm{C}_{22}-\mathrm{C}_{26}$ & Ohtsu et al., 1998 \\
\hline Musa textilis & Leaf fiber & N.A. & $\begin{array}{c}\text { Alkyl ferulates } \\
\text { Alkyl coumarates }\end{array}$ & $\mathrm{C}_{20}-\mathrm{C}_{28}$ & Del Río et al., 2004 \\
\hline $\begin{array}{c}\text { Picea } \\
\text { ajanensis, } P . \\
\text { koraiensis, and } \\
\text { P. obovata }\end{array}$ & Bark & N.A. & $\begin{array}{c}\text { Alkyl ferulates } \\
\text { Alkyl coumarates }\end{array}$ & $\mathrm{C}_{16}-\mathrm{C}_{24}$ & $\begin{array}{c}\text { Gromova et al., } \\
1976\end{array}$ \\
\hline $\begin{array}{l}\text { Solanum } \\
\text { tuberosum }\end{array}$ & Pulp & $\begin{array}{l}\text { Hokkaido, } \\
\text { Japan }\end{array}$ & Alkyl ferulates & $\mathrm{C}_{16}-\mathrm{C}_{30}$ & Yunoki et al., 2004 \\
\hline $\begin{array}{l}\text { Solanum } \\
\text { tuberosum }\end{array}$ & $\begin{array}{l}\text { Periderm } \\
\text { (wound) }\end{array}$ & $\begin{array}{l}\text { Bonn, } \\
\text { Germany; } \\
\text { N.A. }\end{array}$ & Alkyl ferulates & $\mathrm{C}_{18}-\mathrm{C}_{31}$ & $\begin{array}{l}\text { Schreiber et al., } \\
\text { 2005; Serra et al., } \\
2010\end{array}$ \\
\hline $\begin{array}{c}\text { Typha } \\
\text { domingensis }\end{array}$ & $\begin{array}{l}\text { Leaf, root, } \\
\text { detritus }\end{array}$ & Florida, USA & $\begin{array}{c}\text { Alkyl ferulates } \\
\text { Alkyl coumarates }\end{array}$ & $\mathrm{C}_{14}-\mathrm{C}_{28}$ & This study \\
\hline Typha latifolia & Leaf, root & Florida, USA & $\begin{array}{c}\text { Alkyl ferulates } \\
\text { Alkyl coumarates }\end{array}$ & $\mathrm{C}_{14}-\mathrm{C}_{22}$ & This study \\
\hline
\end{tabular}

N.A. $=$ not available. 
Here, a series of $n$-alkyl E-ferulates (I), with $\mathrm{C}_{16}$ to $\mathrm{C}_{28}$ alkyl moieties, was detected in the polar (alcohol, F7) fractions of the cattails, with both even and odd carbon numbered homologues, as well as one Z-hexadecyl ferulate (II, Figs. 4.2 and 4.3, Table 4.2). $n$-Alkyl ferulates with odd numbered carbon chains and $n$-alkyl Z-ferulates have rarely been reported before (Baldé et al., 1991; Del Río et al., 2004). The mass spectra of two selected $n$-alkyl ferulates (E-hexadecyl ferulate, I, and Z-hexadecyl ferulate, II) are shown in Fig. 4.4. On the basis of the mass spectra themselves, it is difficult to differentiate trans and cis isomers. However, on the basis of the elution order, where the trans-isomer elutes at longer retention times compared to the cis-isomer, and the concentration difference where the trans-isomers are usually more abundant than the cisisomers (Snook et al., 1994; del Río et al., 2004), these isomers can be tentatively assigned. 


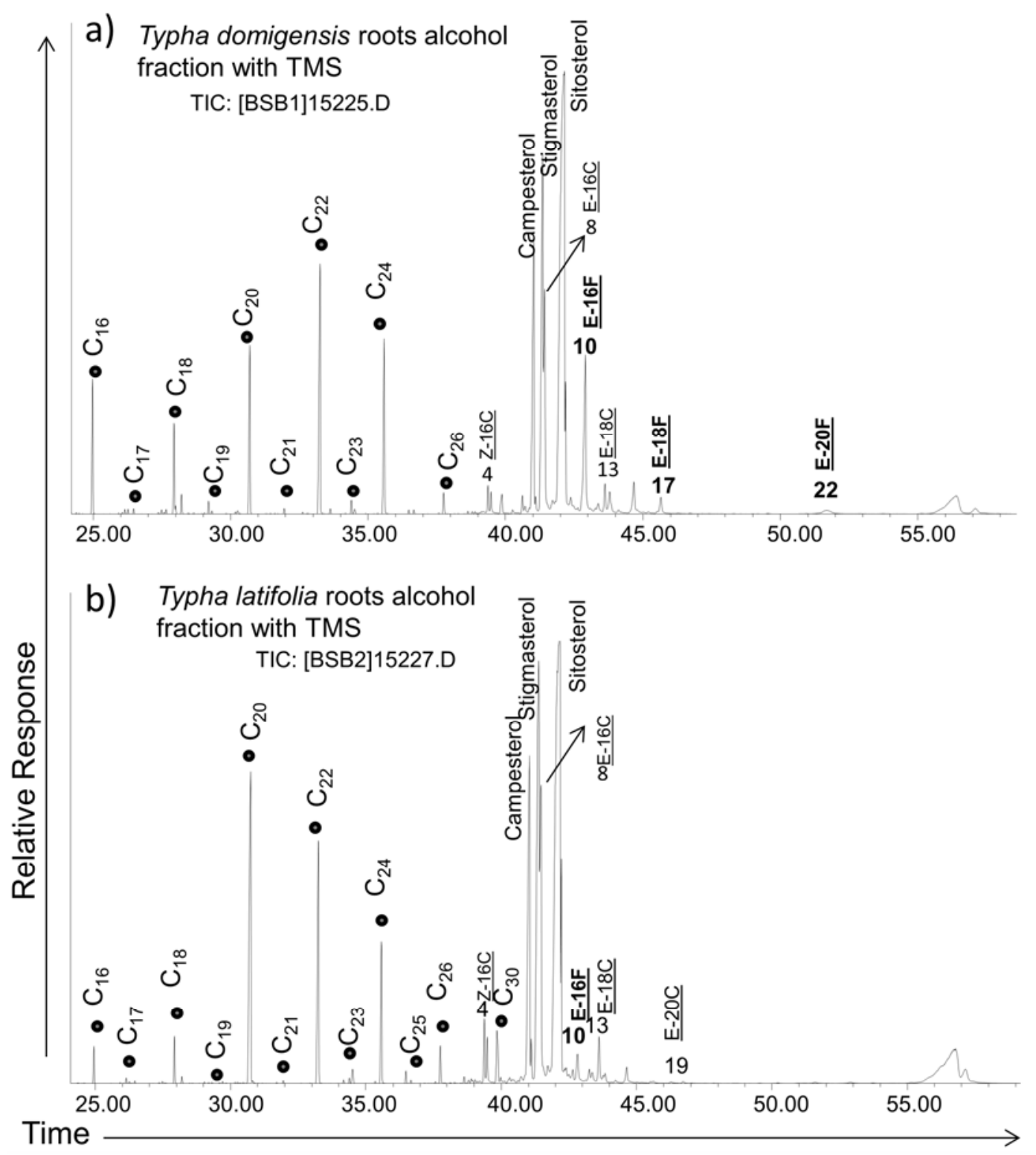

Figure 4.2 Mass-chromatogram (partial, total ion total ion current, TIC trace) of alcohol fractions from fresh cattail species.

Note: $n$-alcohols are represented by dots, alkyl-ferulates and alkyl-p-coumarates are marked by numbers, E-nF ( $\mathrm{n}=$ number of alcohol moieties) means trans- $n$-alkyl-ferulate, $\mathrm{E}-\mathrm{nC}(\mathrm{n}=$ number of alcohol moieties) means trans- $n$-alkyl-coumarate. 

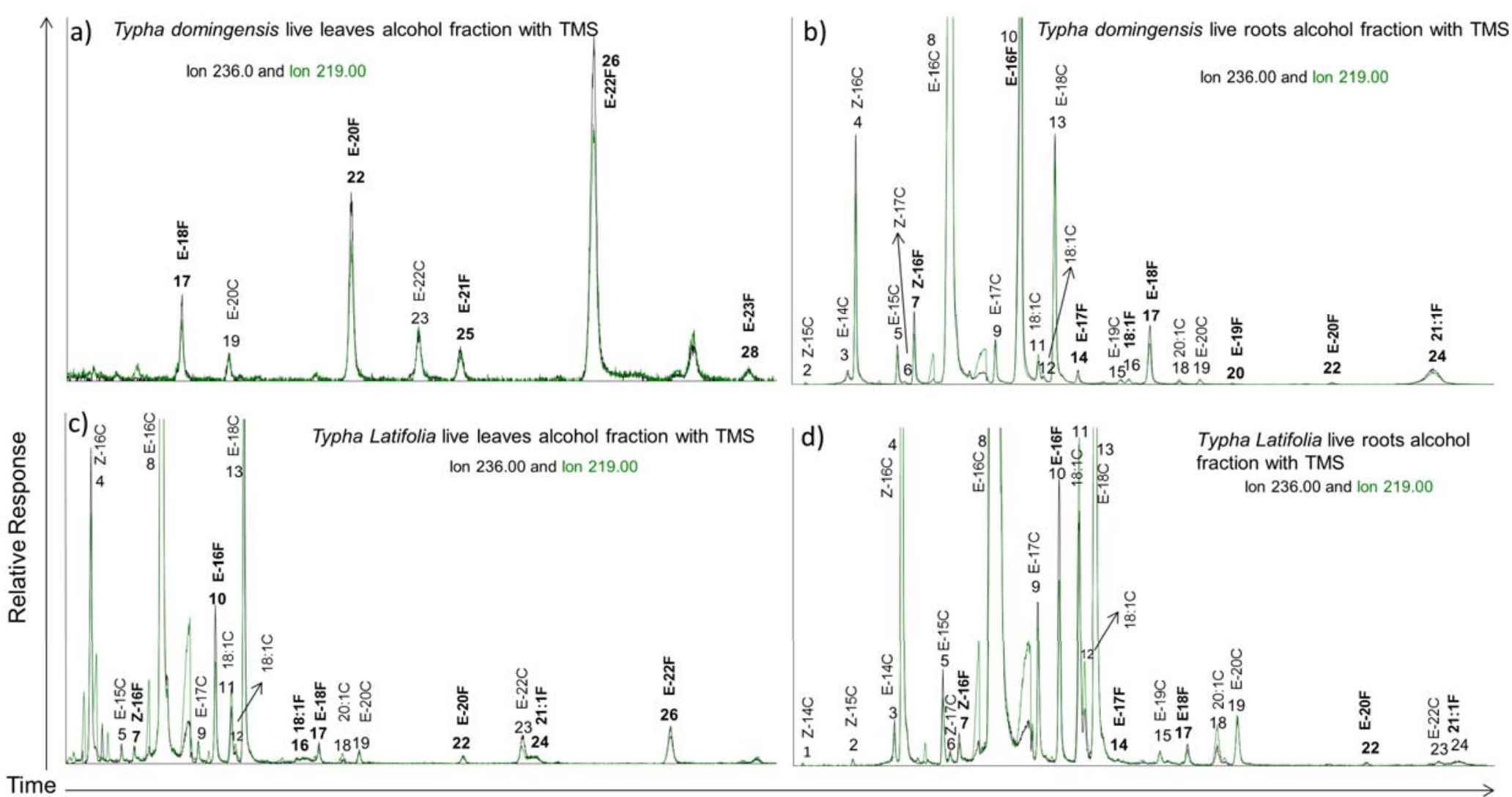

Figure 4.3 Mass-chromatogram of alcohol fractions (ion 236/219 extracted) from fresh cattail species to show alkyl ferulates and alkyl $p$-coumarates.

Note: Alkyl- $p$-coumarates and alkyl-ferulates were listed by elution order from no. 1 to 34 . Alkyl-ferulates and alkyl- $p$-coumarates are marked by numbers, E- $\mathrm{nF}(\mathrm{n}=$ number of alcohol moieties) means trans- $n$-alkyl-ferulate, E- $\mathrm{nC}(\mathrm{n}=$ number of alcohol moieties) means trans- $n$-alkyl-coumarate. The structure and name of each marked compound are shown in Figure 4.1, Table 4.1 and 4.2 . 
Table 4.2 Alkyl-ferulate distributions in leaves, roots and detritus from Typha domingensis P., and Typha latifolia L.

\begin{tabular}{|c|c|c|c|c|c|c|c|c|c|c|}
\hline $\begin{array}{c}\text { Compound } \\
\text { No. }\end{array}$ & Ferulates & $\begin{array}{l}\text { Underi } \\
\text { vatize } \\
\text { d MW }\end{array}$ & $\begin{array}{l}\text { TMS } \\
\text { ether } \\
\text { MW }\end{array}$ & $\begin{array}{c}\text { Typha } \\
\text { domingens } \\
\text { is leaves } \\
(\mu \mathrm{g} / \mathrm{gdw} \\
\mathrm{n}=3)\end{array}$ & $\begin{array}{c}\text { Typha } \\
\text { domingensis } \\
\text { roots } \\
(\mu \mathrm{g} / \mathrm{gdw} \\
\mathrm{n}=3)\end{array}$ & $\begin{array}{c}\text { Typha } \\
\text { latifolia } \\
\text { leaves } \\
(\mu \mathrm{g} / \mathrm{gdw} \\
; \mathrm{n}=3)\end{array}$ & $\begin{array}{c}\text { Typha } \\
\text { latifolia } \\
\text { roots } \\
(\mu \mathrm{g} / \mathrm{gdw} \\
; \mathrm{n}=3)\end{array}$ & $\begin{array}{c}\text { Typha } \\
\text { domingen } \\
\text { sis above } \\
\text { water } \\
(\mathrm{dead}) \\
(\mu \mathrm{g} / \mathrm{gdw} ; \\
\mathrm{n}=2)\end{array}$ & $\begin{array}{c}\text { Typha } \\
\text { domingen } \\
\text { sis below } \\
\text { water } \\
(\mathrm{dead}) \\
(\mu \mathrm{g} / \mathrm{gdw} ; \\
\mathrm{n}=2)\end{array}$ & $\begin{array}{c}\text { Typha } \\
\text { domingen } \\
\text { sis detritus } \\
(\mathrm{dead}) \\
(\mu \mathrm{g} / \mathrm{gdw} ; \\
\mathrm{n}=1)\end{array}$ \\
\hline 7 & Z-Hexadecyl ferulate & 418 & 490 & - & 9.79 & 0.28 & 0.69 & - & - & - \\
\hline 10 & E-Hexadecyl ferulate & 418 & 490 & - & 138.01 & 3.04 & 7.28 & - & - & 9.57 \\
\hline 14 & E-Heptadecyl ferulate & 432 & 504 & - & 1.66 & - & 0.10 & - & - & - \\
\hline 16 & Octadecenyl ferulate & 444 & 516 & - & 1.18 & 0.17 & - & - & - & - \\
\hline 17 & E-Octadecyl ferulate & 446 & 518 & - & 12.79 & 0.47 & 0.82 & 4.26 & - & 13.98 \\
\hline 20 & E-Nonadecyl ferulate & 460 & 532 & - & 0.21 & - & - & 0.23 & - & 0.52 \\
\hline 22 & E-Eicosyl ferulate & 474 & 546 & 2.93 & 0.50 & 0.30 & 0.15 & 9.06 & 3.84 & 48.83 \\
\hline 24 & Eicosenyl ferulate & 486 & 558 & - & 13.21 & 0.36 & 0.45 & - & - & - \\
\hline 25 & E-Heneicosyl ferulate & 488 & 560 & 0.56 & - & - & - & 1.12 & 0.54 & 6.11 \\
\hline 26 & E-Docosyl ferulate & 502 & 574 & 7.53 & - & 1.82 & - & 20.86 & 10.22 & 97.85 \\
\hline 28 & E-Tricosyl ferulate & 516 & 588 & 0.22 & - & - & - & 0.35 & 0.23 & 1.41 \\
\hline 29 & E-Tetracosyl ferulate & 530 & 602 & - & - & - & - & 20.04 & 7.88 & 69.25 \\
\hline 31 & E-Pentacosyl ferulate & 544 & 616 & - & - & - & - & 0.82 & 0.37 & 2.10 \\
\hline 32 & E-Hexacosyl ferulate & 558 & 630 & - & - & - & - & 32.19 & 9.67 & 74.24 \\
\hline 33 & E-Heptacosyl ferulate & 572 & 644 & - & - & - & - & 0.30 & - & 0.50 \\
\hline 34 & E-Octacosyl ferulate & 586 & 658 & - & - & - & - & 1.79 & 0.56 & 6.31 \\
\hline
\end{tabular}

Note: Compounds listed according to sequential retention time. $\mathrm{Z}(\mathrm{E})-\mathrm{C}_{\mathrm{n}}$-ferulate indicates the cis (trans)-n-alkyl- $p$ - ferulates; '-' $=$ not detected. Bold numbers $=$ most dominant alkyl-ferulates. 
Table 4.3 Alkyl-p-coumarate distributions in leaves, roots and detritus from Typha domingensis P., and Typha latifolia L.

\begin{tabular}{|c|c|c|c|c|c|c|c|c|c|c|}
\hline $\begin{array}{c}\text { Compound } \\
\text { No. }\end{array}$ & $p$-Coumarates & $\begin{array}{c}\text { Underivatized } \\
\text { MW }\end{array}$ & $\begin{array}{l}\text { TMS } \\
\text { ether } \\
\text { MW }\end{array}$ & $\begin{array}{c}\text { Typha } \\
\text { domingensis } \\
\text { leaves } \\
(\mu \mathrm{g} / \mathrm{gdw} ; \\
\mathrm{n}=3)\end{array}$ & $\begin{array}{c}\text { Typha } \\
\text { domingensis } \\
\text { roots } \\
(\mu \mathrm{g} / \mathrm{gdw} \\
\mathrm{n}=3)\end{array}$ & $\begin{array}{c}\text { Typha } \\
\text { latifolia } \\
\text { leaves } \\
(\mu \mathrm{g} / \mathrm{gdw} \\
\mathrm{n}=3)\end{array}$ & $\begin{array}{c}\text { Typha } \\
\text { latifolia } \\
\text { roots } \\
(\mu \mathrm{g} / \mathrm{gdw} \\
\mathrm{n}=3)\end{array}$ & $\begin{array}{c}\text { Typha } \\
\text { domingensis } \\
\text { above water } \\
\text { (dead) } \\
(\mu \mathrm{g} / \mathrm{gdw} ; \\
\mathrm{n}=2)\end{array}$ & $\begin{array}{c}\text { Typha } \\
\text { domingensis } \\
\text { below water } \\
\text { (dead) } \\
(\mu \mathrm{g} / \mathrm{gdw} ; \\
\mathrm{n}=2)\end{array}$ & $\begin{array}{c}\text { Typha } \\
\text { domingensis } \\
\text { detritus } \\
\text { (dead) } \\
(\mu \mathrm{g} / \mathrm{gdw} ; \\
\mathrm{n}=1)\end{array}$ \\
\hline 1 & Z-Tetradecyl coumarate & 360 & 432 & - & 0.13 & - & 0.05 & - & - & - \\
\hline 2 & Z-Pentadecyl coumarate & 374 & 446 & - & 0.65 & - & 0.13 & - & - & - \\
\hline 3 & E-Tetradecyl coumarate & 360 & 432 & - & 2.42 & - & 0.88 & - & - & - \\
\hline 4 & Z-Hexadecyl coumarate & 388 & 460 & - & 30.01 & 6.78 & 37.20 & - & - & - \\
\hline 5 & E-Pentadecyl coumarate & 374 & 446 & - & 7.57 & 0.25 & 2.17 & - & - & - \\
\hline 6 & Z-Heptadecyl coumarate & 402 & 474 & - & 0.87 & - & 0.29 & - & - & - \\
\hline 8 & E-Hexadecyl coumarate & 388 & 460 & - & 428.04 & 73.60 & 416.42 & - & - & - \\
\hline 9 & E-Heptadecyl coumarate & 402 & 474 & - & 6.37 & 0.39 & 3.59 & - & - & - \\
\hline 11 & Octadecenyl coumarate ${ }^{a}$ & 414 & 486 & - & 3.28 & 1.52 & 6.67 & - & - & - \\
\hline 12 & Octadecenyl coumarate ${ }^{b}$ & 414 & 486 & - & 0.39 & 0.18 & 0.86 & - & - & - \\
\hline 13 & E-Octadecyl coumarate & 416 & 488 & - & 41.76 & 10.05 & 37.69 & - & - & 2.91 \\
\hline 15 & E-Nonadecyl coumarate & 430 & 502 & - & 0.90 & - & 0.41 & - & - & - \\
\hline 18 & Eicosenyl coumarate & 442 & 514 & - & 0.89 & 0.23 & 0.65 & - & - & - \\
\hline 19 & E-Eicosyl coumarate & 444 & 516 & 0.30 & 1.00 & 0.31 & 1.85 & 1.14 & 0.68 & 4.51 \\
\hline 21 & E-Heneicosyl coumarate & 458 & 530 & - & - & - & - & 0.19 & 0.23 & 1.01 \\
\hline 23 & E-Docosyl coumarate & 472 & 544 & 0.80 & - & 1.11 & 0.35 & 2.42 & 1.83 & 10.42 \\
\hline 27 & E-Tetracosyl coumarate & 500 & 572 & - & - & - & - & 1.46 & 1.15 & 5.62 \\
\hline 30 & E-Hexacosyl coumarate & 628 & 600 & - & - & - & - & 1.15 & 0.76 & 2.72 \\
\hline
\end{tabular}


Note: Compounds listed according to sequential retention time. $\mathrm{Z}(\mathrm{E})-\mathrm{C}_{\mathrm{n}} \mathrm{p}$-coumarate indicates the cis (trans)- $n$-alkyl-pcoumarates; '-' = not detected. Bold numbers = most dominant alkyl- $p$-coumarates; "a,b" refers two isomers of octadecenyl coumarates. 
The mass spectra of hexadecyl E- and Z-ferulate-TMS (Fig. 4.4a, b) are characterized by an abundant molecular ion $\left(\mathrm{M}^{+}\right)$as the base peak and only a minor loss of $\mathrm{CH}_{3}$ (M-15, Fig. 4.5a). The loss of the alkyl group with transfer of $\mathrm{H}_{\text {from }} \mathrm{M}^{+}$yields the minor ferulic acid-TMS ion at $\mathrm{m} / z 266\left(\mathrm{C}_{13} \mathrm{H}_{18} \mathrm{O}_{4} \mathrm{Si}\right)$, which with subsequent loss of two $\mathrm{CH}_{3}$ forms the bridged dimethylsilyl ether ion at $\mathrm{m} / \mathrm{z} 236$ as reported in a previous study (Evershed et al., 1988). The direct cleavage of the carbonyl-alkoxy (ester) bond results in the second most intense ion at $\mathrm{m} / \mathrm{z} 249$ for the ferulyl-TMS moiety $\left(\mathrm{C}_{13} \mathrm{H}_{17} \mathrm{O}_{3} \mathrm{Si}\right)$, which in turn also eliminates two $\mathrm{CH}_{3} \cdot$ to form the bridged dimethylsilyl ether ion at $m / z 219$. The docosyl E-ferulate was confirmed by comparison with the $n$ docosyl E-ferulate standard as their TMS derivatives (Fig. 4.4c, d), showing excellent agreement. The distributions and concentrations of the alkyl ferulates in both leaf and root parts of Typha domingensis P. and Typha latifolia L. are given in Table 4.2. Higher concentrations of ferulates were found in roots of both species compared to the leaves. 


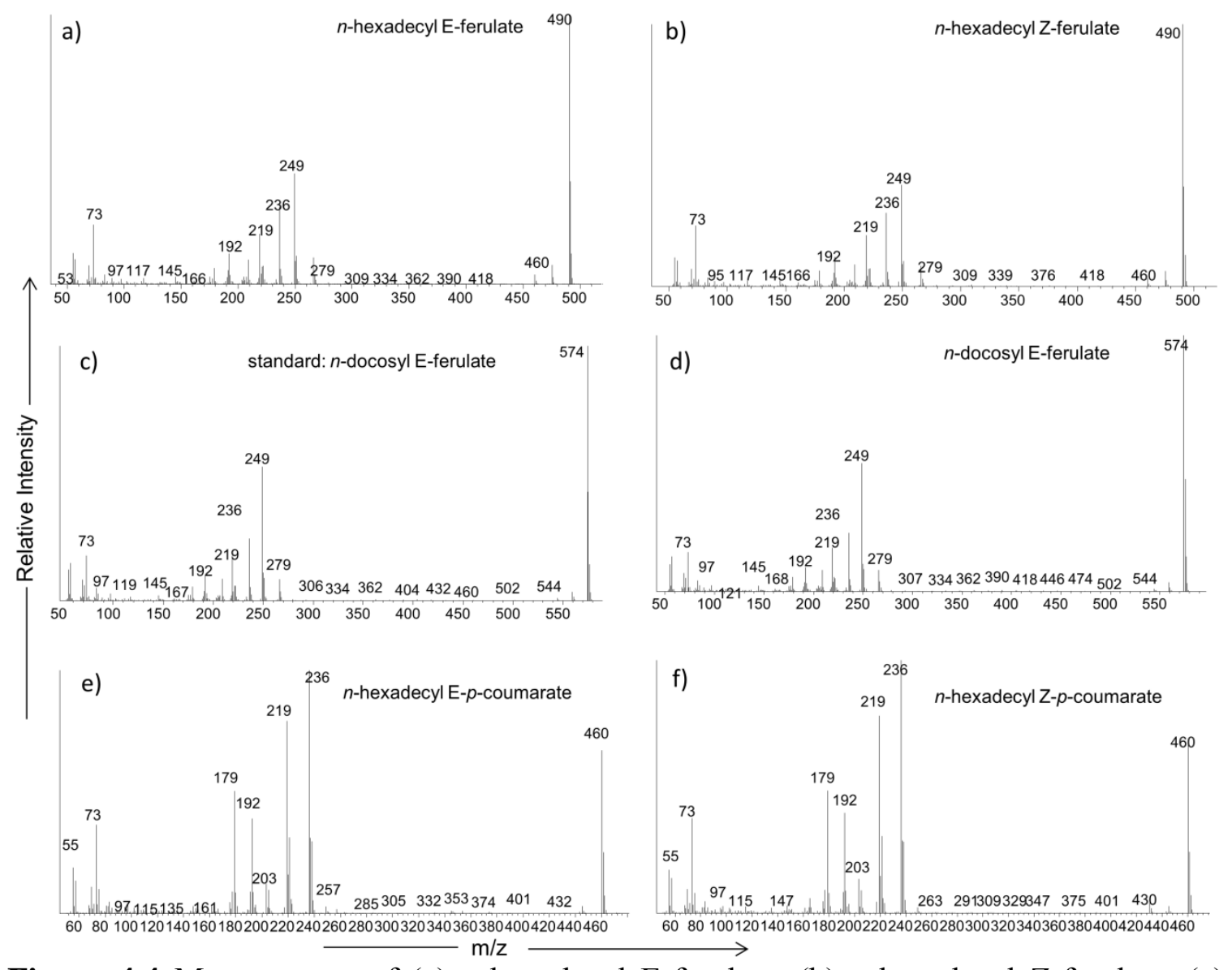

Figure 4.4 Mass spectra of (a) $n$-hexadecyl E-ferulate, (b) $n$-hexadecyl Z-ferulate, (c) standard: $n$-docosyl E-ferulate, (d) $n$-docosyl E-ferulate (e) $n$-hexadecyl E- $p$-coumarate, and (f) $n$-hexadecyl Z- $p$-coumarate. All compounds are TMS ether derivatives. 
(a)

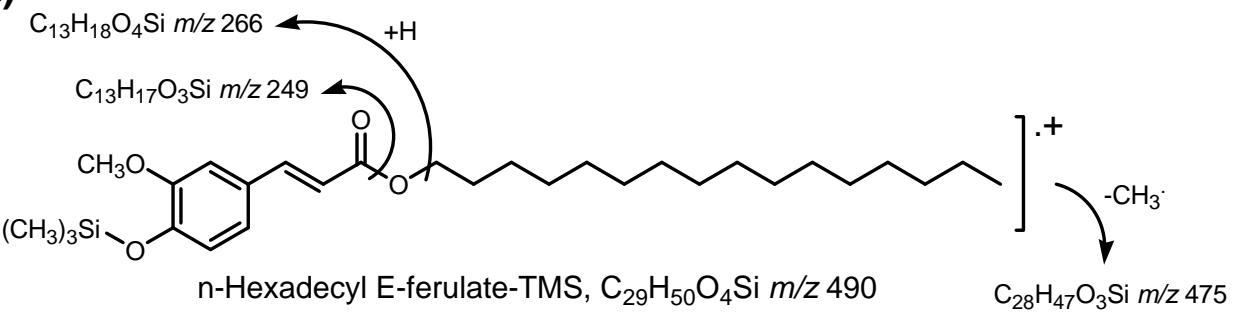

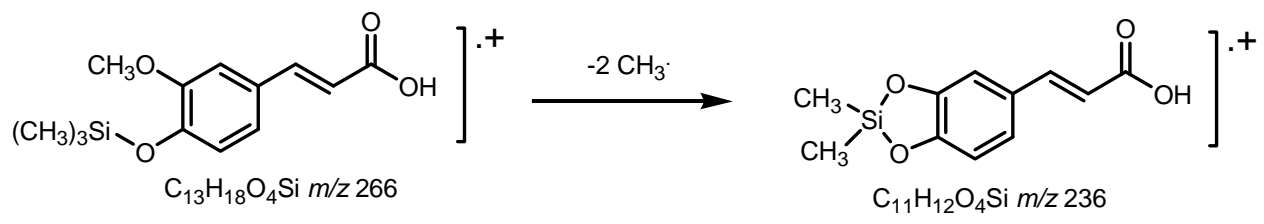

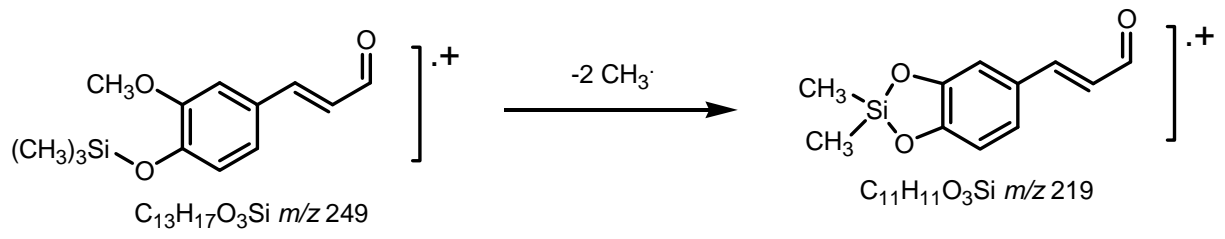

(b)
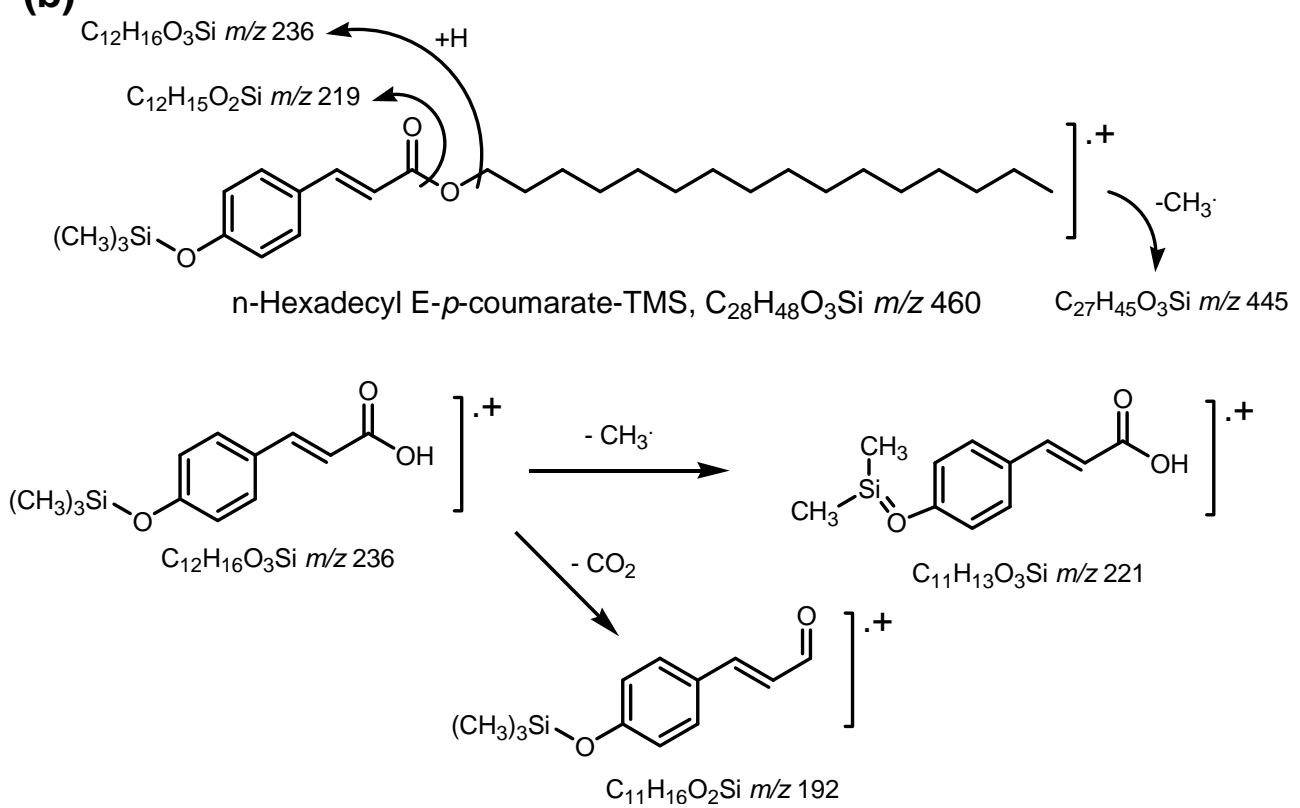

Figure 4.5 Interpretation of the mass spectrometric fragmentation pattern for: (a) $n$ hexadecyl E-ferulate-TMS, and (b) $n$-hexadecyl E- $p$-coumarate-TMS.

In contrast to the ferulates, more prominent series of $n$-alkyl E and Z-pcoumarates (III and IV) were detected with alkyl moieties ranging from $\mathrm{C}_{14}$ to $\mathrm{C}_{26}$, and both even and odd carbon homologues (Figs. 4.2 and 4.3, Table 4.3). The mass spectra 
were interpreted on the basis of comparison with literature reports and retention indices (Snook et al., 1994; Keriko et al, 1997; Del Rio et al., 2004; Cefarelli et al., 2005). The mass spectra of two representative compounds (hexadecyl E-p-coumarate and hexadecyl Z-p-coumarate; TMS ethers) are shown in Figure 4.4 e, f. They are characterized by intense molecular ions at $\mathrm{m} / \mathrm{z} 460$ with only a minor loss of $\mathrm{CH}_{3}$ (M-15, Fig. 4.5b). However, the base peak is at $\mathrm{m} / \mathrm{z} 236$, with other abundant ions at $\mathrm{m} / \mathrm{z} 221,219,192$ and 179 (Fig. 4.4 e, f). This base peak at $\mathrm{m} / z 236$ is formed by loss of the alkyl moiety with $\mathrm{H}$ transfer from $\mathrm{M}^{+}$yielding the $p$-coumaric acid-TMS ion. The ion at $m / z 219$ is the $p$ coumaroyl-TMS moiety from simple homolytic cleavage of the $p$-coumarate ester bond. The ion at $\mathrm{m} / \mathrm{z} 221$ can be rationalized by the mechanism proposed by Snook et al. (1994), where the loss of a $\mathrm{CH}_{3}$ from the silicon atom of the $o$-coumaric acid-TMS group yields an eight-member cyclic ion as $m / z 221\left(\mathrm{C}_{11} \mathrm{H}_{13} \mathrm{O}_{3} \mathrm{Si}\right)$. However, in the case of the $p$ coumaric acid isomer this mechanism is not favored and the ion at $\mathrm{m} / \mathrm{z} 221$ represents the simple loss of $\mathrm{CH}_{3}$ from the TMS group. The ion at $\mathrm{m} / z 192$ represents the loss of $\mathrm{CO}_{2}$ with retention of $\mathrm{H}$ from $p$-coumaric acid-TMS at $m / z 236$. The E- and Z-p-coumarate esters have essentially identical mass spectra (e.g., Fig. 4.4 e, f; Snook et al., 1994) but can be distinguished on the basis of their GC retention indices. As mentioned above for the alkyl fumarates, the elution order for the alkyl $p$-coumarates is the same, i.e. $\mathrm{Z}$ before E.

This $n$-alkyl-p-coumarate compound class (with different alcohol moieties, Table 4.1) has also been reported for other plants such as Ivy leaves (Santos et al., 2007), leaf fibers of abaca (del Río et al., 2004), vine and root latex of sweet potato (Snook et al., 1994), and others. Alkyl coumarates exhibit a wide range of biological activities such as 
phytotoxicity (Keriko et al., 1997), antibacterial effect against Pseudomonas fluorescens (Baranowski and Nagel, 1983), insect-resistance (Snook et al., 1994), antioxidant activities (Nidiry and Lokesha, 2013), and antifungal activity (Nidiry et al., 2011).

Among all $n$-alkyl ferulates and $p$-coumarates identified in fresh cattails (Tables 4.2 and 4.3), the E (trans)-isomers are dominant, and they are usually the common natural products. However, the $\mathrm{Z}$ (cis)-isomers can also be detected at lower retention times with lower abundances. These Z-isomers may form during extraction, because these compounds are light sensitive and can be transformed from trans-isomers (Faulds and Williamson, 1999). However, some Z (cis)-isomers have also been unambiguously identified and reported in plants such as Rosa rugosa (Hashidoko et al., 1992).

\subsubsection{Distribution of alkyl hydroxycinnamates in cattail: leaves vs. roots}

Both alkyl ferulates and alkyl $p$-coumarates were more abundant in live roots than in live leaves for both cattail species. Similar different lipid compositions between leaves and roots were also reported for some other plants growing in peatland (Huang et al., 2011). This different "fingerprint" of phenylpropanoid esters between cattail leaves and roots (for both species) could also be because of different local stress. The concept of stress-induced phenylpropanoid metabolism was introduced by Dixon and Paiva (1995), suggesting that different stresses such as high UV intensity, wounding, pathogen attack, low temperature, low ion strength, and nutrient limitations, may induce the biosynthesis of different types of phenylpropanoid esters. Actually, alkyl ferulate esters can be induced by injury and act directly as defense compounds or indirectly as precursors for the synthesis of other wound-induced polyphenolic barriers (Bernards and Lewis, 1992). 


\subsection{3n-Alkyl ferulates and p-coumarates in scenescent cattail and its detritus}

$n$-Alkyl ferulates and coumarates were also determined in senescent cattail leaves, roots and detritus from the cattail enriched area (only Typha domingensis was analyzed), and differences in composition and distribution were observed compared to fresh leaves (Figs. 4.6 and 4.7, Tables 4.2 and 4.3). Senescent cattail tissues and detritus samples featured higher molecular weight $n$-alkyl ferulates with longer alkyl chains ranging from $\mathrm{C}_{24}$ to $\mathrm{C}_{28}$, a dominance of the $\mathrm{C}_{22}, \mathrm{C}_{24}$ and $\mathrm{C}_{26}$ homologues and low concentrations of the homologues $<\mathrm{C}_{20}$. Also, senescent cattail and its detritus lack the presence of short chain alkyl $p$-coumarates from $\mathrm{C}_{14}$ to $\mathrm{C}_{18}$, while two longer chain alkyl $p$-coumarates $\left(\mathrm{C}_{24}\right.$ and $\mathrm{C}_{26}$ ) were observed in low abundance. These observations may be explained through trans-esterification reactions during decay (see below). 


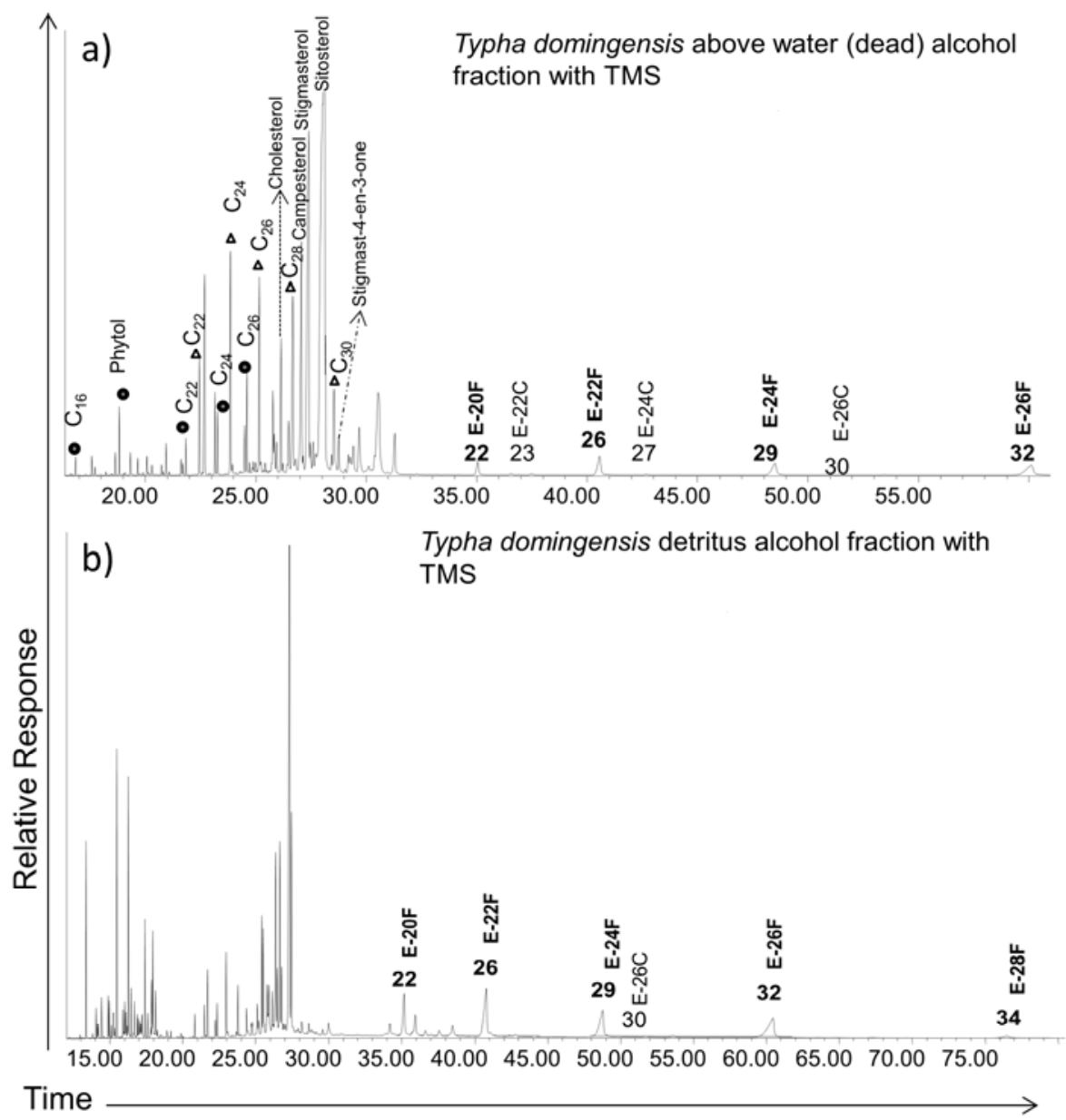

Figure 4.6 Mass-chromatogram (partial, total ion total ion current, TIC trace) of alcohol fractions from dead cattail and its detritus. Note: n-alcohols are represented by dots, $n$ fatty acids are shown by triangles, alkyl-ferulates and alkyl-p-coumarates are marked by numbers, E- $\mathrm{nF}$ ( $\mathrm{n}=$ number of alcohol moieties) means trans- $n$-alkyl-ferulate, E-nC ( $\mathrm{n}=$ number of alcohol moieties) means trans- $n$-alkyl-coumarate. 


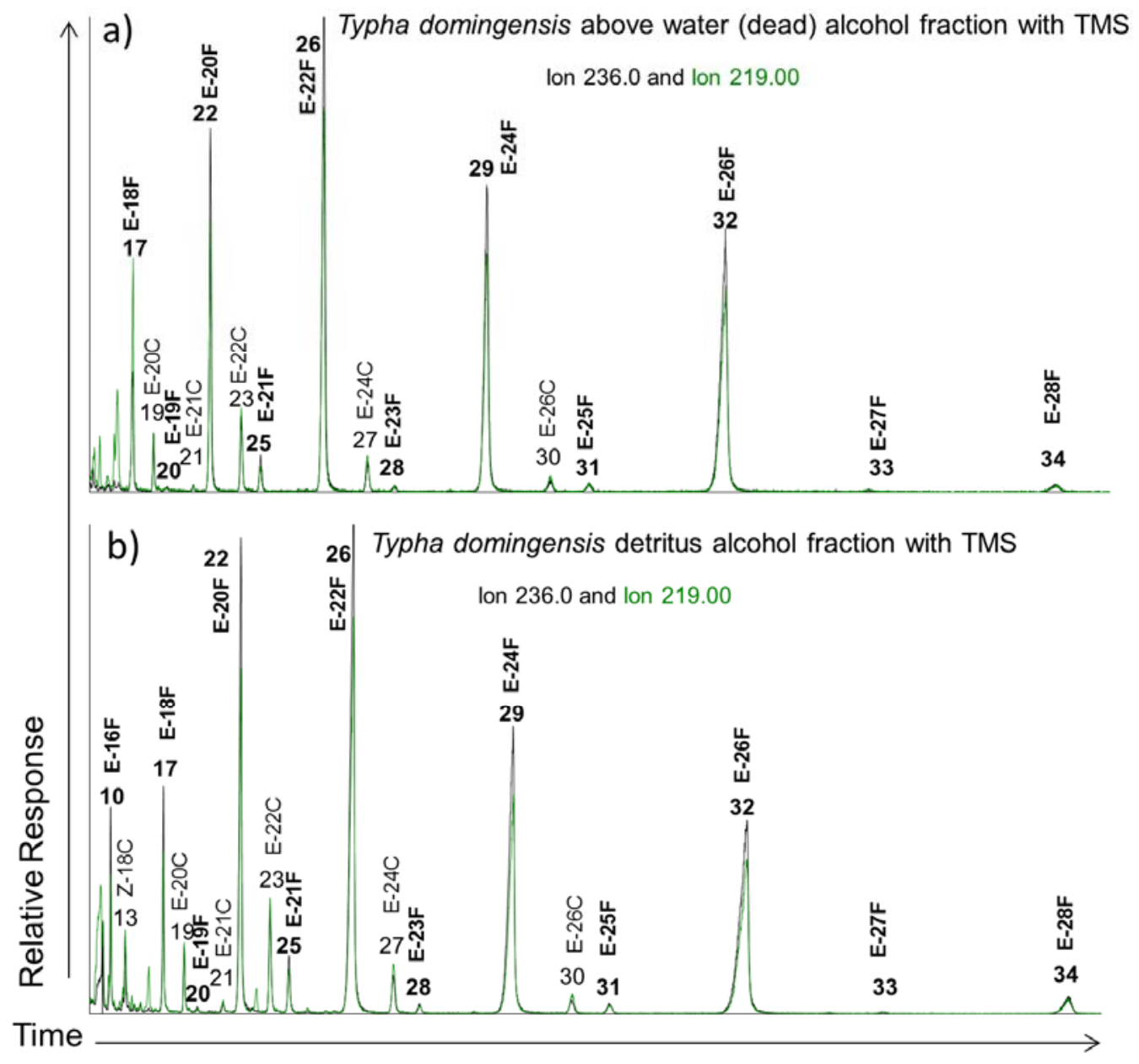

Figure 4.7 Mass-chromatogram of alcohol fractions (ion 236/219 extracted) from dead cattail and its detritus to show alkyl ferulates and alkyl $p$-coumarates.

Note: Alkyl- $p$-coumarates and alkyl-ferulates were listed by elution order from no. 10 to 34. Alkyl-ferulates and alkyl- $p$-coumarates are marked by numbers, $\mathrm{E}-\mathrm{nF}$ ( $\mathrm{n}=$ number of alcohol moieties) means trans- $n$-alkyl-ferulate, $\mathrm{E}-\mathrm{nC}(\mathrm{n}=$ number of alcohol moieties) means trans- $n$-alkyl-coumarate. The structure and name of each marked compound are shown in Figure 4.1, Table 4.1 and 4.2.

\subsubsection{Potential biomarkers for cattail in southern Florida Everglades}

Dominant wetland plants and algae such as Cladium, Eleocharis, Nymphaeaceae, Utricularia, Chara, and periphyton were sampled in the Everglades. Both leaves and roots (for plants) and bulk periphyton tissues were extracted and analyzed the same way as the Typha biomass samples. Neither alkyl-coumarates nor ferulates were detected in 
these species surveyed, where each species was sampled at five different locations. This suggests that these compounds could potentially be applied as molecular tracers for cattails in the Everglades wetland ecosystem.

n-Alkyl-ferulates (alkyl $\mathrm{C}_{20}-\mathrm{C}_{26}$ ) were also found in soil from Oregon (Medeiros et al., unpublished data), suggesting that they may survive early diagenetic transformations and can be preserved under anoxic or sub-oxic conditions. In this study, $n$-alkyl-coumarates and ferulates were detected in all cattail samples (fresh, senescent and detritus), but senescent cattails and detritus samples featured longer chain $n$-alkylcoumarate and ferulate distributions compared to the living plant extracts (Tables 4.2 and 4.3). This was an unexpected finding but can be explained through potential transesterification reactions during decay. In the early phases of plant biomass degradation, the depolymerization of suberin or suberin-rich tissues produces fatty acids, fatty alcohols, hydroxycinnamic acids, among other lipids (Li et al., 2007). Through enzymatic reactions, these hydroxycinnamic acids could potentially be esterified with fatty alcohols to form esters. Such trans-esterification reactions with the aid of enzymes (biocatalysts), particularly lipases, have previously been reported (Stamatis et al., 2001). It is also known that anaerobic fungi contain feruloyl and $p$-coumaroyl esterase (Borneman et al., 1990) and can degrade plant tissues, releasing the trans isomers of ferulic and $p$-coumaric acids. In addition, the enzymatic esterification (or lipophilization) of phenolic acids with aliphatic alcohols catalyzed by different lipases has been reported for numerous plant species (Candida antarctica, Candida cylindracae, Candida rugosa, Geotrichum candidum, Humicola lanuginose, Mucor miehei, Pseudomonas sp., Rhizomucor miehei, Rhizopus; Buisman et al., 1998; Figueroa-Espinoza and Villeneuve, 2005). Taken 
together, it seems quite possible that the longer-chain $n$-alkyl-coumarates and ferulates detected in senescent cattail tissues and detritus are indeed the result of transesterification reactions during early decay.

\subsection{Conclusion}

A comprehensive report on the molecular composition and concentrations in Everglades vegetation of $n$-alkyl ferulates and $n$-alkyl $p$-coumarates is presented. The structures of the different series is successfully deduced from the mass spectra of their TMS derivatives, and by comparision with literature reports and available standards. This is the first time that these phenolic compounds have been reported in cattail species. These compounds seem specific for cattails as they were not detected in other Everglades vegetation samples. Longer chain homologues were present in cattail detritus as a likely result of trans-esterification reactions during early diagenetic decay of this organic matter. However, more detailed studies are needed to determine the ultimate fate of these potential cattail tracers. 


\section{REFERENCES}

Aliotta, G., Della Greca, M., Monaco, P., Pinto, G., Pollio, A., Previtera, L. (1990). In vitro algal growth inhibition by phytotoxins of Typha latifolia L. Journal of Chemical Ecology, 16(9), 2637-2646.

Baldé, A. M., Claeys, M., Pieters, L. A., Wray, V., Vlietinck, A. J. (1991). Ferulic acid esters from stem bark of Pavetta owariensis. Phytochemistry, 30(3), 1024-1026.

Baranowski, J. D. and Nagel, C. W. (1983). Properties of alkyl hydroxycinnamates and effects on Pseudomonas fluorescens. Applied and Environmental Microbiology, 45(1), 218-222.

Baranowski, J. D. and Nagel, C. W. (1984). Antimicrobial and antioxidant activities of alkyl hydroxycinnamates (alkacins) in model systems and food products. Canadian Institute of Food Science and Technology Journal, 17(2), 79-85.

Bernards, M. A., Lewis, N. G. (1992). Alkyl ferulates in wound healing potato tubers. Phytochemistry, 31(10), 3409-3412.

Borneman, W. S., Hartley, R. D., Morrison, W. H., Akin, D. E., Ljungdahl, L. G. (1990). Feruloyl and p-coumaroyl esterase from anaerobic fungi in relation to plant cell wall degradation. Applied Microbiology and Biotechnology, 33(3), 345-351.

Buisman, G. J. H., Van Helteren, C. T. W., Kramer, G. F. H., Veldsink, J. W., Derksen, J. T. P., Cuperus, F. P. (1998). Enzymatic esterifications of functionalized phenols for the synthesis of lipophilic antioxidants. Biotechnology Letters, 20(2), 131-136.

Cefarelli, G., D'Abrosca, B., Fiorentino, A., Izzo, A., Monaco, P. (2005). Isolation, characterization, and antioxidant activity of E-and Z-p-coumaryl fatty acid esters from $\mathrm{Cv}$ Annurca apple fruits. Journal of Agricultural and Food Chemistry, 53(9), 3525-3529.

Daniels, D. G. H., and Martin, H. F. (1967). Antioxidants in oats: Mono-esters of caffeic and ferulic acids. Journal of the Science of Food and Agriculture, 18(12), 589-595.

Del Río, J. C., Rodríguez, I. M., Gutierrez, A. (2004). Identification of intact long-chain p-hydroxycinnamate esters in leaf fibers of abaca (Musa textilis) using gas chromatography/mass spectrometry. Rapid Communications in Mass Spectrometry, 18(22), 2691-2696.

Della Greca, M., Monaco, P., Previtera, L. (1990a). Stigmasterols from Typha latifolia. Journal of Natural Products, 53(6), 1430-1435. 
Della Greca, M., Monaco, P., Previtera, L., Aliotta, G., Pinto, G. (1990b). Carotenoidlike compounds from Typha latifolia. Journal of Natural Products, 53(4), 972-974.

Dixon, R. A., Achnine, L., Kota, P., Liu, C. J., Reddy, M. S., Wang, L. (2002). The phenylpropanoid pathway and plant defence-a genomics perspective. Molecular Plant Pathology, 3(5), 371-390.

Dixon, R. A. and Paiva, N. L. (1995). Stress-induced phenylpropanoid metabolism. The Plant Cell, 7(7), 1085-1097.

Evershed, R. P., Spooner, N., Prescott, M. C., John Goad, L. (1988). Isolation and characterisation of intact steryl ferulates from seeds. Journal of Chromatography A, 440, 23-35.

Faulds, C. B. and Williamson, G. (1999). The role of hydroxycinnamates in the plant cell wall. Journal of the Science of Food and Agriculture, 79(3), 393-395.

Figueroa-Espinoza, M. C. Villeneuve, P. (2005). Phenolic acids enzymatic lipophilization. Journal of Agricultural and Food Chemistry, 53(8), 2779-2787.

Folch, J., Lees, M., Sloane-Stanley, G. H. (1957). A simple method for the isolation and purification of total lipids from animal tissues. Journal of Biological Chemistry, 226(1), 497-509.

Freire, C. S., Silvestre, A. J., Neto, C. P. (2007). Demonstration of long-chain n-alkyl caffeates and $\Delta 7$-steryl glucosides in the bark of Acacia species by gas chromatographymass spectrometry. Phytochemical Analysis, 18(2), 151-156.

Gallardo, M. T., Martin, B. B., Martin, D. F. (1998). Inhibition of water fern Salvinia minima by cattail (Typha domingensis) extracts and by 2-chlorophenol and salicyl aldehyde. Journal of Chemical Ecology, 24(9), 1483-1490.

Gallardo-Williams, M. T., Geiger, C. L., Pidala, J. A., Martin, D. F. (2002). Essential fatty acids and phenolic acids from extracts and leachates of southern cattail (Typha domingensis P.). Phytochemistry, 59(3), 305-308.

Griffiths, D. W., Robertson, G. W., Shepherd, T., Ramsey, G. (1999). Epicuticular waxes and volatiles from faba bean (Vicia faba) flowers. Phytochemistry, 52(4), 607-612.

Gromova, A. S., Lutskii, V. I., Rykova, T. V., Tyukavkina, N. A. (1976). Esters of phenolic acids of the bark of Picea ajanensis, P. koraiensis, and P. obovata. Chemistry of Natural Compounds, 12(2), 233-234. 
Gutiérrez, A., Rodríguez, I. M., del Río, J. C. (2008). Chemical composition of lipophilic extractives from sisal (Agave sisalana) fibers. Industrial Crops and Products, 28(1), 8187.

Hashidoko, Y., Tahara, S., Mizutani, J. (1992). Rugosal A and related carotane sesquiterpenes in the glandular trichome exudate of Rosa rugosa. Phytochemistry, 31(3), $779-782$.

Huang, X., Wang, C., Zhang, J., Wiesenberg, G. L., Zhang, Z., Xie, S. (2011). Comparison of free lipid compositions between roots and leaves of plants in the Dajiuhu Peatland, central China. Geochemical Journal, 45(5), 365-373.

Ishida, H., Umino, T., Tsuji, K., Kosuge, T. (1988). Studies on the antihemorrhagic substances in herbs classified as hemostatics in Chinese medicine. IX.: On the antihemorrhagic principles in Typha lactifolia L. Chemical and Pharmaceutical Bulletin, 36(11), 4414-4420.

Jaffé, R., Mead, R., Hernandez, M. E., Peralba, M. C., DiGuida, O. A. (2001). Origin and transport of sedimentary organic matter in two subtropical estuaries: a comparative, biomarker-based study. Organic Geochemistry, 32, 507-526.

Jetter, R., Klinger, A., \& Schäffer, S. (2002). Very long-chain phenylpropyl and phenylbutyl esters from Taxus baccata needle cuticular waxes. Phytochemistry, 61(5), $579-587$.

Kawanishi, K., Yasufuku, J., Ishikawa, A., Hashimoto, Y. (1990). Long-chain alkyl ferulates in three varieties of Ipomoea batatas (L.) Lam. Journal of Agricultural and Food Chemistry, 38(1), 105-108.

Kisiel, W., Jakupowic, J. (1995). Long-chain alkyl hydroxycinnamates from Crepis taraxacifolia. Planta Medica, 61(01), 87-88.

Keriko, J. M., Nakajima, S., Baba, N., Iwasa, J. (1997). Eicosanyl p-coumarates from a Kenyan plant, Psiadia punctulata: Plant growth inhibitors. Bioscience, Biotechnology, and Biochemistry, 61(12), 2127-2128.

Lakela, O. and Long, R. W. (1976). Ferns of Florida. Miami: Banyan Books.

Lee, J. Y., Yoon, J. W., Kim, C. T., Lim, S. T. (2004). Antioxidant activity of phenylpropanoid esters isolated and identified from Platycodon grandiflorum A. DC. Phytochemistry, 65(22), 3033-3039.

Li, Y., Beisson, F., Ohlrogge, J., Pollard, M. (2007). Monoacylglycerols are components of root waxes and can be produced in the aerial cuticle by ectopic expression of a suberin-associated acyltransferase. Plant Physiology, 144(3), 1267-1277. 
Medeiros P. M., Oros D. R., Al-Mutlaq K. F., Rushdi, A. I., Simoneit, B. R. T. (2014). Lipid, sterol and carbohydrate metabolism, dynamics and diagenesis in surface soil during an annual cycle in a temperate climate region. Chemosphere, submitted.

Millar, A. A. and Kunst, L. (1997). Very-long-chain fatty acid biosynthesis is controlled through the expression and specificity of the condensing enzyme. The Plant Journal, 12(1), 121-131.

Molina, I., Li-Beisson, Y., Beisson, F., Ohlrogge, J. B., Pollard, M. (2009). Identification of an Arabidopsis feruloyl-coenzyme A transferase required for suberin synthesis. Plant Physiology, 151(3), 1317-1328.

Nidiry, E. S. J. and Lokesha, A. N. (2013). A rapid spectrophotometric method for the quantitative estimation of octadecyl p-coumarates. Journal of Applied Spectroscopy, 1-4.

Nidiry, E. S. J., Ganeshan, G., Lokesha, A. N. (2011). Antifungal activity and Isomerization of octadecyl p-coumarates from Ipomoea carnea subsp. fistulosa. NPC Natural Product Communications, 6(12), 1889-1892.

Ohtsu, H., Tanaka, R., Michida, T., Shingu, T., Matsunaga, S. (1998). Tetracyclic triterpenes and other constituents from the leaves and bark of Larix kaempferi. Phytochemistry, 49(6), 1761-1768.

Ou, S., Kwok, K. C. (2004). Ferulic acid: pharmaceutical functions, preparation and applications in foods. Journal of the Science of Food and Agriculture, 84(11), 1261-1269.

Ozawa, T. and Imagawa, H. (1988). Polyphenolic compounds from female flowers of Typha latifolia L. Agricultural and Biological Chemistry, 52(2), 595-597.

Santos, S., Schreiber, L., Graça, J. (2007). Cuticular waxes from Ivy leaves (Hedera helix L.): analysis of high-molecular-weight esters. Phytochemical Analysis, 18(1), 60-69.

Schardt, J. D. 1997. 1994 Florida Aquatic Plant Survey. Dominant Plants in Public Waters. Tech Report \#972-CGA. Bureau of Aquatic Plant Management. Florida Department of Environmental Protection. Tallahassee, FL.85 pp.

Schreiber, L., Franke, R., Hartmann, K. (2005). Wax and suberin development of native and wound periderm of potato (Solanum tuberosum L.) and its relation to peridermal transpiration. Planta, 220(4), 520-530.

Serra, O., Hohn, C., Franke, R., Prat, S., Molinas, M., Figueras, M. (2010). A feruloyl transferase involved in the biosynthesis of suberin and suberin-associated wax is required for maturation and sealing properties of potato periderm. The Plant Journal, 62(2), 277290. 
Snook, M. E., Data, E. S., Kays, S. J. (1994). Characterization and quantitation of hexadecyl, octadecyl, and eicosyl esters of p-coumaric acid in the vine and root latex of sweet potato [Ipomoea batatas (L.) Lam.]. Journal of Agricultural and Food Chemistry, 42(11), 2589-2595.

Stamatis, H., Sereti, V., Kolisis, F. N. (2001). Enzymatic synthesis of hydrophilic and hydrophobic derivatives of natural phenolic acids in organic media. Journal of Molecular Catalysis B: Enzymatic, 11(4), 323-328.

Tapia, A., Rodriguez, J., Theoduloz, C., Lopez, S., Feresin, G. E., Schmeda-Hirschmann, G. (2004). Free radical scavengers and antioxidants from Baccharis grisebachii. Journal of Ethnopharmacology, 95(2), 155-161.

Whitaker, B. D., Schmidt, W. F., Kirk, M. C., Barnes, S. (2001). Novel fatty acid esters of p-coumaryl alcohol in epicuticular wax of apple fruit. Journal of Agricultural and Food Chemistry, 49(8), 3787-3792.

Yunoki, K., Musa, R., Kinoshita, M., Tazaki, H., Oda, Y., Ohnishi, M. (2004). Presence of higher alcohols as ferulates in potato pulp and its radical-scavenging activity. Bioscience, Biotechnology, and Biochemistry, 68(12), 2619-2622. 
CHAPTER V

SHEET FLOW EFFECTS AND CANAL BACKFILLING ON SEDIMENT SOURCE AND TRANSPORT IN THE DECOMP PHYSICAL MODEL: ANALYSIS OF MOLECULAR ORGANIC BIOMARKERS

(This chapter is modified with permission from the 2012-2013 annual report to the granting agency: South Florida Water Management District) 


\subsection{Abstract}

The goal of this study is to support Decomp Physical Model (DPM) science by quantify the sources and transport of sediments under low and increased sheet flow conditions in the fresh water Everglades ecosystem, USA. During the initial phase of the project (phase-1; 2012-2013) specific molecular marker analyses of 153 samples were conducted on vegetation, floc and sediment trap material. All samples analyzed were collected under pre-flow conditions (2010-2012) and analyzed for the biomarker proxies Paq, kaurenes, $\mathrm{C}_{20} \mathrm{HBI}$ and botryococcenes, as well as bulk stable carbon isotopes. Proof of concept with regards to the application of these biomarker parameters as proxies for ridge vs. slough organic matter sources was demonstrated. Moreover, the biomarker conceptual model was ultimately applied to determine the organic matter sources of sediments accumulating in canals and across the ridge-and-slough landscape. The data collected to this date suggests that the conceptual biomarker model indeed applies to the DPM site environment, and that the great majority $(80 \%$ or more) of the organic matter accumulated in the sediment traps collected during phase-1 of the project is derived from slough environments.

\subsection{Introduction}

Restoration of the south Florida Everglades is a massive and complex undertaking with numerous socio-ecological challenges (Richardson, 2010). The ultimate goal is the hydrologic restoration of the quantity, quality, timing, and distribution of water deliveries to the landscape while maintaining drainage, flood control, water retention, water supply, irrigation, and transportation for the more than 7 million people that inhabit south Florida. 
To balance the needs of the ecosystem and society, an adaptive management approach is an integral part of the Comprehensive Everglades Restoration Plan (CERP). This approach utilizes best available science and adaptive assessment for planning, implementation, and modification as more information is obtained.

The US Army Corps of Engineers and the CERP have identified the need to better understand the ecological and biological benefits of restoring historic sheet flow, which is widely recognized as a critical mechanism in rebuilding the patterned, corrugated landscape of the pre-drainage Everglades. Historically, water velocities were greater than $2 \mathrm{~cm} \mathrm{~s}^{-1}$, several-fold higher than measured in the current system, and served to redistribute sediment to build landscape patterning and topography (Larsen et al., 2011). Today, in most areas of the system, reduced or nonexistent shee tflow coupled with either drainage or impoundment has steadily degraded the linear patterning and microtopography. The resulting loss of connected, deep water sloughs equates to a reduction in the aquatic productivity and ecological connectivity those habitats once provided in sustaining trophic food webs. To date, my understanding of the mechanisms of landscape formation and degradation has been limited to small-scale experiments and large-scale modeling. Scientific and engineering uncertainties remain over the extent to which the ridge and slough landscape can be restored with greater shee tflow and, furthermore, what role canals play in altering landscape responses to sheetflow.

The CERP-funded DECOMP project (short for decompartmentalization) aims to restore sheet flow to the central (water conservation area $3 \mathrm{~A}$ and $3 \mathrm{~B}$ ) and southern Everglades (Everglades National Park) by re-engineering the existing barriers to flow. The DECOMP Physical Model (DPM) is a multi-agency, multidisciplinary, landscape- 
scale project designed to address two uncertainties associated with the effects of shee tflow and canal backfilling options on the ridge-and-slough landscape. The central research questions addressed by the DPM are mainly focused on canal backfill and sheet flow questions, and are summarized as follows. Canal Backfill Questions: (1) Will canals act as sediment traps, reducing overland transport of sediment under increased sheetflow? (2) Will high flows entrain high-nutrient canal sediments and carry them into downstream areas? (3) To what extent are these responses altered by different canal backfilling options, including partial and full backfills? Shee tflow Questions: (1) To what extent do entrainment, transport, and settling of sediments differ in ridge and slough habitats under high and low flow conditions? (2) Specifically, does sediment entrained from the slough eventually settle in ridges, rebuilding microtopography? (3) How fast can the microtopography and patterning be restored given sediment redistribution by increased sheetflow?

In order to address most of the main questions above, molecular marker approaches were applied. Molecular markers or biomarkers were originally referred to as 'chemical fossils' since they maintain molecular features that can be traced back to their origin, even after significant degradation (Eglinton \& Hamilton, 1967). While this is true for some biomarkers, others are less resistant to degradation and are more indicative of recent organic matter sources. The concept of using biomarkers to assess organic matter dynamics in the greater Everglades has been successfully applied in recent years to characterize sources in floc, soils/sediments and suspended particles in freshwater marsh, estuarine and coastal environments (Hernandez et al., 2001; Jaffé et al., 2001; Mead et al., 2005; Neto et al., 2006; Hajje and Jaffé, 2006; Xu et al., 2006a; Jaffé et al., 2006; Gao et 
al., 2007; Xu and Jaffé, 2007). In addition, this approach has shown much potential for paleo-reconstructions and assessment of environmental change in both freshwater marsh (Saunders et al., 2006) and marine (Xu et al., 2006b; Xu et al., 2007) environments. Through these studies, source-specific molecular markers have been developed and applied as a useful approach to identify the sources, transport and ultimately the fate of organic matter in the Everglades. Specifically, lipid biomarkers have been shown to provide information on vegetation- sources of organic matter. For example, a $n$-alkanederived proxy, Paq, was found to effectively distinguish Cladium (sawgrass) from deeper water slough sources such as Eleocharis spp., Nymphaea odorata, submerged aquatic vegetation (such as Chara spp.; Mead et al. 2005; Saunders et al., 2006). Recent evidence shows $\mathrm{P} a q$ can also be used to distinguish sediments derived from tree islands versus sawgrass and slough habitats (Jaffé and Belicka, 2010). Other useful proxies include a group of diterpenoids termed Kaurenes, biomarkers that are highly enriched in (although not exclusive to) sawgrass root tissue in the Everglades (Saunders et al., 2006). Other biomarkers have been identified as being indicative of green algae (Botryococcenes) and to cyanobacteria (highly branched isoprenoids; $\mathrm{C}_{20} \mathrm{HBIs}$ ) (Saunders et al., 2006; Gao et al., 2007; Gao, 2007). As such, a combination of the Paq value, the $\mathrm{C}_{20} \mathrm{HBI}$, the Kaurenes and the Botriococcanes might be applicable to the assessment of organic matter sources in floc and sediments, and a useful tool to determine hydrologically induced changes in organic matter composition of such materials.

The goal of this study is to support DPM science to quantify the sources and transport of sediments under low and increased shee tflow conditions. This goal was accomplished by field and laboratory analyses on biomass, floc and soil/sediment 
samples (153 samples in total during the natural low shee tflow condition). All these analyses were used to accomplish the following objectives: (1) Assess spatial gradients in sediment organic matter $(\mathrm{OM})$ sources across the DPM experiment and determine baseline relationships between sediment OM source and local vegetation, soil quality and other covariates under low flow conditions; (2) Assess changes in the contributions of ridge and slough OM sources to sediments accumulating in canal backfill treatments under high and low sheetflow; (3) Assess changes in the contributions of slough-derived OM sediment in ridges, and conversely, of ridge-OM in sloughs under high and low flow; (4) Assess changes in the contributions of ridge and slough OM sources to sediments transported across the landscape (km-scale) under high and low sheetflow.

\subsection{Samples and Methods}

A total of 46 vegetation samples, including above- and belowground biomass, 87 floc and 20 sediment trap samples were analyzed during this time period as described in the methods section of the work plan (DPMST, 2010). General information describing above-mentioned samples and indicating the sample locations on the basis of the general DPM site map (Fig. 5.1) is summarized in Table 5.1. Samples were grouped as above- vs. belowground biomass, sediment traps, ridge floc and slough floc.

All samples were freeze dried with a LabconcoFreeZone $6 \mathrm{~L}$ bench-top freezedrying system at $-40{ }^{\circ} \mathrm{C}$ and $0.133 \mathrm{mBar}$ for 24 hours or until no further change in mass is detected. All freeze-dried sample were sifted through a 35 mesh sieve to remove larger vegetation and root debris. Then the samples were ultrasonically extracted in glass test tube with Teflon-lined caps, following a modified Folch (1957) protocol. Total lipid 
extracts are then be fractionated via silica gel column chromatography for further purification and separation of lipid classes (Jaffé et al., 2001). The hydrocarbons fraction (fractions 1) is spiked with an internal standard (Squalane) for quantification and analyzed on an Agilent 6890 Gas Chromatograph (GC) coupled to an Agilent 5973 Mass Spectrometer (MS) in electron ionization mode at $70 \mathrm{eV}$. Identification of the lipids is performed in several ways by (a) comparison of chromatographic retention times, (b) comparison of the mass spectra with those of authentic standards or literature reports, (c) and through mass spectral interpretation. Retention times and mass spectra are recorded electronically and stored on the computer using the ChemStation software provided by the manufacturer. 


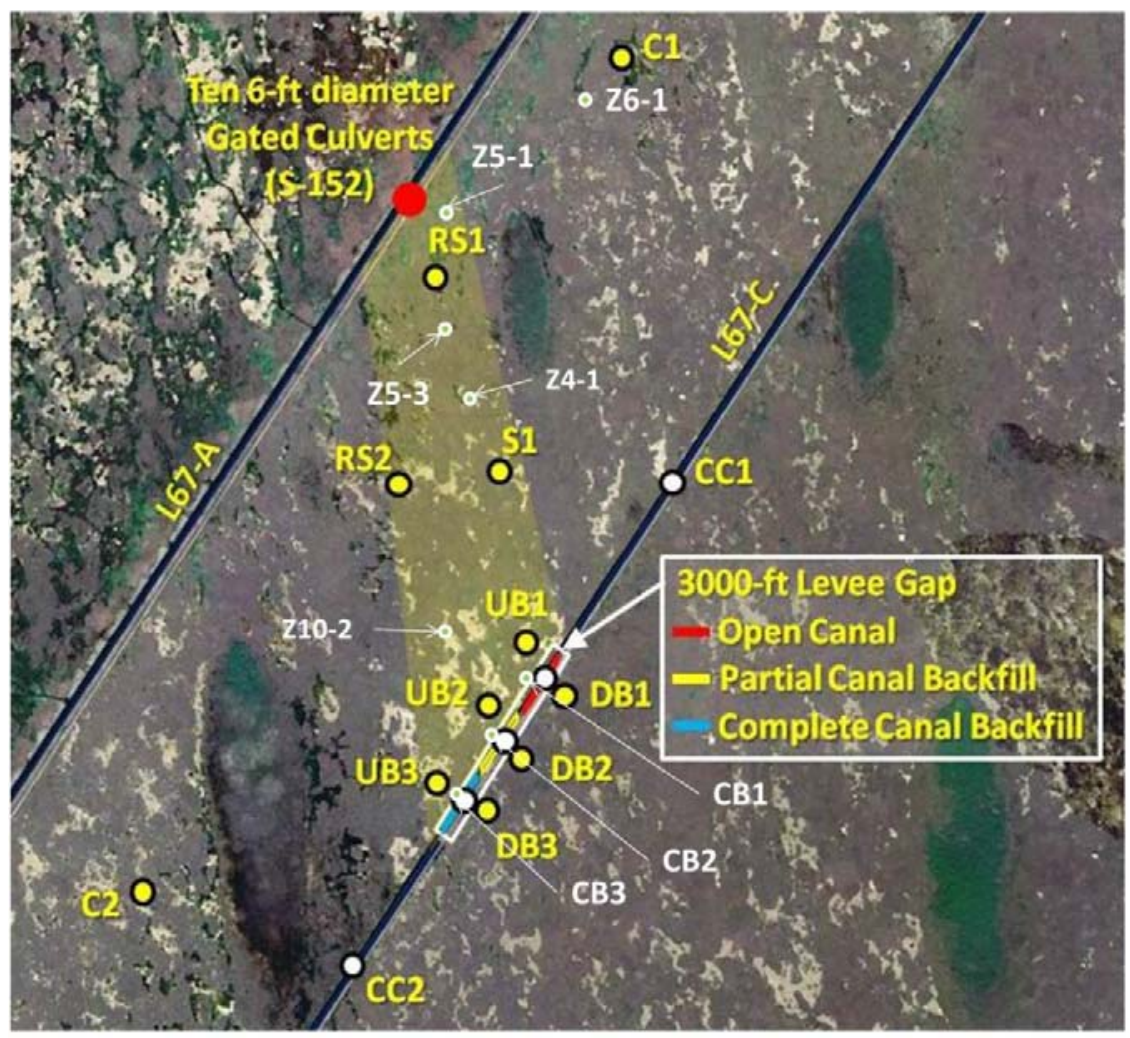

Figure 5.1 Map of DPM study site indicating sampling sites for the biomarker study (provided by C. Saunders).

Note: $(\mathrm{R}=$ ridge; $\mathrm{S}=$ slough; $\mathrm{C}=$ control; $\mathrm{CC}=$ canal control site; $\mathrm{UB}=\mathrm{Slough}$ sites; $\mathrm{UB} 1=$ northeast downstream slough site; UB2 = central down-stream slough site; UB3 = Southwest downstream slough site; $\mathrm{DB}=$ Canal effects, no backfill WCA-3B sites; DB1 = no backfill; DB2 = partial backfill; DB3= complete backfill; $Z=$ Slough sites for Spatial Soil Survey).

Table 5.1 Sample classification and location information (for a total of 153 samples).

\begin{tabular}{|c|c|c|}
\hline Sample type & Sample locations & Comments \\
\hline Ridge \& Slough transect & Z6-1, Z5-1 & \\
\hline Ridge \& Slough floc & $\mathrm{RS} 1, \mathrm{RS} 2, \mathrm{C} 1$ & \\
\hline Slough floc & $\begin{array}{c}\text { Z4-1, Z10-2, Z5-3, DCC2S, DB1, DB2, } \\
\text { DB3 }\end{array}$ & \\
\hline
\end{tabular}


Ridge floc

Sediment trap samples

Sediment trap samples

Sediment trap samples

Sediment trap samples

Sediment trap samples

Cladium

Typha domigensis

Typha latifolia

Eleocharis sp.

Nymphaeaceae

Utricularia foliosa

Utricularia purpurea

Bacopa sp.

Periphyton
$\mathrm{CC} 1 \mathrm{~N}, \mathrm{CC} 2 \mathrm{~S}, \mathrm{CB} 1, \mathrm{CB} 2, \mathrm{CB} 3$

$\mathrm{CC} 1$

A

A

B

CB2

C

CB3

D
Z5-1, RS2, UB1

Z11-3, UB1

C2, DB1, WCA3B

RS2, DB1

RS2, Z5-1

RS2, Z5-1, DB1

$\mathrm{CC} 2$

DB3

RS2, Z5-1, DB2

*Notes (Canal and levee types):
A. open canal + intact levee; B. open canal + degraded levee
C. partially backfilled canal + degraded levee; D. full-backfilled canal + degraded levee.

\subsection{Results and Discussion}

The collection and analysis of ridge and slough vegetation was primarily performed to assess the applicability of the proposed biomarker conceptual model for the 
DPM site. Previous vegetation samples for biomarker studies were mainly performed at Everglades National Park, although the biomarker composition at DPM is likely to be very similar (Mead et al., 2005). Plant sample analyses were focused specifically on the $n$-alkane proxy $\mathrm{P} a q$, which has been used to differentiate between aquatic and emergent plant-derived organic matter (OM) (Ficken et al., 2000; Mead et al., 2005; Pisani et al., 2013). It is usually observed that aquatic vegetation, including the typical species present in long hydroperiod environments of the Everglades (Eleocharis, Nymphaeceae, Utricularia), are characterized by elevated $\mathrm{P} a q$ values, while emergent vegetation and the species characteristic for short hydroperiod environments (Cladium, Typha) in the Everglades have lower Paq values. Shown in Figure 5.2 is the $\mathrm{P} a q$ distribution for the plant samples determined in this study.

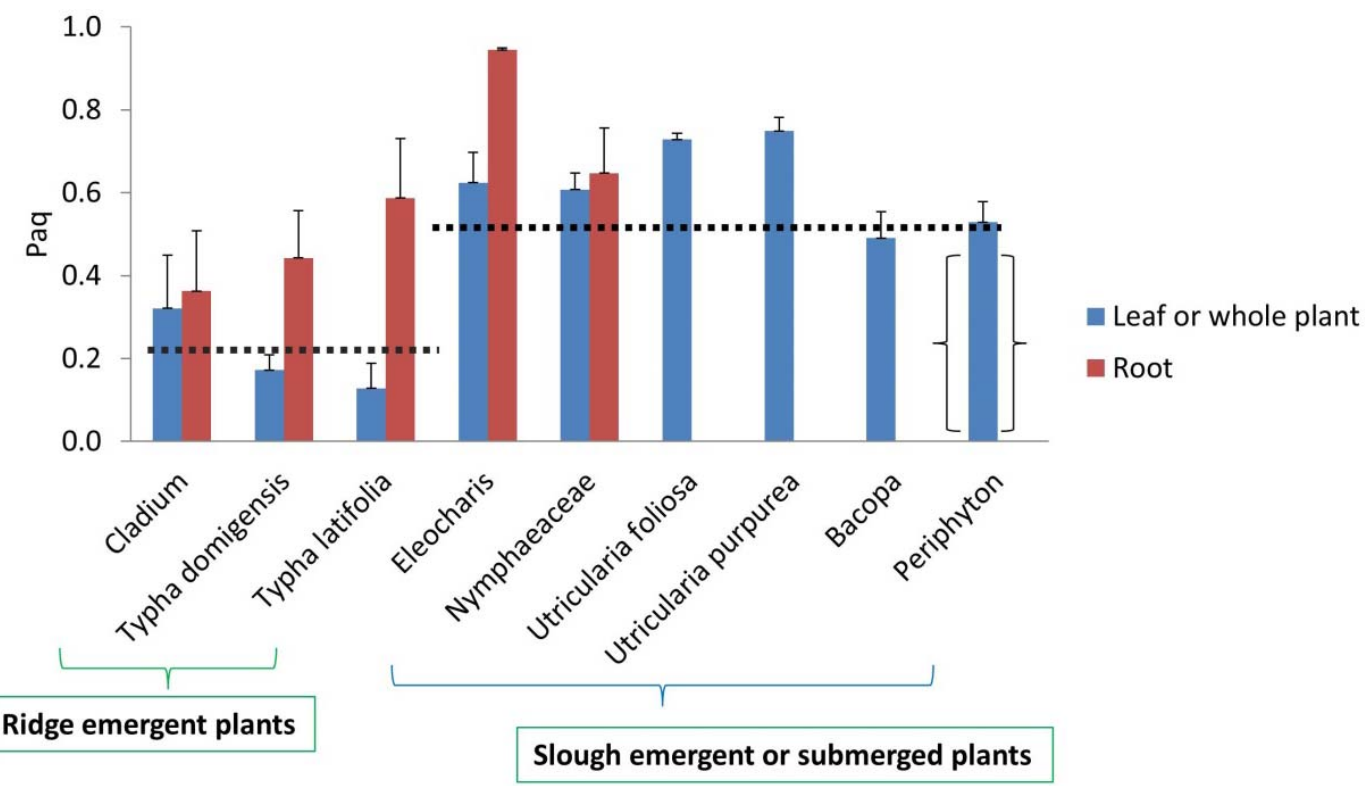

Figure 5.2 Distribution of $\mathrm{P} a q$ values determined for selected vegetation samples. Some samples include both above- and belowground tissues. Periphyton values in brackets since plankton does not contribute significantly to mid-to-long chain $n$-alkanes (see text for further details). Dotted lines show average values for ridge and slough vegetation. 
It is clear that in general terms the abovementioned conceptual model for $\mathrm{P} a q$ as an OM source proxy for long vs. short or slough vs. ridge environments applies well. Periphyton is included in the figure, but planktonic organism do not generate significant amounts of mid to long chain $n$-alkanes, and as such the Paq reported for the periphyton represents other $\mathrm{OM}$ sources such as detritus of emergent vegetation, remains of Utricularia and others which are part of the algal mat sample. With the exception of the kaurenes, which have been observed in higher plants, specifically in Cladium (Neto et al., 2006; Saunders et al., 2006), the other biomarkers $\mathrm{C}_{20} \mathrm{HBI}$ and the botryococcanes are exclusively produced by plankton and were not analyzed in the plant samples.

For further proof of concept, floc from two ridge-to-slough transects (Z5-1 and Z6-1) were sampled during 2012 and 2013 and the biomarkers determined (Figure 5.3). 

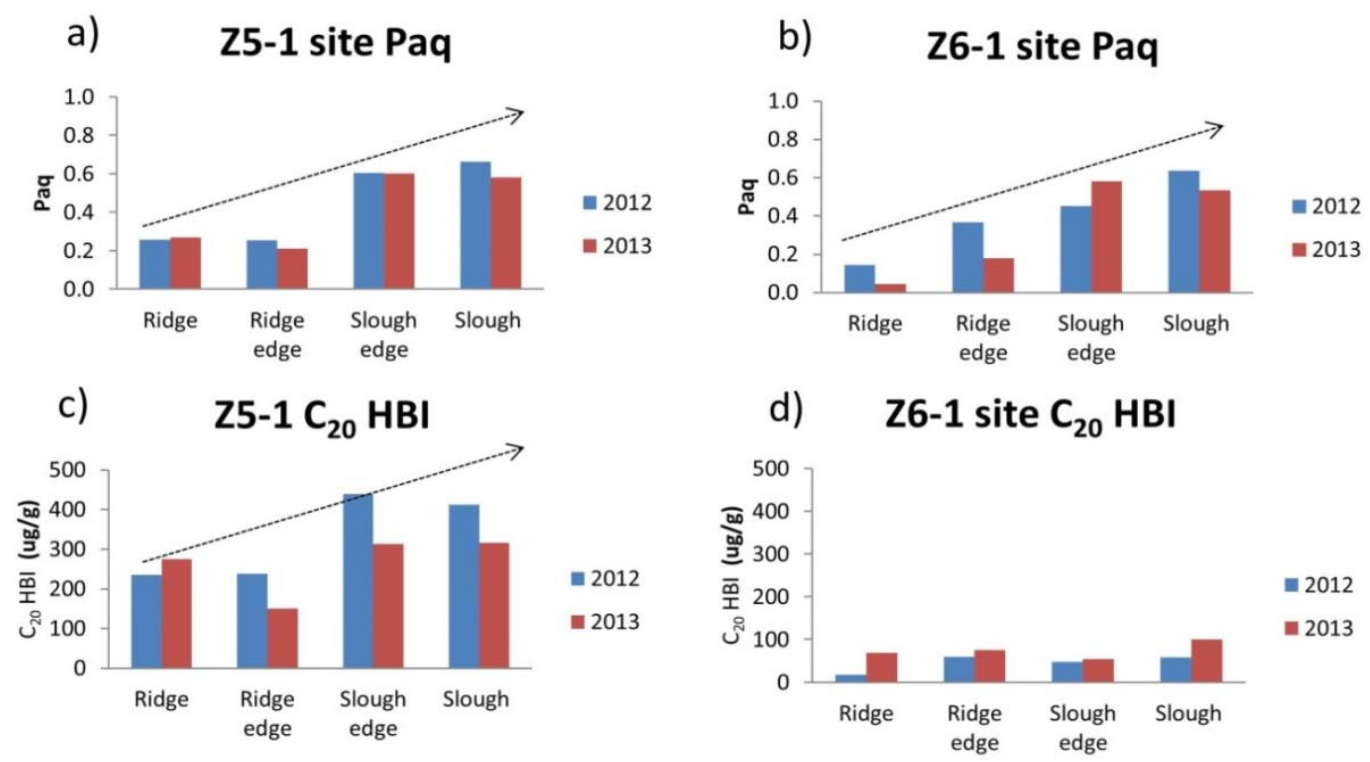

d) Z6-1 site $\mathrm{C}_{20} \mathrm{HBI}$
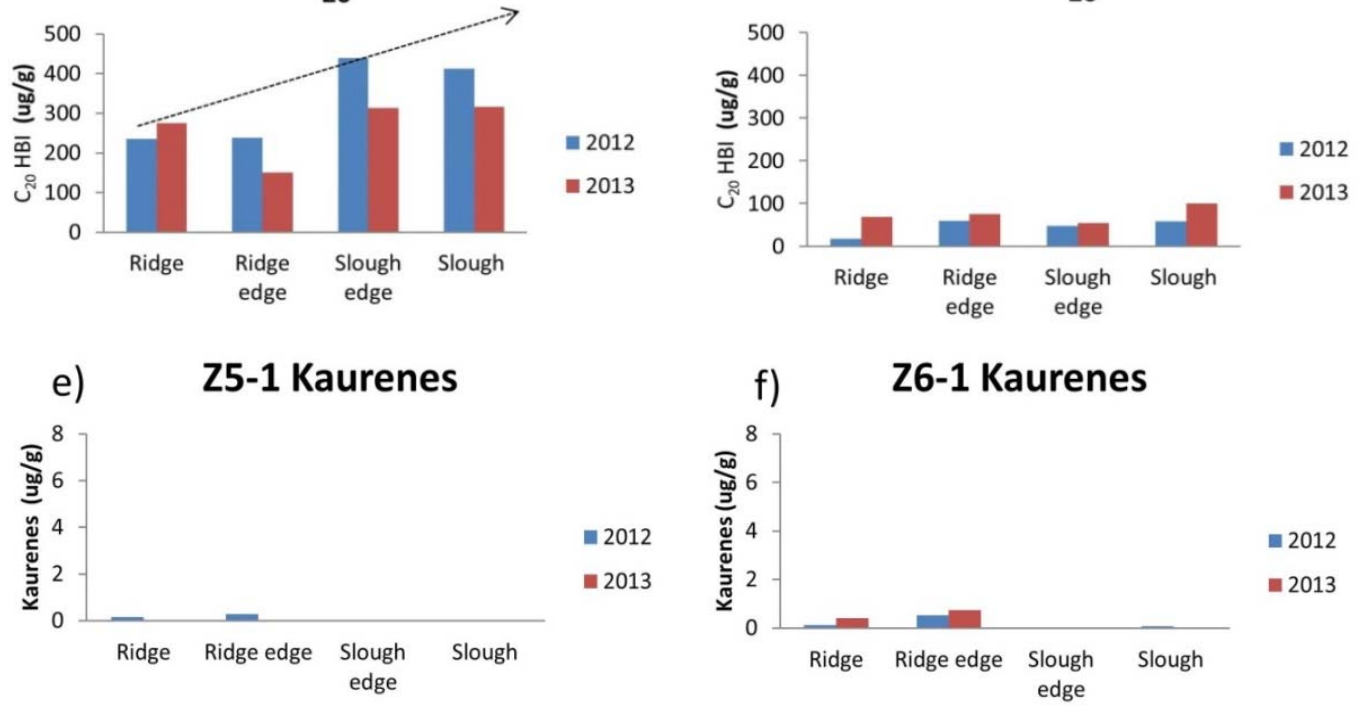

g) Z5-1 Botryococcens
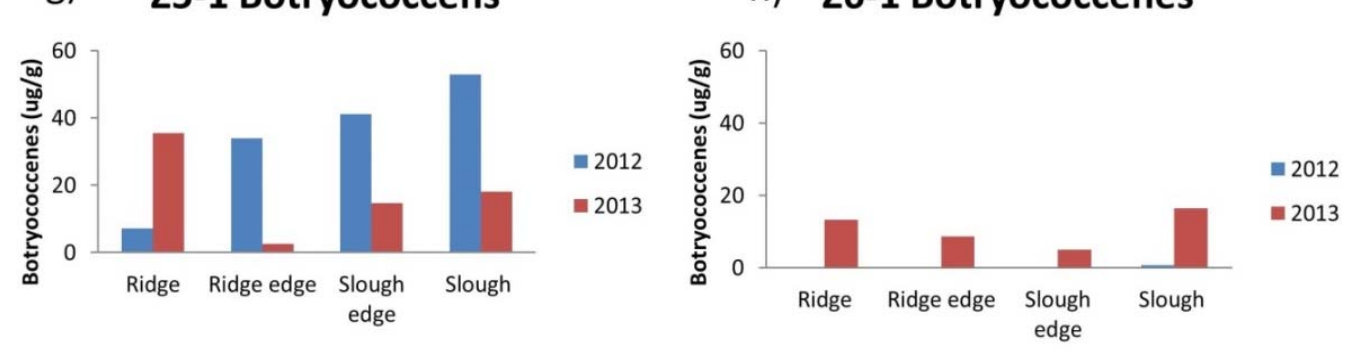

Figure 5.3 Biomarker distributions along ridge-to-slough transects for two different sampling events at sites Z5-1 and Z6-1. Dotted arrows indicate general trend of change.

As expected in all cases the Paq increased along the ridge-to-slough gradient. For the other biomarkers, although the $\mathrm{C}_{20} \mathrm{HBI}$ abundance for Z5-1 increased along the gradient, this trend was not obvious for the Z6-1 transect. $\mathrm{C}_{20} \mathrm{HBI}$ is associated with cyanobacterial biomass in periphyton derived OM (Pisani et al., 2013), and thus expected 
to be enriched in slough environments compared to ridges. Similarly, the botryococcenes are presumably associated with green algae in periphyton (Gao et al., 2007) but showed an increasing abundance along the ridge-to-slough gradient only for the Z5-1 sample collected in 2012, but not for 2013 nor for the Z6-1 transect. The data suggests that the distribution of periphyton-derived OM in floc at the DPM site is not strongly associated with ridge or slough sites specifically. The higher $\mathrm{C}_{20} \mathrm{HBI}$ and botryococcene concentrations for Z5-1 are likely the result of nutrient enrichments at this site compared to others in the pocket area (except RS-1). Lastly, the kaurene distribution along the transects agreed with their main source from Cladium, as they were present in higher abundance in the ridge compared to the slough.

Three sampling stations, namely RS1, RS2 and C1 were used to specifically compare ridge and slough composition of floc. They were also sampled every 3- to 6weeks between October 2012 to March 2013 (Choi et al., 2013) although not all during the exact same times. The biomarker distributions for these samples are shown in Figures 5.4-5.6 for RS1, RS2 and C1 respectively. 

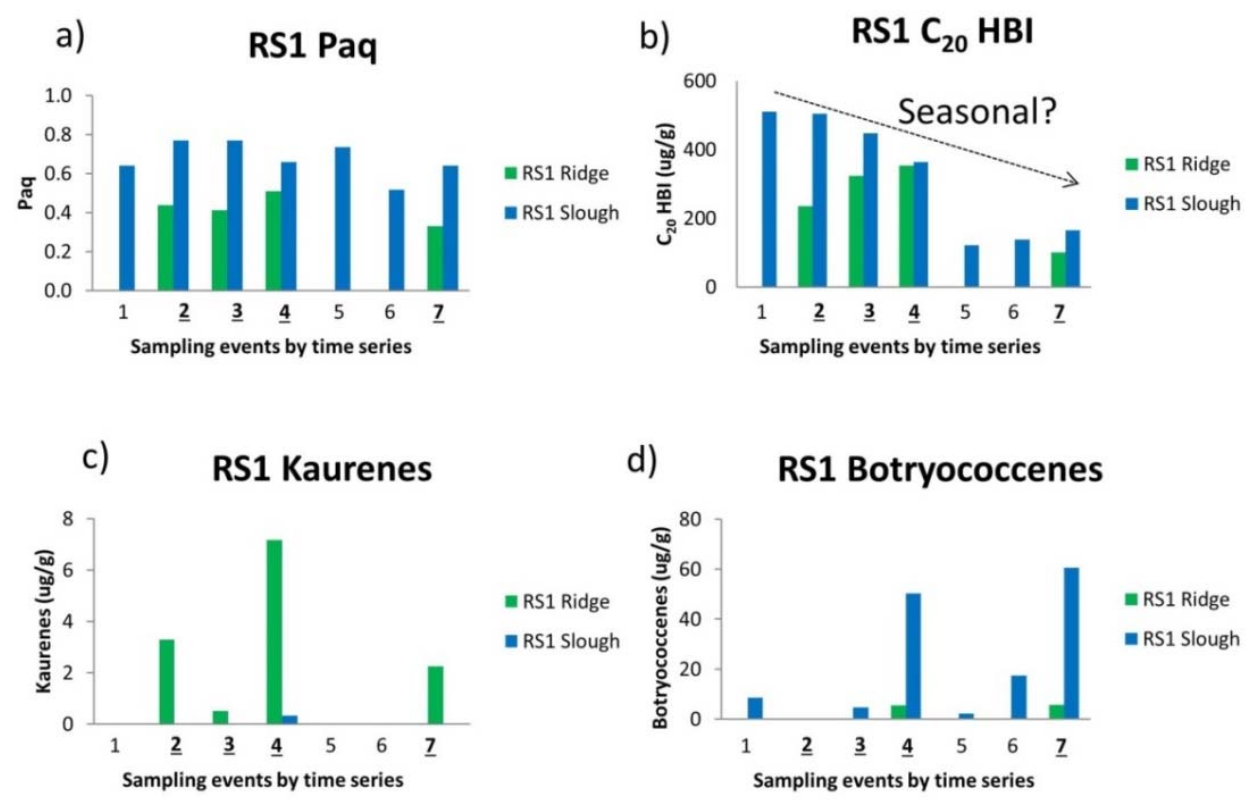

Figure 5.4 Ridge and slough floc biomarker distribution time series for site RS1. 7 sampling events are sampled on: 10/9/2012, 11/27/2012, 12/19/2012, 1/9/2013/, $1 / 22 / 2013,3 / 4 / 2013,3 / 27 / 2013$. Dotted arrows indicate general trend of change. Dotted arrows indicate general trend of change. 


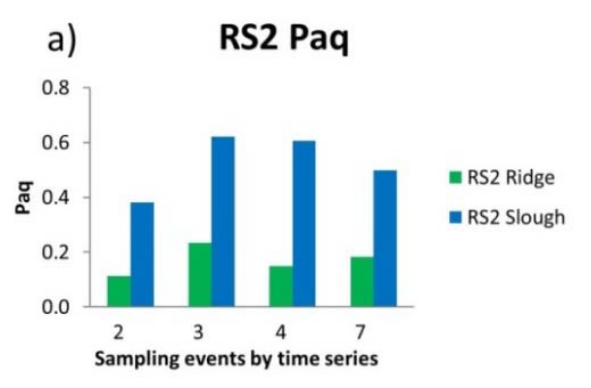

c) RS2 Kaurenes

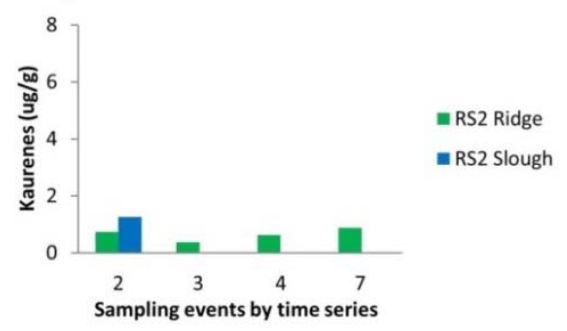

b) $\quad \mathrm{RS} 2 \mathrm{C}_{20} \mathrm{HBI}$

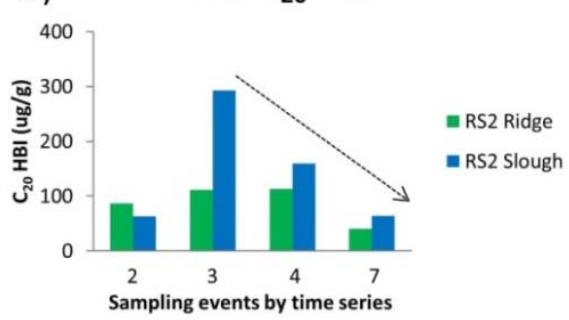

d)

Botryococcenes: not detected

Figure 5.5 Ridge and slough floc biomarker distribution time series for site RS2. 8 samples on the basis of 4 sampling events 11/27/2012, 12/19/2012, 01/09/2013/, $03 / 27 / 2013$. Dotted arrows indicate general trend of change. Dotted arrows indicate general trend of change.

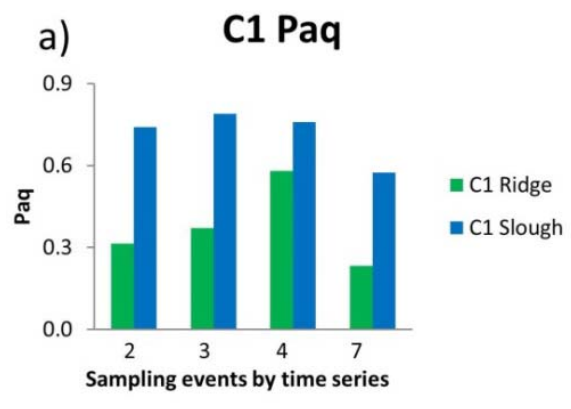

c) C1 Kaurene

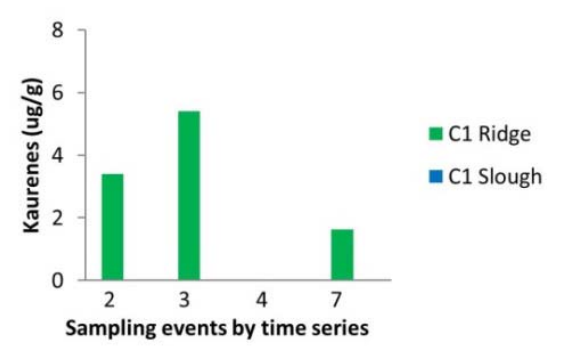

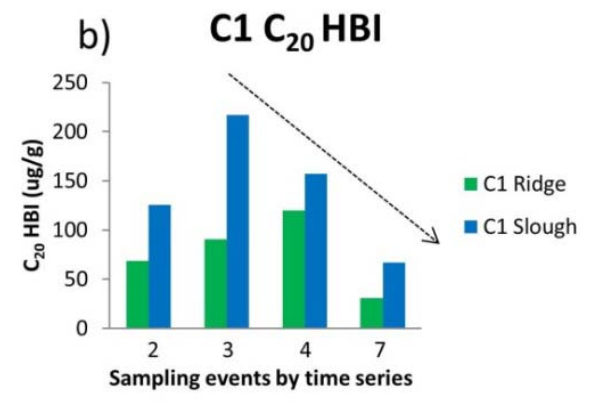

d) C1 Botryococcenes

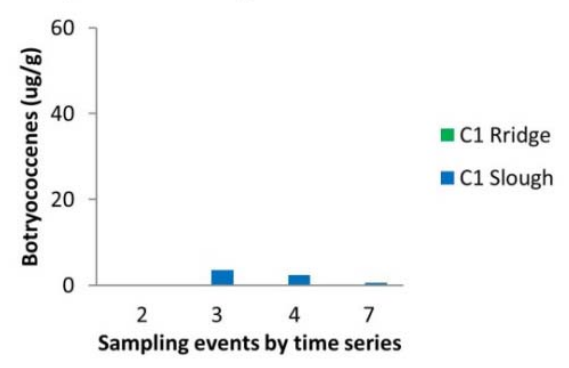

Figure 5.6 Ridge and slough floc biomarker distribution time series for site C1. 8 samples on the basis of four sampling events: 11/27/2012, 12/19/2012, 01/09/2013/, $03 / 27 / 2013$. Dotted arrows indicate general trend of change. 
The Paq values were consistently higher for all sites for slough samples compared to ridge samples and presented a fairly high consistency in the valued over time. No temporal trend was identified for the Paq. With respect to the $\mathrm{C}_{20} \mathrm{HBI}$, The concentration values for the RS1 site were significantly higher compared to the RS2 and C1 sites. This is in agreement with the observations mentioned above concerning high $\mathrm{C}_{20} \mathrm{HBI}$ levels for the Z5-1 site which is located in close proximity to RS1. Both sites are likely influenced by high nutrient seepage from the L67A and thus show enhanced periphyton abundance on the basis of the biomarker distributions. On a seasonal scale, the $\mathrm{C}_{20} \mathrm{HBI}$ showed a clearly decreasing abundance from the wet to the dry season for RS1. This is in agreement with reports that periphyton abundance is highest during the late wet season in the Everglades (Pisani et al., 2013 and references therein). Similar trends were observed for sites RS2 and C1, with peak abundances for December 2012 and decreasing values from there on. However, the decrease in the $\mathrm{C}_{20} \mathrm{HBI}$ abundance is not mimicked by the other periphyton marker, the botryococcanes, with the possible exception of $\mathrm{C} 1$. It is likely that the two periphyton components are uncoupled and do not share the same ecological drivers. Additional biomarker information obtained during year-2 of this contract may allow clarifying these observations. Lastly, the kaurene distribution was seemingly unrelated to season, but was consistent with regards to the fact that this biomarker was in all cases more abundant in the ridge samples and mostly absent in the sloughs.

With regards to time series, the longest seasonal monitoring of floc was performed at sites DB1, DB2 and DB3. Comparative time series biomarker results are 
shown in Figure 5.7, including a mark indicating the time of the breach in the L67C structure (potential water flow increase effect on the DB sites).
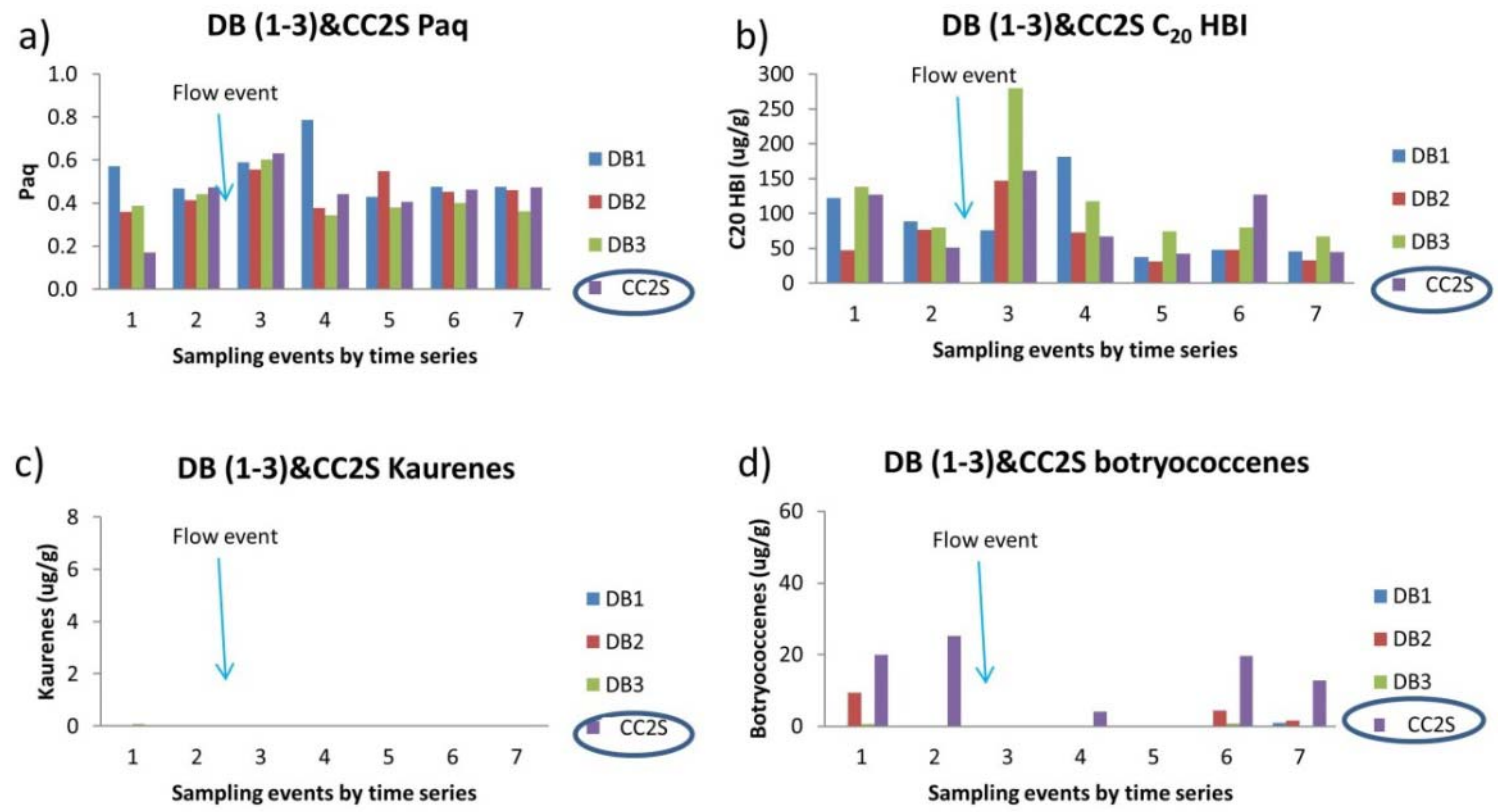

Figure 5.7 Biomarker distribution time series for slough floc at sites DB1-3 and CC2S. Control site is circled.

In agreement with the abovementioned time series, average $\mathrm{P} a q$ values were similar for the seasonal samples, although some variations at the DCC2S site (reference site) and DB1 were observed. Average Paq values peaked after the canal breach suggesting enhanced OM inputs from the canal itself. No other consistent trends over time were observed. In contrast to the $\mathrm{P} a q$, the $\mathrm{C}_{20} \mathrm{HBI}$ distribution over time and between sites was quite variable, again pointing towards a very dynamic nature of the periphyton inputs to the floc. Previous reports on seasonality of periphyton on the basis of $\mathrm{C}_{20} \mathrm{HBI}$ measurements are in agreement with this suggestion (Pisani et al., 2013). However, and in agreement with the $\mathrm{P} a q$, an average high $\mathrm{C}_{20} \mathrm{HBI}$ abundance during the 
sampling period following the canal breach and associated high flow event was observed, followed by a reduction in abundance. Similar to the explanations for the higher $\mathrm{C}_{20} \mathrm{HBI}$ abundance at sites Z5-1 and RS1, this observation could be related to an increase in nutrients after the breach. As in previous examples, the botryococcenes were decoupled from the $\mathrm{C}_{20} \mathrm{HBI}$, while levels of the kaurenes were very small to undetected for these slough sites (Note: Concentration scale for kaurenes is kept the same throughout these figures to facilitate comparisons between samples).

The time series for the biomarker parameters determined for the sediment traps located at sites $\mathrm{CB} 1-3$ and two reference sites $\mathrm{CC} 1$ and $\mathrm{CC} 2$ are presented in Figure 5.8.

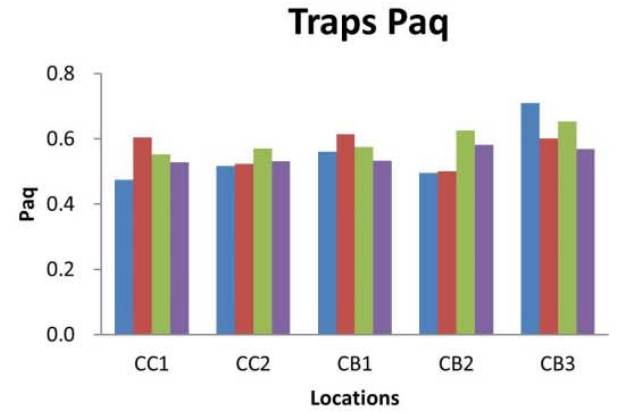

Traps kaurenes

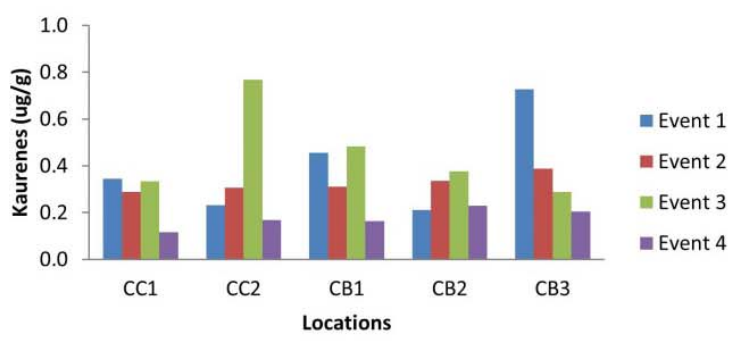

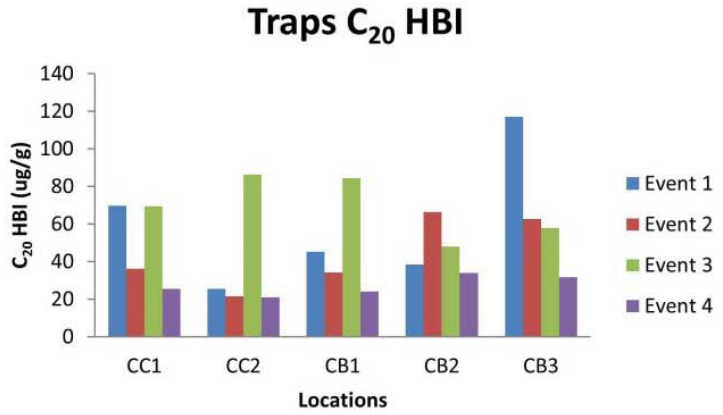

Traps botryococcenes

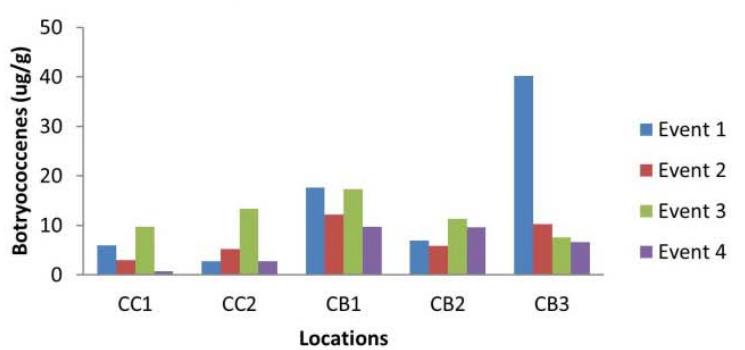

Figure 5.8 Biomarker distribution time series for sediment trap samples at CB1-3 and CC1-2. 4 sampling events: 11/17/2011, 12/13/2011, 01/04/2012, 11/20/2012 (20 samples total). 
The Paq values by season showed a remarkable constancy with notable lower variability than the seasonally monitored floc samples. The $\mathrm{P} a q$ values were consistently high and in the expected range for slough-derived OM. No significant differences were observed between the CB1-3 and the corresponding reference sites CC1-2. In contrast, the variability of the periphyton markers, the $\mathrm{C}_{20} \mathrm{HBI}$ and botryococcanes, was significantly higher, but more similar to each other than for the floc sample time series or other samples throughout the dataset. The previously observed maximum for the floc $\mathrm{C}_{20}$ HBI for the end of wet season sampling period (Event 3) was not observed in this sample set possibly because the years sampled were different, with different hydrology. Similarly, the variability in the kaurene concentration was fairly high seasonally and for the different samples, with no clear temporal trends.

The average values of the $\mathrm{P} a q$ and the biomarker concentrations for all sample types (ridges, sloughs and sediment traps), regardless of season, are shown in Figure 5.9. The Paq values were found to be consistently and statistically significantly higher for the slough than for the ridge samples demonstrating the viability of the conceptual biomarker model with regards to OM source differentiation. Interestingly, the average $\mathrm{P} a q$ value for the 20 sediment trap samples was similar and not statistically different from that of the slough samples. This fact suggests that indeed, the bulk of the OM in the sediment traps is derived from a slough-like environment, where velocities typically are a little higher compared to ridge-like environments (Choi et al., 2013). Higher flow will enhance entrainment and consequently mobilization of slough-like OM compared to ridge-like OM leading to a preferential accumulation of high Paq material in the traps. While this observation seems to be in complete agreement with the conceptual biomarker model, it 
is important to consider that canal inputs may also influence the materials collected in the sediment traps. As such, highest values for the Paq were observed at stations DB1-3 precisely after the breach, when canal inputs to the floc may have been higher. This issue needs to be further investigated to clarify potential effects. On the basis of the fact that $\mathrm{P} a q$ values are not different between slough and sediment traps, it can be assumed that most of the $\mathrm{OM}$ in the traps is slough-derived.
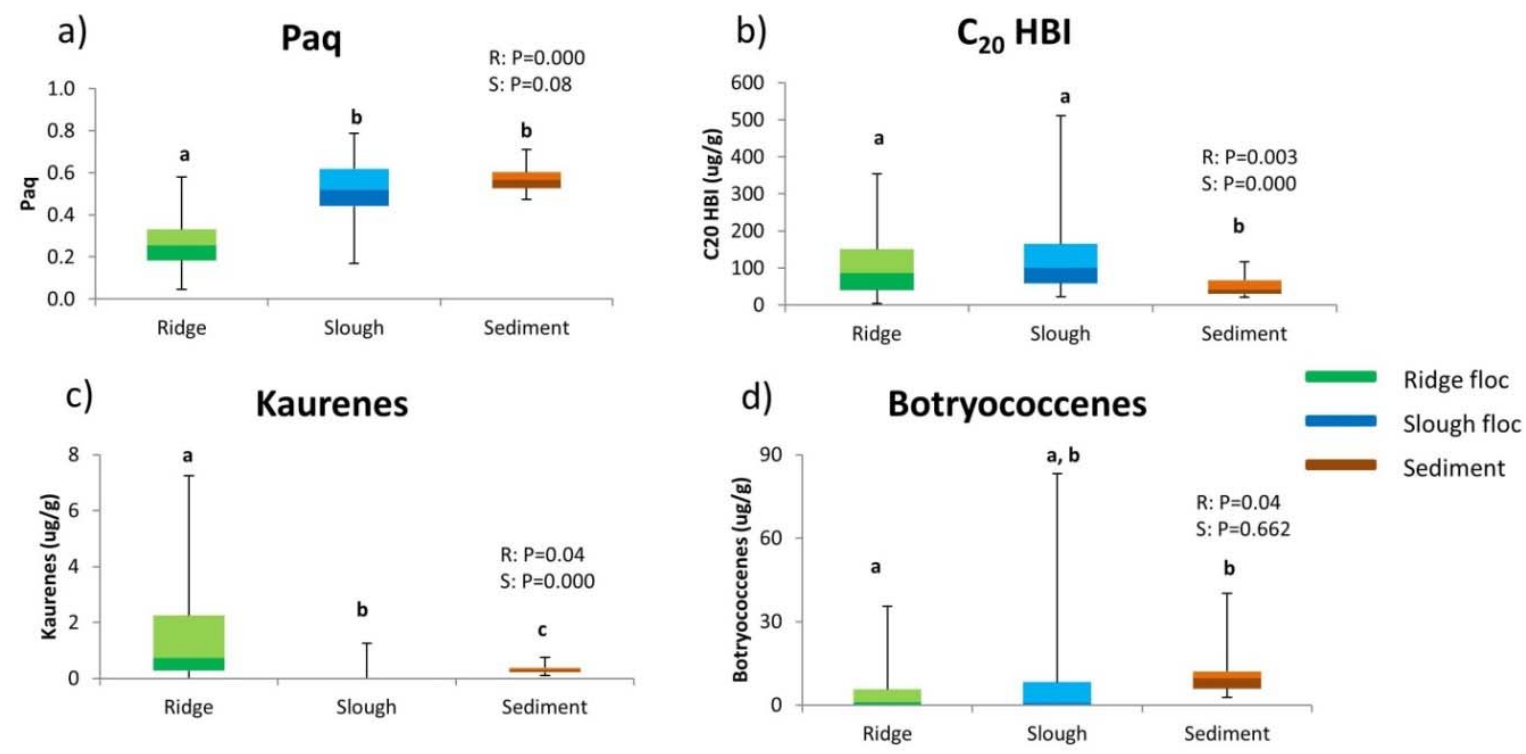

Figure 5.9 Comparison between average biomarker distributions for all slough, ridge and sediment trap samples (107 in total).

Average concentration values for the biomarkers for all sites are also shown in Figure 5.9. No statistically significant differences were observed between ridge and slough samples for the $\mathrm{C}_{20} \mathrm{HBI}$ or the botryococcenes, suggesting that at least in at the DPM study site the dynamics of periphyton seem uncoupled from the ridge and slough landscape. The kaurenes on the contrary were consistently and statistically significantly more abundant throughout the DPM site at the ridges compared to the sloughs. Very 
interestingly, kaurenes were consistently detected in all sediment trap samples. This is somewhat unexpected considering that these compounds were very low in abundance or even undetected in the slough samples. Their consistent presence in the traps suggests that some constant contribution of ridge-like OM is also mobilized in the DPM area. Simple two end-member mixing calculation using average kaurene concentrations from ridges and sloughs suggests that in excess of $80 \%$ of the OM in sediment traps is sloughlike and below $20 \%$ ridge-like. This estimate is different from the $100 \%$ estimated slough-derived $\mathrm{OM}$ on the basis of the $\mathrm{P} a q$ estimations. However, considering that at many stations in the DPM study site the water depth difference is very small $(9 \mathrm{~cm})$ it can be expected that some ridge-derived OM will also accumulate in the sloughs. Regardless, although these are very rough estimated on the basis of a limited dataset, the sediment mobilization in the DPM study site under present pre-flow conditions seem primarily slough derived. While the carbon stable isotope values $\left(\delta^{13} \mathrm{C}\right)$ for the floc from ridges and sloughs were not statistically different, the values for the sediment trap materials were slightly, but statistically significantly enriched, suggesting that the fine sediments accumulating in the traps are more highly reworked ('aged') compared to the ridge and slough floc samples.

Spatial distributions throughout the DPM site were plotted for the biomarker data, both for the slough and ridge datasets (data not shown). However, although some N-to-S trends seem visible, the dataset is not large enough to ensure that these trends are indeed statistically significant. Consequently these spatial distribution results are not discussed further in this chapter, but are expected to be enhanced significantly with new data to be generated during phase- 2 of this study. 
Both cluster analysis and principal components analyses were performed on the entire biomarker dataset (vegetation samples excluded). Cluster analysis for only the four biomarker concentrations averaged for each site regardless of time of sample collection is shown in Figure 5.10.

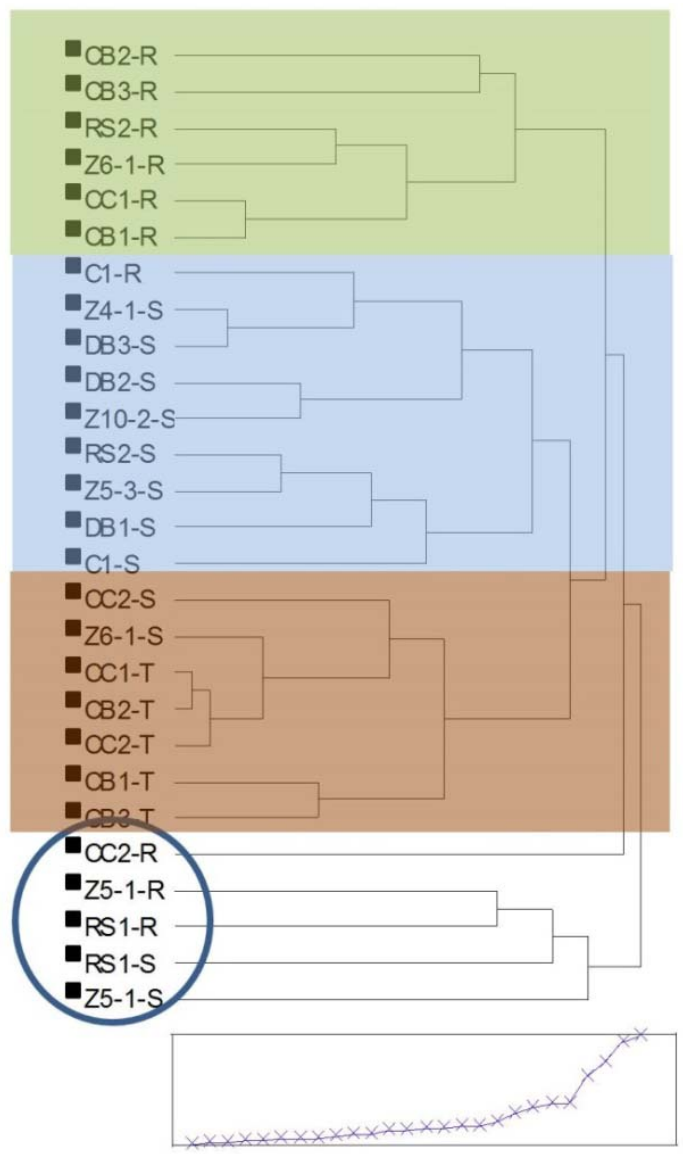

Figure 5.10 Cluster analyses for biomarker distributions for all slough, ridge and sediment trap samples (107 in total). Groupings are indicated by different colors. Group circled is considered an outlier cluster.

A clear pattern of four clusters emerges, which are primarily categorized into ridge, slough, trap and 'other' samples, with 'other' referring to three sites which although fitting well into the conceptual biomarker model, showed some high biomarker 
concentration values leading to separate clusters. These sites are RS1 and the co-located Z5-1 sites, which feature high $\mathrm{C}_{20} \mathrm{HBI}$ and botryococcene values likely resulting from nutrient enrichment at this site (see above), and site CC2-R which was enriched in kaurenes. High kaurene concentrations may arise from significant Cladium OM input at this site, which might also be derived from soil erosion causing an enhanced signal of belowground derived OM which is particularly enriched in kaurenes (Fig. 5.2). It is important to note that biomarker concentration data needs to be normalized to OC content for comparative purposes (to be completed once $\% \mathrm{OC}$ data for all samples are available). PCA of the biomarker data reiterates the cluster analysis in that ridge, slough/traps and 'other' emerged as separate entities (Fig. 5.11). Here, the ridge sites consistently feature more negative PC1 values compared to the more positive PC1 values for the slough samples. This pattern includes the most negative PC1 value for $\mathrm{CC} 2-\mathrm{R}$ and the most positive PC1 values for RS1-S and Z5-1S. The sediment traps were located close to the origin but generally inside the general sample scores for the slough sites. Biomarker parameter loadings seem to define $\mathrm{PC} 1$ on the basis of source (positive $\mathrm{PC} 1=$ high $\mathrm{P} a q /$ slough vs. negative $\mathrm{PC} 1=$ high kaurene/ridge). In contrast, $\mathrm{PC} 2$ seems to be indicative of peripyton inputs with both $\mathrm{C}_{20} \mathrm{HBI}$ and botryococcane loadings at positive PC2 values. While Z5-1 is expected to follow this pattern it is unclear why CC2-R would score at a high PC2 if this principal component is indeed linked to periphyton. Overall, while the drivers for the variations in PC1 and particularly PC2 are not fully determined, it is clear that OM in sediment traps is mostly slough-like. 


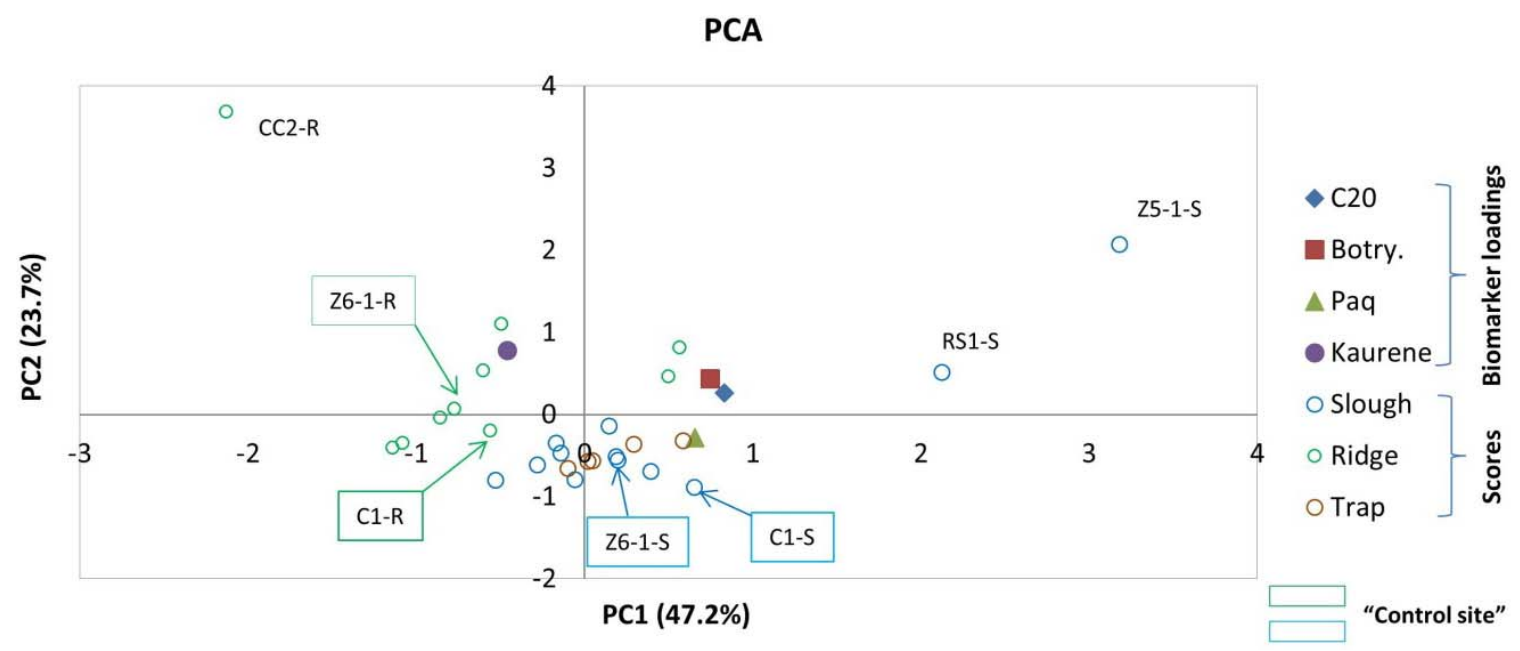

Figure 5.11 PCA analyses for biomarker distributions for all slough, ridge and sediment trap samples (107 in total). Note: PCA using averaged values for each location (group), 27 groups (107 samples) included; 4 biomarkers as variables (Paq, $\mathrm{C}_{20} \mathrm{HBI}$, Kaurenes, Botryococcenes).

\subsection{Conclusions}

The preliminary biomarker data presented and discussed in this annual report suggests that indeed the conceptual biomarker model, where $\mathrm{P} a q$ and kaurene data can be used as proxies of ridge and slough OM contributions to the sediment traps, was confirmed. The application of periphyton biomarkers $\mathrm{C}_{20} \mathrm{HBI}$ and botryococcanes did not show to this point a direct applicability towards discerning ridge vs. slough OM sources, but suggests that the contributions of periphyton to floc and sediment traps is highly dynamic and in part controlled by nutrient enrichment at some locations, or driven by water flow/ hydrology, on the basis of observed the time series distributions (particularly for the cyanobacteria-derived $\mathrm{C}_{20} \mathrm{HBI}$ ). While Paq-based two end-member mixing suggests that the bulk of the $\mathrm{OM}$ in the sediment traps is slough-like, the consistent presence of kaurene in the traps implies that ridge-derived OM is also present. Two end-member mixing on the basis of average kaurene levels in floc and sediments 
suggests that at most $20 \%$ of the OM in sediment traps is ridge-like. More data is needed to better constrain these estimates. 


\section{REFERENCES}

Choi, J., C. Coronado-Molina, J. Harvey, D. T. Ho, L. Larsen, S. Newman, C. J. Saunders, K. Skalak, F. H. Sklar, E. Tate-Boldt, and J. Trexler. 2013. The Decomp Physical Model (DPM), Year 3 Annual Report: Pre-Flow Baseline Monitoring of the Water Conservation Area (WCA) 3 Decompartmentalization and Sheet Flow Enhancement Project. Final Report, US Geological Survey.

Decomp Physical Model Science Team (DPMST). (2010). The Decomp Physical Model Science Plan. 52pp.

http://www.evergladesplan.org/pm/projects/project docs/pdp_12_decomp/060410_deco

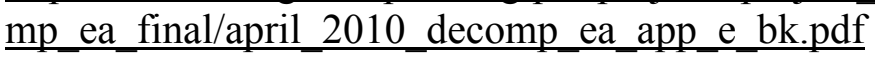

Eglinton, G., Hamilton, R.J. (1967). Leaf epicuticular waxes. Science, 156(3780), 13221335.

Ellis, J. I. and Schneider, D. C. (1997). Evaluatoin of a gradient sampling design for environmental impact assessment. Environmental Monitoring and Assessment. 48: 157172.

Ficken, K. J., Li, B., Swain, D. L., Eglinton, G. (2000). An n-alkane proxy for the sedimentary input of submerged/floating freshwater aquatic macrophytes. Organic Geochemistry, 31(7), 745-749.

Folch, J., Lees, M., Sloane-Stanley, G. H. (1957). A simple method for the isolation and purification of total lipids from animal tissues. Journal of biological Chemistry, 226(1), 497-509.

Gao, M. (2007). Chemical Characterization of Soil Organic Matter in an Oligotrophic, Subtropical, Freshwater Wetland System: Sources, Diagenesis, and Preservation. Ph.D. Thesis, Florida International University, Miami, FL.

Gao, M., Simoneit, B.R.T., Gantar, M., Jaffé. R. (2007). Occurrence and distribution of novel botryococcene hydrocarbons in freshwater wetlands of the Florida Everglades. Chemosphere, 70:224-236.

Hajje, N. and Jaffé, R. (2006). Lipids associated with peat humic fractions from Everglades National Park (USA). Hydrobiologia. 569: 99-112.

Hernandez, M.E., Mead, R., Peralba, M.C., Jaffé, R. (2001). Origin and transport of nalkane-2-ones in a sub-tropical estuary: Potential biomarkers for seagrass-derived organic matter. Organic Geochemistry, 32: 21-32. 
Jaffé, R., Belicka, L.L. (2010). Biomarker Analysis of Tree Island and Marsh Soils. Report submitted to South Florida Water Management District. 31 pp.

Jaffé, R., Mead, R., Hernandez, M. E., Peralba, M. C., DiGuida, O. A. (2001). Origin and transport of sedimentary organic matter in two subtropical estuaries: a comparative, biomarker-based study. Organic Geochemistry, 32(4), 507-526.

Jaffé, R., Rushdi, A.I., Medeiros, P.M., Simoneit, B.R.T. (2006). Natural product biomarkers as indicators of sources and transport of sedimentary lipids in a subtropical river. Chemosphere, 64: 1870-1884.

Larsen, L. G., J. W. Harvey, and J. P. Crimaldi. (2009). Predicting bed shear stress and its role in sediment dynamics and restoration potential of the Everglades and other vegetated flow systems. Ecological Engineering, 35:1773-1785.

Larsen, L., N. Aumen, C. Bernhardt, V. Engel, T. Givnish, S. Hagerthey, J. Harvey, L. Leonard, P. McCormick, C. McVoy, G. Noe, M. Nungesser, K. Rutchey, F. Sklar, T. Troxler, J. Volin, and D. Willard. (2011). Recent and Historic Drivers of Landscape Change in the Everglades Ridge, Slough, and Tree Island Mosaic. Critical Reviews in Environmental Science and Technology, 41:344-381.

Mead, R., Xu, Y., Chong, J., Jaffé, R. (2005). Sediment and soil organic matter source assessment as revealed by the molecular distribution and carbon isotopic composition of $n$-alkanes. Organic Geochemistry, 36(3), 363-370.

Neto, R., Mead R.N., Louda W., Jaffé, R. (2006). Organic biogeochemistry of detrital flocculent material (floc) in a subtropical, coastal wetland. Biogeochemistry, 77: 283304.

Pisani, O., Louda, J. W., Jaffé, R. (2013). Biomarker assessment of spatial and temporal changes in the composition of flocculent material (floc) in the subtropical wetland of the Florida Coastal Everglades. Environmental Chemistry, 10(5), 424-436.

Richardson, C.J. (2010). The Everglades: North America's subtropical wetland. Wetlands Ecology and Management, 18(5), 517-542.

Saunders, C.J., Gao, M., Lynch, J. A., Jaffé, R., and Childers, D. L. (2006). Using Soil Profiles of Seeds and Molecular Markers as Proxies for Sawgrass and Wet Prairie Slough Vegetation in Shark Slough, Everglades National Park. Hydrobiologia, 569:475-492.

Stewart-Oaten, A. and Bence, J.R. (2001). Temporal and spatial variation in environmental impact assessment. Ecological Monographs, 71: 305-339. 
Xu, Y. and Jaffé, R. (2007). Lipid biomarkers in suspended particulates from a subtropical estuary: Assessment of seasonal changes in sources and transport of organic matter. Marine Environmental Research, 64:666-678.

Xu, Y., Holmes, C., and Jaffé, R. (2007). A lipid biomarker record of environmental change in Florida Bay over the past 150 years. Estuarine, Coastal and Shelf Science, 73: 201-210.

Xu, Y., Mead, R.N. and Jaffé, R. (2006a). A molecular marker-based assessment of sedimentary organic matter sources and distributions in Florida Bay. Hydrobiologia, 569: 179-192.

Xu, Y., Wachnicka, A., Gaiser, E.E. and Jaffé, R. (2006b). Occurrence of $\mathrm{C}_{25}$ highly branched isoprenoids in Florida Bay: Paleoenvironmental indicators of diatom-derived organic matter inputs. Organic Geochemistry, 37:847-859. 
CHAPTER VI

DISTRIBUTION OF $N$-ALKANES AND THE $\delta$ D AND $\delta^{13} \mathrm{C}$ PATERNS IN TYPICAL PLANTS ACROSS A SUBTROPICAL TREE ISLAND TO WETLAND GRADIENT AND ESTUARY SYSTEM: IMPLICATION FOR PALEORECONSTRUCTION 


\subsection{Abstract}

The main objective of this study was to characterize plant material from the Everglades, using biomarkers and compound-specific isotope measurements, to calibrate potential organic geochemical tools for paleo-hydrological studies. The aims of this study were to (1) document the variations in plant (aboveground biomass; leaf or stem) $n$ alkane molecular distributions and the corresponding $\delta \mathrm{D}$ and $\delta^{13} \mathrm{C}$ values within a spatially constrained region (from $25^{\circ} \mathrm{N}$ to $26^{\circ} \mathrm{N}$; i.e. same climatic conditions), but along hydrological gradients; (2) examine the difference in $n$-alkane distribution, abundances and the corresponding $\delta \mathrm{D}$ and $\delta^{13} \mathrm{C}$ values between aboveground leaf or stem and belowground root in typical Everglades weland plant species. For this purpose, $n$ Alkane abundance and distributions as well as their compound-specific carbon and hydrogen isotopic ratios were measured from the leaves of 87 typical plants $(25$ species, representing 19 families) distributed across the Everglades, ranging from species abundant in tree islands and freshwater marshes, to the mangrove ecotone of the Shark River estuary, and into Florida Bay, are presented. In addition, molecular characteristics and compound specific isotopes for 23 wetland plant roots $(5$ species, representing 3 families) within the Everglades freshwater wetland were also reported.

Leaf wax $n$-alkane abundance, molecular distribution (Paq, ACL), $\delta \mathrm{D}$ and $\delta^{13} \mathrm{C}$ values ranged from 2.1 to $473 \mu \mathrm{g} / \mathrm{gdw}, 0.0$ to $1.0,25.3$ to $30.8,-231.1$ to $-77.7 \%$ and 38.8 to $-14.2 \%$, respectively, among the studied plants (both aboveground leaf or stem and belowground root). Most of the geochemical parameters differ significantly among terrestrial trees, wetland macrophtes, mangroves and seagrass. Root derived $n$-alkane 
abundances, molecular distribution (Paq, ACL), $\delta \mathrm{D}$ and $\delta^{13} \mathrm{C}$ values of studied freshwater wetland plants ranged from 6.3 to $267.8 \mu \mathrm{g} / \mathrm{gdw}, 0.19$ to $0.96,25.6$ to $27.8,-227.0$ to $117.0 \%$ and -33.0 to $-30.6 \%$, respectively. Among different potential factors affecting the $\delta \mathrm{D}$ and $\delta^{13} \mathrm{C}$ values, the plant life form (functional type) and source water are suggested to be the dominant drivers. Marine seagrass (C4 like plant) was consistently more enriched in $\delta^{13} \mathrm{C}$ than all other $\mathrm{C} 3$ plants. No significant difference of $\delta^{13} \mathrm{C}$ among other $\mathrm{C} 3$ vegetation from the tree islands, freshwater marshes and the mangrove estuary were observed. However, large $\delta \mathrm{D}$ variations within $\mathrm{C} 3$ palnts such as the terrestrial woody plants, wetland macrophytes and mangroves, were observed. Terrestrial woody plants and seagrasses were more $\delta \mathrm{D}$ enriched than wetland macrophytes. Mangroves were more $\delta \mathrm{D}$ depleted than terrestrial woody vegetation mainly as a result of salinity differences. Comparing surveyed typical wetland plant leaves and roots, no significant differences in $\delta^{13} \mathrm{C}$ values of $n$-alkanes were found, while significant differences in $n$ alkane abundance, $\mathrm{P} a q$, and $\delta \mathrm{D}$ values were found for some of emergent wetland plants surveyed, such as Typha sp., Cladium, and Eleocharis. This variability between leaves and roots could be caused by several factors such as different lipid composition, deuterium enrichment difference of biosynthetic water, or different biosynthetic fractionation among plants. All in all, the observed variability in molecular and isotopic composition among Everglades plants could be caused by different ecological drivers, especially hydrological variations and salinity gradients. This suggests that attention should carefully be considered when paleo-environmental assessments are made based on organic geochemical data in subtropical wetland ecosystems. 


\subsection{Introduction:}

n-Alkanes are abundant lipids biosynthesized by most plants, but their molecular distributions vary. As such they have been shown to be effective indicators for different plant sources to sedimentary OM, and have been widely used for variety of purposes especially in paleo-climatic and paleo-ecological reconstructions. For example, relatively short chain $n$-alkanes $\left(\mathrm{C}_{15}, \mathrm{C}_{17}\right.$ and $\left.\mathrm{C}_{19}\right)$ are mainly attributed to algae and/or bacteria (Gelpi et al., 1970), while mid-chain alkanes $\left(\mathrm{C}_{21}\right.$ to $\left.\mathrm{C}_{25}\right)$ are commonly enriched in aquatic submerged or floating plants and mosses (Ficken et al., 2000). In contrast, terrestrial woody plants are mainly characterized by the dominance of the longer chain $n$ alkanes $\left(\mathrm{C}_{27}\right.$ to $\mathrm{C}_{35}$; Rieley et al., 1991; Collister et al., 1994). On the basis of these distribution patterns, an $n$-alkane based proxy, the Paq, indicative of the relative abundance of aquatic vs. terrestrial plants (Ficken et al., 2000) was developed. Other descriptors of the $n$-alkane distributions such as the average chain length (ACL), and other numerical parameters (Rieley et al., 1991; Marzi et al., 1993; Jansen et al., 2006), have also been used to differentiate between sources of $\mathrm{OM}$ and as paleo-environmental indicators (e.g., Poynter et al., 1989; Meyers et al., 1997 and references therein; Hinrichs et al., 1999; Eglinton and Eglinton, 2008 and references therein).

$n$-Alkanes, with hydrogen covalently bounded to carbon, are stable to preserve long term isotopic information in sediments (Schimmelmann et al., 1999) for paleoclimatic reconstruction (Sachse et al., 2004; Pagani et al., 2006). As such, $n$-alkanes in sediments and soils are well known to record the plant $\delta^{13} \mathrm{C}$ and $\delta \mathrm{D}$ signatures (Chikaraishi and Naraoka, 2003; Sachse et al., 2004), and numerous studies have been 
carried out to examine the variations in the molecular distribution and the isotopic compositions $\left(\delta^{13} \mathrm{C}\right.$ and $\left.\delta \mathrm{D}\right)$ of leaf waxes $n$-alkanes in different kinds of modern plants and surface sediments (Chikaraishi et al., 2004; Sachse et al., 2006; Smith and Freeman, 2006; Sessions et al., 2006; Pedentchouk et al., 2008). Such data has been applied in the assessment of OM sources in sedimentary environments (e.g., Seki et al., 2010). Generally, $\delta^{13} \mathrm{C}$ values of $n$-alkanes have been widely used to both assess vegetation type change (C3 vs. C4 plants; e.g., Bi et al., 2005), and infer variations in climatic conditions (e.g., Yamada and Ishiwatari, 1999; Huang et al., 2001). In contrast, the $\delta \mathrm{D}$ values of $n$ alkanes have been used more specifically as a proxy to assess hydrological parameters and processes such as changes or variations in precipitation, relative humidity, temperature and salinity (Xie et al., 2000; Liu and Huang, 2005; Sachse and Sachs, 2008; Sachse et al., 2012 and reference therein).

Previous studies applying $\delta^{13} \mathrm{C}$ and $\delta \mathrm{D}$ measurements of $n$-alkanes in sediments have provided diverse geological information on past environmental conditions (e.g., Diefendorf et al., 2011; Sachse et al., 2012 and reference therein). Other studies have focused on variations in the plant leaf wax distribution across large scale climatic gradients, representing large changes in source water (especially precipitation) and plant types or distributions (e.g., Liu et al., 2008). On the basis of such studies, paleoenvironmental assessments have been performed with the goal to reconstruct past climatic conditions, and have successfully been used in a variety of environmental settings (Huang et al., 2002; Sachse et al., 2012 and reference therein). Such $n$-alkane based $\delta \mathrm{D}$ studies are commonly based on the assumption that the $\delta \mathrm{D}$ variations among 
different plants is relatively small compared with the $\delta \mathrm{D}$ changes caused by environmental effects, or that the biosynthetic isotopic fractionation among different plants is relatively constant. In fact the accuracy of these assumptions might be questionable, and few published works have challenged them. Hou et al. (2007) reported significant variations in the $\delta \mathrm{D}$ values of plant $n$-alkanes in a small area where no obvious climatic gradient or differences in environmental waters $\delta \mathrm{D}$ values were apparent. This suggested that different biosynthetic fractionation mechanisms for D may exist among plants. However, information on the $\delta^{13} \mathrm{C}$ and $\delta \mathrm{D}$ of $n$-alkanes from plants on spatially constrained scales, without significant spatial variations in climate, are still limited (Hou et al., 2007). Moreover, most peleo-reonstruction studies assume that leaf wax derived $n$ alkanes are most representative of all $n$-alkanes deposited in the soils. While aboveground biomass (including leaves) is likely the dominant OM source for most sediments, contributions from belowground biomass (including roots) through soil erosion have not specifically been considered and $n$-alkanes derived from sources other than leave litter cannot be assumed as negligible (Gocke et al., 2010; Mendez-Millan et al., 2010; Huang et al., 2011). Especially in typical subtropical wetland ecosystem such as the Everglades, OM contributions to the soil OM derived from belowground biomass (e.g., Busch et al., 2004; Poret et al., 2007) is likely to be quite significant. In addition, different plants have been reported to produce significantly different amount of $n$-alkanes in their leaf waxes. For instance, angiosperm species generate significantly more $n$-alkane than gymnosperms (Diefendorf et al., 2011). In other words, from a quantitative perspective, different plants and different plant parts can make different contributions to 
the $n$-alkane pool in soils and sediments. With this in mind and little available infromation of $n$-alkane $\delta^{13} \mathrm{C}$ and $\delta \mathrm{D}$ on typical subtropical wetland plants, there is a need to systematicly examine $n$-alkane distribution, abundances and their isotopic signal for both aboveground and belowground biomass. Such data is needed to decrease uncertainty in interpreting $n$-alkane abundance and their isotopic signals in wetland soils, which could be crucial for the paleo-reconstruction of such ecosystems.

With this in mind, the $n$-alkane abundances, distribution (Paq and ACL), and their $\delta \mathrm{D}$ and $\delta^{13} \mathrm{C}$ values from 25 species, including 87 leaves or stems (representing 19 families) along a large hydrology gradient but within small geological gradient, were determined to contribute needed data to the information gap for wetland ecosystem. Moreover, the $n$-alkane distribution patterns for both leaf (or stem) and root materials from 23 plants (5 species, representing 3 families) were also determined to explore the variation in $n$-alkane abundance, distribution and their isotope values between aboveground and belowground biomass within the same wetland plant species.

\subsection{Samples and Methods:}

\subsubsection{Site Description and samples:}

The Everglades ecosystem is one of the largest subtropical wetlands (610,483 ha) and located in southern Florida, USA. Vegetation samples were collected at diverse sites

across the greater Everglades freshwater marshes, through the Shark River estuary and into Florida Bay $\left(25^{\circ} 70^{\prime}\right.$ to $24^{\circ} 70^{\prime} \mathrm{N}$; $81^{\circ} 15^{\prime}$ to $80^{\circ} 30^{\prime} \mathrm{E}$; less than $10 \mathrm{~m}$ above sea level; Fig. 6.1). Since sampling locations fall within a very minor latitudinal scale range and 
negligible altitude differences (Klein et al., 1964), the climatic conditions in the study region are constrained as subtropical. Mean annual air temperature for all locations is about $25{ }^{\circ} \mathrm{C}$, with the difference between the warmest month (July) and the coolest month (January) of less than $10{ }^{\circ} \mathrm{C}$ (Ross et al., 2000). Generally, clearly seasonal wet and dry periods are typical and precipitation driven. Mean annual precipitation is $c a .120 \mathrm{~cm}$ with $21 \mathrm{~cm}$ falling during the dry season (December to April) and $99 \mathrm{~cm}$ falling during the wet season (May to November; Southeast Regional Climate Center, http://www.sercc.com).

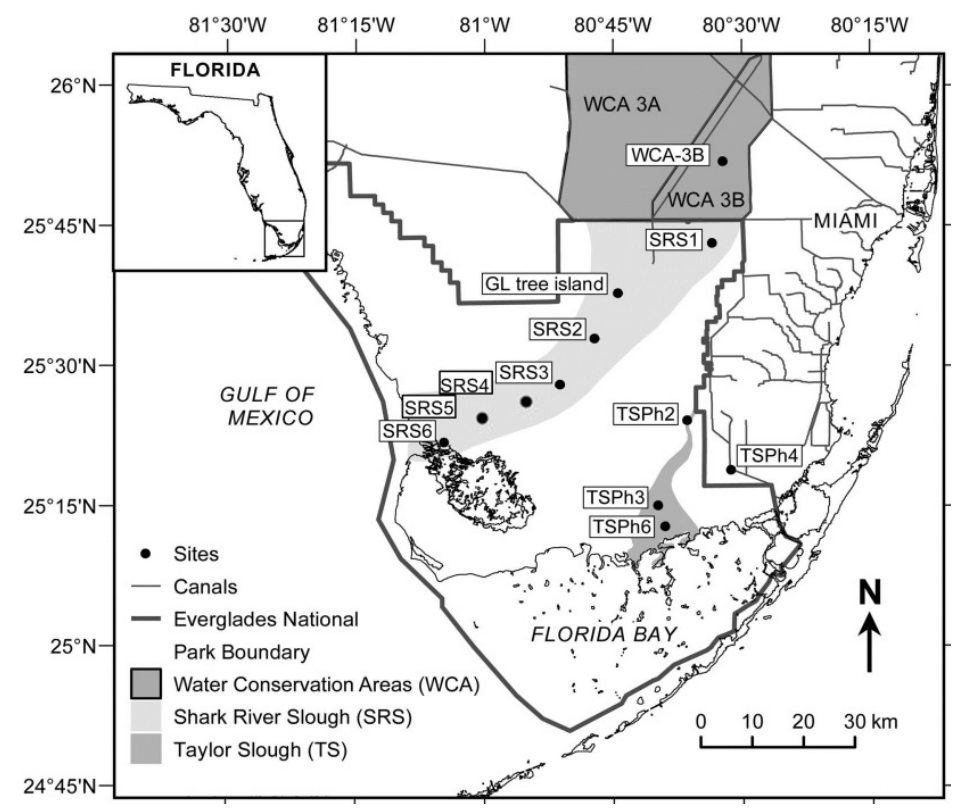

Figure 6.1 Map showing the study area.

The freshwater area of the Everglades consists primarily of seasonally inundated ridge and slough landscapes with some small stands of trees on higher ground (tree islands). This wetland ecosystem is commonly referred to as the "river of grass" (Douglas, 1947), which is characterized by grassy marshes dominated by sawgrass (Cladium jamaciensis) in the more shallow, ridge environments, and by spikerush, bladderwort and 
water lily (Eleocharis, Utricularia and Nymphaeaceae respectively) in the deeper, slough environments. Mangrove forests dominate along the Shark River estuary and coastal fringe including red mangroves (Rhizophora mangle), black mangrove (Avicennia germinans) and white mangrove (Laguncularia racemosa).

A total of 110 separate plant samples (leaves and roots, consisting of 25 families) including 18 trees (sampled from Gumbo Limbo island and tree island near Everglades Water Conservation Areas 3A and 3B), 2 ferns, 73 wetland plants (50 leaves or stems and 23 roots (sampled from WCA 3A, 3B, SRS 1-3, TSPh 2 and 3), 14 mangrove leaves, 3 seagrass (sampled from Florida Bay), were collected in multiple years (Table 6.1). Mangrove leaves (three species, white, red and black) were sampled along a salinity gradient along the Shark River estuary (Table 6.1). The entire geographical sampling scale represented less than $1^{\circ}$ latitude difference, suggesting no significant variations in climatic conditions, but with distinctive changes in environmental settings ranging from terrestrial environments to fresh water wetlands to estuarine and coastal marine environments. All plants were classified as different functional types on the basis of phylogenetic domain and growth habit (Table 6.1).

Plants (leaves, stems and roots) were collected by hand, placed in clean ziploc bags, and stored on ice immediately after collection. After transport to the lab (within 8 hours max), they were briefly, but repeatedly (three times) rinsed with deionized water to remove dust particles, frozen, freeze dried, crushed to a fine powder and kept frozen (-20 $\left.{ }^{\circ} \mathrm{C}\right)$ until analysis. 
Table 6.1 Sampling information of plants from the Florida Coastal Everglades

\begin{tabular}{|c|c|c|c|c|}
\hline Species & Sampling time & $\begin{array}{l}\text { Sampling } \\
\text { Locations }\end{array}$ & $\begin{array}{l}\text { Functional } \\
\text { type }\end{array}$ & $\begin{array}{l}\text { Sample } \\
\text { number }\end{array}$ \\
\hline Taxodium distichum & 2003 & Tree Island & TT & 1 \\
\hline Pinus elliottii & May. 2011 & Tree Island & TT & 1 \\
\hline Blechnum chilense & May. 2011 & Tree Island & $\mathrm{TF}$ & 1 \\
\hline Osmunda regalis & May. 2011 & Tree Island & $\mathrm{TF}$ & 1 \\
\hline Magnolia virginiana & Aug. 2004; May. 2011 & Tree Island & TT & 2 \\
\hline Annona glabra & Aug. 2004; May. 2011 & Tree Island & TT & 6 \\
\hline Persea borbonia & May. 2011 & Tree Island & TT & 1 \\
\hline Myrica cerifera & Aug. 2004; May. 2011 & Tree Island & TT & 2 \\
\hline Salix Caroliniana & Aug. 2004; May. 2011 & Tree Island & $\mathrm{TT}$ & 3 \\
\hline Chrysobalanus icaco & Aug. 2004 & Tree Island & $\mathrm{TT}$ & 1 \\
\hline $\begin{array}{l}\text { Cephalanthus } \\
\text { occidentalis }\end{array}$ & May. 2011 & Tree Island & $\mathrm{TT}$ & 1 \\
\hline Typha latifolia ${ }^{\mathrm{a}}$ & $\begin{array}{l}\text { May. 2011; Mar. 2012; } \\
\text { Mar. } 2013\end{array}$ & Wetland & WE & $3+3$ \\
\hline Typha domingensis ${ }^{\mathrm{a}}$ & $\begin{array}{l}\text { May. 2011; Mar. 2012; } \\
\text { Mar. } 2013\end{array}$ & Wetland & WE & $4+4$ \\
\hline Cladium jamaicense $^{\mathrm{a}}$ & $\begin{array}{l}\text { May. 2011; Mar. 2012; } \\
\text { Mar. } 2013\end{array}$ & Wetland & WE & $12+6$ \\
\hline Eleocharis cellulosa ${ }^{\mathrm{a}}$ & $\begin{array}{l}\text { May. 2011; Mar. 2012; } \\
\text { Mar. } 2013\end{array}$ & Wetland & WE & $10+4$ \\
\hline Nymphaeaceae ${ }^{\text {a }}$ & $\begin{array}{l}\text { May. 2011; Mar. 2012; } \\
\text { Mar. } 2013\end{array}$ & Wetland & WF & $8+6$ \\
\hline Utricularia foliosa & $\begin{array}{l}\text { May. 2011; Mar. 2012; } \\
\text { Mar. } 2013\end{array}$ & Wetland & WS & 8 \\
\hline Utricularia Purpurea & $\begin{array}{l}\text { May. 2011; Mar. 2012; } \\
\text { Mar. } 2013\end{array}$ & Wetland & WS & 3 \\
\hline Bacopa caroliniana & Mar. 2013 & Wetland & WS & 2 \\
\hline Laguncularia racemosa & Mar. and Nov. 2013 & $\begin{array}{l}\text { Shark River } \\
\text { Estuary }\end{array}$ & ET & 5 \\
\hline Avicennia germinans & Mar. and Nov. 2013 & $\begin{array}{l}\text { Shark River } \\
\text { Estuary }\end{array}$ & ET & 3 \\
\hline Rhizophora mangle & Mar. and Nov. 2013 & $\begin{array}{l}\text { Shark River } \\
\text { Estuary }\end{array}$ & ET & 6 \\
\hline Syringodium filiforme & 2003 & Florida Bay & MS & 1 \\
\hline Halodule wrightii & 2003 & Florida Bay & MS & 1 \\
\hline Halophila decipiens & 2003 & Florida Bay & MS & 1 \\
\hline
\end{tabular}

Note: a, both aboveground (leaf or stem) and belowground (root) biomass was sampled, $\mathrm{X}+\mathrm{X}$ in column "Sample Number" denote for X (Plant leaves or stems) + X (Plant roots); for all the other plant species, only leaves were sampled. For the functional type, TT, TF, WE, WF, WS, ET and MS denote for Terrestrial Tree, Terrestrial Fern, Wetland Emergent, Wetland Floating, Wetland Sumerged, Estuary Tree, and Marine Seagrass, respectively. 


\subsubsection{Determination of $n$-alkanes by $G C / M S$}

$n$-Alkanes were extracted following a protocol slightly modified after Folch (1957). Briefly, freeze dried biomass (1 to $2 \mathrm{~g}$ ) were subjected to sonication extraction three times (0.5 hours each) with pure methylene chloride (Optima, Fisher, USA) as solvent. Total extracts were concentrated by rotary evaporation. The extracts were further fractionated as previously described (e.g., Jaffé et al., 2001) by adsorption chromatography over silica gel, and the saturated hydrocarbon fraction was obtained after

elution with n-hexane. Then a known amount of squalane was added as internal standard to the isolated fraction. The GC/MS analyses were performed on a Hewlett-Packard 6890 GC linked to a HP 5973 MS system in the electron impact (EI) ionization mode at $70 \mathrm{eV}$, and fitted with Rtx-1 (30 meters long, 0.25 mm ID, 0.25 um df) from RESTEK, USA., The $\mathrm{GC}$ oven was programmed from 60 to $300^{\circ} \mathrm{C}$ at a rate of $6^{\circ} \mathrm{C} / \mathrm{min}$ after $1 \mathrm{~min}$ at the initial temperature, and was kept at $300^{\circ} \mathrm{C}$ for $20 \mathrm{~min}$. Identification of the $n$-alkanes was performed by comparison of chromatographic retention time, reported mass spectra, the mass spectral library and mass spectra of authentic standards.

\subsection{3. n-Alkane molecular parameters:}

Average $n$-alkane chain lengths (ACL; Eglinton and Hamilton, 1967) and the relative abundance of mid-chain to long-chain $n$-alkanes (Paq; Ficken et al., 2000) were determined for all samples. $A C L=\left(23 n-C_{23}+25 n-C_{25}+27 n-C_{27}+29 n-C_{29}+31 n-C_{31}+\right.$ $\left.33 n-C_{33}\right) /\left(n-C_{23}+n-C_{25}+n-C_{27}+n-C_{29}+n-C_{31}+n-C_{33}\right)(1) ; P a q=\left(n-C_{23}+n-C_{25}\right) /(n-$ $\left.\mathrm{C}_{23}+\mathrm{n}-\mathrm{C}_{25}+\mathrm{n}-\mathrm{C}_{29}+\mathrm{n}-\mathrm{C}_{31}\right)(2)$. 


\subsubsection{Compound specific carbon and hydrogen isotope analysis}

Compound-specific $\delta^{13} \mathrm{C}$ values of individual $n$-alkanes were measured using a gas chromatography-isotope ratio mass spectrometry (GC-IRMS) system, consisting of a HP 6890 GC equipped with a DB-1 fused silica capillary column (30 meters long, 0.25 $\mathrm{mm}$ ID, 0.25 um $\mathrm{df}$, a combustion interface (Finnigan GC combustion IV), and a Finnigan MAT delta Plus mass spectrometer. Between every four samples, three external standard mixtures containing $\mathrm{C}_{17} n$-alkane and squalane, and at different concentrations (30 ng/ $\mu \mathrm{L}, 200 \mathrm{ng} / \mu \mathrm{L}$ and $500 \mathrm{ng} / \mu \mathrm{L}$ ), with known $\delta^{13} \mathrm{C}$ values for each pure compound), were measured to check machine performance during the entire analyses period and for size correction when necessary. $\delta^{13} \mathrm{C}$ values are given in per mil (\%) notation relative to the Peedee Belemnite (PDB) standard.

Compound-specific $\delta \mathrm{D}$ values of individual $n$-alkanes were measured using a GC/Pyrolysis/IRMS system consisting of a HP 6890 GC connected to a Finnigan MAT delta Plus V mass spectrometer. The same GC column as described above was used. Pyrolysis temperature was set as $1440{ }^{\circ} \mathrm{C}$ in a micro volume ceramic tube. Helium was used as carrier gas at $1.2 \mathrm{ml} / \mathrm{min}$. The oven temperature program was the same as previously described. Methyl palmitate $(-255 \%)$ and squalane $(-107 \%)$ mixtures with different concentrations ( $200 \mathrm{ng} / \mu \mathrm{L}, 800 \mathrm{ng} / \mu \mathrm{L}$ and $1200 \mathrm{ng} / \mu \mathrm{L}$ for both of them) were used as external standards. An external standard calibration was performed between every four samples measurements. The F8 standard (purchased from Indiana University, Bloomington, USA) was used to check accuracy of the instrumentation periodically. The $\mathrm{H}_{3}{ }^{+}$factor was measured daily prior to sample analysis (average values 5.3 during this 
study, and the daily variability is within 0.1 ). Isotopic values for each sample were size corrected by the nearest two groups of standards ( 6 total), and the internal co-injected squalane for each sample if necessary. Samples were analyzed two or three times and the standard deviations were smaller than $\pm 5 \%$.

\subsubsection{Mean annual precipitation $\delta D$ values}

The mean annual precipitation $\delta \mathrm{D}$ values reported here were obtained primarily from several published sources (Price et al., 2006; Ewe et al., 2007; Price et al., 2008; Saha et al., 2009). The Online Isotopes in Precipitation Calculator (OIPC; www.waterisotopes.org) was also used to obtain reference values.

\subsection{Results and discussion:}

6.4.1 n-Alkane abundance and distribution patterns in aboveground vegetation (leaves and stems):

For discussion purposes, plants were classified mainly on the basis of phylogenetic domain, but also on growth habitat (Table 6.1, Table 6.2). The total concentration of $n$-alkanes for each species (89 leaves and/or stems in total were obtained) is shown in Table 6.2. $n$-Alkane abundances showed a large (two orders of magnitude) range from $2.1 \mu \mathrm{g} / \mathrm{gdw}$ in Halophila decipiens to $473 \mu \mathrm{g} / \mathrm{gdw}$ in Chrysobalanus icaco (Table 6.2), suggesting that the amount of biomass per area and associated contributions of litter may be critical in driving the molecular distribution values in soils because of quantitative differences between plants. Large variations in $n$-alkane abundances among 
plants are crucial to be considered when paleo-reconstruction is performed. For example, two gymnosperms contained $n$-alkanes at less than $10 \%$ by dry weight compared with most of other angiosperm species studied here. Similar lower $n$-alkane contents in gymnosperms were also reported by Diefendorf et al (2011).

$\mathrm{P} a q$ and ACL values ranged from 0.00 to 1.00 and from 25.3 to 30.8 respectively. These ranges are similar to those reported in previous studies (Eglinton et al., 1962; Eglinton and Hamilton, 1967; Simoneit et al., 1991; Ficken et al., 2000; Mead et al., 2005). The distribution of $n$-alkanes in this study ranged from $\mathrm{C}_{13}$ to $\mathrm{C}_{35}$ presenting a characteristic odd/even predominance in all plants. The $\mathrm{C}_{23}$ or $\mathrm{C}_{25} n$-alkanes were the most dominant in the aquatic submerged plants (Utricularia sp., Halodule, Ruppia etc.). The emergent plants (Eleocharis, Typha sp. etc.) were dominanted by $\mathrm{C}_{25}, \mathrm{C}_{27}$ or $\mathrm{C}_{29}$ nalkanes, while woody terrestrial vegetation as well as the mangroves had a maximum at $\mathrm{C}_{27}, \mathrm{C}_{29}, \mathrm{C}_{31}$ or $\mathrm{C}_{33}$ n-alkanes.

A general increasing trend for $\mathrm{P} a q$ and a decreasing trend for ACL were found along a vegetation gradient from TT (terrestrial trees) and ET (estuary trees) and TF (terrestrial ferns) to WE (wetland emergent plants), WF (wetland floating plants), WS (submerged aquatic plants), and then MS (marine seagrass; Table 6.1 and Fig. 6.2). The Paq trend and range generally agreed with Ficken et al. (2000). The different ACL across different classified groups may suggest that ACL can reflect change in community composition which would provide some indirect information for paleo reconstruction. Actually ACL was found lower in cooler climates than warmer climates (Simoneit et al., 
1977). However, other parameters should also be considered when applying these qualitative proxies. 
Table 6.2 $n$-Alkane concentrations and distributions across studied plant leaves of the Florida Everglades.

Note: n (SD) means "number of separate samples (standard deviation)"

\begin{tabular}{|c|c|c|c|c|c|c|c|c|c|c|}
\hline Unranked & Unranked & Order & Family & Species & $\begin{array}{l}\text { Total } n \text { - } \\
\text { alkanes } \\
(\mu \mathrm{g} / \mathrm{gdw})\end{array}$ & n (SD) & $\mathrm{P} a q$ & $\mathrm{n}(\mathrm{SD})$ & $\mathrm{ACL}$ & n (SD) \\
\hline Gymnosperms & & Pinales & Cupressaceae & Taxodium distichum & 6.7 & 1 & 0.17 & 1 & 29.2 & 1 \\
\hline Gymnosperms & Pinopsida & Pinales & Pinaceae & Pinus elliottii & 7.6 & 1 & 0.20 & 1 & 29.6 & 1 \\
\hline Pteridophyta & Polypodiopsida & Polypodiales & Blechnaceae & Blechnum chilense & 3.5 & 1 & 0.05 & 1 & 28.3 & 1 \\
\hline Pteridophyta & Polypodiopsida & Osmundales & Osmundaceae & Osmunda regalis & 61.5 & 1 & 0.05 & 1 & 28.7 & 1 \\
\hline Angiosperms & & Magnoliales & Magnoliaceae & Magnolia virginiana & 251.6 & $2(158.0)$ & 0.12 & $2(0.04)$ & 28.0 & $2(0.2)$ \\
\hline Angiosperms & & Magnoliales & Annonaceae & Annona glabra & 88.3 & $6(78.9)$ & 0.09 & $6(0.07)$ & 28.5 & $6(0.8)$ \\
\hline Angiosperms & & Laurales & Lauraceae & Persea borbonia & 29.6 & 1 & 0.21 & 1 & 28.7 & 1 \\
\hline Angiosperms & Eudicots & Fagales & Myricaceae & Myrica cerifera & 77.5 & $2(10.1)$ & 0.01 & $2(0.00)$ & 30.8 & $2(0.1)$ \\
\hline Angiosperms & Eudicots & Malpighiales & Salicaceae & Salix Caroliniana & 214.0 & 3 & 0.10 & $3(0.08)$ & 28.4 & $3(0.4)$ \\
\hline Angiosperms & Eudicots & Malpighiales & Chrysobalanaceae & $\begin{array}{l}\text { Chrysobalanus } \\
\text { icaco }\end{array}$ & 473.2 & 1 & 0.00 & 1 & 29.7 & 1 \\
\hline Angiosperms & Eudicots & Gentianales & Rubiaceae & $\begin{array}{l}\text { Cephalanthus } \\
\text { occidentalis }\end{array}$ & 281.0 & 1 & 0.01 & 1 & 29.2 & 1 \\
\hline Angiosperms & Monocots & Poales & Typhaceae & Typha latifolia & 153.0 & $3(76.1)$ & 0.13 & $3(0.06)$ & 28.3 & $3(0.3)$ \\
\hline Angiosperms & Monocots & Poales & Typhaceae & Typha domingensis & 23.0 & $4(8.2)$ & 0.23 & $4(0.11)$ & 27.9 & $4(0.2)$ \\
\hline Angiosperms & Monocots & Poales & Typhaceae & Cladium jamaicense & 240.5 & $\begin{array}{c}13 \\
(210.0)\end{array}$ & 0.23 & $13(0.11)$ & 27.8 & $13(0.3)$ \\
\hline Angiosperms & Monocots & Poales & Cyperaceae & Eleocharis cellulosa & 28.0 & $10(22.0)$ & 0.46 & $10(0.18)$ & 27.7 & $10(1.1)$ \\
\hline Angiosperms & & Nymphaeales & Nymphaeaceae & Nymphaeaceae & 83.3 & $7(67.3)$ & 0.57 & $7(0.19)$ & 27.6 & $7(0.8)$ \\
\hline
\end{tabular}




\begin{tabular}{|c|c|c|c|c|c|c|c|c|c|c|}
\hline Angiosperms & Eudicots & Lamiales & Lentibulariaceae & Utricularia foliosa & 115.4 & $6(57.1)$ & 0.67 & $6(0.13)$ & 27.0 & $6(0.3)$ \\
\hline Angiosperms & Eudicots & Lamiales & Lentibulariaceae & $\begin{array}{c}\text { Utricularia } \\
\text { Purpurea }\end{array}$ & 97.4 & $4(34.2)$ & 0.83 & $4(0.10)$ & 26.3 & $4(0.5)$ \\
\hline Angiosperms & Eudicots & Lamiales & Scrophulariaceae & Bacopa caroliniana & 72.8 & $2(61.4)$ & 0.49 & $2(0.06)$ & 28.5 & $2(0.6)$ \\
\hline Angiosperms & Eudicots & Lamiales & Combretaceae & $\begin{array}{c}\text { Laguncularia } \\
\text { racemosa }\end{array}$ & 114.8 & $6(53.1)$ & 0.08 & $6(0.03)$ & 28.3 & $6(0.3)$ \\
\hline Angiosperms & Eudicots & Lamiales & Acanthaceae & $\begin{array}{l}\text { Avicennia } \\
\text { germinans }\end{array}$ & 77.8 & $3(15.3)$ & 0.23 & $3(0.02)$ & 29.6 & $3(0.2)$ \\
\hline Angiosperms & Eudicots & Malpighiales & Rhizophoraceae & Rhizophora mangle & 58.7 & $7(20.1)$ & 0.10 & $7(0.08)$ & 29.3 & $7(0.4)$ \\
\hline Angiosperms & Monocots & Alismatales & Cymodoceaceae & $\begin{array}{l}\text { Syringodium } \\
\text { filiforme }\end{array}$ & 88.1 & 1 & 0.97 & 1 & 25.6 & 1 \\
\hline Angiosperms & Monocots & Alismatales & Cymodoceaceae & Halodule wrightii & 372.5 & 1 & 0.95 & 1 & 25.7 & 1 \\
\hline Angiosperms & Monocots & Alismatales & Hydrocharitaceae & $\begin{array}{l}\text { Halophila } \\
\text { decipiens }\end{array}$ & 2.1 & 1 & 1.00 & 1 & 25.3 & 1 \\
\hline
\end{tabular}




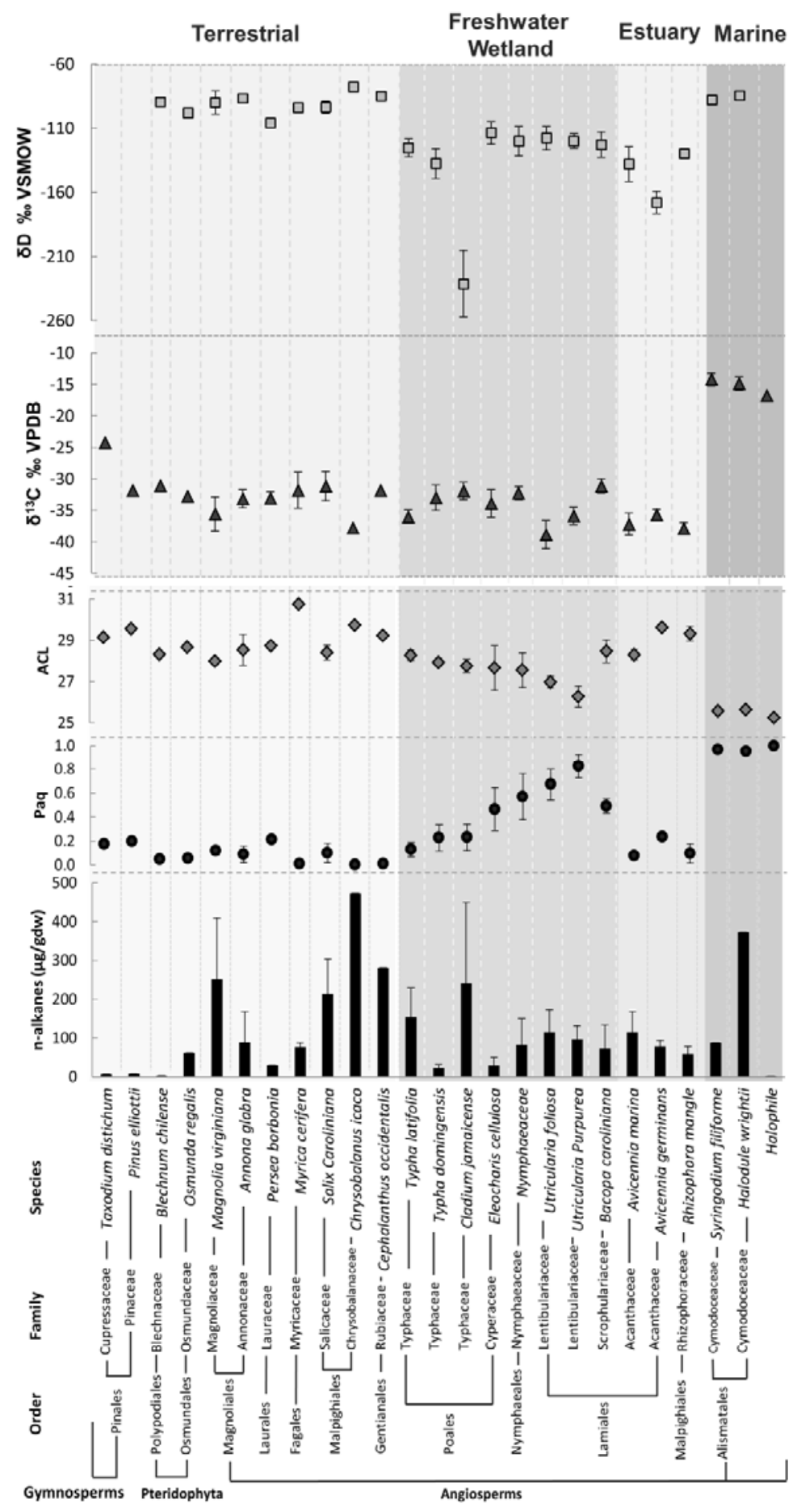

Figure 6.2 $n$-Alkanes distribution and their $\delta \mathrm{D}$ and $\delta^{13} \mathrm{C}$ values across studied plant leaves.

Note: all the $\delta \mathrm{D}$ and $\delta^{13} \mathrm{C}$ values are concentration weighted average of odd $n$-alkanes (n$\mathrm{C}_{21}$ to $\mathrm{n}-\mathrm{C}_{35}$ ). 


\subsubsection{Roots (below ground) $n$-alkanes abundance and distribution pattern}

Wetland plants can develop shallow but flourishing root systems such as rootlets (Rydin and Jeglum, 2006), which can compete with leaf litter fall for the flux of plant carbon to soils (Fahey et al., 2005). In other words, roots can potentially represent a significant source of lipids to wetland soils/sediments. In order to assess differences in the $n$-alkane distributions between above and belowground biomass, roots from cattails, sawgrass, spikerush and water lily samples were analysed and compared to the corresponding aboveground biomass (Table 6.3). Quantitatively, Typha domingensis leaves contained significantly higher (student T test, two tailed, p $<0.05$ ) amounts of $n$ alkanes than their root counterparts (Fig. 6.3). However, no significant $n$-alkane concentration difference was observed between leaves and roots for Typha latifolia, and Nymphaeaceae. Interestingly, Eleocharis cellulosa root produce higher amounts of $n$ alkanes than its leaves (Table 6.3 and Fig. 6.3). Similar results have been reported by Huang et al (2011), where roots of M. trifoliate and C. dimorpholepis contained more $n$ alkanes than their leaves. $\mathrm{P} a q$ and $\mathrm{ACL}$ values range from 0.13 to $0.96,25.5$ to 28.3 , respectively, across all roots surveyed (Table 6.3 and Fig. 6.3). Most plant roots, such as Typha latifolia, Typha domingensis and Eleocharis cellulose, had significantly higher Paq values compared to their leaves counterparts (Fig. 6.3). The Paq values of other plant species (Cladium jamaicense and Nymphaeaceae) seemed also higher in roots than leaves, but these differences were found to be not statistically significant. The observed Paq differences between above- and below-ground biomass may result from the fact that 
compared to roots, leaves are more subject to evapotranspiration and cuticles may produce more longer chain $n$-alkanes $\left(n-\mathrm{C}_{29}\right.$ and $\left.n-\mathrm{C}_{31}\right)$ to form a epicuticular barrier in order to reduce the loss of water (e.g., Eglinton and Hamilton, 1967; Hauke and Scheriber, 1998). These preliminary results, even just by a paucity of root data, suggest that attention should be paid to root-derived OM when interpreting lipid signals from wetland soil. Moreover, Rasse et al. (2005) hypothesized that plant roots could make significant contributions to soil OM (SOM), and Bull et al. (2000) suggested that the predominant source of aliphatic acids in the temperate grassland soil was root material.

While the data show that root derived OM should be considered when paleoreconstruction is performed in wetland soils, unique biomarkes to diffrenciate OM from root and leaves in the Everglades wetland plants (e.g., Chapter IV) have not been identified. Although kauranes were reported to be significantly more abundant in Cladium root than its leaves (Saunders et al., 2006), no direct evidence was found to support that kaurene is generated directly from Cladium root. Thus, the difficulty in distinguish between leaf and root derived OM in soils remains a challenge when applying biomarkers and stable isotopes in paleoenvironmental assessments of wetland soils. 
Table 6.3n-Alkane concentrations and distributions across studied plant roots of the Everglades freshwater wetland.

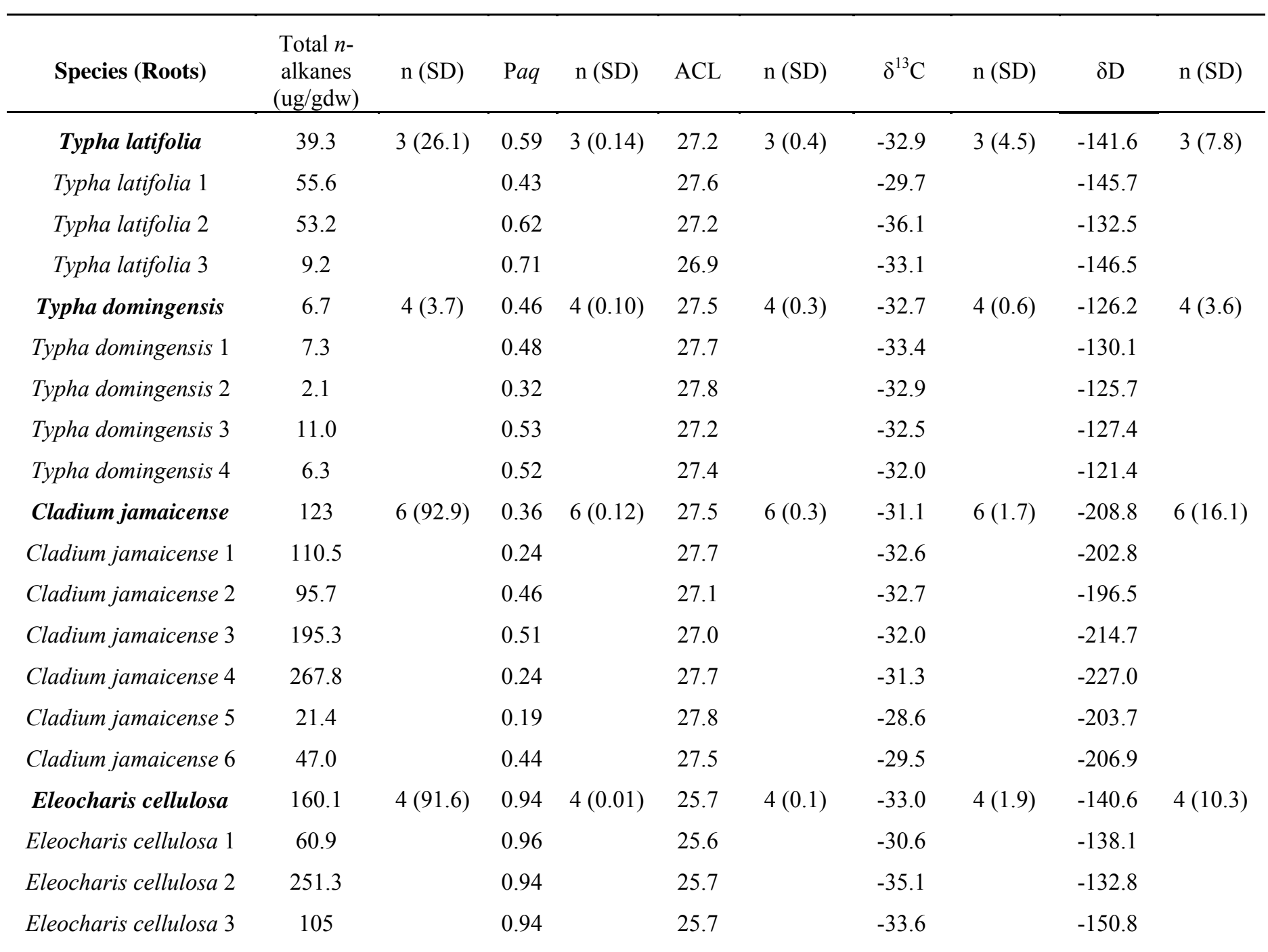




\begin{tabular}{|c|c|c|c|c|c|c|c|c|c|c|}
\hline Eleocharis cellulosa 4 & 223.2 & & 0.95 & & 25.7 & & -32.6 & & -126.4 & \\
\hline Nymphaeaceae & 78.5 & $6(66.6)$ & 0.76 & $6(0.15)$ & 26.9 & $6(0.5)$ & -30.6 & $5(1.27)$ & -130.6 & $3(11.1)$ \\
\hline Nymphaeaceae 1 & 38.7 & & 0.56 & & 27.2 & & -32.5 & & -135.4 & \\
\hline Nymphaeaceae 2 & 82.2 & & 0.61 & & 27.3 & & -29.9 & & -138.6 & \\
\hline Nymphaeaceae 3 & 28.3 & & 0.77 & & 26.8 & & -30.5 & & -117.9 & \\
\hline Nymphaeaceae 4 & 45.9 & & 0.88 & & 26.4 & & -29.2 & & N.A. & \\
\hline Nymphaeaceae 5 & 127.7 & & 0.94 & & 26.3 & & -30.9 & & N.A. & \\
\hline Nymphaeaceae 6 & 147.9 & & 0.82 & & 27.3 & & N.A. & & N.A. & \\
\hline
\end{tabular}



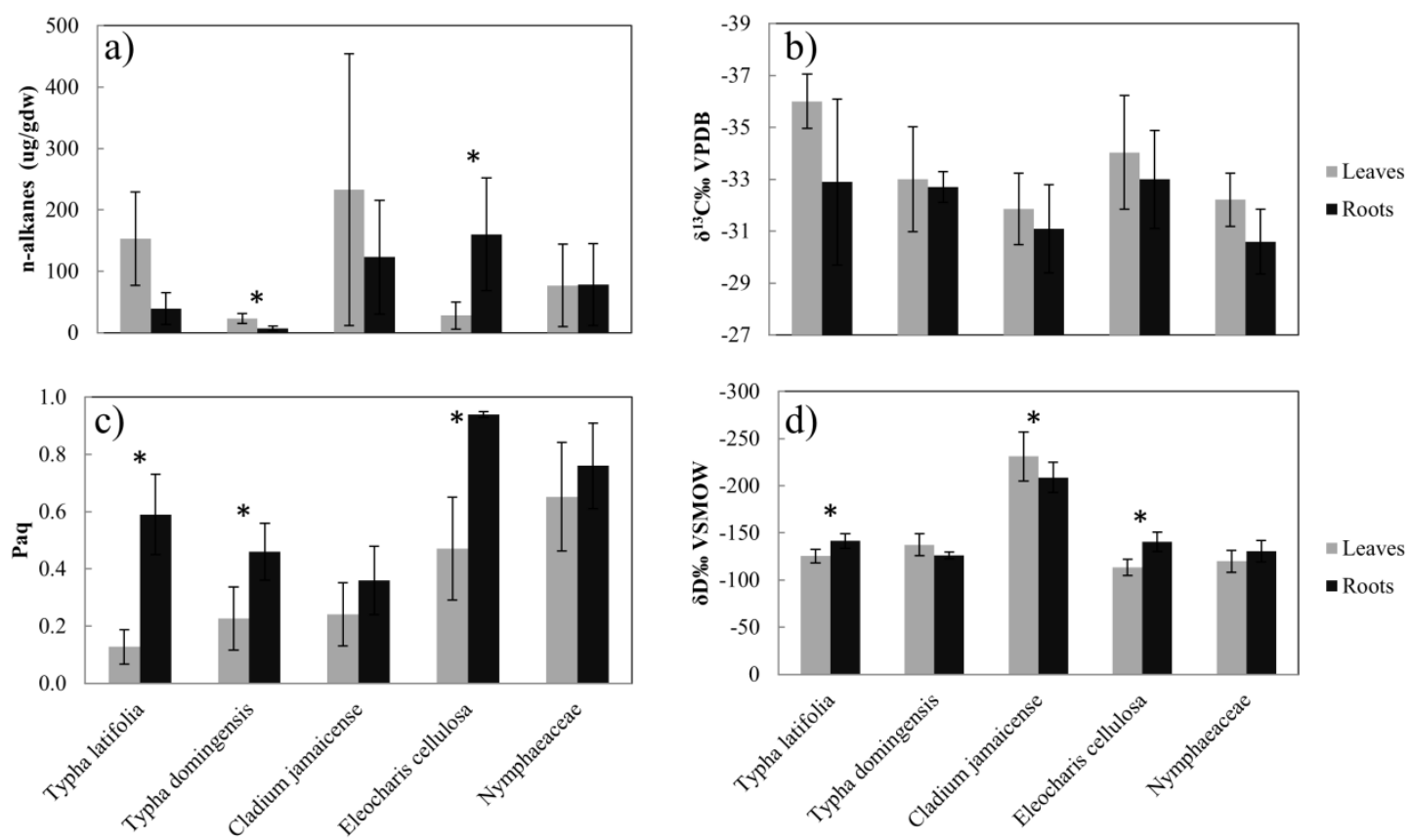

Figure 6.3 $n$-Alkane distribution and the average $\delta \mathrm{D}$ and $\delta^{13} \mathrm{C}$ values between leaf and root among typical Everglades wetland plants.

\subsubsection{Compound-specific stable carbon and hydrogen isotopic compositions- Aboveground biomass}

Determining the $\delta \mathrm{D}$ values of $n$-alkanes in typical plants from the Everglades will provide basic background information for future organic geochemical applications. Considering that significant quantitative and qualitative differences in the $n$-alkane distribution were observed, concentration-weighted average leaf-wax isotope values ( $\delta^{13} \mathrm{C}$ and $\delta \mathrm{D}$ for odd $n$-alkanes from $n-\mathrm{C}_{21}$ to $n$-C $\mathrm{C}_{35}$, when available) were reported here (Chikaraishi and Naraoka, 2003). No successful $\delta$ D measurements were obtained for $n$ alkanes of Taxodium distichum, Pinus elliottii and Halophila decipiens due to excessively low $n$-alkane concentrations. Detailed average $\delta \mathrm{D}$ and $\delta^{13} \mathrm{C}$ values for each plant are shown in Appendix 6.1. The isotopic values from different plant types sampled across the 
Everglades tree island/wetland/estuary differ significantly (, where compound-specific $\delta^{13} \mathrm{C}$ values ranged from -38.8 to $-24.2 \%$ and from -16.7 to $-14.2 \%$ among studied $\mathrm{C} 3$ and C4-type (seagrass) plant leaves, respectively. $\delta \mathrm{D}$ values ranged from -231.1 to $-77.7 \%$ among all studied plant leaves. These ranges generally agreed with other studies from modern plants from other parts of the world (Chikaraishi and Noraoka, 2003; Hou et al., 2006; Liu et al., 2006).

$n$-Alkanes from terrestrial woody and shrub plants had significantly (student $\mathrm{T}$ test, two tailed, $\mathrm{P}=0.03$ ) more enriched average $\delta \mathrm{D}$ values (averaged as $-91.2 \%$ on the basis of 9 species; 19 separate samples; $\mathrm{SD}=8.0 \%$ ) compared to wetland emergent, floating and submerged plants (averaged as $-135.7 \%$; on the basis of 8 species; 51 separate samples; $\mathrm{SD}=39.2 \%$ ). Several factors can lead to variability between terrestrial trees and wetland macrophytes. It has been reported that terrestrial trees may absorb much deeper soil water because of its root system than macrophytes, where deeper soil water is more $\delta \mathrm{D}$ depleted compared with the shallow or surface soil water (Barnes and Turner, 1998). However, other factor than water source difference can be controlling the $\delta \mathrm{D}$ values in this dataset. For example, the relative humidity is expected to be lower for the tree island plants compared to the wetland plants. Therefore, a higher degree of evapotranspiration, because of much "drier" micro-environment for the tree island vegetation as a result of wind and direct sunlight, could be a major factor causing higher $\delta \mathrm{D}$ values for trees relative to aquatic plants. This interpretation is also supported by the fact that more enriched $\delta \mathrm{D}$ values $(\sim 40 \%$ ) for terrestrial plant lipids compared to those of aquatic plants have been reported (Chikaraishi and Naraoka, 2003; Huang et al., 2004; 
Sachse et al., 2004). Moreover, Raven et al., (2005) showed that the deep root of trees would also increase transpiration rate, which will also cause enriched $\delta \mathrm{D}$ values for terrestrial trees.

The $\delta \mathrm{D}$ values of $n$-alkanes in terrestrial plants from the Tree Island and Gumbo Limbo Island range from -105.9 to $-77.7 \%$. The mean $\delta \mathrm{D}$ value of $n$-alkanes in Chrysobalanus icaco (Cocoplum) leaves were most enriched (-77.7\%o), while the mean $\delta \mathrm{D}$ value for the $n$-alkanes in the other terrestrial tree leaves were more depleted (by up to 29.2\%o), although all those woody plants were growing at the same site. The ferns (Blechnum chilense and Osmunda regalis) living in the same area have mean values of 89.6 and $-97.8 \%$, respectively. No significant difference in $n$-alkanes $\delta \mathrm{D}$ values between terrestrial tree leaves and terrestrial fern plants were observed, although Liu et al. (2008) suggested that trees may have a higher evapotranspiration compared to ferns.

The $\delta \mathrm{D}$ values of $n$-alkanes in the freshwater plants from the Everglades vary between -114.6 to $-232.2 \%$ (concentration weighted average, Appendix 6.1). Within each particular plant species, the $\delta \mathrm{D}$ variations can also be significant (up to $55.5 \%$ ). Interestingly, sawgrass (Cladium jamaicense) has a significantly depleted $\delta \mathrm{D}$ value for the $n$-alkanes (averaged as $-232.2 \%$; $\mathrm{SD}=25.9 \%$ ). This was the case for all 11 sawgrass samples collected from various locations within Evergaldes. In agreement with this observation, Gao et al. (2011) showed that emergent plants had highly depleted $\delta \mathrm{D}$ values (-240 to $-200 \%$ for $\mathrm{C}_{29} n$-alkane, $\left.\mathrm{n}=7\right)$. However, the exact mechanism for thisvery strongly depleted value is not presently known, but may possibly be caused by (1) different biosynthetic mechanisms specific to sawgrass, resulting in a stronger isotopic 
depletion compared with other wetland plants; (2) differences in water use efficiency; (3) differences in the timing of lipid biosynthesis; or (4) deeper roots to allow access to deeper soil water. Because of the highly prevalent distribution (about $60 \%$ by coverage) of sawgrass across Everglades system and its strongly depleted $\delta \mathrm{D}$ values, there is a significant potential to apply compound specific $\delta \mathrm{D}$ for the paleo-environmental assessment of pland successions in the Everglades wetlands (see Chapter VII below).

The $\delta \mathrm{D}$ values of mangrove leaves (Rhizophora mangle, Laguncularia racemosa and Avicennia germinans) range from -129.7 to $-168.0 \%$, which are more depleted than the terrestrial tree leaves analyzed. This is unexpected at first glance since estuary surface brackish water is more $\delta \mathrm{D}$ enriched than fresh water (Price et al., 2008). Similar range of highly depleted $\delta \mathrm{D}$ values for $n$-alkanes have previously been reported for Avicennia marina leaves (Ladd and Sachs, 2012), and (1) increased discrimination against deuterium during water uptake; (2) different production of compatible solutes from Denriched pyruvate; (3) different relative humidity at the leaf surface among others (Ladd and Sachs, 2012)

The $n$-alkanes for the C4-type seagrasses (Syringodium filiforme and Halodule wrightii) had average $\delta \mathrm{D}$ values of -88.0 and -84.8 , respectively, which were more enriched compared to freshwater aquatic plants and close to the $\mathrm{C} 3$ tree leaves. While no significant difference in $\delta \mathrm{D}$ values of lipids among plants with different biosynthesis pathways were reported by Sternberg et al. $(1983,1984)$, a recent study by Chikaraishi and Naraoka (2003) showed that $\delta$ D values of leaf wax from C3 plants were slightly more enriched than those of $\mathrm{C} 4$ plants, and suggested that the $\delta \mathrm{D}$ value difference 
can be associated with evapotranspiration and $n$-alkane biosynthesis. However, Smith and Freeman (2006) found that for grasses grown in both green houses and US Great Plains, $n$-alkanes from $\mathrm{C} 4$ grasses are more $\delta \mathrm{D}$ enriched by over $20 \%$ compared to those from $\mathrm{C} 3$ grasses. C4-type sea grasses in this study were sampled from Florida Bay, and the $\delta \mathrm{D}$ value of the marine water source is also more $\delta \mathrm{D}$ enriched.

Plant leaf $n$-alkane $\delta^{13} \mathrm{C}$ values are also important and can be applied to estimate plant community and climate in the geologic past (Diefendorf et al., 2010). Plant leaf $n$ alkane $\delta^{13} \mathrm{C}$ values are presented in Table 6.1. Similar to the $\delta \mathrm{D}$ measurement, the $\delta^{13} \mathrm{C}$ values were not reported for some plant $n$-alkanes because of their low concentrations. The odd carbon numbered $n$-alkanes seemed to be more enriched in ${ }^{13} \mathrm{C}$ than the even ones, which has also previously been reported (Collister et al., 1994; Chikaraishi and Naraoka, 2003). No clear correlation between the carbon chain length of $n$-alkane and their $\delta^{13} \mathrm{C}$ values were observed.

Seagrass had significantly enriched $n$-alkane $\delta^{13} \mathrm{C}$ valuess (averaged as $-16.7 \%$ and $-14.2 \%$ ) than all other C3 plants $(-37.9 \%$ to $-24.2 \%$ ) were observed. This was consistent with literature values (Bi et al., 2005; Collister et al., 1994; Lockheart et al., 1997). A large range of $n$-alkane $\delta^{13} \mathrm{C}$ values (-38.8 to $-24.2 \%$ ) was observed among all C3 plants studied. Utricularia foliosa had very depleted values averaged as $-38.8 \%$ ( $\mathrm{n}=$ $8 ; \mathrm{SD}=2.2 \%$ ), which is in agreement with data by Mead et al. (2005) who reported $-40.7 \%$ o for averaged $n$-alkane $\delta^{13} \mathrm{C}$ values of Utricularia $s p$. Such significantly depleted values have also been observed for Utricularia foliosa $(-31.5 \pm 2.0 \% ; \mathrm{n}=4)$. Taxodium distichum was more enriched in $\delta^{13} \mathrm{C}(-24.2 \%)$ and a little more depleted than the 
corresponding bulk carbon values (Anderson et al. 2005) of about -20.0\%o. The variation among C3 plants could be influenced by several factors such as water availability and plant types (Kohn, 2010; Freeman et al., 2011).

6.4.4 Compound-specific stable carbon and hydrogen isotopic compositions Belowground biomass

Root-derived lipids can also make a significant contribution to OM in sediments (Gocke et al., 2010; Huang et al., 2011; Mendez-Millan et al., 2010). For this present study, no significantly difference in $\delta \mathrm{D}$ values between leaves and roots were found for Typha latifolia, Eleocharis, and Nymphaeaceae, while for Cladium and Typha domingensis, significantly more enriched $\delta \mathrm{D}$ values in roots (student $\mathrm{T}$ test, two tailed, $\mathrm{P}$ $<0.05$ ) compared to their leaf counterparts (Fig. 6.3) were observed. Cladium roots can develop as deep or more than $2 \mathrm{~m}$ (Goslee and Richardson, 2008), which may allow the root to access more $\delta \mathrm{D}$ depleted water in deeper soil. All plant roots seemed more enriched in $\delta^{13} \mathrm{C}$ (although not statistically significant) than their leaf conterparts. This $\delta \mathrm{D}$ and $\delta^{13} \mathrm{C}$ values difference between leaves and roots may infer different biosynthetic depletion between roots and leaves for some plant species. However further studies need to be performed to address further issue. 
Table 6.4 $\delta \mathrm{D}$ and $\delta^{13} \mathrm{C}$ values of $n$-alkanes between plants leaf and root of the Florida Coastal Everglades.

\begin{tabular}{|c|c|c|c|c|}
\hline Species (leaves) & $\delta^{13} \mathrm{C}$ & $\mathrm{n}(\mathrm{SD})$ & $\delta \mathrm{D}$ & $\mathrm{n}(\mathrm{SD})$ \\
\hline Taxodium distichum & -24.2 & 1 & N.A. & 1 \\
\hline Pinus elliottii & -31.8 & 1 & N.A. & 1 \\
\hline Blechnum chilense & -31.1 & 1 & -89.6 & 1 \\
\hline Osmunda regalis & -32.7 & 1 & -97.8 & 1 \\
\hline Magnolia virginiana & -35.6 & $2(2.7)$ & -90.0 & $2(9.0)$ \\
\hline Annona glabra & -33.2 & $3(1.5)$ & -86.9 & $3(6.7)$ \\
\hline Persea borbonia & -33.1 & 1 & -105.9 & 1 \\
\hline Myrica cerifera & -31.8 & $2(2.9)$ & -94.1 & $2(1.1)$ \\
\hline Salix Caroliniana & -31.5 & $3(2.3)$ & -93.6 & $2(4.8)$ \\
\hline Chrysobalanus icaco & -37.8 & 1 & -77.7 & 1 \\
\hline Cephalanthus occidentalis & -31.8 & 1 & -85.0 & 1 \\
\hline Typha latifolia & -36.0 & $3(1.1)$ & -125.4 & $3(7.1)$ \\
\hline Typha domingensis & -33.0 & $4(2.0)$ & -137.5 & $4(11.5)$ \\
\hline Cladium jamaicense & -31.9 & $13(1.5)$ & -231.1 & $11(25.9)$ \\
\hline Eleocharis cellulosa & -34.0 & $10(2.5)$ & -113.5 & $6(8.7)$ \\
\hline Nymphaeaceae sp. & -32.2 & $7(1.0)$ & -120.0 & $6(11.7)$ \\
\hline Utricularia foliosa & -38.8 & $8(2.2)$ & -116.0 & $8(9.0)$ \\
\hline Utricularia Purpurea & -35.9 & $3(1.4)$ & -119.9 & $2(5.6)$ \\
\hline Bacopa caroliniana & -31.1 & $2(1.2)$ & -122.8 & $2(10.0)$ \\
\hline Laguncularia racemosa & -37.2 & $6(1.7)$ & -137.9 & $6(13.8)$ \\
\hline Avicennia germinans & -35.7 & $3(0.9)$ & -167.9 & $3(8.9)$ \\
\hline Rhizophora mangle & -37.9 & $7(0.9)$ & -129.7 & $7(2.3)$ \\
\hline Syringodium filiforme & -14.2 & 1 & -88.0 & 1 \\
\hline Halodule wrightii & -14.9 & 1 & -84.7 & 1 \\
\hline Halophila decipiens & -16.7 & 1 & N.A. & 1 \\
\hline Species (Roots) & $\delta^{13} \mathrm{C}$ & $\mathrm{n}(\mathrm{SD})$ & $\delta \mathrm{D}$ & $\mathrm{n}(\mathrm{SD})$ \\
\hline Typha latifolia & -32.9 & $3(3.2)$ & -141.6 & $3(7.8)$ \\
\hline Typha domingensis & -32.7 & $4(0.6)$ & -126.2 & $4(3.6)$ \\
\hline Cladium jamaicense & -31.1 & $6(1.7)$ & -208.8 & $6(16.1)$ \\
\hline Eleocharis cellulosa & -33.0 & $4(1.9)$ & -140.6 & $4(10.3)$ \\
\hline Nymphaeaceae & -30.6 & $5(1.3)$ & -130.6 & $3(11.1)$ \\
\hline
\end{tabular}




\subsection{Conclusions}

The mid to long chain $\left(\mathrm{C}_{21}\right.$ to $\left.\mathrm{C}_{35}\right) n$-alkanes in subtropical plant leaves, subtropical wetland plant roots are documented in this study. The $n$-alkane abundances between different plant group leaves will help to find the dominant $n$-alkane signal preserved in soils and sediments, which will provide clear information to interpret $\delta \mathrm{D}$ and $\delta^{13} \mathrm{C}$ values from the geologic past. Generally, gymnosperms leaves investigated here produced much lower $n$-alkane concentrationsthan gymnosperms. As expected, terrestrial trees and mangroves were more enriched in higher chain $n$-alkanes $\left(\mathrm{C}_{29}, \mathrm{C}_{31}\right.$ and $\mathrm{C}_{33}$; with lower $\mathrm{P} a q$ ) compared with freshwater wetland macrophytes. Most wetland plant roots have higher Paq and ACL values than their leaf counterparts. For instance, for the emergent Eleocharis cellulosa, (1) the $n$-alkane abundance is significantly much higher in the roots; (2) roots are relatively more enriched in longer chain $n$-alkanes $\left(n-\mathrm{C}_{29}\right.$ and $n$ $\mathrm{C}_{31}$ ). This "lipid behavior" inconsistence between leaf and root calls for further wider scope analysis, and caution has to be taken in settings where the root derived lipid cannot be neglected. Although the number of samples is limited, the difference in composition between these plants suggests that studies using $n$-alkanes and their isotope values to track paleoclimate or peleoecology need to consider both signals from above and belowground biomass.

Although my study is limited to a small geographical scale, the abundance and distribution of $n$-alkanes and their $\delta^{13} \mathrm{C}$ and $\delta \mathrm{D}$ values showed variation among plant leaves studied and also between above- and belowground biomass components. The $\delta^{13} \mathrm{C}$ values of $n$-alkanes showed large variation within C3 plants. $n$-Alkanes from terrestrial 
trees and seagrass are more enriched in $\delta \mathrm{D}$ values compared with those of wetland macrophytes. While mangroves are more $\delta \mathrm{D}$ depleted in $n$-alkanes compared with the terrestrial trees, a significant difference in $\delta \mathrm{D}$ values of $n$-alkanes were observed between leaf and root counterparts for some wetland plants. For instance, for the emergent Eleocharis cellulosa, the averaged $\delta \mathrm{D}$ value is more depleted in root compared with its leaf counterpart. $n$-Alkanes from wetland plant roots seemed to be more $\delta^{13} \mathrm{C}$ enriched than that of leaves. These isotopic variations can be affected by various parameters such as different biosynthetic process, precipitation, temperature, latitude, relative humidity, water source (availabitity or stress), taxonomy, leaf autonomy, wind, time of lipid synthesis, plant ecological life forms etc. All in all, more detailed study needs to be performed to better strengthen future paleo-reconstructions using $n$-alkanes and their isotopic compositions. 


\section{REFERENCES}

Anderson, W. T., Sternberg, L. S. L., Pinzon, M. C., Gann-Troxler, T., Childers, D. L., Duever, M. (2005). Carbon isotopic composition of cypress trees from South Florida and changing hydrologic conditions. Dendrochronologia, 23(1), 1-10.

Barnes, C.J., Turner, J.V. (1998). Isotopic exchange in soil water. In: Kendall, C., MacDonnell, J. J. (Eds.), Isotope tracers in catchment hydrology. Access Online via Elsevier, pp. 137-163.

Bi, X., Sheng, G., Liu, X., Li, C., Fu, J. (2005). Molecular and carbon and hydrogen isotopic composition of $n$-alkanes in plant leaf waxes.Organic Geochemistry, 36(10), 1405-1417.

Bowen, G.J. and Revenaugh, J. (2003). Interpolating the isotopic composition of modern meteoric precipitation. Water Resources Research 39(10), 1299, doi:10.129/2003WR002086.

Busch, J., Mendelssohn, I. A., Lorenzen, B., Brix, H., Miao, S. (2004). Growth responses of the Everglades wet prairie species Eleocharis cellulosa and Rhynchospora tracyi to water level and phosphate availability. Aquatic Botany, 78(1), 37-54.

Bull, I.D., Nott, C.J., van Bergen, P. F., Poulton, P. R., Evershed, R. P. (2000). Organic geochemical studies of soils from the Rothamsted classical experiments-VI. The occurrence and source of organic acids in an experimental grassland soil. Soil Biology and Biochemistry, 32(10), 1367-1376.

Chikaraishi, Y., Naraoka, H. (2003). Compound-specific $\delta D-\delta 13 \mathrm{C}$ analyses of $n$-alkanes extracted from terrestrial and aquatic plants. Phytochemistry, 63(3), 361-371.

Chikaraishi, Y., Naraoka, H., Poulson, S. R. (2004). Hydrogen and carbon isotopic fractionations of lipid biosynthesis among terrestrial (C3, C4 and CAM) and aquatic plants. Phytochemistry, 65(10), 1369-1381.

Collister, J.W., Rieley, G., Stern, B., Eglinton, G., Fry, B. (1994). Compound-specific $\delta^{13} \mathrm{C}$ analyses of leaf lipids from plants with differing carbon dioxide metabolisms. Organic Geochemistry, 21(6), 619-627.

Collister, J. W., Rieley, G., Stern, B., Eglinton, G., Fry, B. (1994). Compound-specific $\delta^{13} \mathrm{C}$ analyses of leaf lipids from plants with differing carbon dioxide metabolisms. Organic Geochemistry, 21(6), 619-627. 
Diefendorf, A. F., Freeman, K. H., Wing, S. L., Graham, H. V. (2011). Production of $n$ alkyl lipids in living plants and implications for the geologic past. Geochimica et Cosmochimica Acta, 75(23), 7472-7485.

Diefendorf, A. F., Mueller, K. E., Wing, S. L., Koch, P. L., Freeman, K. H. (2010). Global patterns in leaf $13 \mathrm{C}$ discrimination and implications for studies of past and future climate. Proceedings of the National Academy of Sciences, 107(13), 5738-5743.

Douglas, M.S., (1947) The Everglades river of grass (revised edition, 1988). Pineapple, Sarasota, Florida.

Douglas, P. M., Pagani, M., Brenner, M., Hodell, D.A., Curtis, J.H. (2012). Aridity and vegetation composition are important determinants of leaf-wax $\delta \mathrm{D}$ values in southeastern Mexico and Central America. Geochimica et Cosmochimica Acta, 97, 24-45.

Dutton A., Wilkinson B. H., Welker J. M., Bowen G.J. and Lohmann K. C. (2005) Spatial distribution and seasonal variation in ${ }^{18} \mathrm{O} /{ }^{16} \mathrm{O}$ of modern precipitation and river water across the conterminous United States. Hydrological Processes 19, 4121-4146.

Eglinton, T. I., Eglinton, G. (2008). Molecular proxies for paleoclimatology. Earth and Planetary Science Letters, 275(1), 1-16.

Eglinton, G., Gonzalez, A.G., Hamilton, R.J., Raphael, R.A. (1962). Hydrocarbon constituents of the wax coatings of plant leaves: a taxonomic survey. Phytochemistry, $1(2), 89-102$.

Eglinton, G., Hamilton, R. J. (1967). Leaf epicuticular waxes. Science, 156(3780), 13221335.

Ewe, S.M., da SL Sternberg, L., Childers, D.L. (2007). Seasonal plant water uptake patterns in the saline southeast Everglades ecotone. Oecologia, 152(4), 607-616.

Fahey, T. J., Siccama, T. G., Driscoll, C.T., Likens, G.E., Campbell, J., Johnson, C.E., ... Yanai, R.D. (2005). The biogeochemistry of carbon at Hubbard Brook. Biogeochemistry, 75(1), 109-176.

Feakins, S. J., Sessions, A. L. (2010). Controls on the D/H ratios of plant leaf waxes in an arid ecosystem. Geochimica et Cosmochimica Acta, 74(7), 2128-2141.

Ficken, K.J., Li, B., Swain, D.L., Eglinton, G. (2000). An n-alkane proxy for the sedimentary input of submerged/floating freshwater aquatic macrophytes. Organic Geochemistry, 31(7), 745-749. 
Freeman, K. H., Mueller, K. E., Diefendorf, A. F., Wing, S. L., Koch, P. L. (2011). Clarifying the influence of water availability and plant types on carbon isotope discrimination by C3 plants. Proceedings of the National Academy of Sciences, 108(16), E59-E60.

Gat, J.R. (1996). Oxygen and hydrogen isotopes in the hydrologic cycle. Annual Review of Earth and Planetary Sciences, 24(1), 225-262.

Gelpi, E., Schneider, H., Mann, J., Oro, J. (1970). Hydrocarbons of geochemical significance in microscopic algae. Phytochemistry, 9(3), 603-612.

Gocke, M., Kuzyakov, Y., Wiesenberg, G. L. B. (2010). Rhizoliths in loess-evidence for post-sedimentary incorporation of root-derived organic matter in terrestrial sediments as assessed from molecular proxies. Organic Geochemistry, 41(11), 1198-1206.

Goslee, S.C., Richardson, C.J. (2008). Establishment and seedling growth of sawgrass and cattail from the Everglades. In Everglades Experiments (pp. 547-564). Springer New York.

Hauke, V., Schreiber, L. (1998). Ontogenetic and seasonal development of wax composition and cuticular transpiration of ivy (Hedera helix L.) sun and shade leaves. Planta, 207(1), 67-75.

Hinrichs, K.U., Schneider, R.R., Müller, P.J., Rullkötter, J. (1999). A biomarker perspective on paleoproductivity variations in two Late Quaternary sediment sections from the Southeast Atlantic Ocean. Organic Geochemistry, 30(5), 341-366.

Hou, J., D’Andrea, W.J., MacDonald, D., Huang, Y. (2007). Hydrogen isotopic variability in leaf waxes among terrestrial and aquatic plants around Blood Pond, Massachusetts (USA). Organic Geochemistry, 38(6), 977-984.

Huang, X., Wang, C., Zhang, J., Wiesenberg, G.L., Zhang, Z., Xie, S. (2011). Comparison of free lipid compositions between roots and leaves of plants in the Dajiuhu Peatland, central China. Geochemical Journal, 45(5), 365.

Huang, Y.A., Street-Perrott, F. A., Metcalfe, S.E., Brenner, M., Moreland, M., Freeman, K.H. (2001). Climate change as the dominant control on glacial-interglacial variations in C3 and C4 plant abundance. Science, 293(5535), 1647-1651.

Huang, Y., Shuman, B., Wang, Y., Webb, T. (2002). Hydrogen isotope ratios of palmitic acid in lacustrine sediments record late Quaternary climate variations. Geology, 30(12), 1103-1106. 
Jansen, B., Nierop, K.G., Hageman, J.A., Cleef, A.M., Verstraten, J.M. (2006). The straight-chain lipid biomarker composition of plant species responsible for the dominant biomass production along two altitudinal transects in the Ecuadorian Andes. Organic Geochemistry, 37(11), 1514-1536.

Klein, H., Schroeder, M. C., Lichtler, W. F. (1964). Geology and groundwater resources of Glades and Hendry counties, Florida. Report of Investigations, (37).

Kohn, M.J. (2010). Carbon isotope compositions of terrestrial C3 plants as indicators of (paleo) ecology and (paleo) climate. Proceedings of the National Academy of Sciences, 107(46), 19691-19695.

Ladd, S.N., Sachs, J.P. (2012). Inverse relationship between salinity and $n$-alkane $\delta \mathrm{D}$ values in the mangrove Avicennia marina. Organic Geochemistry, 48, 25-36.

Ladd, S.N., Sachs, J.P. (2013). Positive correlation between salinity and $n$-alkane $\delta^{13} \mathrm{C}$ values in the mangrove Avicennia marina. Organic Geochemistry, 64, 1-8.

Liu, W., Huang, Y. (2005). Compound specific D/H ratios and molecular distributions of higher plant leaf waxes as novel paleoenvironmental indicators in the Chinese Loess Plateau. Organic Geochemistry, 36(6), 851-860.

Liu, W., Yang, H. (2008). Multiple controls for the variability of hydrogen isotopic compositions in higher plant $n$-alkanes from modern ecosystems. Global Change Biology, 14(9), 2166-2177.

Liu, W., Yang, H., Li, L. (2006). Hydrogen isotopic compositions of $n$-alkanes from terrestrial plants correlate with their ecological life forms. Oecologia, 150(2), 330-338.

Lockheart, M. J., Van Bergen, P.F., Evershed, R.P. (1997). Variations in the stable carbon isotope compositions of individual lipids from the leaves of modern angiosperms: implications for the study of higher land plant-derived sedimentary organic matter. Organic Geochemistry, 26(1), 137-153.

Marzi, R., Torkelson, B.E., Olson, R.K. (1993). A revised carbon preference index. Organic Geochemistry, 20(8), 1303-1306.

Mead, R., Xu, Y., Chong, J., Jaffé, R. (2005). Sediment and soil organic matter source assessment as revealed by the molecular distribution and carbon isotopic composition of n-alkanes. Organic Geochemistry, 36(3), 363-370.

Mendez-Millan, M., Dignac, M.F., Rumpel, C., Rasse, D.P., Derenne, S. (2010). Molecular dynamics of shoot vs. root biomarkers in an agricultural soil estimated by natural abundance ${ }^{13} \mathrm{C}$ labelling. Soil Biology and Biochemistry, 42(2), 169-177. 
Meyers, P.A. (1997). Organic geochemical proxies of paleoceanographic, paleolimnologic, and paleoclimatic processes. Organic geochemistry, 27(5-6), 213-250.

Pedentchouk, N., Sumner, W., Tipple, B., Pagani, M. (2008). $\delta^{13}$ C and $\delta D$ compositions of $n$-alkanes from modern angiosperms and conifers: An experimental set up in central Washington State, USA. Organic Geochemistry, 39(8), 1066-1071.

Poret, N., Twilley, R. R., Rivera-Monroy, V. H., and Coronado-Molina, C. (2007). Belowground decomposition of mangrove roots in Florida Coastal Everglades. Estuaries and coasts, 30(3), 491-496.

Poynter, J.G., Farrimond, P., Robinson, N., Eglinton, G. (1989). Aeolian-derived higher plant lipids in the marine sedimentary record: Links with palaeoclimate. In Paleoclimatology and paleometeorology: modern and past patterns of global atmospheric transport (pp. 435-462). Springer Netherlands.

Price, R.M., Swart, P.K. (2006). Geochemical indicators of groundwater recharge in the surficial aquifer system: Everglades National Park, Florida, USA. SPECIAL PAPERSGEOLOGICAL SOCIETY OF AMERICA, 404, 251.

Price, R.M., Swart, P.K., Willoughby, H.E. (2008). Seasonal and spatial variation in the stable isotopic composition $\left(\delta^{18} \mathrm{O}\right.$ and $\left.\delta \mathrm{D}\right)$ of precipitation in south Florida. Journal of Hydrology, 358(3), 193-205.

Rasse, D.P., Rumpel, C., Dignac, M.F. (2005). Is soil carbon mostly root carbon? Mechanisms for a specific stabilisation. Plant and Soil, 269(1-2), 341-356.

Raven, P.H., Evert, R. F., Eichhorn, S.E. (2005). Biology of plants. Macmillan.

Rieley, G., Collier, R. J., Jones, D. M., Eglinton, G., Eakin, P. A., Fallick, A. E. (1991). Sources of sedimentary lipids deduced from stable carbon-isotope analyses of individual compounds. Nature, 352, 425-427.

Rydin, H., Jeglum, J., Jeglum, J.K. (2006). The biology of peatlands. Oxford University Press.

Sachse, D., Billault, I., Bowen, G.J., Chikaraishi, Y., Dawson, T.E., Feakins, S.J., ... and Kahmen, A. (2012). Molecular paleo-hydrology: interpreting the hydrogen isotopic composition of lipid biomarkers from photosynthetic organisms. Annual Review of Earth Planetary Science, 40, 221-249.

Sachse, D., Radke, J., Gleixner, G. (2004). Hydrogen isotope ratios of recent lacustrine sedimentary $n$-alkanes record modern climate variability. Geochimica et Cosmochimica Acta, 68(23), 4877-4889. 
Sachse, D., Radke, J., Gleixner, G. (2006). $\delta$ D values of individual $n$-alkanes from terrestrial plants along a climatic gradient-Implications for the sedimentary biomarker record. Organic Geochemistry, 37(4), 469-483.

Sachse, D., Sachs, J.P. (2008). Inverse relationship between D/H fractionation in cyanobacterial lipids and salinity in Christmas Island saline ponds. Geochimica et Cosmochimica Acta, 72(3), 793-806.

Saha, A.K., Sternberg, L. O. R., da Silviera, L., Miralles-Wilhelm, F. (2009). Linking water sources with foliar nutrient status in upland plant communities in the Everglades National Park, USA. Ecohydrology, 2(1), 42-54.

Saunders, C.J., Gao, M., Lynch, J.A., Jaffé, R., Childers, D.L. (2006). Using soil profiles of seeds and molecular markers as proxies for sawgrass and wet prairie slough vegetation in Shark Slough, Everglades National Park. Hydrobiologia, 569(1), 475-492.

Schimmelmann, A., Lewan, M. D., \& Wintsch, R. P. (1999). D/H isotope ratios of kerogen, bitumen, oil, and water in hydrous pyrolysis of source rocks containing kerogen types I, II, IIS, and III. Geochimica et Cosmochimica Acta, 63(22), 3751-3766.

Seki, O., Nakatsuka, T., Shibata, H., Kawamura, K. (2010). A compound-specific nalkane $\delta 13 \mathrm{C}$ and $\delta \mathrm{D}$ approach for assessing source and delivery processes of terrestrial organic matter within a forested watershed in northern Japan. Geochimica et Cosmochimica Acta, 74(2), 599-613.

Sessions, A. L. (2006). Seasonal changes in $\mathrm{D} / \mathrm{H}$ fractionation accompanying lipid biosynthesis in Spartina alterniflora. Geochimica et Cosmochimica Acta, 70(9), 21532162.

Simoneit, B. R. (1977). Biogenic lipids in particulates from the lower atmosphere over the eastern Atlantic. Nature, 267, 682-685.

Simoneit, B. R., Sheng, G., Chen, X., Fu, J., Zhang, J., Xu, Y. (1991). Molecular marker study of extractable organic matter in aerosols from urban areas of China. Atmospheric Environment. Part A. General Topics, 25(10), 2111-2129.

Smith, F. A., Freeman, K. H. (2006). Influence of physiology and climate on $\delta \mathrm{D}$ of leaf wax $n$-alkanes from $\mathrm{C}_{3}$ and $\mathrm{C}_{4}$ grasses. Geochimica et Cosmochimica Acta, 70(5), 11721187.

Sternberg, L. D. S. L. (1988). D/H ratios of environmental water recorded by D/H ratios of plant lipids. Nature, 333(6168), 59-61. 
Sternberg, L., Deniro, M.J. (1983). Isotopic composition of cellulose from $\mathrm{C}_{3}, \mathrm{C}_{4}$, and CAM plants growing near one another. Science, 220(4600), 947-949.

Sternberg, L., Deniro, M.J., Ajie, H. (1984). Stable hydrogen isotope ratios of saponifiable lipids and cellulose nitrate from cam, $\mathrm{C}_{3}$ and $\mathrm{C}_{4}$ plants. Phytochemistry, 23(11), 2475-2477.

Xie, S., Nott, C.J., Avsejs, L.A., Volders, F., Maddy, D., Chambers, F.M., ... Evershed, R. P. (2000). Palaeoclimate records in compound-specific $\delta D$ values of a lipid biomarker in ombrotrophic peat. Organic Geochemistry, 31(10), 1053-1057.

Yamada, K., Ishiwatari, R. (1999). Carbon isotopic compositions of long-chain nalkanes in the Japan Sea sediments: implications for paleoenvironmental changes over the past 85 kyr. Organic Geochemistry, 30(5), 367-377.

Zhou, Y., Grice, K., Stuart-Williams, H., Farquhar, G.D., Hocart, C.H., Lu, H., Liu, W. (2010). Biosynthetic origin of the saw-toothed profile in $\delta^{13} \mathrm{C}$ and $\delta^{2} \mathrm{H}$ of $n$-alkanes and systematic isotopic differences between $n$-, iso-and anteiso-alkanes in leaf waxes of land plants. Phytochemistry, 71(4), 388-403. 


\section{CHAPTER VII}

COMPOUND SPECIFIC $\delta$ D AND $\delta{ }^{13} \mathrm{C}$ ANALYSES AS A TOOL FOR THE ASSESSMENT OF HYDROLOGICAL CHANGE IN A SUBTROPICAL WETLAND 


\subsection{Abstract}

Compound-specific carbon and hydrogen isotopic ratios and the molecular distribution of $n$-alkanes from important plants, surface soil transects and soil cores from the Florida Everglades wetland, USA, are reported. The aim of this study was to test the potential of compound specific $\delta \mathrm{D}$ and $\delta^{13} \mathrm{C}$ isotope data as a means to assess historical vegetation successions induced by hydrological modification in an anthropogenically impacted, subtropical wetland. Compound specific stable isotope values and the $n$-alkane based aquatic proxy $(\mathrm{P} a q)$ for a series of wetland plants which are dominant in long hydroperiod, slough and short hydoperiod, ridge landscapes of the Everglades were determined and compared with a transect of ridge-to-slough surface soil organic matter as a calibration exercise. The plant data show that $\delta^{13} \mathrm{C}$ and $\delta \mathrm{D}$ values of $n$-alkanes differ significantly (by 6.4\%o and 150\%, respectively) among all the studied wetland plants. Not all emergent macrophytes had similar values, and difference of as much as 3.6\% and 130\% were observed between the two most abundant species (Cladium and Eleocharis) for $\delta^{13} \mathrm{C}$ and $\delta \mathrm{D}$ values, respectively. A clear $n$-alkane $\delta \mathrm{D}$ value depletion $(-130 \%$ to 167\%) was observed along slough-ridge soil transects (with water depth ranging from $\sim 70$ to $\sim 40 \mathrm{~cm}$ along the transect) from this wetland setting. This $n$-alkane $\delta \mathrm{D}$ depletion trend correlated with a decrease in Paq, and was likely the result of a transition from slough to ridge dominated vegetation (Eleocharis to Cladium). Two soil cores were also analyzed and the $\delta^{13} \mathrm{C}$ values of $n$-alkanes were found to be enriched by as much as $4.6 \%$ and 3.9\%o with depth for both the slough (dating back to $\sim 40 \mathrm{BC}$ ) and ridge (dating back to $\sim 1800 \mathrm{AD}$ ) cores, respectively. In agreement with the relatively constant Paq values, 
the lack of significant changes in the trend of $\delta \mathrm{D}$ vs. depth for the slough core suggest a consistent slough type of vegetation composition over time at that location.. In contrast changes of both $n$-alkane $\delta^{13} \mathrm{C}$ and $\delta \mathrm{D}$ values for the ridge core, especially after $\sim 1960$ $\mathrm{AD}$, coincide with the expected plant successions from historically long hydroperiod, slough type plants (Eleocharis, Utricularia, Nymphaea) to present day, short hydroperiod, ridge type plant (Cladium). These $\delta^{13} \mathrm{C}$ and $\delta \mathrm{D}$ changes may be driven by a combination of plant primary productivity and vegetation shifts associated with hydrological change. The application of the compound-specific stable isotope determinations strongly complements the biomarker approach for paleo-hydrological assessments in wetland ecosystems.

\subsection{Introduction}

The Florida Everglades wetland ecosystem consists of a mosaic of tree islands within a slough and ridge landscape (Larsen et al., 2011), and is the largest subtropical freshwater wetland ecosystem in North America. The Everglades is commonly referred to as the "River of Grass" (Douglas, 1947) because of the prevalent presence of sawgrass marshes (Cladium jamaicense), which account for over 65\% vegetation of the Everglades landscape. Vegetation distribution in the Everglades wetland is controlled by various drivers including hydroperiod (water depth and duration of inundation as related to precipitation and/or water management), water quality, fire frequency and soil type (Ross et al., 2003). Since the Everglades is characterized by of low velocity sheet flow (Riscassi and Schaffranek, 2004), hydroperiod and associated historical changes are important 
factors affecting the landscape as well as vegetation type and distribution. Anthropogenic effects through water management over the last century (Davis et al., 1994) are likely the most critical influence of present day Everglades ecohydrology.

In the Everglades, water flow has been significantly altered over the past few decades because of structural modifications for flood control, urban and agricultural development. These changes resulted in reduced water delivery coupled with altered seasonal pulsing because of regulated flow, and in general depriving the system of the needed water quantity and quality (Larsen et al., 2011). As a result, Everglades National Park (ENP) is undergoing an unprecedented restoration effort with the ultimate goal to re-establish water quantity, quality and timing to conditions similar to those existing prior to anthropogenic alteration (Richardson et al., 2008). To establish benchmarks for hydrological restoration, paleo-hydrological information is needed to assess changes from past conditions to the present in order to predict the potential effectiveness of restoring the system. For the purpose of paleo-ecological and paleo-hydrological studies, sourcespecific biomarkers have already successfully been applied in the Everglades (Saunders et al., 2006; Saunders et al., in review) and have confirmed a vegetation shift with the reduction of hydroperiod over the past decades, especially during the latter part of the 20th Century ( $>1960$ ). Among the biomarkers applied, the aquatic proxy, Paq (Ficken et al., 2000; Mead et al., 2005) was found to be most successful to differentiate between ridge type plants (lower $\mathrm{P} a q$ ) and slough type plants (higher $\mathrm{P} a q$ ), and consequentially between ridge and slough surface soil organic matter (Saunders et al., 2006; in review). However, in some instances, even when a clear trend in plants distribution along the 
ridge-to-slough was apparent, no obvious Paq changes were observed. In addition, variations of $\mathrm{Paq}$ within the same plant species sampled from different locations or during different years have also been observed (Mead et al., 2005; Pisani et al., 2013; Saunders et al., 2006), suggesting that this parameter may have some limitations in its application as a paleo-proxy. Moreover, it is still unclear how environmental variables (climate variations) or stresses (hydroperiod changes) would affect the wax lipid composition or $\mathrm{P} a q$ for the same plants (Jetter et al., 2006). The other biomarkers previously applied to assess hydrological change and associated vegetation shifts in the Everglades (Saunders et al., 2006; in review) are either associated with organic matter derived from periphyton $\left(\mathrm{C}_{20} \mathrm{HBI}\right.$ and botryococcenes; Jaffé et al., 2001 and Gao et al., 2006, respectively) or primarily with root derived organic matter (kaurenes; Saunders et al., 2006). As such, these biomarkers also have some limitations to assess historical variations in the ridge and slough landscape because of the mobility of the sources of the former and the belowground generation of the latter. It is therefore of interest to develop additional paleo-indicators to be applied to better constrain historical hydroperiod variations in wetlands and serve as complementary information to those already being applied.

On the basis of literature reports, I hypothesize that the combination of this $n$ alkane proxy $(\mathrm{P} a q)$ with compound specific $\delta \mathrm{D}$ and/or $\delta^{13} \mathrm{C}$ isotope data for $n$-alkanes would provide further confirmation regarding plant successions induced through hydrological changes. Since compound specific $\delta D$ and $\delta^{13} \mathrm{C}$ values of lipids can be directly related to hydrological changes (Sachse et al., 2012 and references therein) and 
changes in primary productivity (Shemesh et al., 1993; Gu et al., 1996), I expect that this approach will not only complement information suggested by biomarkers (Diefendorf et al., 2011), but may be even more sensitive and accurate than molecular distributions (e.g., Paq) alone. Previous literature reports have confirmed this assumption. Seki et al. (2009) applied a combined compound-specific $\delta^{13} \mathrm{C}$ and $\delta \mathrm{D}$ to study a peat core from the Hani bog of northeast China with the objective to reconstruct local changes in effective precipitation and land vegetation cover over the last $16 \mathrm{Kyr}$. They suggested an increase in the contribution of aquatic plants and a higher water level during the 14 to $11 \mathrm{Ka}$ period on the basis of the depleted $\delta \mathrm{D}$ values of mid-chain $n$-alkanes $\left(\mathrm{C}_{23}, \mathrm{C}_{25}\right.$ and $\left.\mathrm{C}_{27}\right)$ relative to the long chain $n$-alkane $\left(\mathrm{C}_{31}\right)$ and the higher $\mathrm{P} a q$ values during that time. In addition, Seki et al. (2010) combined compound-specific $\delta \mathrm{D}$ and $\delta^{13} \mathrm{C}$ of $n$-alkanes in forest soil, wetland peat and lake sediments within the Dorokawa watershed, Japan, to understand sources and delivery processes of terrestrial organic matter to the lake sediments. Krull et al. (2006) measured compound specific $\delta \mathrm{D}$ and $\delta^{13} \mathrm{C}$ analyses of lipids from a modern, water-limited ecosystem with a mixed tree-grass vegetation distribution to provide different water use strategies of plants and plant induced changes in soil hydrology. Leider et al. (2013) reported on the distribution and stable isotopic compositions of $\delta \mathrm{D}$ and $\delta^{13} \mathrm{C}$ of plant-wax derived $n$-alkanes $\left(\mathrm{C}_{27}\right.$ and $\left.\mathrm{C}_{29}\right)$ in terrestrial, coastal and offshore surface sediments in relation to hydrology, suggesting they could be applied as paleohyrologic proxies and that combined $\delta \mathrm{D}$ and $\delta^{13} \mathrm{C}$ of plant $n$-alkanes could discriminate potential source of $n$-alkanes deposited in the marine environment. Similarly, 
Chikaraishi et al. (2005) successfully evaluated the source input for phytol and sterols from sediments of Lake Haruna in Japan using both $\delta^{13} \mathrm{C}$ and $\delta \mathrm{D}$ data.

Thus, combining molecular distribution patterns with compound-specific stable

$\delta^{13} \mathrm{C}$ and $\delta \mathrm{D}$ measurements is a promising approach to assess paleo-hydrology in the Everglades wetland. In this study, I report the $\delta^{13} \mathrm{C}$ and $\delta \mathrm{D}$ composition of leaf wax $n$ alkanes from dominant wetland plants, surface soil transects, and soil cores in Everglades National Park, USA. The objectives of this effort were to test whether stable isotope signatures of sub-tropical wetland plants are recorded in wetland surface soils, and if so, if they can be applied to wetland soil cores for paleo-environmental assessments. Combined with other studies that have already provided information on historical vegetation shifts because of hydrological variations in the system (Cohen et al., 1999; Saunders et al., 2006; in review), the Everglades ecosystem seems ideally suited to test this hypothesis.

\subsection{Samples and methods}

\subsubsection{Samples}

\subsubsection{Site description and samples}

The oligotrophic Florida Everglades freshwater wetland system is extremely sensitive to anthropogenic forcing and stress. Two major drainage basins exist within the southern Everglades; the Shark River Slough (SRS) and the Taylor Slough/Panhandle area (TSPh; Fig. 7.1). Differences in hydrological conditions between the freshwater marshes in SRS and TSPh (long vs short hydroperiod respectively; Chen et al., 2013) 
result in different soil types. However, the vegetation community structures are quite similar between the two. As such, TSPh marshes are characterized by marl type soils, while peats are typical for the freshwater SRS. Freshwater marshes in the Everglades are dominated by Cladium (sawgrass), whose productivity is lower at TSPh relative to SRS marsh sites (Daoust and Childers, 2004; Ewe et al., 2006). The major plants species at both sampling stations (SRS2 and TSPh2; Fig. 7.1) are Cladium, Eleocharis, Nymphaea, Utricularia sp. and periphyton. While Cladium is usually more abundant at the ridges (shallow water), Eleocharis, Utricularia and Nymphaea are more common in the sloughs (deeper water, Gunderson, 1994).

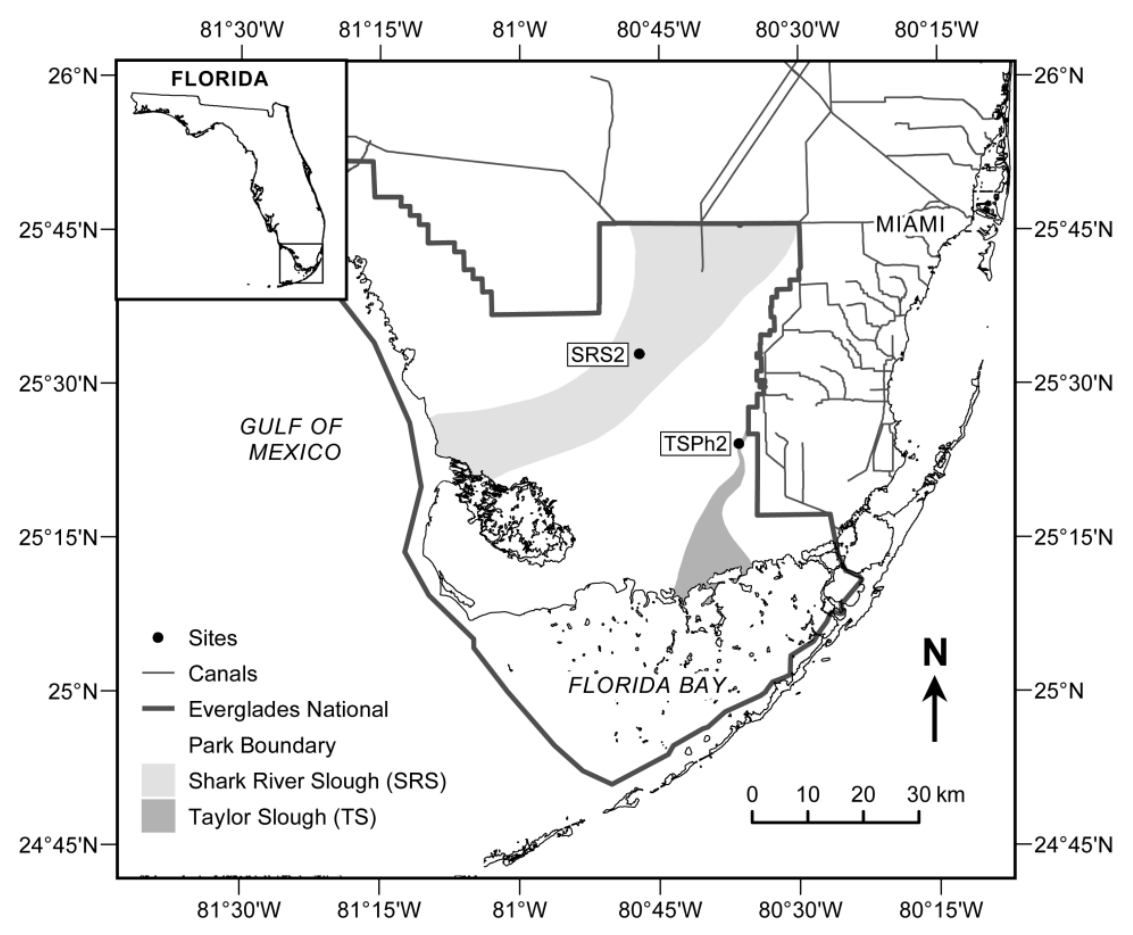

Figure 7.1 Map of sampling locations. 


\subsubsection{Vegetation survey}

Typical freshwater plants (Cladium, Eleocharis, Utricularia and Nymphaea) and freshwater periphyton were collected at sites SRS2 and TSPh2 in 2012 (Fig. 7.1, for details see fcelter.fiu.edu/). Additionally, all these plants mentioned above and Bacopa Caroliniana, Typha domingensis, Typha latifolia were also sampled from various locations such as Water Conservation Area 3B (WCA3B) and SRS3 across the Florida Everglades freshwater wetland. Plant materials were wrapped in clean aluminum foil, put in pre-combusted glass jars and then stored on ice. After transport to the lab, they were washed repeatedly with deionized water, frozen, freeze dried, crushed to a fine powder and kept frozen $\left(-20^{\circ} \mathrm{C}\right)$ until analysis.

\subsubsection{Surface soil transects}

Surface soil transect samples were obtained from archived samples from a previous study (Saunders et al., 2006). Briefly, soils were collected by pushing sharpened, butyrate coring sleeves ( $7.3 \mathrm{~cm}$ i.d.) into the soil and extruding the top $4 \mathrm{~cm}$ of soil. Surface soil (11 samples, $5 \mathrm{~m}$ intervals) were collected at SRS2 along a $50 \mathrm{~m}$ transect from deep (wet prairie/slough) to shallow (sawgrass mash/ridge) water depth. The surface soil samples were labeled as $\operatorname{SRS} 2(\times, 0)$, where ' $x$ ' is the distance in $m$ away from the deep slough site along the transect, and ' 0 ' stands for surface sample. Thus, samples covering the range from deep slough (start of transect), through the intermediate depth transition zone (half-way point of transect), to the shallow sawgrass marsh ridge (end of transect) would be labeled as $\operatorname{SRS} 2(0,0), \operatorname{SRS} 2(25,0)$ and $\operatorname{SRS} 2(50,0)$, respectively. 


\subsubsection{Soil cores}

Two archived soil cores (Saunders et al., 2006; in review) were obtained from the SRS2 site; one at wet prairie/slough and the other one at a Cladium marsh/ridge (Fig. 7.1). While the marsh/ridge landscape is covered dominantly by Cladium, the wet prairie/slough landscape is primarily covered by emergent Eleocharis, floating aquatic Nymphaea and submerged Utricularia. The transition zone between marsh/ridge and wet prairie/slough are usually covered by the mixture of Cladium and Eleocharis (Saunders et al., 2006, in review). Periphyton was well distributed throughout both Cladium marshes/ridges and wet prairies/sloughs. The core from wet prairie/slough (deep water; longest hydroperiod) will be referred to as 'slough core' while the other one from the Cladium marshes (shallow waters; short hydroperiod) will be referred to as 'ridge core'. The two soil cores ( $25 \mathrm{~cm}$ deep for each) were collected and sectioned as previously described (Saunders et al., 2006).

\subsubsection{Analytical methods}

\subsubsection{Biomarker analyses}

All samples (plants, surface soils and soil core segments) were frozen, freezedried $\left(-50^{\circ} \mathrm{C} ; 0.01 \mathrm{~m}\right.$ bar) and ground. The dried samples are Soxhlet-extracted with pure methylene chloride (Optima, Fisher, USA) for 24 hours. Activated copper is added to the total extract to remove elemental sulfur. Total extractable organics were saponified with 0.5 $\mathrm{M} \mathrm{KOH}$ and separated into neutral and acid fractions. The neutral fraction was further fractionated over silica gel to obtain the saturated hydrocarbons (Jaffé et al., 1995) using 
$n$-hexane $(20 \mathrm{ml})$ as eluent. A capillary GC/MS system (Hewlett-Packard 6890 GC interfaced to a Hewlett-Packard 5973 quadrupole scanning mass spectrometer) was used to analyze all the samples, and operated in the electron impact (EI) ionization mode at 70 $\mathrm{eV}$. Identifications of individual compounds such as $n$-alkanes and $\mathrm{C}_{20} \mathrm{HBI}$ (Highly Branched Isoprenoid) were performed by comparisons with previously reported mass spectra and chromatographic elution patterns.

\subsubsection{Soil core dating}

Previous studies have shown that soil accretion rates, which are controlled by diverse environmental factors, vary widely in the Everglades wetlands ecosystem (Willard et al., 2002). In this study, soil core ages were obtained from (Saunders et al., in review), which were approximated primarily using radiometric dates, or from literature values (Willard et al., 2001a; Willard et al., 2001b). The age model of the ridge core was on the basis of ${ }^{14} \mathrm{C}$ AMS dates of seeds collected at two depths $(8-10$ and $22-24 \mathrm{~cm})$, while for the slough core, a single ${ }^{14} \mathrm{C}$ date provided an age at $21-22 \mathrm{~cm}$, and ages for 0 $20 \mathrm{~cm}$ were approximated by averaging depth-age data from 5 other dated Shark River Slough cores. Average depth approximations were consistent with age models from previous Shark River slough cores (Craft and Richardson 1998; Glaser et al. 2012; Willard et al. 2006). 


\subsubsection{Compound specific isotope $(C$ and $H)$ analyses}

For the specific purpose of testing whether compound-specific isotope measurements will provide complementary and more sensitive information compared to biomarker proxies, I analyzed some of the same surface soil transects (ridge to slough; Saunders et al., in review) with closer space intervals, for locations with clear vegetation transitions. Similarly, two soil cores (one ridge, one slough; see above) at SRS2 from Saunders et al. (in review) were also analyzed for this purpose.

The aliphatic hydrocarbon fraction was analyzed to obtain the $\delta \mathrm{D}$ and $\delta^{13} \mathrm{C}$ values for targeted compounds. Compound-specific $\delta^{13} \mathrm{C}$ values of $n$-alkanes and the $\mathrm{C}_{20} \mathrm{HBI}$ were measured using a gas chromatography-isotope ratio mass spectrometry (GC-IRMS) system, consisting of a Thermo Trace GC Ultra system equipped with a DB-1 fused silica capillary column (30 meters long, $0.25 \mathrm{~mm}$ ID, $0.25 \mu \mathrm{m} \mathrm{df}$ ), a Thermo GC/TC 2 interface, and a Thermo Delta V IRMS. Oven temperature for conversion of compounds to $\mathrm{CO}_{2}$ was held at $960^{\circ} \mathrm{C}$. Between every four samples, three standard mixtures containing $\mathrm{C}_{17}$ $n$-alkane and squalane (different concentrations as $30 \mathrm{ng} / \mu \mathrm{L}, 200 \mathrm{ng} / \mu \mathrm{L}$ and $500 \mathrm{ng} / \mu \mathrm{L}$, with known $\delta^{13} \mathrm{C}$ values for each) were measured to check instrument performance and was also used for size correction if necessary. A known amount of squalane was also coinjected with samples as internal standard for stable carbon and hydrogen isotopic measurements. The $\delta^{13} \mathrm{C}$ values are given in per mil (\%o) notation relative to the Vienna Peedee Belemnite (VPDB) standard (Coplen et al., 1983).

Compound-specific $\delta \mathrm{D}$ values of $n$-alkanes and the $\mathrm{C}_{20} \mathrm{HBI}$ were measured using the same system as for carbon, but with the DB-1 fused silica capillary GC column 
connected to the higher temperature oven for pyrolysis set at a temperature of $1440^{\circ} \mathrm{C}$ in a micro volume ceramic tube. Helium was used as carrier gas at $1.6 \mathrm{ml} / \mathrm{min}$. The oven temperature program was the same as that described above. F8 standard (purchased from Indiana University, Bloomington, USA) was used to check accuracy of the instrumentation periodically. Methyl palmitate (-255\%) and squalane (-107\%) mixtures with different concentrations $(150 \mathrm{ng} / \mu \mathrm{L}, 800 \mathrm{ng} / \mu \mathrm{L}$ and $1500 \mathrm{ng} / \mu \mathrm{L}$ for both compounds) were used as external standards, and were analyzed between every four sample measurements. An additional external standard (B3; Indiana University, Bloomington, USA) consisting of a mixture of $n$-alkanes from $\mathrm{C}_{16}$ to $\mathrm{C}_{30}$ (with different concentrations) and known $\delta \mathrm{D}$ values, was also analyzed and used for size correction purpose. The $\mathrm{H}_{3}{ }^{+}$factor was measured daily prior to sample analysis (average values 5.3 during this study, with a daily variability within 0.1 ). Isotopic values for each sample were size corrected by the nearest two groups of standards ( 6 methyl palimitate/squalane mixture standards and 2 B3 standards), and the internal co-injected squalane for each sample if necessary. Good replicates for all $\delta \mathrm{D}$ values for standards (different concentration) were obtained, with a standard deviation $< \pm 5 \%$. Error was estimated through the repeat analyses of selected samples $(n=3)$, which yielded standard deviations within $\pm 5 \%$. Only compounsd (mostly odd carbon numbered $n$-alkanes) present in sufficient quantities (intensity above $500 \mathrm{mVs}$ ) for reliable $\delta^{13} \mathrm{C}$ and $\delta \mathrm{D}$ measurements are reported and discussed herein. 


\subsubsection{Mean annual precipitation and surface water $\delta D$ values}

The mean annual precipitation $\delta \mathrm{D}$ values in my study area were obtained from several published sources (Ewe et al., 2007; Price and Swart, 2006; Price et al., 2008; Saha et al., 2009). If no published values are accessible, OIPC: The Online Isotopes in Precipitation Calculator (www.waterisotopes.org) was also used to estimate the annual $\delta \mathrm{D}$ values of meteoric water from the sampling sites (Bowen and Revenaugh, 2003).

\subsubsection{Calculation of the net "apparent" isotopic fractionations}

The isotopic difference between leaf $n$-alkanes and source water was calculated using follow equation 1: $\varepsilon_{n \text {-alkane/water }}=\alpha_{n \text {-alkane/water }}-1=\left(\frac{\delta \text { D } n \text {-alkane+1 }}{\delta \text { Dwater+1 }}-1\right) \times 1000 \%$.

\subsection{Results and Discussion}

\subsubsection{Paq and $C_{20} H B I$ in dominant wetland plants, surface soil and soil cores}

This sub-section is intended to provide a synthesis of existing literature data plus some complimentary results from some additional samples from this study on the distribution of the $\mathrm{P} a q$ and $\mathrm{C}_{20} \mathrm{HBI}$ in the studied samples leading into the results and discussion of the compound-specific stable isotope data. The values of $\mathrm{P} a q$ for Everglades wetland plants from various previous studies (Mead et al., 2005; Neto et al., 2006; Pisani et al., 2013; Saunders et al., 2006, in review) and this present study are summarized in Table 7.1. Since periphyton consists mainly of planktonic organisms, and doesn't produce $n$-alkanes in the range used for the Paq determination, it is therefore not listed. In general, the Paq values agreed with those reported by Ficken et al. (2000), 
where emergent plants and submerged-floating plants showed values ranging from 0.07 0.61 and $0.48 \sim 0.94$, respectively. A general and consistent trend of lower Paq values was observed for ridge type vegetation (Cladium) compared to slough type vegetation (Eleocharis, Utricularia and Nymphaea) (Saunders et al., 2006; in review; Table 7.1). Cladium sampled at both SRS2 and TSPh2 had lower Paq compared with Eleocharis, Utricularia and Nymphaea (Table 7.2). However, some overlap of Paq values across plant types (emergent vs. submerged) was also observed. Paq values from the same plant species sampled at different time (different studies) were also different (Table 7.1). For instance, the mean Paq values of Cladium leaves and Eleocharis stems sampled during different studies ranged from $0.13 \sim 0.27$ and $0.27 \sim 0.51$, respectively. Similar observations applied to samples of the same species collected at different locations (SRS2 compared with TSPh2; Table 7.2). Previous reports have shown that $n$-alkane distributions can vary within species both in long evolutional perspective and across environmental gradient scale (Dodd and Afzal-Rafii, 2000; Dodd and Poveda, 2003). These variations (both within and between plants) could be because of factors such as: (i) different time for leaf wax $n$-alkanes synthesis and accumulation (Stránský et al., 1967); (ii) different environmental variables and environmental stresses, such as temperature, water stress or ablation by wind (Jetter et al., 2006); (iii) variation of leaf physiology because of different sun-exposure time (Dyson and Herbin, 1968); and potentially other unknown factors. While the $\mathrm{P} a q$ values presented some degree of variation, in general terms they were consistently higher and lower for slough and ridge plants respectively and as such applicable as a paleo-hydrology proxy. However, the observed variability 
also implies some limitations in the use of this biomarker.

Table 7.1 Paq values of the dominant plant species in the Everglades freshwater wetlands.

\begin{tabular}{|c|c|c|c|c|c|}
\hline \multirow{2}{*}{ Species } & \multirow{2}{*}{$\begin{array}{c}\text { Biomass } \\
\text { Allocatio } \\
\mathrm{n}(\%)\end{array}$} & $\begin{array}{c}\text { Saunders et } \\
\text { al., } 2006, \\
2014 \\
\end{array}$ & $\begin{array}{l}\text { Mead et al. } \\
\text { 2005; Neto et } \\
\text { al., } 2006\end{array}$ & $\begin{array}{c}\text { Pisani et al., } \\
2013\end{array}$ & This study \\
\hline & & $\begin{array}{l}\text { Paq Mean (n; } \\
\text { SD) }\end{array}$ & $\begin{array}{l}\text { Paq Mean (n; } \\
\text { SD) }\end{array}$ & $\begin{array}{c}\mathrm{Paq} \text { Mean } \\
(\mathrm{n} ; \mathrm{SD})\end{array}$ & $\begin{array}{c}\text { Paq Mean (n; } \\
\text { SD) }\end{array}$ \\
\hline \multicolumn{6}{|c|}{ Emergent species } \\
\hline \multicolumn{6}{|c|}{ Cladium jamaicense } \\
\hline Leaves & $76 \%^{\mathrm{a}}$ & $0.18(6 ; 0.06)$ & $\begin{array}{c}0.13\left(3-5^{\mathrm{c}}\right. \\
0.02)\end{array}$ & $0.27(1)$ & $\begin{array}{l}0.23(13 \\
0.11)\end{array}$ \\
\hline Rhizomes & $5 \%{ }^{\mathrm{a}}$ & $0.55(6 ; 0.05)$ & - & - & - \\
\hline Roots & $19 \%^{\mathrm{a}}$ & $0.54(6 ; 0.16)$ & - & - & $0.36(6 ; 0.12)$ \\
\hline \multicolumn{6}{|c|}{ Eleocharis spp. } \\
\hline Stems & $75 \%^{\mathrm{a}}$ & $0.43(5 ; 0.16)$ & $\begin{array}{l}0.51\left(3-5^{c}\right. \\
\quad 0.02)\end{array}$ & $0.27(1)$ & $\begin{array}{c}0.46(10 \\
0.18)\end{array}$ \\
\hline Rhizomes & $\underset{\mathrm{b}}{12.5 \%}$ & $0.96(3 ; 0.01)$ & - & - & - \\
\hline Roots & $\underset{\mathrm{b}}{12.5 \%}$ & $0.88(3 ; 0.08)$ & - & - & $0.94(5 ; 0.01)$ \\
\hline
\end{tabular}

Typha domingensis

Leaves $\quad 50 \%$

Roots $\quad 50 \%$

Typha latifolia

Leaves $\quad 50 \%$

Roots $\quad 50 \%{ }^{\mathrm{b}}$

Nymphaea odorata

Leaves $\quad 50 \%{ }^{\mathrm{b}}$

- $\quad 0.57(7 ; 0.19)$ 


\begin{tabular}{|c|c|c|c|c|c|}
\hline Roots & $50 \%{ }^{b}$ & - & - & - & $0.76(6 ; 0.15)$ \\
\hline \multicolumn{6}{|c|}{ Nuphar lutea } \\
\hline Leaves & $25 \% \%^{\mathrm{b}}$ & $0.05(3 ; 0.01)$ & - & - & - \\
\hline Stems & $25 \% \%^{\mathrm{b}}$ & $0.20(3 ; 0.03)$ & - & - & - \\
\hline Rhizomes & $25 \%{ }^{\mathrm{b}}$ & $0.91(3 ; 0.04)$ & - & - & - \\
\hline Roots & $25 \%{ }^{\mathrm{b}}$ & $0.94(3 ; 0.01)$ & - & - & - \\
\hline \multicolumn{2}{|c|}{ Panicum hemitomon } & - & - & $0.13(1)$ & - \\
\hline \multicolumn{2}{|c|}{ Bacopa Caroliniana } & - & - & $0.24(1)$ & $0.49(2 ; 0.06)$ \\
\hline \multicolumn{6}{|c|}{ Submerged Species } \\
\hline \multicolumn{2}{|l|}{ Chara sp. } & - & $\begin{array}{c}0.89\left(3-5^{\mathrm{c}}\right. \\
0.06)\end{array}$ & - & - \\
\hline \multicolumn{2}{|c|}{ Ruppia maritima } & & $0.67(1)$ & - & - \\
\hline \multicolumn{2}{|c|}{ Utricularia foliosa } & - & $0.93^{\mathrm{d}}(3 ; 0.01)$ & - & $0.67(4 ; 0.13)$ \\
\hline \multicolumn{2}{|c|}{$\begin{array}{l}\text { Utricularia } \\
\text { purpurea }\end{array}$} & - & $0.85(1)$ & $0.83(1)$ & $0.83(2 ; 0.10)$ \\
\hline
\end{tabular}

${ }^{a}$ Busch et al. 2004

${ }^{\mathrm{b}}$ parsimoniously assuming equal proportions

${ }^{c}$ on the basis of 3-5 measurements

${ }^{\mathrm{h}}$ Neto et al. 2006

$\mathrm{SD}=$ standard deviation; $\mathrm{n}=$ sample size; ' - ' = not accessible 
Table 7.2 Summary of plants biomarker and hydrology in adjacent ridge and slough communities in the two study sites SRS2 and TSPh2. Note: Hydroperiods and elevation differences (Saunders et al., in review) are representative of points centrally located in adjacent ridge and slough habitats (15-25 $\mathrm{m}$ from the ridge/slough ecotone).

\begin{tabular}{|c|c|c|c|c|c|c|c|}
\hline $\begin{array}{l}\text { Plant common name } \\
\text { (scientific name) }\end{array}$ & Location & Plant type & $\begin{array}{c}\text { Average } \\
\text { Hydroperiod } \\
\text { from } 2001 \text { to } \\
2007 \\
\text { (min, max) }\end{array}$ & $\begin{array}{l}\text { Ridge- } \\
\text { Slough } \\
\text { Elevation } \\
\text { Difference } \\
\quad(\mathrm{cm}) \\
\end{array}$ & $\mathrm{P} a q$ & $\mathrm{C}_{\max }$ & $\mathrm{C}_{\text {range }}$ \\
\hline Cladium (Sawgrass) & SRS2 ridge & Emergent & $304(196,365)$ & \multirow{4}{*}{13.7} & 0.17 & 29 & $17-33$ \\
\hline Eleocharis (Spikerush) & SRS2 slough & Emergent & \multirow{3}{*}{$351(282,365)$} & & 0.29 & 27 & $15-33$ \\
\hline Utricularia (Bladderwort) & SRS2 slough & Submerged & & & 0.40 & 27 & $15-33$ \\
\hline Nymphaea (Water lily) & SRS2 slough & Floating aquatic & & & 0.78 & 23 & $15-33$ \\
\hline Cladium (Sawgrass) & $\mathrm{TSPh} 2$ ridge & Emergent & $171(114,233)$ & \multirow{4}{*}{30.5} & 0.18 & 27 & $15-33$ \\
\hline Eleocharis (Spikerush) & TSPh2 slough & Emergent & \multirow{3}{*}{$275(238,335)$} & & 0.52 & 27 & $17-33$ \\
\hline Utricularia (Bladderwort) & TSPh2 slough & Submerged & & & 0.71 & 27 & $17-33$ \\
\hline Nymphaea (Water lily) & TSPh2 slough & Floating aquatic & & & 0.82 & 23 & $15-33$ \\
\hline
\end{tabular}


The $\mathrm{P} a q$ ranged from 0.33 to 0.67 across the surface soil transect showing a clear decreasing trend from slough to ridge (Saunders et al., 2006; in review). $\mathrm{C}_{20} \mathrm{HBI}$, originally attributed to cyanobacteria in periphyton (Jaffé et al., 2001), was consistently detected at large concentration across the surface soil transect. No obvious trend was observed for the $\mathrm{C}_{20} \mathrm{HBI}$ abundance (average cover percentage is about $40 \%$ ) across the surface soil transect, which suggests no clear variations in periphyton cover.

With regard to the slough and ridge cores, total alkane concentrations ranged from 82 to $271 \mu \mathrm{g} / \mathrm{gdw}$ (205 to $729 \mu \mathrm{g} / \mathrm{g}$ OC) and 60 to $247 \mu \mathrm{g} / \mathrm{gdw}$ (145 to $561 \mu \mathrm{g} / \mathrm{g} \mathrm{OC}$ ), respectively. These values are similar to those reported by Seki et al. (2010) and probably reflects the preservation of organic matter under anoxic or sub-oxic conditions in wetlands with peat accumulation. Paq values varied only slightly in the range of 0.57 to 0.64 down the slough core (Saunders et al., in review), which may probably be caused by the relatively high OM inputs from Eleocharis, and/or Utricularia and/or Nymphaea. In contrast, the ridge core could be divided into two zones on the basis of biomarker (Paq) distributions; zone-1 (0 - $9 \mathrm{~cm})$ and zone-2 $(9-25 \mathrm{~cm}$; Saunders et al., in review). The recorded ranges for zones 1 and 2 are $0.38-0.54$ and $0.59-0.70$, respectively, which may suggest a vegetation type change from zone-1 (enriched in Cladium) to the higher Paq of zone-2 (dominated by Eleocharis and/or Nymphaea). On the basis of the Paq survey from the plants and the surface soil calibration, it is possible to suggest that a vegetation shift did happen though my ridge core. However, considering the potentially large variations in $\mathrm{P} a q$ even for the same plant (see Table 7.1), additional information is needed to better constrain such changes. $\mathrm{C}_{20} \mathrm{HBI}$ was consistently detected throughout both cores showing a concentration increases up to $500 \mu \mathrm{g} / \mathrm{g}$ OC for upper soils in both 
cores. Higher organic matter inputs from periphyton during the last few decades has been suggested to explain this trend (Saunders et al., in review), possibly as a result of higher nutrients input derived from water runoff from urban and agricultural areas (Davis, 1991).

\subsubsection{Isotopic ( $C$ and $H$ ) compositions of $n$-alkanes in typical Everglades wetland plants}

All average $\delta^{13} \mathrm{C}$ and $\delta \mathrm{D}$ values shown (Table 7.3 and Fig. 7.2) were calculated by concentration-weighted average of the odd $n$-alkanes from $\mathrm{C}_{21}$ to $\mathrm{C}_{33}$ for better comparison. The $\delta^{13} \mathrm{C}$ and $\delta \mathrm{D}$ values of $n$-alkanes $\left(\mathrm{C}_{21}\right.$ to $\left.\mathrm{C}_{33}\right)$ differed significantly (6.4\%o for $\delta^{13} \mathrm{C}$ and $154.7 \%$ for $\delta \mathrm{D}$; Table 7.3 ) among the whole plants dataset (SRS2 and $\mathrm{TSPh} 2$, Table 7.3). Generally, Utricularia had the most depleted $\delta^{13} \mathrm{C}$ values (concentration-weighted average, -35.1 to $-37.7 \%$ ), while Cladium and Nymphaea were more enriched in ${ }^{13} \mathrm{C}$ (-31.3 to $-33.6 \%$ and -32.5 to $-33.3 \%$, respectively). Comparing the same plants between SRS2 and TSPh2 sites, $\delta^{13} \mathrm{C}$ values differed significantly for Cladium $(\mathrm{P}<0.01)$ and Utricularia $(\mathrm{P}<0.01)$, while no significant changes were observed for Eleocharis and Nymphaea. The $\delta^{13} \mathrm{C}$ difference may be explained by various factors mainly related with different environmental conditions affecting primary productivity (Shemesh et al., 1993; Gu et al., 1996). Relative ${ }^{13}$ C-enrichment for Cladium (emergent plant) in SRS2 compared with TSPh2 (2.3\% difference) could have resulted from a relative decrease in primary productivity of Cladium in $\mathrm{TSPh} 2$ due to enhanced water-stress (Anderson et al., 2005). Alternatively the reduction of stomatal conductance and/or an increase in biochemical C-assimilation into lipids for Cladium grown at SRS2 with higher water level and longer hydroperiod (Ewe and Sternberg, 2002) could explain this observation. This relationship is different from terrestrial trees growing in a 
temperate environment, where water stress causes changes in water-use efficiency (WUE) and carbon assimilation resulting in a relative isotopic enrichment (Francey and Farquhar, 1982; Saurer et al., 1995). Yet, my data shows that plants growing in wetland settings may not respond in the same manner as previously observed in other wetland based studies (Anderson et al., 2005). Utricularia (submerged plant) showed significantly more depleted $\delta^{13} \mathrm{C}$ at SRS2 compared with $\mathrm{TSPh} 2$ (2.6\% difference), and similar negative correlation between water level and $\delta^{13} \mathrm{C}$ was also reported in Sphagnum (Huang et al., 2014). This inverse relationship between water level and $\delta^{13} \mathrm{C}$ is potentially controlled by a relative decrease in primary productivity at SRS2 (longer hydroperiod) possibly because of less light penetration. Since the dissolve organic matter (DOM) concentration is much higher at SRS2 $(21.0 \pm 9.7 \mathrm{mg} / \mathrm{L}, \mathrm{n}=67)$ compared with that of TSPh2 $(7.8 \pm$ $3.5 \mathrm{mg} / \mathrm{L}, \mathrm{n}=44$; Chen et al., 2013), and DOM can absorb light (Coble et al., 1998), light availability at SRS2 may indeed limit primary productivity of submerged species. The decrease of $\delta^{13} \mathrm{C}$ value coincides with primary productivity decrease and is supported by other studies from sediments (O'Reilly et al., 2003), lake environments (Schelske and Hodell, 1991; Gu et al., 1996) and ocean systems (Shemesh et al., 1993). In addition, water use efficiency can also cause $\delta^{13} \mathrm{C}$ variations in plants (Hubick et al., 1986; Ehleringer and Cooper, 1988; Ehleringer 1990), and is possible that such mechanism may also contribute to the observed $\delta^{13} \mathrm{C}$ value difference observed between these two sites. 
a) SRS2\&TSPh2 plants $\mathrm{n}$-alkanes $\left(\delta^{13} \mathrm{C}\right)$ mean values

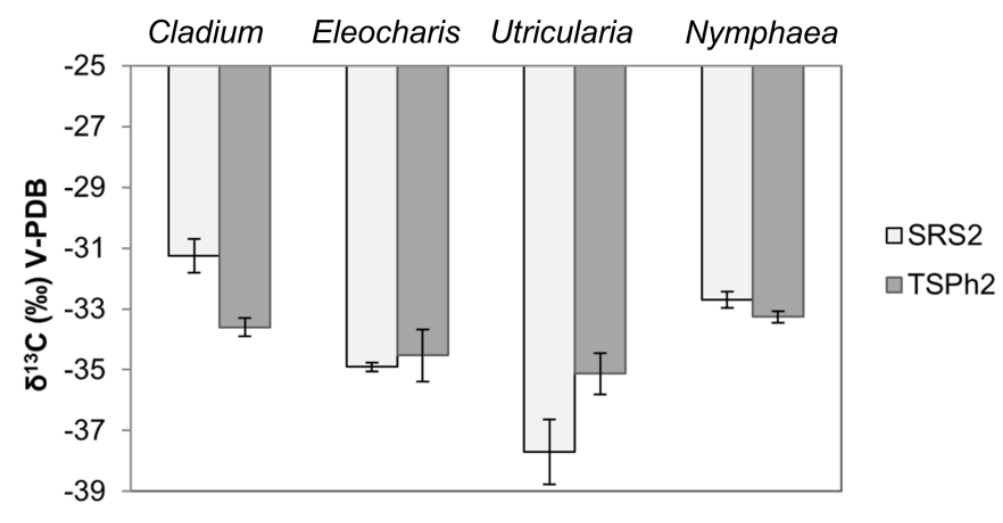

b) SRS2\&TSPh2 plants $\mathbf{n}$-alkanes (סD) mean values

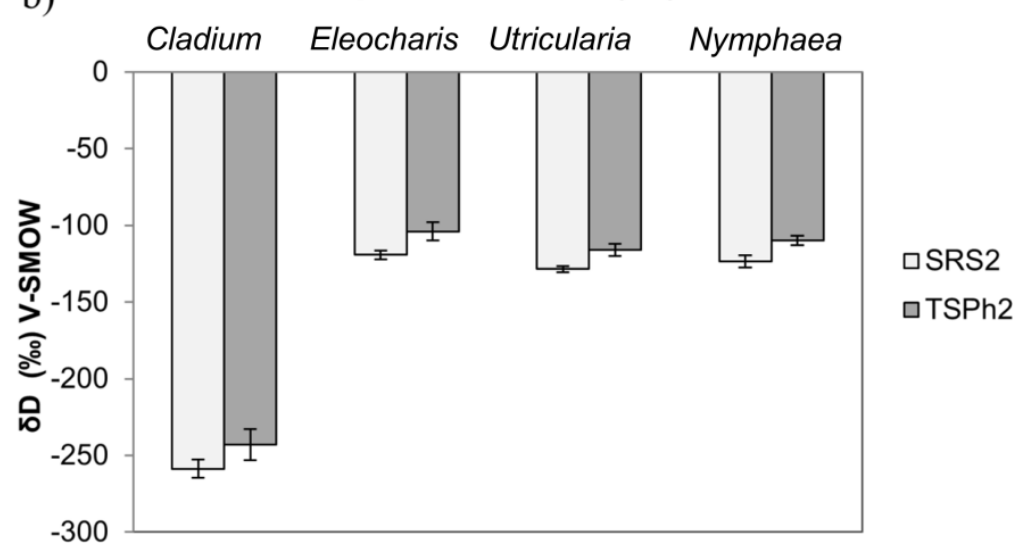

Figure 7.2 SRS2 and TSPh2 plants $n$-alkane $\delta^{13} \mathrm{C}$ and $\delta \mathrm{D}$ mean values distribution. 
Table 7.3 SRS2 and TSPh2 plants $n$-alkane $\delta^{13} \mathrm{C}$ and $\delta \mathrm{D}$ values distribution (N.A. means not analyzed).

Note: all mean $n$-alkane values reported are concentration weighted average values of odd $n$-alkanes from $\mathrm{C}_{21}$ to $\mathrm{C}_{31}$, when reportable.

\begin{tabular}{|c|c|c|c|c|c|c|c|c|}
\hline Plant species & $\begin{array}{l}\text { Odd } n \text { - } \\
\text { alkanes } \\
\text { (mean) }\end{array}$ & $\mathrm{nC}_{21}$ & $\mathrm{nC}_{23}$ & $\mathrm{nC}_{25}$ & $\mathrm{nC}_{27}$ & $\mathrm{nC}_{29}$ & $\mathrm{nC}_{31}$ & $\mathrm{nC}_{33}$ \\
\hline SRS2 Cladium $\left(\delta^{13} \mathrm{C}\right)$ & -31.3 & -32.4 & -29.8 & -31.1 & -29.5 & -29.3 & -33.5 & -33.1 \\
\hline SRS2 Eleocharis $\left(\delta^{13} \mathrm{C}\right)$ & -34.9 & -31.8 & -32.5 & -34.5 & -35.8 & -37.2 & -37.8 & N.A. \\
\hline SRS2 Utricularia $\left(\delta^{13} \mathrm{C}\right)$ & -37.7 & N.A. & -37.5 & -38.0 & -40.5 & -36.2 & -36.3 & N.A. \\
\hline SRS2 Nymphaea $\left(\delta^{13} \mathrm{C}\right)$ & -32.5 & N.A. & -33.2 & -31.3 & -32.3 & -31.9 & -33.9 & N.A. \\
\hline TSPh2 Cladium $\left(\delta^{13} \mathrm{C}\right)$ & -33.6 & N.A. & -32.4 & -32.6 & -33.5 & -33.3 & -36.2 & N.A. \\
\hline TSPh2 Eleocharis $\left(\delta^{13} \mathrm{C}\right)$ & -34.5 & N.A. & -33.2 & -34.4 & -33.0 & -35.5 & -36.6 & N.A. \\
\hline $\mathrm{TSPh} 2$ Utricularia $\left(\delta^{13} \mathrm{C}\right)$ & -35.1 & -33.1 & -35.8 & -37.0 & -36.4 & -33.3 & -35.0 & N.A. \\
\hline TSPh2 Nymphaea $\left(\delta^{13} \mathrm{C}\right)$ & -33.3 & -33.4 & -34.6 & -35.5 & -33.1 & -32.0 & -31.0 & N.A. \\
\hline SRS2 Cladium ( $\delta \mathrm{D})$ & -258.7 & N.A. & -229 & -282.7 & -275.1 & -263.4 & -243 & N.A. \\
\hline SRS2 Eleocharis ( $\delta \mathrm{D})$ & -119.3 & -100.4 & -109.8 & -113.4 & -115.9 & -129.7 & -127.5 & -85.9 \\
\hline SRS2 Utricularia $(\delta \mathrm{D})$ & -128.5 & -99.2 & -132.2 & -140.8 & -118.8 & -131.4 & -119.1 & N.A. \\
\hline SRS2 Nymphaea $(\delta \mathrm{D})$ & -118.5 & N.A. & -98.9 & -113.1 & -144.9 & -152.9 & -102.4 & N.A. \\
\hline TSPh2 Cladium ( $\delta \mathrm{D})$ & -243.0 & N.A. & -242.7 & -270.8 & -228.2 & -221.1 & -252.0 & -175.2 \\
\hline TSPh2 Eleocharis ( $\delta \mathrm{D})$ & -104.0 & N.A. & N.A. & -95.4 & -116.1 & -121.5 & -84.0 & -75.3 \\
\hline TSPh2 Utricularia $(\delta \mathrm{D})$ & -116.1 & -110.2 & -112.8 & -123.5 & -124.1 & -122.2 & -103.9 & N.A. \\
\hline TSPh2 Nymphaea $(\delta \mathrm{D})$ & -109.9 & -129.9 & -94.6 & -103.5 & -108.3 & -113.4 & N.A. & N.A. \\
\hline
\end{tabular}


The mean $\delta \mathrm{D}$ values shown in Table 7.2 indicate no significant difference among Utricularia (submerged plant), Eleocharis (slough type emergent plant), and Nymphaea (slough type floating plant). For Cladium (ridge type emergent plant), relative $\delta \mathrm{D}$ enrichment would be expected because of the effect of evaporation at the shallower ridge habitat. However, the mean $\delta \mathrm{D}$ values are most depleted for Cladium, with a difference of about $120 \%$ compared to all other slough type plants studied. This large depleted $\delta \mathrm{D}$ value agrees with a report by Gao et al. (2011) who showed that emergent plants had the most depleted $\delta \mathrm{D}$ values ( -240 to $-200 \%$ for $\mathrm{C}_{29} n$-alkane, $\mathrm{n}=7$ ). In order to test the consistency of this highly depleted $\delta \mathrm{D}$ value for Cladium, several Cladium samples from other locations (with different hydroperiod) across the Southern Everglades ecosystem were measured, and consistently largely depleted $\delta \mathrm{D}$ values $(-232.2 \% \mathrm{o} \pm 29.4 \%, \mathrm{n}=13)$ were obtained. Several possible explanations could be ascribed for these depleted $\delta \mathrm{D}$ values of Cladium. First, although most plants studied were from the same site (SRS2 or TSPh2) and grew under almost equal conditions, the species may have unequal autecology (Brader et al., 2010). Cladium has a really high relative growth rate (RGR) and can develop roots as deep as more than $2 \mathrm{~m}$ (Goslee and Richardson, 2008), which would allow it to exploit groundwater (less evaporative/more D depleted compared with upper soil water or surface water). Second, enriched $\delta^{13} \mathrm{C}$ value for Cladium (Table 7.2) may infer its greater water use efficiency (WUE) when compare with the others plants. Hou et al. (2007a) reported plants with higher WUE (inferred from enriched $\delta^{13} \mathrm{C}_{\text {wax }}$ value) were found to have more depleted $\delta \mathrm{D}$ values. This possible higher water use strategy for Cladium might be another possible reason for its stress-tolerant and widespread across Everglades system not only because of its low nutrient requirement, dense stands and 
adaptation to fire ecology (Steward and Ornes, 1975, 1983; Miao et al., 1997). Third, precipitation with different $\delta \mathrm{D}$ values because of seasonality change. It is known that the precipitation $\delta \mathrm{D}$ values vary though out the year from Price et al. (2008, Table 7.2), especially during wet season (May to Oct.) where precipitation amounts are significantly higher. The $\delta \mathrm{D}$ values of precipitation during wet season can vary from $-62.0 \%$ to $8.4 \%$ and it is known that Cladium grows mostly during the wet season (Lorenzen et al., 2001). This typical seasonal pattern in precipitation $\delta \mathrm{D}$ values among sub-environments may also partly explain the large variability of interspecies leaf wax $n$-alkane ${ }^{2} \mathrm{H} /{ }^{1} \mathrm{H}$ composition. Actually, not only the precipitation, but the leaf water $\delta \mathrm{D}$ values can change significantly even during a single day. In a field-grown barley study performed by Sachse et al. (2010), the $\delta \mathrm{D}$ difference between midday leaf water and leaf water pre-dawn can be $\sim 50 \%$. However, more studies are needed to determine the timing of leaf development for Cladium, especially when Cladium start using precipitation or soil water forming leaf wax $n$-alkane along the whole growing season. Fourth, greater biosynthesis depletion, indicating Cladium has slightly different biosynthetic path compared with other wetland plants (Eleocharis, Utricularia and Nymphaea) studied. This difference might be explained by former studies such as Sessions et al. (1999), in which $\delta \mathrm{D}$ values of biosynthetically related compounds such as $n$-alkanes were reported to differ substantially among different species even growing in water with same hydrogen isotope composition.

In contrast to Cladium, no significant $\delta \mathrm{D}$ differences were found between slough species such as Eleocharis, Utricularia and Nymphaea. However, when comparing same plants between two sites, TSPh2 plants were more enriched in $\delta \mathrm{D}(16 \%, 15 \%, 12 \%$ and 
9\% more enriched for Cladium, Eleocharis, Utricularia and Nymphaea, respectively; $\mathrm{P}<$ 0.05 all four plant species). This site difference could be mainly caused by higher evaporation at $\mathrm{TSPh} 2$ than that of SRS2, which would isotopically enrich water column because of evaporative enrichment at $\mathrm{TSPh}$. Additionally, there is a hydroperiod difference between the sites, where TSPh2 has a short hydroperiod and a seasonal drydown (Schedlbauer et al., 2010), while SRS2 is usually inundated year-round (Ogden, 2005). Increasing inundation time, and associated higher relative humidity, can result in a reduction of evaporation and evapotranspiration, and similar patterns have been reported for coastal salt marsh species (Romero and Feakins, 2011).

\subsubsection{Isotopic ( $C$ and $H$ ) compositions of $n$-alkanes and $C_{20} H B I$ across wetland surface soil transect}

Wetland surface soil transects (from slough to ridge) were analyzed to test if compound specific isotopic information $(\mathrm{C}$ and $\mathrm{H})$ from plants can be recorded in wetland surface soils. The $\delta^{13} \mathrm{C}$ values of individual $n$-alkanes across this surface soil transect range from $-27.9 \%$ to $-33.6 \%$ and concentration weighted average $\delta^{13} \mathrm{C}$ values varied between $-29.5 \%$ to $-32.3 \%$ (Table 7.4, Fig. 7.3a). Comparatively, the $\delta \mathrm{D}$ values of individual $n$-alkanes along this surface soil transect ranged from $-99.2 \%$ to $-200.3 \%$ and concentration weighted average $\delta \mathrm{D}$ values between $-131.7 \%$ to $-166.9 \%$ (Table 7.4 , Fig. 7.3b). $\delta^{13} \mathrm{C}$ and $\delta \mathrm{D}$ values of the $\mathrm{C}_{20} \mathrm{HBI}$ were also obtained and ranged from $-37.0 \%$ to $-40.6 \%$ and $-127.6 \%$ to $-153.2 \%$, respectively (Fig. $7.3 \mathrm{a}, \mathrm{b}$ ). 
Table 7.4 $n$-Alkane and $\mathrm{C}_{20} \mathrm{HBI} \delta^{13} \mathrm{C}$ and $\delta \mathrm{D}$ values across SRS2 surface soil transects (N.A. means not analyzed).

Note: all mean $n$-alkane values reported are concentration weighted average values of odd $n$-alkanes from $\mathrm{C}_{21}$ to $\mathrm{C}_{31}$, when reportable.

\begin{tabular}{llllllllll}
\hline $\begin{array}{l}\text { SRS2 surface soil } \\
\text { transect }\end{array}$ & $\begin{array}{l}\text { Odd } n- \\
\text { alkanes } \\
(\text { mean })\end{array}$ & $\mathrm{C}_{20} \mathrm{HBI}$ & $\mathrm{nC}_{21}$ & $\mathrm{nC}_{23}$ & $\mathrm{nC}_{25}$ & $\mathrm{nC}_{27}$ & $\mathrm{nC}_{29}$ & $\mathrm{nC}_{31}$ & $\mathrm{nC}_{33}$ \\
\hline SRS2 0,0 $\left(\delta^{13} \mathrm{C}\right)$ & -32.3 & -38.3 & -32.1 & -31.4 & -33.0 & -32.2 & -32.1 & -33.1 & -32.2 \\
SRS2 5,0 $\left(\delta^{13} \mathrm{C}\right)$ & -31.1 & -37.3 & -32.2 & -29.4 & -30.4 & -31.0 & -31.3 & -32.3 & N.A. \\
SRS2 10,0 $\left(\delta^{13} \mathrm{C}\right)$ & -30.4 & -37.4 & -30.1 & -28.1 & -30.3 & -31.2 & -31.0 & -31.5 & $\mathrm{~N} . \mathrm{A}$. \\
SRS2 15,0 $\left(\delta^{13} \mathrm{C}\right)$ & -30.0 & -37.0 & -29.6 & -28.4 & -29.1 & -30.7 & -31.1 & -30.3 & -31.1 \\
SRS2 20,0 $\left(\delta^{13} \mathrm{C}\right)$ & -30.0 & -37.1 & -30.6 & -27.9 & -30.0 & -30.5 & -30.9 & N.A. & N.A. \\
SRS2 25,0 $\left(\delta^{13} \mathrm{C}\right)$ & -30.4 & -38.5 & -30.9 & -29.0 & -28.2 & -31.2 & -30.6 & -31.7 & -31.5 \\
SRS2 30,0 $\left(\delta^{13} \mathrm{C}\right)$ & -30.4 & -39.3 & N.A. & $\mathrm{N} . \mathrm{A}$. & -28.5 & -30.2 & -30.7 & -32.3 & $\mathrm{~N} . \mathrm{A}$. \\
SRS2 35,0 $\left(\delta^{13} \mathrm{C}\right)$ & -30.7 & -39.2 & N.A. & -29.7 & -29.3 & -30.5 & -31.1 & -31.5 & -32.3 \\
SRS2 40,0 $\left(\delta^{13} \mathrm{C}\right)$ & -29.5 & -40.6 & N.A. & -28.5 & -28.2 & -29.4 & -28.6 & -30.6 & -31.8 \\
SRS2 45,0 $\left(\delta^{13} \mathrm{C}\right)$ & -30.6 & -38.3 & N.A. & -29.4 & -28.6 & -29.3 & -30.4 & -32.0 & -33.6 \\
SRS2 50,0 $\left(\delta^{13} \mathrm{C}\right)$ & -30.3 & -38.5 & N.A. & -30.5 & -28.3 & -29.8 & -29.5 & -31.6 & -32.1 \\
\hline SRS2 0,0 $(\delta \mathrm{D})$ & -132.7 & -148.8 & -131.5 & -117.2 & -122.2 & -163.1 & -140.6 & -117.1 & -137.0 \\
SRS2 5,0 $(\delta \mathrm{D})$ & -130.1 & -141.2 & N.A. & -103.8 & -111.3 & -156.2 & -151.9 & -115.1 & -141.9 \\
SRS2 10,0 $(\delta \mathrm{D})$ & -136.8 & -147.0 & N.A. & -104.2 & -141.5 & -175.5 & -163.5 & -99.2 & N.A. \\
SRS2 15,0 $(\delta \mathrm{D})$ & -149.7 & -153.2 & N.A. & -141.1 & -148.4 & -177.9 & -174.2 & -112.2 & -144.2 \\
SRS2 20,0 $(\delta \mathrm{D})$ & -151.7 & -145.5 & -137.3 & -142.0 & -170.2 & -186.6 & -187.5 & -126.8 & -111.5 \\
SRS2 25,0 $(\delta \mathrm{D})$ & -158.7 & -140.1 & N.A. & -122.2 & -150.9 & -178.9 & -196.1 & -144.8 & -159.4 \\
SRS2 30,0 $(\delta \mathrm{D})$ & -154.8 & -143.6 & N.A. & -142.1 & -126.4 & -195.2 & -200.3 & -110.2 & N.A.
\end{tabular}




\begin{tabular}{|c|c|c|c|c|c|c|c|c|c|}
\hline SRS2 35,0 ( $\delta \mathrm{D})$ & -161.9 & -144.1 & N.A. & -147.5 & -151.9 & -174.6 & -195.1 & -125.6 & -176.7 \\
\hline SRS2 40,0 ( $\delta \mathrm{D})$ & -166.9 & -140.2 & N.A. & -134.9 & -165.1 & -190.3 & -191.0 & -157.2 & -162.8 \\
\hline SRS2 45,0 ( $\delta \mathrm{D})$ & -162.0 & -141.2 & N.A. & -122.4 & -155.4 & -198.6 & -197.1 & -125.1 & -173.3 \\
\hline SRS2 50,0 ( $\delta \mathrm{D})$ & -160.6 & -127.6 & N.A. & -123.9 & -142.7 & -199.8 & -201.7 & -132.5 & -163.0 \\
\hline
\end{tabular}




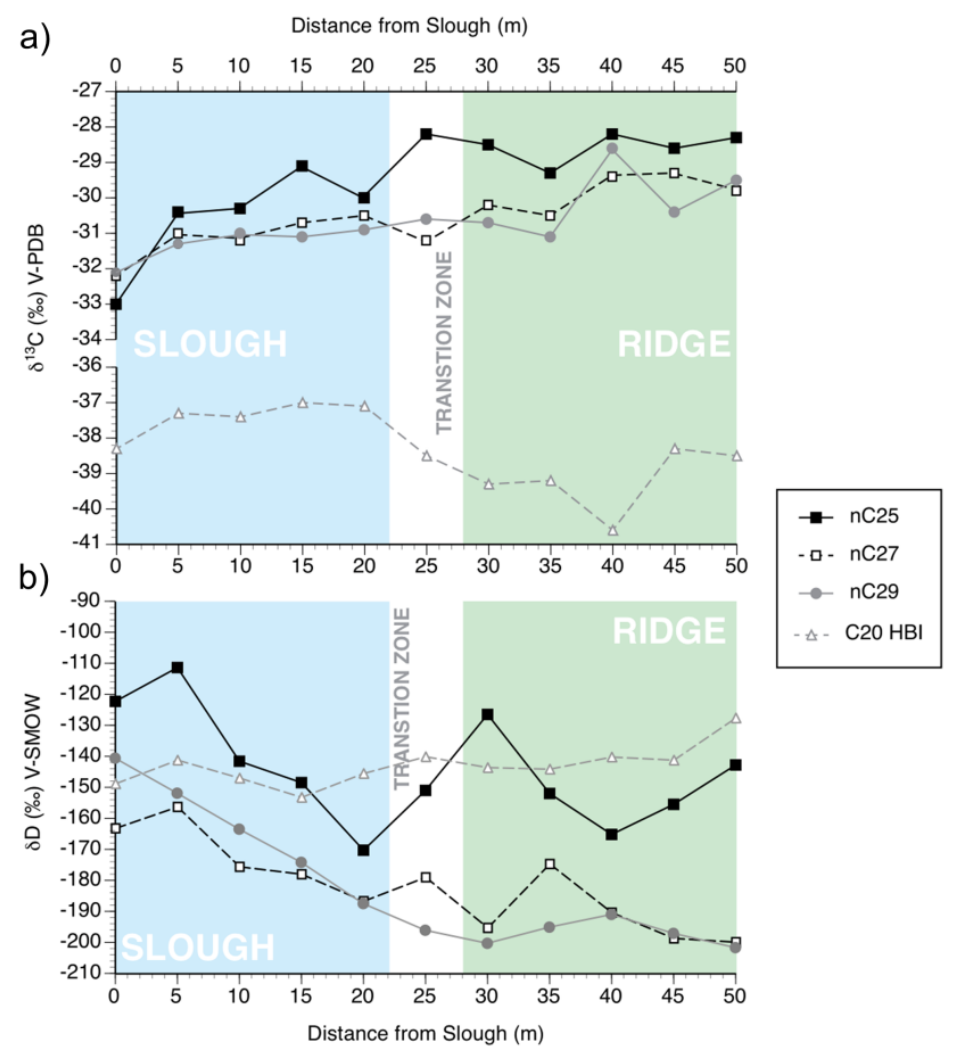

Figure 7.3 a) SRS2 surface soil $n$-alkane and $\mathrm{C}_{20} \mathrm{HBI} \delta^{13} \mathrm{C}$ values; b) SRS2 surface soil $n$-alkane and $\mathrm{C}_{20} \mathrm{HBI} \delta \mathrm{D}$ values.

Biomass cover for the slough section of the freshwater marsh soil transect (SRS2) was reported at an average density of 50 stems $\mathrm{m}^{-2}$, including Utricularia, Nymphaea, and Eleocharis. While periphyton average aerial cover was determined to be $40 \%$, no Caldium (average densities of Claidum about 0 stems $\mathrm{m}^{-2}$ or roots $\mathrm{m}^{-2}$ ) was observed at this site (Saunders et al., 2006). In contrast ridge type soils were covered dominantly by Cladium with an average density of 60 stems $\mathrm{m}^{-2}$ and 15 roots $\mathrm{m}^{-2}$, and a limited presence of Eleocharis (less than 5 stems $\mathrm{m}^{-2}$ ). Only minor amounts of periphyton were observed at the ridge site (less than $15 \%$ areal cover; Saunders et al., 2006). The $\delta^{13} \mathrm{C}$ values of $\mathrm{C}_{25}$, $\mathrm{C}_{27}$ and $\mathrm{C}_{29} n$-alkanes and averaged $\delta^{13} \mathrm{C}$ values increased along the slough-ridge transect, 
which also changed from longer to shorter hydroperiod conditions; higher to lower water level and is likely coupled to changes in plant composition (Fig. 7.3a). From the plant analyses (see Table 7.2), Utricularia, a slough type submerged plant, had the most depleted $\delta^{13} \mathrm{C}$ signal for $n$-alkanes, while Cladium, a primarily ridge type emergent plant was the most enriched in ${ }^{13} \mathrm{C}$. In addition, slightly different patterns along the transect were observed for $\mathrm{C}_{25} n$-alkane compared with $\mathrm{C}_{29} n$-alkane probably as a result of the differences in relative abundance of mid-chain to long-chain $n$-alkanes between ridge and slough plants (see Paq, Table 7.1 and 7.2). A similarly negative correlation between water level and $\delta^{13} \mathrm{C}$ for $n$-alkanes was also reported for a peatland study by Huang et al. (2014).

It has been reported that sedimentary $n$-alkane $\delta \mathrm{D}$ values can reflect biological sources combined with environmental effects (Sachse et al., 2004; Chikaraishi and Naraoka, 2006; Huang et al., 2006). In this study, $n$-alkane $\delta \mathrm{D}$ values (concentration weighted average) from surface soil samples range from $-131.7 \%$ to $-166.9 \%$. This range was within the $\delta \mathrm{D}$ values measured from the plant survey $(-103.9 \sim-258.7 \%)$. If $\delta \mathrm{D}$ values of $n$-alkanes among non-woody plants living in the same location do not change significantly, a slight $\delta \mathrm{D}$ enrichment trend would be expected from slough to ridge because of the higher evaporation (less water inundation time) for the relatively drier soil conditions of the ridge samples. However, an opposite decreasing trend along this transect (from slough to ridge) was observed (Fig. 7.3b). Generally $\mathrm{C}_{25} n$-alkane $\delta \mathrm{D}$ values were significantly more enriched compared to those of the $\mathrm{C}_{29} n$-alkanes, and a consistent trend of more depleted $\delta \mathrm{D}$ was observed for $\mathrm{C}_{29} n$-alkane. This trend was less obvious for the $\mathrm{C}_{25} n$-alkane. This relationship is suggested as the result of organic matter 
contributions from the significantly more depleted $\delta \mathrm{D}$ values of $n$-alkanes derived from Cladium. In addition, Cladium has significantly higher $n$-alkanes average concentration (298 $\mu \mathrm{g} / \mathrm{gdw}, \mathrm{n}=6)$ compared with Eleocharis, Utricularia, Nymphaea (30, 143, 128 $\mu \mathrm{g} / \mathrm{gdw}, \mathrm{n}=6$ for each plant species). Actually, variations of production of $\mathrm{n}$-alkyl lipids have also been suggested by Diefendorf et al. (2011) between plant functional type and phylogeny. Moreover, $\mathrm{C}_{29} n$-alkane is dominantly generated by Cladium compared with other slough type of vegetation, while $\mathrm{C}_{25} n$-alkane is mainly derived from slough type of vegetation along this transect. In other words, the effect of vegetation changes seems to outweigh effect of evaporation, as previously suggested for other environmental settings ( Hou et al., 2008; Polissar and Freeman, 2010; Douglas et al., 2012; Nelson et al., 2013). This observation has important implications for paleo reconstruction studies since in many instances it is assumed that hydrogen isotope fractionations among different plants (C3 vs. C4 or CAM, gymnosperm vs. angiosperm) are relatively minor compared to environmental/climatic drivers (Sachse et al., 2004, 2006). However, as this study and several others suggest this assumption may not always apply. Hou et al. (2007b) reported that leaf wax $\delta \mathrm{D}$ values can differ significantly among different plant types (terrestrial trees vs. aquatic plants) even under the same precipitation conditions and environmental regime. Pedentchouk et al. (2008) suggested that $\delta \mathrm{D}$ and $\delta^{13} \mathrm{C}$ values of sedimentary leaf wax may also result from temporal shifts of plants distribution between angiosperms and conifers as well as plants metabolic changes, instead of only from the paleoclimatic changes. My results show that significant variability can be observed for wetlands plants within a geographically specific environment. Thus caution must be taken for paleoclimatic applications on the basis of sediment leaf wax $\delta \mathrm{D}$ values, and regional 
proxy calibrations should ideally be performed to aid in the interpretation of paleoenvironmental data obtained from sedimentary $n$-alkane $\delta \mathrm{D}$ values. Future studies, especially those focused on modeling approaches (Gao et al., 2011), may provide better ways to constrain source contributions through vegetation change in comparison with environmental or climatic factors.

For $\delta^{13} \mathrm{C}$ values of the $\mathrm{C}_{20} \mathrm{HBI}$ along the soil transect, they were consistently more depleted by over $5-11 \%$ relative to the corresponding long-chain $n$-alkanes for each sample $(\mathrm{P}<0.01)$. Their large depleted $\delta^{13} \mathrm{C}$ values may suggest that $\mathrm{C}_{20} \mathrm{HBI}$-producing organisms at least partially utilize recycled $\left({ }^{13} \mathrm{C}\right.$ depleted) $\mathrm{CO}_{2}$ produced from the decomposition of $\mathrm{OM}$ as their carbon sources rather than atmospheric $\left({ }^{13} \mathrm{C}\right.$ enriched) $\mathrm{CO}_{2}$. A depletion trend was observed $\left(\mathrm{R}^{2}=0.35\right)$ along the slough to ridge transect, which is opposite to that observed for $n$-alkanes. Several factors could explain such a trend, including (a) although $\mathrm{C}_{20} \mathrm{HBI}$ was used as a marker for periphyton in the Everglades, the biosynthesis of the $\mathrm{C}_{20} \mathrm{HBI}$ is not limited to only one unique organism, which seems to be supported by its ubiquitous distribution; (b) the $\mathrm{C}_{20} \mathrm{HBI}$ is biosynthesized by a unique but widespread organism (e.g., cyanobacteria) who uses different carbon pools with different hydroperiod, or the combination of both. The exact explanations for this pattern remains undetermined and more research is needed to calrifyclarify this observation.

For $\delta \mathrm{D}$ values of the $\mathrm{C}_{20} \mathrm{HBI}$ (large concentration in all surface soil samples because of high coverage of periphyton in Everglades wetland system), a slight trend of isotopic enrichment was observed, which is opposite to the $n$-alkane $\delta \mathrm{D}$ trend. Since this biomarker in not produced by higher plants, and has been used as a marker for periphyton 
in the Everglades (Jaffé et al., 2001; Pisani et al., 2013), it could be a potential way to trace environmental drivers such as hydroperiod without the influence of vegetation change effects. Indeed, the $\delta \mathrm{D}$ trend of the $\mathrm{C}_{20} \mathrm{HBI}$ for the soil transect seems to be consistent with the hydroperiod changes or water inundation patterns between ridge and slough environments. This hypothesis will be further tested through sediment core analyses and comparison with $n$-alkane trends below.

\subsubsection{Isotopic ( $C$ and $H$ ) compositions of n-alkanes and $C_{20} H B I$ in wetland soil cores}

Leaf wax $\delta \mathrm{D}$ and $\delta^{13} \mathrm{C}$ values, preserved in sediments, can be used to track past precipitation history, hydrological changes, and primary productivity (Shemesh et al., 1993; Gu et al., 1996; Liu and Huang, 2005; Pagani et al., 2006; Huang et al., 2007).

Depth profiles determined for the slough and ridge cores showed that the $\mathrm{C}_{21}-\mathrm{C}_{31}$ $n$-alkanes have gradually enriched in $\delta^{13} \mathrm{C}$ values with increasing depth by up to $5 \%$ (Table 7.5, 7.6, Fig. 7.4a, c). Similar general $\delta^{13} \mathrm{C}$ enrichment trends were observed for $\mathrm{C}_{20}$ HBI down both cores by up to $7 \%$. These $\delta^{13} \mathrm{C}$ enrichments with depth have also been reported in other soil core studies, where no change in $\mathrm{C} 3$ vs. $\mathrm{C} 4$ vegetation was observed (Huang et al., 1996; Ficken et al., 1998; Seki et al., 2010). Several possible factors can influence this enrichment including (a) relatively ${ }^{13} \mathrm{C}$ enriched $\mathrm{CO}_{2}$ in the preindustrial past, (b) possible isotopic fractionation of $n$-alkanes during early diagenesis, (c) vegetation shift and plant isotope fractionation changes driven by climatic variations and hydrological change. 
Table 7.5 $n$-Alkane and $\mathrm{C}_{20} \mathrm{HBI} \delta^{13} \mathrm{C}$ and $\delta \mathrm{D}$ values down SRS2 ridge core (N.A. means not analyzed).

Note: all mean $n$-alkane values reported are concentration weighted average values of odd $n$-alkanes from $\mathrm{C}_{21}$ to $\mathrm{C}_{31}$, when reportable.

\begin{tabular}{llllllllll}
\hline $\begin{array}{l}\text { Ridge core } \\
\text { depth }\end{array}$ & $\begin{array}{l}\text { Odd } n- \\
\text { alkanes } \\
(\text { mean })\end{array}$ & $\begin{array}{l}\mathrm{C}_{20} \\
\mathrm{HBI}\end{array}$ & $\mathrm{nC}_{21}$ & $\mathrm{nC}_{23}$ & $\mathrm{nC}_{25}$ & $\mathrm{nC}_{27}$ & $\mathrm{nC}_{29}$ & $\mathrm{nC}_{31}$ & $\mathrm{nC}_{33}$ \\
\hline $0-3 \mathrm{~cm}\left(\delta^{13} \mathrm{C}\right)$ & -30.3 & -38.5 & $\mathrm{~N} . \mathrm{A}$. & -30.5 & -28.3 & -29.8 & -29.5 & -31.6 & -32.1 \\
$6-8 \mathrm{~cm}\left(\delta^{13} \mathrm{C}\right)$ & -29.6 & -39.4 & -30.3 & $\mathrm{~N} . \mathrm{A}$. & -28.2 & -30.0 & -30.1 & N.A. & N.A. \\
$8-10 \mathrm{~cm}\left(\delta^{13} \mathrm{C}\right)$ & -27.6 & -37.3 & -29.4 & -27.3 & -25.3 & -28.4 & -27.5 & N.A. & N.A. \\
$10-12 \mathrm{~cm}\left(\delta^{13} \mathrm{C}\right)$ & -27.2 & -35.9 & -28.6 & -26.1 & -27.0 & -26.8 & -27.7 & N.A. & N.A. \\
$12-14 \mathrm{~cm}\left(\delta^{13} \mathrm{C}\right)$ & -27.8 & -36.3 & -29.5 & -26.8 & -27.7 & -27.7 & -27.4 & N.A. & N.A. \\
$14-16 \mathrm{~cm}\left(\delta^{13} \mathrm{C}\right)$ & -27.5 & -34.8 & -30.0 & -26.4 & -27.0 & -26.9 & -27.3 & N.A. & N.A. \\
$16-18 \mathrm{~cm}\left(\delta^{13} \mathrm{C}\right)$ & -27.2 & -35.9 & -29.3 & -26.3 & -26.8 & -26.6 & -26.9 & N.A. & N.A. \\
$18-20 \mathrm{~cm}\left(\delta^{13} \mathrm{C}\right)$ & -26.7 & -34.0 & -27.9 & -25.4 & -26.1 & -25.9 & -26.2 & -28.5 & N.A. \\
$20-22 \mathrm{~cm}\left(\delta^{13} \mathrm{C}\right)$ & -26.6 & -32.3 & -27.3 & -25.5 & -26.2 & -25.8 & -26.0 & -29.0 & N.A. \\
$22-24 \mathrm{~cm}\left(\delta^{13} \mathrm{C}\right)$ & -26.4 & -33.0 & -21.8 & -25.5 & -26.2 & -25.9 & -26.6 & -28.0 & -31.0 \\
$24-26 \mathrm{~cm}\left(\delta^{13} \mathrm{C}\right)$ & -26.4 & -32.4 & -21.1 & -25.7 & -26.5 & -26.2 & -26.5 & -28.1 & -30.7 \\
\hline $0-3 \mathrm{~cm}(\delta \mathrm{D})$ & -160.6 & -127.6 & N.A. & -123.9 & -142.7 & -199.8 & -201.7 & -132.5 & -163.0 \\
$6-8 \mathrm{~cm}(\delta \mathrm{D})$ & -130.0 & -131.1 & N.A. & -96.3 & -114.0 & -174.8 & -160.1 & -104.6 & N.A. \\
$8-10 \mathrm{~cm}(\delta \mathrm{D})$ & -116.2 & -127.5 & N.A. & -99.1 & -94.0 & -138.2 & -126.6 & -130.5 & -109.0 \\
$10-12 \mathrm{~cm}(\delta \mathrm{D})$ & -132.0 & -135.9 & N.A. & -111.4 & -126.1 & -156.9 & -161.0 & -111.0 & -125.3
\end{tabular}




\begin{tabular}{llllllllll}
$12-14 \mathrm{~cm}(\delta \mathrm{D})$ & -145.8 & -145.7 & $\mathrm{~N} . \mathrm{A}$. & -113.3 & -131.4 & -161.2 & -153.9 & -156.0 & -159.2 \\
$14-16 \mathrm{~cm}(\delta \mathrm{D})$ & -130.7 & -135.2 & -133.5 & -98.6 & -108.4 & -141.9 & -142.0 & -144.3 & -146.0 \\
$16-18 \mathrm{~cm}(\delta \mathrm{D})$ & -137.0 & -135.8 & -188.2 & -98.5 & -101.1 & -116.6 & -129.7 & -153.6 & -171.2 \\
$18-20 \mathrm{~cm}(\delta \mathrm{D})$ & -136.9 & -137.2 & -175.5 & -113.3 & -99.1 & -119.5 & -134.4 & -155.9 & -160.4 \\
$20-22 \mathrm{~cm}(\delta \mathrm{D})$ & -133.8 & -132.2 & -174.9 & -107.3 & -101.3 & -128.5 & -123.5 & -152.0 & -149.0 \\
$22-24 \mathrm{~cm}(\delta \mathrm{D})$ & -131.1 & -141.1 & -184.0 & -102.5 & -98.1 & -121.8 & -126.2 & -128.3 & -156.9 \\
$24-26 \mathrm{~cm}(\delta \mathrm{D})$ & -133.9 & -138.6 & -160.8 & -116.1 & -98.0 & -165.1 & -131.4 & -130.6 & -135.3 \\
\hline
\end{tabular}


Table 7.6 $n$-Alkane and $\mathrm{C}_{20} \mathrm{HBI} \delta^{13} \mathrm{C}$ and $\delta \mathrm{D}$ values down SRS2 slough core (N.A. means not analyzed).

Note: all mean $n$-alkane values reported are concentration weighted average values of odd $n$-alkanes from $\mathrm{C}_{21}$ to $\mathrm{C}_{31}$, when reportable.

\begin{tabular}{llllllllll}
\hline $\begin{array}{l}\text { Slough core } \\
\text { depth }\end{array}$ & $\begin{array}{l}\text { Odd } n- \\
\text { alkanes } \\
(m e a n)\end{array}$ & $\begin{array}{l}\mathrm{C}_{20} \\
\mathrm{HBI}\end{array}$ & $\mathrm{nC}_{21}$ & $\mathrm{nC}_{23}$ & $\mathrm{nC}_{25}$ & $\mathrm{nC}_{27}$ & $\mathrm{nC}_{29}$ & $\mathrm{nC}_{31}$ & $\mathrm{nC}_{33}$ \\
\hline $0-3 \mathrm{~cm}\left(\delta^{13} \mathrm{C}\right)$ & -31.1 & -37.3 & -32.2 & -29.4 & -30.4 & -31.0 & -31.3 & -32.3 & N.A. \\
$3-6 \mathrm{~cm}\left(\delta^{13} \mathrm{C}\right)$ & -30.6 & -38.0 & $\mathrm{~N} . \mathrm{A}$. & $\mathrm{N} . \mathrm{A}$. & -30.0 & -30.6 & -31.1 & N.A. & N.A. \\
$6-9 \mathrm{~cm}\left(\delta^{13} \mathrm{C}\right)$ & -31.3 & -37.9 & -32.2 & -29.7 & -29.2 & -29.4 & -30.6 & -32.4 & -35.4 \\
$9-12 \mathrm{~cm}\left(\delta^{13} \mathrm{C}\right)$ & -29.2 & -37.8 & $\mathrm{~N} . \mathrm{A}$. & -29.0 & -29.1 & -28.7 & -29.9 & N.A. & N.A. \\
$12-15 \mathrm{~cm}\left(\delta^{13} \mathrm{C}\right)$ & -29.7 & -38.1 & -29.5 & -28.3 & -28.5 & -28.2 & -28.5 & -30.3 & -34.6 \\
$15-18 \mathrm{~cm}\left(\delta^{13} \mathrm{C}\right)$ & -28.5 & -37.4 & -28.5 & -27.7 & -28.4 & -27.9 & -28.1 & -30.5 & N.A. \\
$18-20 \mathrm{~cm}\left(\delta^{13} \mathrm{C}\right)$ & -28.9 & -37.9 & -28.2 & -27.0 & -27.4 & -26.9 & -28.0 & -29.8 & -35.1 \\
$20-22 \mathrm{~cm}\left(\delta^{13} \mathrm{C}\right)$ & -27.8 & -36.6 & -27.9 & -25.7 & -25.9 & -25.6 & -26.9 & -28.8 & -33.7 \\
$22-24 \mathrm{~cm}\left(\delta^{13} \mathrm{C}\right)$ & -28.2 & -35.0 & -26.1 & -26.1 & -26.5 & -25.9 & -27.4 & -29.4 & -35.7 \\
$24-26 \mathrm{~cm}\left(\delta^{13} \mathrm{C}\right)$ & -26.7 & -31.3 & -24.5 & -24.5 & -25.0 & -24.4 & -25.7 & -28.4 & -34.6 \\
\hline $0-3 \mathrm{~cm}(\delta \mathrm{D})$ & -130.1 & -141.2 & $\mathrm{~N} . \mathrm{A}$. & $\mathrm{N} . \mathrm{A}$. & -103.8 & -111.3 & -156.2 & -151.9 & -115.1 \\
$3-6 \mathrm{~cm}(\delta \mathrm{D})$ & -134.4 & -134.6 & -135.6 & -135.5 & -105.7 & -159.5 & -142.6 & -124.9 & -137.3 \\
$6-9 \mathrm{~cm}(\delta \mathrm{D})$ & -125.5 & -139.7 & -140.7 & -112.9 & -100.0 & -127.3 & -128.7 & -130.0 & -139.0 \\
$9-12 \mathrm{~cm}(\delta \mathrm{D})$ & -126.9 & -149.7 & -134.2 & -118.2 & -113.6 & -126.7 & -129.2 & -128.8 & -137.6 \\
$12-15 \mathrm{~cm}(\delta \mathrm{D})$ & -123.2 & -134.9 & $\mathrm{~N} . \mathrm{A}$. & -106.8 & -109.6 & -126.3 & -131.1 & -142.4 & N.A.
\end{tabular}




\begin{tabular}{llllllllll}
$15-18 \mathrm{~cm}(\delta \mathrm{D})$ & -139.6 & -140.5 & -163.8 & -141.8 & -110.6 & -132.2 & -151.1 & -138.3 & N.A. \\
$18-20 \mathrm{~cm}(\delta \mathrm{D})$ & -129.3 & -150.6 & -139.1 & -116.5 & -114.9 & -132.6 & -139.0 & -145.9 & -117.3 \\
$20-22 \mathrm{~cm}(\delta \mathrm{D})$ & -146.0 & -149.8 & -162.1 & -139.2 & -126.3 & -130.5 & -142.3 & -137.9 & -183.9 \\
$22-24 \mathrm{~cm}(\delta \mathrm{D})$ & -133.0 & -152.4 & N.A. & -162.5 & -149.1 & -118.1 & -119.9 & -109.3 & -121.0 \\
$24-26 \mathrm{~cm}(\delta \mathrm{D})$ & -135.6 & -141.8 & N.A. & -158.9 & -127.3 & -113.8 & -129.8 & -137.0 & -143.7 \\
\hline
\end{tabular}




\section{Ridge core}

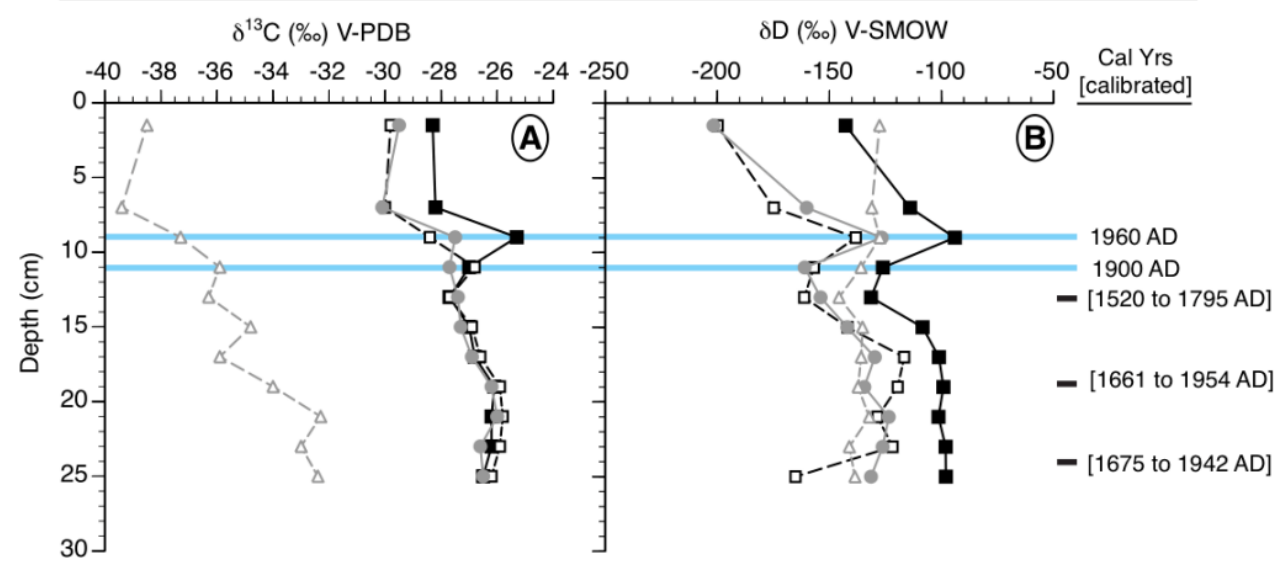

\section{Slough core}

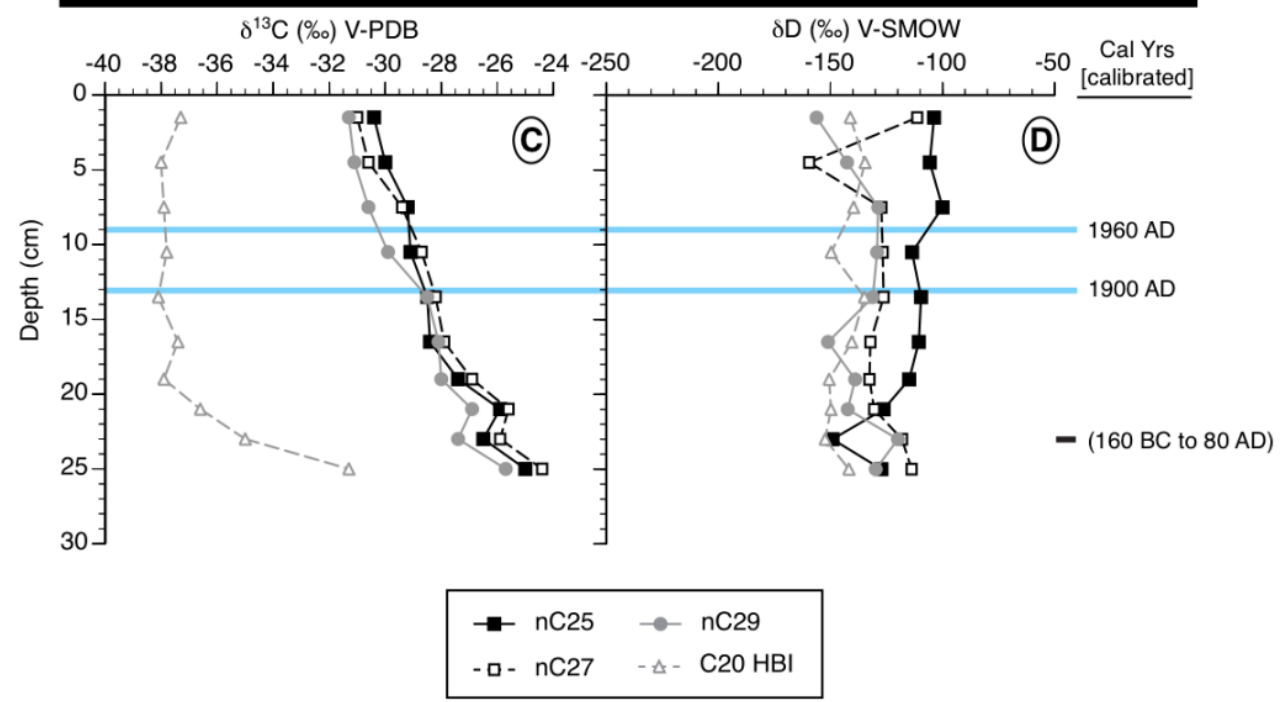

Figure 7.4 a) Ridge core $n$-alkane and $\mathrm{C}_{20} \mathrm{HBI} \delta^{13} \mathrm{C}$ value depth profile; b) Ridge core $n$ alkane and $\mathrm{C}_{20} \mathrm{HBI} \delta \mathrm{D}$ value depth profile; c) Slough core $n$-alkane and $\mathrm{C}_{20} \mathrm{HBI} \delta^{13} \mathrm{C}$ value depth profile; d) Slough core $n$-alkane and $\mathrm{C}_{20} \mathrm{HBI} \delta \mathrm{D}$ value depth profile.

Note: all mean $n$-alkane values reported are concentration weighted average values of odd $n$-alkanes from $\mathrm{C}_{21}$ to $\mathrm{C}_{31}$, when reportable.

Pre-industrial $\delta^{13} \mathrm{C}$ values were $1.3 \%$ more enriched than presently because of fossil fuel burning over the past $130 \mathrm{yr}$ (Keeling et al., 1984). In addition, early diagenesis associated with heterotrophic reworking of sedimentary organic matter can possibly enrich the $\delta^{13} \mathrm{C}$ of $n$-alkanes (Huang et al., 1996; Ficken et al., 1998; Chikaraishi 
and Naraoka, 2005; Seki et al., 2010). However, a 23 yr. Calluna vulgaris decomposition experiment showed that no carbon isotopic fractionation was evident during early diagenesis (Huang et al., 1997), despite a loss of over $90 \%$ of the mass of original longchain $n$-alkanes. Other studies also showed no significant difference in lipid $\delta^{13} \mathrm{C}$ values during early diagenesis (Hayes, 1993; Freeman et al., 1994). Thus early diagenesis cannot explain the large $\delta^{13} \mathrm{C}$ variations reported here. Thus, the observed changes in $\delta^{13} \mathrm{C}$ may be derived from changes in plant species successions (with potentially different $\delta^{13} \mathrm{C}$ values) due to changes in environmental conditions (hydroperiod), changes in primary productivity which also affected plant isotope fractionation, or a combination of both.

The $\delta^{13} \mathrm{C}$ values of ridge core samples ranged from (-25.3 to $\left.-28.3 \%\right),(-25.8$ to $30.0 \%$ ), $\left(-26.0\right.$ to $-30.1 \%$ ) for $\mathrm{C}_{25}, \mathrm{C}_{27}$ and $\mathrm{C}_{29} n$-alkanes, respectively (Table 7.5). Concentration weighted average $n$-alkane $\delta^{13} \mathrm{C}$ values range from -26.4 to $-30.3 \%$ (Table 7.5). Fig. 7.4a and 7.4b show the vertical profiles of organic geochemical indicators across the ridge core clearly indicating an enrichment in $\delta^{13} \mathrm{C}$ with depth. This trend is also consistent with bulk carbon isotope data (which ranges from 25.6 to $28.5 \%$; and increase with depth; data not shown). However, the rate of enrichment (change in slope; Fig. 7.4a) is more significant for the upper soil samples $(0-10 \mathrm{~cm})$ compared with the deeper soil layers $(10-26 \mathrm{~cm})$, and could be caused by a change in vegetation type from Eleocharis (deeper soil) to Cladium (shallower soil). This proposed change is also supported by higher $\mathrm{P} a q(\sim 0.6$ on averages $)$ in the deeper soils and lower $\mathrm{P} a q$ in the upper soils ( $\sim 0.4$ on averages) of the ridge core. The plants survey showed that Cladium is generally more enriched in ${ }^{13} \mathrm{C}$ compared with the slough type vegetation (Eleocharis, Utricularia, Nymphaea). If this is true, $\delta^{13} \mathrm{C}$ enrichment would be expected for the upper 
soils, as was actually observed for the segment $8-10 \mathrm{~cm}$. These data suggest that $\sim 1960$ $\mathrm{AD}$, when the draining of the Everglades system started, a vegetation shift to Cladium as the dominant plant species started under conditions ideal for high primary productivity. However, the surface soils $(0-8 \mathrm{~cm})$ show a continued depletion in $\delta^{13} \mathrm{C}$ likely as a result of continued decrease in hydroperiod leading to a reduction in primary productivity of Cladium at this site. This inferred change in hydrology can also be suggested from the plants calibration for Cladium, where Cladium grow in shorter hydroperiod is more $\delta^{13} \mathrm{C}$ depleted possibly because of the less primary productivity.

The $\delta \mathrm{D}$ values of the ridge core samples ranged from (-94.0 to $-142.7 \%),(-116.6$ to $-199.8 \%$ ), $\left(-123.5\right.$ to $-201.7 \%$ ) for the $\mathrm{C}_{25}, \mathrm{C}_{27}$ and $\mathrm{C}_{29} n$-alkanes, respectively (Table 7.5). Concentration weighted average $\delta \mathrm{D}$ values of $\mathrm{C}_{21}-\mathrm{C}_{31} n$-alkanes across this core showed a range from $-116.2 \%$ to $-160.2 \%$ (Fig. $7.4 \mathrm{~b}$ and Table 7.5 ). The observed large $\delta \mathrm{D}$ variation (by $44.0 \%$ ) may be controlled by several factors, including shifts in precipitation $\delta \mathrm{D}$ values, changes in the evaporation of soil and leaf water, and/or vegetation changes. Shifts in annual weighted precipitation $\delta \mathrm{D}$ values (about $10 \%$ ) and variations in the rate of evaporation of soil-water in the Everglades have been suggested to be small (Price and Swart, 2006; Price et al., 2008). Thus, evaporation and precipitation may not be the dominant drivers controlling the $\delta \mathrm{D}$ values variations observed here. Considering of the large difference of $\delta \mathrm{D}$ between Cladium (ridge type of plants) and all other slough type of vegetation (Eleocharis, Utricularia, Nymphaea), the $\delta \mathrm{D}$ data seem to justify the vegetation change.

For the slough core, $n$-alkane $\delta^{13} \mathrm{C}$ values range from -25.0 to $-30.4 \%$, -24.4 to $31.0 \%$, -25.7 to $-31.3 \%$ for $\mathrm{C}_{25}, \mathrm{C}_{27}$ and $\mathrm{C}_{29} n$-alkanes, respectively (Table 7.6, Fig. 7.4c). 
Concentration weighted average $n$-alkane $\delta^{13} \mathrm{C}$ values range from -26.7 to $-31.3 \%$ (Table 7.6). The $\delta^{13} \mathrm{C}$ enrichment by $4.6 \%$ with increasing depth was also observed. This trend is also consistent with the bulk carbon isotope result (range from -26.2 to $-28.9 \%$, enrichment with depth; data not shown). Depth vs. $\delta^{13} \mathrm{C}$ correlations were found to be significant for the $n$-alkane $\delta^{13} \mathrm{C}\left(\mathrm{R}^{2}>0.7\right)$, and contrary to the ridge core, no obvious slope changes were observed throughout the core. The observed pattern suggests that the slough core site remained as a slough environment, regardless of the on-going changes in hydrology of the system over the past several decades, which could also be partially supported by the relatively higher $\mathrm{P} a q$ values and narrow $\mathrm{P} a q$ range $(0.67-0.84)$ throughout the slough core. However, the general negative depth vs. $\delta^{13} \mathrm{C}$ slope observed would suggest a decreasing trend in the primary productivity of the slough vegetation over time, probably induced by increasing water stress.

The $\delta \mathrm{D}$ values of $\mathrm{C}_{21}-\mathrm{C}_{31} n$-alkanes down this slough core show a relatively narrow range (compare with ridge core) from $-123.1 \%$ to $-146.0 \%$ (Table 7.6, Fig. 7.4d). This narrow range and no obvious trend of variation in $\delta \mathrm{D}$ values for $n$-alkanes down the slough core can also partially suggest a consistent dominant slough type of vegetation and no obvious vegetation change to Cladium (ridge type of vegetation). Instead, the variations within the narrow range of $\delta \mathrm{D}$ values may record the overall effect of various environment factors: 1) annual precipitation variation could be as high as $90 \mathrm{~cm}$ from the reported 30 year mean precipitation value (1976 - 2005; Price et al., 2008); 2) different proportion of precipitation between wet and dry seasons; 3) different water source usage with different $\delta \mathrm{D}$ values: precipitation $(-10.59 \%)$, surface water $(3.34 \%)$ and ground water $(-0.50 \%)$ (data reorganized from Price and Swart, 2006); 4) different evaporation 
conditions between wet and dry seasons, such as higher rainfall in wet season may lead to $\mathrm{D}$ depletion in the plant leaves as a result of the diminished effect of evaporative enrichment. Unfortunately, quantify the influence of each of these environmental factors for the final combined $n$-alkane $\delta \mathrm{D}$ change is difficult.

The $\delta^{13} \mathrm{C}$ values of $\mathrm{C}_{20} \mathrm{HBI}$ down the ridge and slough cores ranged from -39.4 to $-32.4 \%$, -38.1 to $-31.3 \%$, respectively, which are also constantly more depleted $(\mathrm{P}<0.01$ for both cores) by over $6-10 \%$ relative to the corresponding long-chain $n$-alkanes for each sample of both ridge and slough cores. Similar with $n$-alkanes, $\delta^{13} \mathrm{C}$ values of $\mathrm{C}_{20}$ HBI were more enriched in the deeper sections of both cores, which could be explained by factors (a) relatively ${ }^{13} \mathrm{C}$ enriched $\mathrm{CO}_{2}$ in the pre-industrial past (b) possible isotopic fractionation of $\mathrm{C}_{20} \mathrm{HBI}$ during early diagenesis, and possibly some other unknown factors. The $\delta \mathrm{D}$ values of the $\mathrm{C}_{20} \mathrm{HBI}$ measured throughout this study range from -153.2 to $-127.6 \%$ o $(\mathrm{n}=32)$, which is within the range of concentration weighted average $n$ alkane $\delta \mathrm{D}$ values (-166.9 to $-116.2 \%, \mathrm{n}=32)$, and no significant difference was found (P $=0.80)$ compared with that of $n$-alkanes. A similar result was reported by Aichner et al. (2010), where $\delta \mathrm{D}$ values of $\mathrm{C}_{20} \mathrm{HBI}$ in a core from the Tibetan Plateau were measured, showing a variability of about $12 \%$ (ranging from $-184 \%$ o to $-172 \%$ ) and with no significant differences compared with the corresponding $n$-alkanes. However, with regards to the Everglades slough and ridge cores, average $\delta \mathrm{D}$ values of odd $n$-alkanes were $-132.4 \%$ and $-135.2 \%$, for slough and ridge respectively, while $\mathrm{C}_{20} \mathrm{HBI} \delta \mathrm{D}$ averaged values across the same two cores were $-143.5 \%$ and $-135.3 \%$, respectively. Significantly larger difference in $\delta \mathrm{D}$ was recorded for the $\mathrm{C}_{20} \mathrm{HBI}(\mathrm{P}<0.01)$ compared to those of the $n$-alkanes between these two cores. I hypothesize that these $\delta \mathrm{D}$ changes of 
$\mathrm{C}_{20} \mathrm{HBI}$ are related to changes in hydroperiod, since vegetation change should not affect this parameter. In agreement with this hypothesis, the average $\mathrm{C}_{20} \mathrm{HBI} \delta \mathrm{D}$ across ridge core $(-135.3 \%)$ was more enriched compared with that of the slough core $(-143.3 \%)$, consistent with the evaporation/water inundation differences between the two cores. In addition, the $\mathrm{C}_{20} \mathrm{HBI} \delta \mathrm{D}$ did not show a clear trend down the slough core (Fig. 7.4d), which suggest that this site maintained a general slough environment throughout the time period represented in the core, regardless of a reduction in overall hydroperiod. Changes throughout the core could also be related to variations in precipitation for different time periods. For the ridge core (Fig. 7.4b), a similar distribution was observed for the time period prior to $\sim \mathrm{AD} 1900$ (12 $\mathrm{cm}$ and deeper). However, after $\sim \mathrm{AD} 1900$, which coincides with initial hydrological changes in the Everglades, the average $\delta \mathrm{D}$ values of the $\mathrm{C}_{20} \mathrm{HBI}(0-12 \mathrm{~cm})$ are significantly more enriched compared with that of samples before $\sim \mathrm{AD} 1900(12-26 \mathrm{~cm})(\mathrm{P}<0.05)$. While the general trends observed for the $\delta \mathrm{D}$ in the Everglades soil cores seem to agree with the hydroperiod decrease, the application of $\mathrm{C}_{20} \mathrm{HBI}$ specific $\delta \mathrm{D}$ needs more future study.

\subsubsection{Net "apparent" isotopic fractionation and its application in sub-tropical wetland ecosystem}

On the basis of annual weighted average $\delta \mathrm{D}$ values of precipitation $(-10.59 \%)$ at both locations (SRS2 and TSPh2; Price and Swart, 2006), averaged $\varepsilon_{n \text {-alkane/water was }}$ calculated (following equation 1) for my surveyed wetland plants: Cladium ( -240.3\%), Eleocharis $(\sim-102.7 \%)$, Utricularia $(\sim-113.4 \%)$, Nymphaea $(\sim-105.3 \%)$. From a global survey by Liu et al. (2008, and references therein), the plants $\varepsilon_{n \text {-alkane/water range }}$ 
from $-210 \sim-70 \%$ sampled from similar sub-tropical areas (latitude $20 \sim 30{ }^{\circ} \mathrm{N}$ ) in the world. Except for Cladium, which is about 30\% more depleted, all other plants studied are within this previously reported range. However, the precipitation $\delta \mathrm{D}$ used for calculating $\varepsilon_{n \text {-alkane/water }}$ by Liu et al. (2008) was from the 2000 International Atomic Energy Agency and the World Meteorological Organization (IAEA/WMO) data, which is approximately $-30 \%$ and thus $20 \%$ depleted compared with averaged measured values of $-10.59 \%$ for my calculation). Considering this, Cladium measured here showed to be just slightly more depleted (approximately 10\%) compared with the most depleted fractionation from other sub-tropical vegetation globally. This observation is not that surprising considering large difference observed in $\varepsilon_{n \text {-alkane/water }}$ even within the same location.

The hydrogen isotopic fractionation between environmental surface water and surface soil (wet prairie/slough soil and sawgrass marsh/ridge soil) for the $n$-alkanes was assessed as ranging from $-158.0 \%$ to $-120.7 \%$. This estimated hydrogen isotopic fractionation in these wetland soil samples is higher than the $\varepsilon_{n \text {-alkane/water }}(-160 \%)$ between $n$-alkanes and algae uptake water (Huang et al., 2004; Sachse et al., 2006). Therefore I suggest that there may be an enrichment of environmental water $\delta \mathrm{D}$ by up to 2 to $39.3 \%$ because of the evapotranspiration either at the interface between air and soil or within the plant leaf, or both in this area. Seki et al. (2010) reported environmental water $\delta \mathrm{D}$ enrichment range from $(15-40 \%)$ for a forest soil and no water $\delta \mathrm{D}$ enrichment for a wetland soil located in northern Hokkaido, Japan (about $44{ }^{\circ} \mathrm{N}, 142{ }^{\circ} \mathrm{E}$ ). My calculated environmental water $\delta \mathrm{D}$ enrichment range $(2-39.3 \%)$ is similar compared with that of forest soil but much higher compared with that of wetland from Seki et al. 
(2010). The difference between the wetland study sites is probably because of higher evapotranspiration for the Everglades wetland soil (about $25^{\circ} \mathrm{N}, 81^{\circ} \mathrm{E}$ ) due to higher annual temperature and limited seasonal contrast when compared to more temperate climates (wet and dry seasons only). Additional factors that could potential cause this difference include plant morphology and/or plant physiology. The specific role of these other factors were further explored by the global plants calibration results from Liu et al. (2008), where a general negative correlation was found between plants $\varepsilon_{n \text {-alkane/water }}$ and latitude (without considering the woody plants living in the area $>60^{\circ} \mathrm{N}$ ).

\subsection{Conclusion}

This work documents a multi-proxy approach including biomarkers (especially P $a q$ ) and $n$-alkanes and $\mathrm{C}_{20} \mathrm{HBI}$ based compound-specific $\delta{ }^{13} \mathrm{C}$ and $\delta \mathrm{D}$ values applied to assess ecohydrological changes in the subtropical wetland system of the Florida Everglades. The $\delta^{13} \mathrm{C}$ values were observed to be mainly controlled by organic matter inputs from dominant plant types (ridge vs. slough; emergent vs. submerged), while changes in primary productivity determined by changes in hydroperiod were also suggested. The relationship between hydroperiod and carbon isotope values could be additional evidence of plant type change for paleo-reconstructions. On the other hand, compound-specific $\delta \mathrm{D}$ values for emergent and submerged wetland plants were suggested to be strongly affected by vegetation type (ridge vs. slough) and to a less extent by water use efficiency, and hydrological parameters such as precipitation and associated hydroperiod characteristics. This study also demonstrates that caution has to be taken

when applying $n$-alkane $\delta^{13} \mathrm{C}$ and $\delta \mathrm{D}$ for paleo reconstruction because of the fact that 
their values could be significant different for wetland vegetation (non-woody C3 plants) living in similar locations spatially (i.e. ridge vs. slough), but subjected to variations in hydrology and associated conditions controlling primary productivity. The application of $n$-alkane $\delta^{13} \mathrm{C}$ and $\delta \mathrm{D}$ values for deciphering paleo-hydrology in wetlands calls for further examination of larger scale of plant-soil relationships under different hydrological conditions, nutrient levels and climatic conditions. Additional tools such as pollen and plant fossil analyses may be needed to better constrain calibrations for paleohydrological assessments. 


\section{REFERENCES}

Aichner, B., Herzschuh, U., Wilkes, H., Vieth, A., Böhner, J. (2010). $\delta$ D values of $n$ alkanes in Tibetan lake sediments and aquatic macrophytes-A surface sediment study and application to a 16ka record from Lake Koucha. Organic Geochemistry, 41(8), 779790.

Anderson, W. T., Sternberg, L. S. L., Pinzon, M. C., Gann-Troxler, T., Childers, D. L., Duever, M. (2005). Carbon isotopic composition of cypress trees from South Florida and changing hydrologic conditions. Dendrochronologia, 23(1), 1-10.

Bowen, G.J., Revenaugh, J. (2003). Interpolating the isotopic composition of modern meteoric precipitation. Water Resources Research, 39(10).

Brader, A. V., van Winden, J. F., Bohncke, S. J., Beets, C. J., Reichart, G. J., de Leeuw, J. W. (2010). Fractionation of hydrogen, oxygen and carbon isotopes in $n$-alkanes and cellulose of three Sphagnum species. Organic Geochemistry, 41(12), 1277-1284.

Busch, J., Mendelssohn, I. A., Lorenzen, B., Brix, H., Miao, S. (2004). Growth responses of the Everglades wet prairie species Eleocharis cellulosa and Rhynchospora tracyi to water level and phosphate availability. Aquatic Botany, 78(1), 37-54.

Chen, M., Maie, N., Parish, K., Jaffé, R. (2013). Spatial and temporal variability of dissolved organic matter quantity and composition in an oligotrophic subtropical coastal wetland. Biogeochemistry 115, 167-183.

Chikaraishi, Y., Naraoka, H. (2005). $\delta^{13} \mathrm{C}$ and $\delta \mathrm{D}$ identification of sources of lipid biomarkers in sediments of Lake Haruna (Japan). Geochimica et Cosmochimica Acta, 69(13), 3285-3297.

Chikaraishi, Y., Naraoka, H. (2006). Carbon and hydrogen isotope variation of plant biomarkers in a plant-soil system. Chemical Geology, 231(3), 190-202.

Coble, P. G., Del Castillo, C. E., Avril, B. (1998). Distribution and optical properties of CDOM in the Arabian Sea during the 1995 Southwest Monsoon. Deep-Sea Research Part II, 45(10-11), 2195-2223.

Cohen, A. D., Gage, C. P., Moore, W. S. (1999). Combining organic petrography and palynology to assess anthropogenic impacts on peatlands: Part 1. An example from the northern Everglades of Florida. International Journal of Coal Geology, 39(1), 3-45.

Coplen, T.B., Kendall, C., Hopple, J. (1983). Comparison of stable isotope reference samples. Nature 302, 236-238. 
Craft, C. B., Richardson, C. J. (1998). Recent and long-term organic soil accretion and nutrient accumulation in the Everglades. Soil Science Society of America Journal, 62(3), 834-843.

Daoust, R. J., Childers, D. L. (2004). Ecological effects of low-level phosphorus additions on two plant communities in a neotropical freshwater wetland ecosystem. Oecologia, 141(4), 672-686.

Davis, S.M. (1991). Growth, decomposition, and nutrient retention of Cladium jamaicense Crantz and Typha domingensis Pers. in the Florida Everglades. Aquatic Botony. 40(3), 203-224.

Davis, S. M., Gunderson, L. H., Park, W. A., Richardson, J. R., Mattson, J. E. (1994). Landscape dimension, composition, and function in a changing Everglades ecosystem. Everglades: the ecosystem and its restoration, 419-444.

Diefendorf, A. F., Freeman, K. H., Wing, S. L., Graham, H. V. (2011). Production of nalkyl lipids in living plants and implications for the geologic past. Geochimica et Cosmochimica Acta, 75(23), 7472-7485.

Dodd, R. S., Afzal-Rafii, Z. (2000). Habitat-related adaptive properties of plant cuticular lipids. Evolution, 54(4), 1438-1444.

Dodd, R. S., Poveda, M. M. (2003). Environmental gradients and population divergence contribute to variation in cuticular wax composition in Juniperus communis. Biochemical systematics and ecology, 31(11), 1257-1270.

Douglas, M.S. (1947). The Everglades river of grass (revised edition, 1988) Pineapple, Sarasota, Florida.

Douglas, P.M.J., Pagani, M., Brenner, M., Hodell, D.A., Curtis, J.H. (2012). Aridity and vegetation composition are important determinants of leaf-wax delta $D$ values in southeastern Mexico and Central America. Geochimica et Cosmochimica Acta 97, 24-45.

Dyson, W. G., Herbin, G. A. (1968). Studies on plant cuticular waxes-IV: Leaf wax alkanes as a taxonomic discriminant for cypresses grown in Kenya. Phytochemistry, 7(8), 1334-1344.

Ehleringer, J. R. (1990). Correlations between carbon isotope discrimination and leaf conductance to water vapor in common beans. Plant Physiology, 93(4), 1422-1425.

Ehleringer, J. R., Cooper, T. A. (1988). Correlations between carbon isotope ratio and microhabitat in desert plants. Oecologia, 76(4), 562-566. 
Ewe, S., Gaiser, E., Childers, D., Iwaniec, D., Rivera-Monroy, V., Twilley, R. (2006) Spatial and temporal patterns of aboveground net primary productivity (ANPP) along two freshwater-estuarine transects in the Florida Coastal Everglades. Hydrobiologia 569(1), 459-474.

Ewe, S. M., Sternberg, L.d.S.L. (2002). Seasonal water-use by the invasive exotic, Schinus terebinthifolius, in native and disturbed communities. Oecologia, 133(4), 441448.

Ewe, S.M.L., Sternberg, L.d.S.L., Childers, D.L. (2007) Seasonal plant water uptake patterns in the saline southeast Everglades ecotone. Oecologia, 152(4), 607-616.

Ficken, K. J., Li, B., Swain, D. L., Eglinton, G. (2000). An $n$-alkane proxy for the sedimentary input of submerged/floating freshwater aquatic macrophytes. Organic Geochemistry, 31(7), 745-749.

Ficken, K. J., Barber, K. E., Eglinton, G. (1998). Lipid biomarker, $\delta^{13} \mathrm{C}$ and plant macrofossil stratigraphy of a Scottish montane peat bog over the last two millennia. Organic Geochemistry, 28(3), 217-237.

Francey, R., Farquhar, G. (1982) An explanation of ${ }^{13} \mathrm{C} /{ }^{12} \mathrm{C}$ variations in tree rings. Nature 297, 28-31.

Freeman, K. H., Boreham, C. J., Summons, R. E., Hayes, J. M. (1994). The effect of aromatization on the isotopic compositions of hydrocarbons during early diagenesis. Organic geochemistry, 21(10), 1037-1049.

Gao, L., Hou, J., Toney, J., MacDonald, D., Huang, Y. (2011). Mathematical modeling of the aquatic macrophyte inputs of mid-chain $n$-alkyl lipids to lake sediments: Implications for interpreting compound specific hydrogen isotopic records. Geochimica et Cosmochimica Acta, 75(13), 3781-3791.

Gao, M., Simoneit, B. R., Gantar, M., Jaffé, R. (2007). Occurrence and distribution of novel botryococcene hydrocarbons in freshwater wetlands of the Florida Everglades. Chemosphere, 70(2), 224-236.

Glaser, P. H., Volin, J. C., Givnish, T. J., Hansen, B., \& Stricker, C. A. (2012). Carbon and sediment accumulation in the Everglades (USA) during the past 4000 years: Rates, drivers, and sources of error. Journal of Geophysical Research: Biogeosciences (20052012), 117(G3), G03026, doi:10.1029/2011JG001821.

Goslee, S. C., Richardson, C. J. (2008). Establishment and seedling growth of sawgrass and cattail from the Everglades. In Everglades Experiments (pp. 547-564). Springer New York. 
Gu, B.H., Schelske, C.L., Brenner, M. (1996) Relationship between sediment and plankton isotope ratios (delta $\mathrm{C}-13$ and delta $\mathrm{N}-15$ ) and primary productivity in Florida lakes. Canadian Journal of Fisheries and Aquatic Sciences, 53, 875-883.

Hayes, J. M. (1993). Factors controlling ${ }^{13} \mathrm{C}$ contents of sedimentary organic compounds: Principles and evidence. Marine Geology, 113(1), 111-125.

Hou, J., D’Andrea, W. J., Huang, Y. (2008). Can sedimentary leaf waxes record D/H ratios of continental precipitation? Field, model, and experimental assessments. Geochimica et Cosmochimica Acta, 72(14), 3503-3517.

Hou, J., D'Andrea, W. J., MacDonald, D., Huang, Y. (2007a). Evidence for water use efficiency as an important factor in determining the $\delta \mathrm{D}$ values of tree leaf waxes. Organic Geochemistry, 38(8), 1251-1255.

Hou, J., D’Andrea, W. J., MacDonald, D., Huang, Y. (2007). Hydrogen isotopic variability in leaf waxes among terrestrial and aquatic plants around Blood Pond, Massachusetts (USA). Organic Geochemistry, 38(6), 977-984.

Huang, X., Xue, J., Meyers, P. A., Gong, L., Wang, X., Liu, Q., Qin, Y.M., Wang, H. (2014). Hydrologic influence on the $\delta^{13} \mathrm{C}$ variation in long chain $n$-alkanes in the Dajiuhu peatland, central China. Organic Geochemistry, 69, 114-119.

Huang, Y.S., Bol, R., Harkness, D.D., Ineson, P., Eglinton, G. (1996). Post-glacial variations in distributions, ${ }^{13} \mathrm{C}$ and ${ }^{14} \mathrm{C}$ contents of aliphatic hydrocarbons and bulk organic matter in three types of British acid upland soils. Organic Geochemistry, 24(3), 273-287.

Huang, Y.S., Clemens, S.C., Liu, W., Wang, Y., Prell, W.L. (2007). Large-scale hydrological change drove the late Miocene C-4 plant expansion in the Himalayan foreland and Arabian Peninsula. Geology, 35(6), 531-534.

Huang, Y.S., Eglinton, G., Ineson, P., Latter, P. M., Bol, R., Harkness, D. D. (1997). Absence of carbon isotope fractionation of individual n-alkanes in a 23-year field decomposition experiment with Calluna vulgaris. Organic Geochemistry, 26(7), 497-501.

Huang, Y.S., Shuman, B., Wang, Y., Webb III, T., Grimm, E. C., Jacobson Jr, G. L. (2006). Climatic and environmental controls on the variation of $\mathrm{C}_{3}$ and $\mathrm{C}_{4}$ plant abundances in central Florida for the past 62,000 years. Palaeogeography, Palaeoclimatology, Palaeoecology, 237(2), 428-435.

Huang, Y., Shuman, B., Wang, Y., Webb, T. (2004). Hydrogen isotope ratios of individual lipids in lake sediments as novel tracers of climatic and environmental change: a surface sediment test. Journal of Paleolimnology, 31(3), 363-375. 
Hubick, K. T., Farquhar, G. D., Shorter, R. (1986). Correlation between water-use efficiency and carbon isotope discrimination in diverse peanut (Arachis) germplasm. Functional Plant Biology, 13(6), 803-816.

Jaffé, R., Mead, R., Hernandez, M. E., Peralba, M. C., DiGuida, O. A. (2001). Origin and transport of sedimentary organic matter in two subtropical estuaries: a comparative, biomarker-based study. Organic Geochemistry, 32(4), 507-526.

Jaffé, R., Rushdi, A. I., Medeiros, P. M., Simoneit, B. R. (2006). Natural product biomarkers as indicators of sources and transport of sedimentary organic matter in a subtropical river. Chemosphere, 64(11), 1870-1884.

Jaffé, R., Wolff, G. A., Cabrera, A., Carvajal Chitty, H. (1995). The biogeochemistry of lipids in rivers of the Orinoco Basin. Geochimica et Cosmochimica Acta, 59(21), 45074522.

Jetter, R., Kunst, L., Samuels, A. L. (2006). Composition of plant cuticular waxes. In Biology of the Plant Cuticle (eds. M. Riederer and C. Müller). Blackwell Publishing, Oxford.

Keeling, C.D., Carter, A.F., Mook, W.G. (1984). Seasonal, latitudinal, and secular variations in the abundance and isotopic ratios of atmospheric $\mathrm{CO}_{2}: 2$. Results from oceanographic cruises in the tropical Pacific Ocean. Journal of Geophysical Research.: Atmospheres (1984-2012) 89, 4615-4628.

Krull, E., Sachse, D., Mügler, I., Thiele, A., Gleixner, G. (2006). Compound-specific $\delta^{13} \mathrm{C}$ and $\delta^{2} \mathrm{H}$ analyses of plant and soil organic matter: A preliminary assessment of the effects of vegetation change on ecosystem hydrology. Soil Biology and Biochemistry, $38(11), 3211-3221$.

Larsen, L., Aumen, N., Bernhardt, C., Engel, V., Givnish, T., Hagerthey, S., Harvey, J., Leonard, L., McCormick, P., McVoy, C., Noe, G., Nungesser, M., Rutchey, K., Sklar, F., Troxler, T., Volin, J., Willard, D. (2011). Recent and Historic Drivers of Landscape Change in the Everglades Ridge, Slough, and Tree Island Mosaic. Critical Reviews in Environmental Science and Technology 41, no. S1 (2011): 344-381.

Leider, A., Hinrichs, K. U., Schefuß, E., Versteegh, G. J. (2013). Distribution and stable isotopes of plant wax derived n-alkanes in lacustrine, fluvial and marine surface sediments along an Eastern Italian transect and their potential to reconstruct the hydrological cycle. Geochimica et Cosmochimica Acta, 117, 16-32.

Liu, W.G., Huang, Y.S. (2005). Compound specific $\mathrm{D} / \mathrm{H}$ ratios and molecular distributions of higher plant leaf waxes as novel pale oenvironmental indicators in the Chinese Loess Plateau. Organic Geochemistry, 36(6), 851-860. 
Liu, W., Yang, H. (2008). Multiple controls for the variability of hydrogen isotopic compositions in higher plant n-alkanes from modern ecosystems. Global change biology, 14(9), 2166-2177.

Lorenzen, B., Brix, H., Mendelssohn, I. A., McKee, K. L., Miao, S. L. (2001). Growth, biomass allocation and nutrient use efficiency in Cladium jamaicense and Typha domingensis as affected by phosphorus and oxygen availability. Aquatic Botany, 70(2), 117-133.

Mead, R., Xu, Y.P., Chong, J., Jaffé, R. (2005). Sediment and soil organic matter source assessment as revealed by the molecular distribution and carbon isotopic composition of n-alkanes. Organic Geochemistry, 36(3), 363-370.

Miao, S. L., Borer, R. E., Sklar, F. H. (1997). Sawgrass seedling responses to transplanting and nutrient additions. Restoration Ecology, 5(2), 162-168.

Nelson, D.M., Henderson, A.K., Huang, Y., Hu, F.S. (2013). Influence of terrestrial vegetation on leaf wax delta D of Holocene lake sediments. Organic Geochemistry, 56, 106-110.

Neto, R.R, Mead, R.N, Louda, J.W, Jaffé, R. (2006). Organic biogeochemistry of detrital flocculent material (floc) in a subtropical, coastal wetland. Biogeochemistry, 77(3), 283304.

O'Reilly, C.M., Alin, S.R., Plisnier, P.D., Cohen, A.S., McKee, B.A. (2003). Climate change decreases aquatic ecosystem productivity of Lake Tanganyika, Africa. Nature, 424(6950), 766-768.

Ogden, J.C. (2005). Everglades ridge and slough conceptual ecological model. Wetlands, 25(4), 810-820.

Pagani, M., Pedentchouk, N., Huber, M., Sluijs, A., Schouten, S., Brinkhuis, H., Damste, J.S.S., Dickens, G.R., Expedit, S. (2006). Arctic hydrology during global warming at the Palaeocene/Eocene thermal maximum. Nature, 442(7103), 671-675.

Pisani, O., Louda, J. W., Jaffé, R. (2013). Biomarker assessment of spatial and temporal changes in the composition of flocculent material (floc) in the subtropical wetland of the Florida Coastal Everglades. Environmental Chemistry, 10(5), 424-436.

Pedentchouk, N., Sumner, W., Tipple, B., Pagani, M. (2008). $\delta^{13} \mathrm{C}$ and $\delta \mathrm{D}$ compositions of n-alkanes from modern angiosperms and conifers: An experimental set up in central Washington State, USA. Organic Geochemistry, 39(8), 1066-1071.

Polissar, P.J., Freeman, K.H. (2010). Effects of aridity and vegetation on plant-wax delta $\mathrm{D}$ in modern lake sediments. Geochimica et Cosmochimica Acta, 74(20), 5785-5797. 
Price, R.M., Swart, P.K. (2006). Geochemical indicators of groundwater recharge in the surficial aquifer system: Everglades National Park, Florida, USA.Special papersGeological Society of America 404, 251.

Price, R. M., Swart, P. K., Willoughby, H. E. (2008). Seasonal and spatial variation in the stable isotopic composition $\left(\delta^{18} \mathrm{O}\right.$ and $\left.\delta \mathrm{D}\right)$ of precipitation in south Florida. Journal of hydrology, 358(3), 193-205.

Richardson, C.J., Pahl, J.W., Vymazal, J., Vaithiyanathan, P., Qualls, R.G., Sundareshwar, P., Barber, M.L., Johnson, J. (2008). Enrichment Gradients in WCA-2A and Northern WCA-3A: Water, Soil, Plant Biomass, and Nutrient Storage Responses, Everglades Experiments. Springer, pp. 103-165.

Riscassi, A.L., Schaffranek, R.W. (2004). Flow velocity, water temperature, and conductivity in Shark River Slough, Everglades National Park, Florida: June 2002-July 2003. In: U.S. Geological Survey Open-File Report 04, pp. 56.

Romero, I. C., Feakins, S. J. (2011). Spatial gradients in plant leaf wax D/H across a coastal salt marsh in southern California. Organic Geochemistry, 42(6), 618-629.

Ross, M.S., Reed, D.L., Sah, J.P., Ruiz, P.L., Lewin, M. (2003). Vegetation: environment relationships and water management in Shark Slough, Everglades National Park. Wetlands Ecology and Management, 11(5), 291-303.

Sachse, D., Billault, I., Bowen, G. J., Chikaraishi, Y., Dawson, T. E., Feakins, S. J., ... and Kahmen, A. (2012). Molecular paleohydrology: Interpreting the hydrogen-isotopic composition of lipid biomarkers from photosynthesizing organisms. Annual Review of Earth Planetary Science, 40, 221-249.

Sachse, D., Radke, J., Gleixner, G. (2006). delta D values of individual n-alkanes from terrestrial plants along a climatic gradient - Implications for the sedimentary biomarker record. Organic Geochemistry, 37(4), 469-483.

Sachse, D., Gleixner, G., Wilkes, H., Kahmen, A. (2010). Leaf wax n-alkane $\delta$ D values of field-grown barley reflect leaf water $\delta \mathrm{D}$ values at the time of leaf formation. Geochimica et Cosmochimica Acta, 74(23), 6741-6750.

Sachse, D., Radke, J., Gleixner, G. (2004). Hydrogen isotope ratios of recent lacustrine sedimentary n-alkanes record modern climate variability. Geochimica et Cosmochimica Acta, 68(23), 4877-4889.

Saha, A.K., Sternberg, L.d.S.L.O.R., Miralles-Wilhelm, F. (2009). Linking water sources with foliar nutrient status in upland plant communities in the Everglades National Park, USA. Ecohydrology, 2(1), 42-54. 
Saunders, C.J., Gao, M., Lynch, J.A., Jaffé, R., Childers, D.L. (2006). Using soil profiles of seeds and molecular markers as proxies for sawgrass and wet prairie slough vegetation in Shark Slough, Everglades National Park. Hydrobiologia, 569(1), 475-492.

Saunders, C.J., Gao, M., Jaffé, R. (2014). Environmental assessment of vegetation and hydrological conditions in Everglades freshwater marshes using multiple geochemical proxies. Submitted to Aquatic Science.

Saurer, M., Siegenthaler, U., Schweingruber, F. (1995). The climate-carbon isotope relationship in tree rings and the significance of site conditions. Tellus B, 47(3), 320-330.

Schedlbauer, J.L., Oberbauer, S.F., Starr, G., Jimenez, K.L. (2010) Seasonal differences in the $\mathrm{CO}_{2}$ exchange of a short-hydroperiod Florida Everglades marsh. Agricultural and Forest Meteorology, 150(7), 994-1006.

Schelske, C.L., Hodell, D.A. (1991). Recent changes in productivity and climate of lakeOntario detected by isotopic analysis of sediments. Limnology and Oceanography, 36(3), 961-975.

Seki, O., Meyers, P.A., Kawamura, K., Zheng, Y., Zhou, W. (2009). Hydrogen isotopic ratios of plant wax n-alkanes in a peat bog deposited in northeast China during the last 16 kyr. Organic Geochemistry, 40(6), 671-677.

Seki, O., Nakatsuka, T., Shibata, H., Kawamura, K. (2010). A compound-specific nalkane $\delta^{13} \mathrm{C}$ and $\delta \mathrm{D}$ approach for assessing source and delivery processes of terrestrial organic matter within a forested watershed in northern Japan. Geochimica et Cosmochimica Acta, 74(2), 599-613.

Sessions, A.L., Burgoyne, T.W., Schimmelmann, A., Hayes, J.M. (1999). Fractionation of hydrogen isotopes in lipid biosynthesis. Organic Geochemistry, 30(9), 1193-1200.

Shemesh, A., Macko, S.A., Charles, C.D., Rau, G.H. (1993). Isotopic evidence for reduced productivity in the glacial southern-ocean. Science, 262(5132), 407-410.

Steward, K.K., Ornes, W.H. (1975). The autecology of sawgrass in the Florida Everglades. Ecology, 56(1), 162-171.

Steward, K.K., Ornes, W.H. (1983). Mineral nutrition of sawgrass (Cladium jamaicense Crantz) in relation to nutrient supply. Aquatic Botany, 16(4), 349-359.

Stránský, K., Streibl, M., Herout, V. (1967). On natural waxes. VI. Distribution of wax hydrocarbons in plants at different evolutionary levels. Collection of Czechoslovak Chemical Communications, 32(9), 3213-3220. 
Willard, D.A., Bernhardt, C.E., Holmes, C.W., Landacre, B., Marot, M. (2006). Response of Everglades tree islands to environmental change. Ecological Monographs, 76(4), 565583.

Willard, D. A., Murray, J. B., Holmes, C. W., Korvela, M. S., Mason, D., Orem, W. H., Towles, D. T. (2002) Paleoecological insights on fixed tree island development in the Florida Everglades: I. Environmental controls. In Tree islands of the Everglades (pp. 117151). Springer Netherlands.

Willard, D.A., Holmes, C.W., Weimer, L.M. (2001a) The Florida Everglades ecosystem: climatic and anthropogenic impacts over the last two millennia. Bulletins of American Paleontology 361, 41-55.

Willard, D.A., Weimer, L., Riegel, W. (2001b) Pollen assemblages as paleoenvironmental proxies in the Florida Everglades. Review of Palaeobotany and Palynology, 113(4), 213-235.

Xu, Y., Mead, R.N., Jaffé, R. (2006) A molecular marker-based assessment of sedimentary organic matter sources and distributions in Florida Bay. Hydrobiologia, 569(1), 179-192. 


\section{CHAPTER VIII}

\section{GENERAL CONCLUSTION AND REMARKS}


Freshwater wetlands and estuarine ecosystem are recognized as important components of the global carbon cycle because they can generate, accumulate and/or export significantly amounts of OM to the oceans. However, much of the OM generated in freshwater/coastal wetlands and estuarine ecosystems can also be recycled internally. Thus, understanding OM dynamics of these ecosystems is important to constrain local carbon budgets and to assess carbon cycling on a global scale. The Everglades, a subtropical coastal wetland, provides an excellent system for examining OM dynamics in both freshwater and estuary ecosystem. The Everglades is characterized among others by its unique hydrological features which have shaped the landscape of this ecosystem. Significant deposits of OM in the form of peat have been affected by long-term, manmade changes in freshwater delivery, both quantity and quality. As such, this is an ideal ecosystem to test how hydrological changes can affect OM dynamics.

Formation, preservation and transport of $\mathrm{OM}$ in soils and sediments in the Everglades are critical for its sustainability, especially the soil topography and landscape. This information is critical especially during the implementation of the Comprehensive Everglades Restoration Plan (CERP) as hydrological processes are important divers in the origin, transport and fate of OM. Thus, OM dynamics as induced by hydrological changes in the greater Everglades was studied though various organic geochemistry techniques, especially biomarkers and compound specific $\delta^{13} \mathrm{C}$ and $\delta \mathrm{D}$ isotope analysis.

Biomarkers were applied to assess the OM dynamics in the Everglades freshwater wetlands and Shark River Estuary. A three end-member model, including freshwater, estuary and marine end-members, was constructed using specific biomarkers to assess different POM source input across the Shark River Estuary. The dominant POM source 
along the Shark River estuary was found to be derived from the mangroves, which contribute in excess of $70 \%$ to the whole POM pool. Mangrove derived POM export from the Shark River estuary to the Gulf of Mexico was estimated as $9.2 \times 10^{5}$ to $1.8 \times$ $10^{6} \mathrm{~kg} \mathrm{POM} / \mathrm{yr}$, and is about the same magnitude of the reported DOM export from mangroves at the same estuary. This similar magnitude export for both POM and DOM from mangroves was also reported in some other site-specific studies, which could call further studies. As CERP is implemented and water delivery to the Shark River is enhanced, this background information may become important in assessing potential changes in POC export in this sytem.

In the freshwater wetland of Everglades, POM is mostly found as a form of floc, which due to its unconsolidated nature may become mobilized through enhanced flow. One of CERP's objectives is to re-create the ridge and slough landscape that has been lost in several hydrologically impacted regions of the Everglades. As such, assessing floc transport and redistribution is critical. Using biomarkers as proxies for ridge and slough floc POM it was found that the great majority of collected floc ( $80 \%$ or more; POC traps) was derived from slough environments under natural water flow conditions. It is expected that under higher flow conditions (CERP implementation) this slough-derived floc will become deposited on ridges and help re-establish the original marsh landscape in the Everglades.

OM dynamics are linked to various environmental parameters including biomass cover, primary productivity, vegetation type, water quality and hydrological conditions. Thus, in order to better predict the response of the Everglades to the future environmental changes by restoration efforts, it's important to have better understanding of how the 
historical hydrology changes in the Everglades have affected vegetation successions. Biomarkers and compound specific isotopes from wetland soil cores were applied to test their applicability for paleo-hydrology and paleo-vegetation reconstruction in the Everglades freshwater wetlands. These geochemical proxies were successfully applied, and a general vegetation shift was confirmed during last few decades as hydroperiod was reduced in ENP due to changes in water delivery. Thus, the combination of biomarkers and stable isotopes can aid in the assessment of CERP-induced changes in OM dynamics in the future. Overall, biomarkers were found to be excellent proxies for biomass-specific $\mathrm{OM}$ in the Everglades, and as such further enhancing the existing database for such molecular markers in this ecosystem was attempted. This included the identification of unique molecular distributions of mono-methyl alkanes and biomarkers specific to cattails.

A variety of organic geochemical tools needed to assess OM dynamics in the Everglades have been tested and found to properly assess diverse processes affecting this ecosystem. As such, they can be applied to monitor the success of the CERP implementation process in years to come. However, many aspects still remain to be better understood and constrained. One example is the lack of molecular tools to properly quantify OM pools in wetland soils derived from above- or below-ground biomass. Thus, further studies are required in order to better predict the response of the Everglades OM dynamics to CERP. 
APPENDICES 
Appendix 6.1 $n$-Alkane concentrations, distributions and average $\delta^{13} \mathrm{C}$ and $\delta \mathrm{D}$ values across all studied plant leaves.

Note: n (SD) means "number of separate samples (standard deviation)", average $\delta^{13} \mathrm{C}$ and $\delta \mathrm{D}$ values means concentration weighted average of odd $n$-alkanes $\left(n-\mathrm{C}_{21}\right.$ to $n$-C $\left.\mathrm{C}_{35}\right)$, N.A. standards for not accessible.

\begin{tabular}{|c|c|c|c|c|c|c|c|c|c|c|}
\hline Species (leaves or stems) & $\begin{array}{l}\text { Total } n \text { - } \\
\text { alkanes } \\
(\mu \mathrm{g} / \mathrm{gdw})\end{array}$ & $\mathrm{n}(\mathrm{SD})$ & $\mathrm{P} a q$ & n (SD) & $\mathrm{ACL}$ & $\mathrm{n}(\mathrm{SD})$ & $\delta^{13} \mathrm{C}$ & $\mathrm{n}(\mathrm{SD})$ & $\delta \mathrm{D}$ & $\mathrm{n}(\mathrm{SD})$ \\
\hline Taxodium distichum & 6.7 & 1 & 0.17 & 1 & 29.15 & 1 & -24.2 & 1 & N.A. & 1 \\
\hline Pinus elliottii & 7.6 & 1 & 0.20 & 1 & 29.56 & 1 & -31.8 & 1 & N.A. & 1 \\
\hline Blechnum chilense & 3.5 & 1 & 0.05 & 1 & 28.31 & 1 & -31.1 & 1 & -89.6 & 1 \\
\hline Osmunda regalis & 61.5 & 1 & 0.05 & 1 & 28.66 & 1 & -32.7 & 1 & -97.8 & 1 \\
\hline Magnolia virginiana & 251.6 & $2(158.0)$ & 0.12 & $2(0.04)$ & 27.98 & $2(0.19)$ & -35.6 & $2(2.7)$ & -90.0 & $2(9.0)$ \\
\hline Magnolia virginiana 1 & 139.9 & & 0.15 & & 27.85 & & -37.5 & & -81.0 & \\
\hline Magnolia virginiana 2 & 363.4 & & 0.09 & & 28.11 & & -33.7 & & -99.0 & \\
\hline Annona glabra & 88.3 & $6(78.9)$ & 0.09 & $6(0.07)$ & 28.53 & $6(0.75)$ & -33.2 & $3(1.5)$ & -86.9 & $3(6.7)$ \\
\hline Annona glabra 1 & 43.8 & & 0.04 & & 28.99 & & -31.9 & & -93.2 & \\
\hline Annona glabra 2 & 42.5 & & 0.06 & & 29.14 & & -34.8 & & -79.8 & \\
\hline Annona glabra 3 & 56.6 & & 0.02 & & 29.52 & & -32.9 & & -87.7 & \\
\hline Annona glabra 4 & 32.8 & & 0.22 & & 27.96 & & N.A. & & N.A. & \\
\hline
\end{tabular}




\begin{tabular}{|c|c|c|c|c|c|c|c|c|c|c|}
\hline Annona glabra 5 & 237.1 & & 0.10 & & 27.78 & & N.A. & & N.A. & \\
\hline Annona glabra 6 & 117.0 & & 0.11 & & 28.18 & & N.A. & & N.A. & \\
\hline Persea borbonia & 29.6 & 1 & 0.21 & 1 & 28.72 & 1 & -33.1 & 1 & -105.9 & 1 \\
\hline Myrica cerifera & 77.5 & $2(10.1)$ & 0.00 & $2(0.00)$ & 30.78 & $2(0.07)$ & -31.8 & $2(2.9)$ & -94.1 & $2(1.1)$ \\
\hline Myrica cerifera 1 & 70.3 & & 0.00 & & 30.75 & & -29.8 & & -95.2 & \\
\hline Myrica cerifera 2 & 84.6 & & 0.00 & & 30.80 & & -33.9 & & -92.9 & \\
\hline Salix Caroliniana & 214.0 & 3 & 0.10 & $3(0.08)$ & 28.30 & $3(0.36)$ & -31.5 & $3(2.3)$ & -93.6 & $2(4.8)$ \\
\hline Salix Caroliniana 1 & 88.8 & & 0.19 & & 27.90 & & -34.8 & & -91.5 & \\
\hline Salix Caroliniana 2 & 365.6 & & 0.08 & & 28.44 & & -30.1 & & -90.2 & \\
\hline Salix Caroliniana 3 & 187.5 & & 0.03 & & 28.57 & & -29.5 & & -99.2 & \\
\hline Chrysobalanus icaco & 473.2 & 1 & 0.00 & 1 & 29.72 & 1 & -37.8 & 1 & -77.7 & 1 \\
\hline Cephalanthus occidentalis & 281.0 & 1 & 0.01 & 1 & 29.24 & 1 & -31.8 & 1 & -85.0 & 1 \\
\hline $\begin{array}{l}\text { Cephalanthus occidentalis } \\
\text { (flower) }\end{array}$ & 254.7 & 1 & 0.50 & 1 & 27.47 & 1 & -34.2 & 1 & -72.2 & 1 \\
\hline Typha latifolia & 153.0 & $3(76.1)$ & 0.13 & $3(0.06)$ & 28.26 & $3(0.25)$ & -36.0 & $3(1.1)$ & -125.4 & $3(7.1)$ \\
\hline Typha latifolia 1 & 109.0 & & 0.16 & & 28.00 & & -34.8 & & -132.9 & \\
\hline Typha latifolia 2 & 109.0 & & 0.17 & & 28.28 & & -36.8 & & -124.3 & \\
\hline
\end{tabular}




\begin{tabular}{|c|c|c|c|c|c|c|}
\hline Typha latifolia 3 & 240.9 & & 0.06 & 28.51 & -36.5 & -118.9 \\
\hline Typha domingensis & 23.0 & $4(8.2)$ & $0.234(0.11)$ & $27.924(0.20)$ & $-33.04(2.0)$ & $-137.54(11.5)$ \\
\hline Typha domingensis 1 & 31.2 & & 0.21 & 27.91 & -34.3 & -149.8 \\
\hline Typha domingensis 2 & 25.3 & & 0.13 & 28.13 & -35.1 & -144.4 \\
\hline Typha domingensis 3 & 11.6 & & 0.18 & 27.99 & -30.7 & -130.5 \\
\hline Typha domingensis 4 & 23.8 & & 0.39 & 27.66 & -32.0 & -125.2 \\
\hline Typha domingensis (flower) & 198.3 & & 0.87 & 26.30 & -30.8 & -102.2 \\
\hline Cladium jamaicense & 233.1 & $12(221.3)$ & $0.2412(0.11)$ & $27.7112(0.32)$ & $-31.913(1.5)$ & $-231.111(25.9)$ \\
\hline Cladium jamaicense 1 & 77.0 & & 0.34 & 27.33 & -34.2 & -229.7 \\
\hline Cladium jamaicense 2 & 129.6 & & 0.12 & 27.95 & -32.0 & -271.3 \\
\hline Cladium jamaicense 3 & 883.6 & & 0.43 & 27.25 & -31.4 & -203.4 \\
\hline Cladium jamaicense 4 & 244.0 & & 0.41 & 27.26 & -31.4 & -225.8 \\
\hline Cladium jamaicense 5 & 255.4 & & 0.30 & 27.61 & -30.3 & -202.8 \\
\hline Cladium jamaicense 6 & 237.3 & & 0.15 & 27.81 & -30.6 & -198.3 \\
\hline Cladium jamaicense 7 & 76.3 & & 0.17 & 27.94 & -30.0 & -261.3 \\
\hline Cladium jamaicense 8 & 92.5 & & 0.18 & 27.95 & -33.3 & -243.9 \\
\hline
\end{tabular}




\begin{tabular}{|c|c|c|c|c|c|c|c|}
\hline Cladium jamaicense 9 & 169.6 & & 0.20 & 27.91 & -32.7 & -239.5 & \\
\hline Cladium jamaicense 10 & 76.0 & & 0.20 & 27.77 & -32.7 & -234.7 & \\
\hline Cladium jamaicense 11 & 241.7 & & 0.15 & 28.01 & N.A. & N.A. & \\
\hline Cladium jamaicense 12 & 314.0 & & 0.24 & 27.70 & N.A. & N.A. & \\
\hline Eleocharis cellulosa & 28.0 & $10(22.0)$ & $0.4710(0.18)$ & $27.7510(1.08)$ & $-34.010(2.5)$ & -113.5 & $6(8.7)$ \\
\hline Eleocharis cellulosa 1 & 26.6 & & 0.65 & 26.97 & -32.7 & -126.7 & \\
\hline Eleocharis cellulosa 2 & 19.5 & & 0.54 & 27.20 & -29.3 & -118.9 & \\
\hline Eleocharis cellulosa 3 & 42.9 & & 0.68 & 26.73 & -36.0 & -104.7 & \\
\hline Eleocharis cellulosa 4 & 7.8 & & 0.29 & 27.78 & -36.1 & -116.5 & \\
\hline Eleocharis cellulosa 5 & 4.0 & & 0.52 & 27.24 & -34.4 & -105.4 & \\
\hline Eleocharis cellulosa 6 & 13.2 & & 0.15 & 30.74 & -33.9 & -108.5 & \\
\hline Eleocharis cellulosa 7 & 22.8 & & 0.16 & 29.51 & -36.0 & N.A. & \\
\hline Eleocharis cellulosa 8 & 49.3 & & 0.58 & 27.01 & -34.9 & N.A. & \\
\hline Eleocharis cellulosa 9 & 75.9 & & 0.61 & 26.97 & -33.0 & N.A. & \\
\hline Eleocharis cellulosa 10 & 17.6 & & 0.53 & 27.41 & N.A. & N.A. & \\
\hline Nymphaeaceae sp. & 76.7 & $7(67.3)$ & $0.657(0.19)$ & $27.197(0.84)$ & $-32.27(1.0)$ & -120.0 & $6(11.7)$ \\
\hline
\end{tabular}




\begin{tabular}{|c|c|c|c|c|c|c|c|}
\hline Nymphaeaceae sp. 1 & 132.7 & & 0.62 & 27.17 & -32.7 & -139.0 & \\
\hline Nymphaeaceae sp. 2 & 93.3 & & 0.56 & 27.12 & -31.7 & -112.8 & \\
\hline Nymphaeaceae sp. 3 & 201.8 & & 0.64 & 27.15 & -31.1 & -125.8 & \\
\hline Nymphaeaceae sp. 4 & 31.7 & & 0.82 & 27.08 & -32.4 & -123.5 & \\
\hline Nymphaeaceae sp. 5 & 41.9 & & 0.78 & 27.12 & -34.0 & -108.9 & \\
\hline Nymphaeaceae sp. 6 & 10.9 & & 0.68 & 26.12 & -32.6 & -110.0 & \\
\hline Nymphaeaceae sp. 7 & 24.6 & & 0.25 & 28.71 & -31.1 & N.A. & \\
\hline Nymphaeaceae sp. 8 & 76.8 & & 0.86 & 27.02 & N.A. & N.A. & \\
\hline Utricularia foliosa & 99.8 & $8(57.1)$ & $0.658(0.13)$ & $27.058(0.28)$ & $-38.8 \quad 8(2.2)$ & -116.0 & $8(9.0)$ \\
\hline Utricularia foliosa 1 & 204.2 & & 0.71 & 26.80 & -38.7 & -128.8 & \\
\hline Utricularia foliosa 2 & 149.1 & & 0.74 & 26.96 & -42.4 & -123.4 & \\
\hline Utricularia foliosa 3 & 102.9 & & 0.73 & 26.90 & -38.7 & -118.9 & \\
\hline Utricularia foliosa 4 & 54.5 & & 0.74 & 26.90 & -37.9 & -116.7 & \\
\hline Utricularia foliosa 5 & 123.8 & & 0.40 & 27.52 & -38.8 & -126.1 & \\
\hline Utricularia foliosa 6 & 57.8 & & 0.71 & 26.77 & -35.5 & -100.1 & \\
\hline Utricularia foliosa 7 & 85.4 & & 0.45 & 27.56 & -38.8 & -104.8 & \\
\hline
\end{tabular}




\begin{tabular}{|c|c|c|c|c|c|c|c|c|c|c|}
\hline Utricularia foliosa 8 & 20.9 & & 0.76 & & 27.01 & & -39.2 & & -108.9 & \\
\hline Utricularia Purpurea & 114.1 & $3(34.2)$ & 0.78 & $3(0.10)$ & 26.51 & $3(0.51)$ & -35.9 & $3(1.4)$ & -119.9 & $2(5.6)$ \\
\hline Utricularia Purpurea 1 & 113.8 & & 0.77 & & 26.53 & & -36.9 & & -123.8 & \\
\hline Utricularia Purpurea 2 & 122.2 & & 0.72 & & 26.66 & & -34.9 & & -115.9 & \\
\hline Utricularia Purpurea 3 & 106.3 & & 0.85 & & 26.35 & & N.A. & & N.A. & \\
\hline Bacopa caroliniana & 72.8 & $2(61.4)$ & 0.49 & $2(0.06)$ & 28.46 & $2(0.56)$ & -31.1 & $2(1.2)$ & -122.8 & $2(10.0)$ \\
\hline Bacopa caroliniana 1 & 29.4 & & 0.54 & & 28.07 & & -32.0 & & -113.3 & \\
\hline Bacopa caroliniana 2 & 116.2 & & 0.45 & & 28.86 & & -30.3 & & -129.9 & \\
\hline L. racemosa & 114.8 & $6(53.1)$ & 0.08 & $6(0.03)$ & 28.29 & $6(0.26)$ & -37.2 & $6(1.7)$ & -137.9 & $6(13.8)$ \\
\hline L. racemosa 1 & 59.8 & & 0.06 & & 28.69 & & -37.1 & & -123.6 & \\
\hline L. racemosa 2 & 154.2 & & 0.08 & & 28.12 & & -38.3 & & -135.0 & \\
\hline L. racemosa 3 & 152.7 & & 0.13 & & 28.02 & & -38.1 & & -135.0 & \\
\hline L. racemosa 4 & 60.9 & & 0.06 & & 28.36 & & -34.1 & & -152.5 & \\
\hline L. racemosa 5 & 82.0 & & 0.06 & & 28.28 & & -36.2 & & -156.3 & \\
\hline Avicennia germinans & 77.8 & $3(15.3)$ & 0.23 & $3(0.02)$ & 29.63 & $3(0.17)$ & -35.7 & $3(0.9)$ & -167.9 & $3(8.86)$ \\
\hline Avicennia germinans 1 & 95.1 & & 0.26 & & 29.44 & & -34.8 & & -162.8 & \\
\hline
\end{tabular}




\begin{tabular}{|c|c|c|c|c|c|c|c|c|c|c|}
\hline Avicennia germinans 2 & 72.6 & & 0.22 & & 29.68 & & -36.6 & & -178.2 & \\
\hline Avicennia germinans 3 & 65.9 & & 0.22 & & 29.77 & & -35.8 & & -162.8 & \\
\hline Rhizophora mangle & 58.7 & $7(20.1)$ & 0.10 & $7(0.08)$ & 29.31 & $7(0.36)$ & -37.9 & $7(0.9)$ & -129.7 & $7(2.30)$ \\
\hline Rhizophora mangle 1 & 69.6 & & 0.06 & & 28.69 & & -37.1 & & -126.2 & \\
\hline Rhizophora mangle 2 & 61.4 & & 0.08 & & 29.04 & & -38.4 & & -126.9 & \\
\hline Rhizophora mangle 3 & 41.5 & & 0.04 & & 29.50 & & -37.7 & & -128.7 & \\
\hline Rhizophora mangle 4 & 95.1 & & 0.26 & & 29.44 & & -38.9 & & -129.9 & \\
\hline Rhizophora mangle 5 & 47.1 & & 0.10 & & 29.61 & & -38.5 & & -131.2 & \\
\hline Rhizophora mangle 6 & 35.3 & & 0.04 & & 29.56 & & -36.6 & & -130.7 & \\
\hline Syringodium filiforme & 88.1 & 1 & 0.97 & 1 & 25.57 & 1 & -14.2 & 1 & -88.0 & 1 \\
\hline Halodule wrightii & 372.5 & 1 & 0.95 & 1 & 25.65 & 1 & -14.9 & 1 & -84.7 & 1 \\
\hline Halophila decipiens & 2.1 & 1 & 1.00 & 1 & 25.25 & 1 & -16.7 & 1 & N.A. & \\
\hline
\end{tabular}


VITA

\section{DING HE}

Born, Bazhong, China

2005-2009

B.A., Shaanxi Normal University, Xi'an, China

2008-2009

Undergraduate thesis research,

Zhejiang University,

Hangzhou, China

2009-2010

Mater study of Biological Science,

Zhejiang University,

Hangzhou, China

2010-present

Teaching and Researching Assistant,

Florida International University,

Miami, Florida, USA

\section{PUBLICATIONS AND PRESENTATIONS:}

Ding He*, Bernd. R. T. Simoneit, Blanca Jara and Rudolf Jaffé (2015)., Occurrence and distribution of monomethylalkanes in the freshwater wetland of the Florida Everglades. Chemosphere, 119, 258-266.2014.

Ding He, Blanca Jara, Laura Belicka and Rudolf Jaffé, Applications of aliphatic biomarker distributions and compound-specific $\delta{ }^{13} \mathrm{C}$ and $\delta \mathrm{D}$ analyses in assessing long term environmental change in the Florida Everglades, AAPG-SEG, 2013, Houston, USA.

Ding He, Blanca Jara, Peter Reiger and Rudolf Jaffé, Assessing the mobilization of ridge and slough derived particulate organic matter in the Everglades, FCE-ASM, 2014, Miami, USA. 
Ding He, Kaelin Cawley, Laura Belicka, Chao Ya, Sasha Wagner, Annie Palya, William Anderson, and Rudolf Jaffé, Characterization of particulate, dissolved, and black carbon exports from the Shark River Estuary, FCE-ASM, 2012, Miami, USA.

Ding He, Ralph Mead, Laura Belicka and Rudolf Jaffé, Assessing particulate organic matter dynamics in a subtropical estuary: a biomarker approach, ASLO, 2013, New Orleans, USA.

Ding He, Ralph N. Mead, Laura Belicka, Oliva Pisani, and Rudolf Jaffé* (2014), Assessing biomass contributions to particulate organic matter in a subtropical estuary: a biomarker approach. Organic Geochemistry.

Ding He, William T. Anderson, Rudolf Jaffé, Assessment of vegetation shift and hydrological change though biomarkers and compound specific $\delta \mathrm{D}-\delta 13 \mathrm{C}$ analyses in a subtropical wetland, ACS-FAME, 2014, Tampa, USA.

Ding He, William T. Anderson, Rudolf Jaffé, Vegetation change and hydrology period revealed using biomarkers and compound specific $\delta \mathrm{D}-\delta 13 \mathrm{C}$ analyses in a subtropical wetland, Goldschmidt, 2014, Sacramento, USA.

Lixin Xiang and Ding He* et al., Deep sequencing-based transcriptome profiling analysis of bacteria-challenged Lateolabrax japonicas reveals insight into the immune-relevant genes in marine fish. BMC Genomics 2010, 11:472 (Co-first author; IF: 4.21).

Rudolf Jaffé and Ding He, Shee tflow Effects and Canal Backfilling on Sediment Source and Transport in the DECOMP Physical Model: Analysis of Molecular Organic Biomarkers, 2013, Government report submitted to South Florida Water Management District, West Palm Beach, USA.

Rudolf Jaffé, Bernd. R. T. Simoneit, Ding He, and Blanca Jara, Identification of solanesol and a series of long-chain alkyl hydroxycinnamates from two species of cattail (Typha domingensis P. and Typha latifolia L.), 2013, Government report submitted to South Florida Water Management District, West Palm Beach, USA.

Yosmel Sanchez-Hernandez, Florentin J-MR Maurrasse*, Mihaela C Melinte-Dobrinescu, Ding He, Shane K Butler. (2014). Assessing the factors controlling high sedimentation rates from latest Barremian-earliest Aptian in a restricted marginal basin. Cretaceous Research, 51(1-21). 